

\title{
Cuidados básicos de enfermería
}

Desirée Mena Tudela Víctor Manuel González Chordá Águeda Cervera Gasch

Pablo Salas Medina María Isabel Orts Cortés 


\section{Cuidados básicos de enfermería}

Desirée Mena Tudela

Víctor Manuel González Chordá

Águeda Cervera Gasch

Pablo Salas Medina

Maria Isabel Orts Cortés

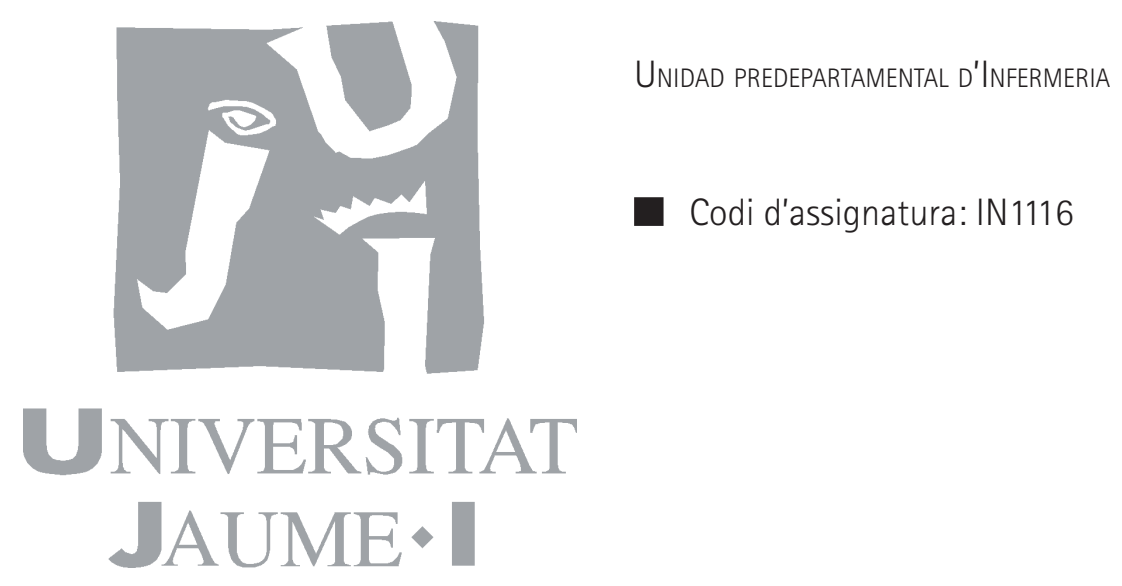


Edita: Publicacions de la Universitat Jaume I. Servei de Comunicació i Publicacions Campus del Riu Sec. Edifici Rectorat i Serveis Centrals. 12071 Castelló de la Plana http://www.tenda.uji.es e-mail: publicacions@uji.es

Col·lecció Sapientia 108

www.sapientia.uji.es

Primera edició, 2016

ISBN: 978-84-16356-30-0

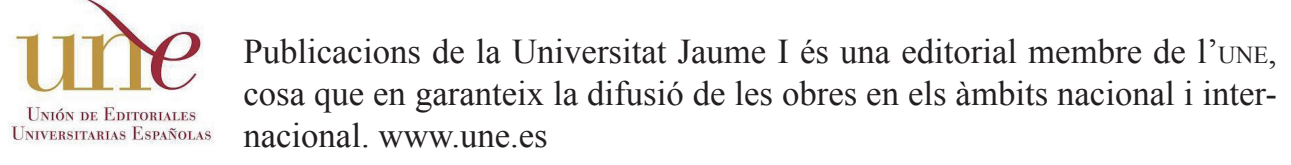

\section{(2) (1) ( $(2)$}

Reconeixement-CompartirIgual

CC BY-SA

Aquest text està subjecte a una llicència Reconeixement-CompartirIgual de Creative Commons, que permet copiar, distribuir i comunicar públicament l'obra sempre que s'especifique l'autor i el nom de la publicació fins i tot amb objectius comercials i també permet crear obres derivades, sempre que siguen distribuïdes amb aquesta mateixa llicència.

http://creativecommons.org/licenses/by-sa/3.0/legalcode

Aquest llibre, de contingut cientific, ha estat avaluat per persones expertes externes a la Universitat Jaume I, mitjançant el mètode denominat revisió per iguals, doble cec. 


\section{ÍNDICE}

Introducción.

Capítulo 1. Atención especializada y profesión de Enfermería.

1. La Atención especializada.

2. El proceso de cuidar y la relación con el paciente.

Capítulo 2. Las etapas del proceso de cuidar.

1. El proceso de cuidar.

2. Valoración: instrumentos a utilizar.

3. Planificación de los cuidados.

4. Etapa de intervención.

5. Evaluación de los cuidados.

Capítulo 3. Los cuidados básicos: definiciones

1. Definición de cuidados básicos de enfermería.

2. Responsabilidad legal.

Capítulo 4. Cuidados básicos basados en la evidencia.

1. Etapas del proceso de investigación.

2. Práctica basada en la evidencia.

3. Pregunta clínica estructurada.

4. Búsqueda de la mejor evidencia

Capítulo 5. Cuidados básicos en la alimentación.

1. Valoración nutricional.

2. Tipos de dietas.

3. Interacción entre los medicamentos y los nutrientes

4. Procedimiento de ayuda en la alimentación oral

Capítulo 6. Cuidados básicos en la movilidad.

1. Higiene postural

2. Posiciones de los pacientes encamados.

3. Plan de cambios posturales.

4. Movilización de los pacientes.

Capítulo 7. Cuidados básicos en el sueño y descanso.

1. Descanso y sueño. Conceptos.

2. La hospitalización y su repercusión en el sueño. 
3. Valoración del sueño.

4. Cuidados para favorecer la calidad del sueño.

Capítulo 8. Cuidados básicos en la eliminación.

1. Tipos de eliminación.

2. Factores que afectan a la micción.

3. Factores que afectan a la eliminación intestinal

4. Manejo del orinal tipo botella.

5. Manejo del orinal tipo cuña.

6. Medición de la diuresis.

7. Balance del equilibrio de líquidos.

Capítulo 9. Cuidados básicos en la higiene.

1. Consideraciones generales en la higiene.

2. Hacer una cama vacía.

3. Hacer una cama ocupada.

4. Aseo en ducha o bañera.

5. Aseo del paciente encamado.

6. Aseo del cabello.

7. Higiene bucal.

8. Higiene de los ojos.

9. Higiene de los pies.

10. Higiene de los genitales.

11. Cuidado de las uñas

Capítulo 10. Cuidados básicos en la comunicación.

1. Definición

2. Niveles de comunicación.

3. Factores que influyen en la comunicación.

4. Tipos de comunicación.

5. Actitudes del receptor.

6. Habilidades, estrategias y gestos de los profesionales de enfermería ...

Capítulo 11. Cuidados básicos en el confort y la seguridad.

1. La habitación del paciente.

2. Promoción de la comodidad.

3. Asepsia, infección nosocomial y manejo de la infección

4. Normas generales de preparación de medicación.

5. Prevención y tratamiento de las úlceras por presión (UPP).

6. Restricciones

Capítulo 12. Cuidados básicos en la hemodinámica.

1. Temperatura corporal.

2. Pulso.

3. Respiración

4. Oximetría del pulso.

5. Tensión arterial. 
Capítulo 13. Cuidados básicos del dolor: valoración y tratamiento.

1. Definición de dolor.

2. Clasificación del dolor.

3. Valoración del dolor.

4. Tratamiento del dolor.

Capítulo 14. Cuidados básicos de los catéteres intravenosos

1. Técnica de inserción de catéteres periféricos.

2. Cuidados de los catéteres periféricos.

Capítulo 15. Cuidados básicos perioperatorios

1. El proceso quirúrgico.

2. Cuidados básicos preoperatorios.

3. Cuidados básicos intraoperatorios

4. Cuidados básicos postoperatorios

Referencias bibliográficas.

Índice de tablas.

Índice de figuras. 


\section{Introducción}

A lo largo de la vida, el acceso a materiales docentes de forma libre y la evidencia científica contrastada son, sin duda, una marca de identidad del aprendizaje continuo, implantado desde finales del siglo xx en toda Europa de acuerdo con la filosofía de transmisión del conocimiento y accesibilidad del mismo, acorde a la era de la comunicación.

Los estudios conducentes al Grado en Enfermería otorgan competencias para el ejercicio profesional de enfermero, responsable de cuidados generales de acuerdo con las directivas comunitarias que regulan la profesión en el entorno de la Unión Europea. En España estos estudios tienen un total de 240 ECTS con una duración de cuatro años.

El título de Grado en Enfermería por la Universitat Jaume I se ajusta a la legislación comunitaria y española y en consecuencia otorga las competencias necesarias para ejercer la profesión de enfermero responsable de cuidados generales en el entorno de la Unión Europea. ${ }^{1}$ La legislación española considera la enfermería como profesión regulada en la Ley 44/2003 de Ordenación de las Profesiones Sanitarias (LOPS).

Una de las características del modelo de aprendizaje a lo largo de la vida es la adquisición de resultados de aprendizaje en forma de competencias, recogido en la precitada legislación, lo que implica una metodología educativa y un perfil de profesorado concretos.

Las características que tienen los estudios de Grado en Enfermería en la Universitat Jaume I son la filosofía integradora de tres tipos de enseñanza-aprendizaje: teórica, práctica de simulación y práctica clínica.

Una de las asignaturas troncales en el inicio de la formación de enfermera es la de Cuidados básicos impartida en segundo curso. Esta asignatura aporta los conocimientos, destrezas y habilidades sobre las necesidades básicas que todo el estudiantado debe adquirir en el contexto asistencial especializado y comunitario.

Los cuidados básicos de enfermería son la base disciplinar sobre la que pivota el conocimiento enfermero y su desarrollo investigador. Es el campo donde la enfermería toma decisiones sobre todos los cuidados de enfermería de los pacientes con problemas de salud agudos, crónicos, críticos y al final de la vida.

La profesionalización del cuidado, su aplicación y desarrollo empieza en el momento del aprendizaje. Utilizar herramientas validadas, conocimiento científico

1. El soporte legislativo comunitario de la titulación se encuentra recogido en el RD 1837/200818, de 8 de noviembre, por el que se incorporan al ordenamiento jurídico español la Directiva 2005/36/CE, del Parlamento Europeo y del Consejo, de 7 de septiembre de 2005, y la Directiva 2006/100/CE, del Consejo, de 20 de noviembre de 2006, relativas al reconocimiento de cualificaciones profesionales. 
e instrumentalizar los cuidados, orientarán una formación posterior clave para el logro de los estudios.

La compilación de cuidados básicos que se presenta en acceso libre, aporta conocimiento enfermero y difusión del mismo a la población en general. Difunde el cuidado profesional desde la disciplina que mejor lo puede difundir, la Enfermería.

Loreto Maciá Soler y María Isabel Orts Cortés 


\section{Atención especializada y profesión de Enfermería}

\section{Introducción}

Los servicios de Atención primaria se consideran el nivel básico en los sistemas de salud, pero cuando los medios que posee para satisfacer las necesidades asistenciales de la población se han agotado, hay que acudir al segundo nivel asistencial: la Atención especializada.

En este tema se realiza una revisión de las características fundamentales de la Atención especializada y aspectos generales de la enfermería en este ámbito, antes de introducirnos de lleno en los cuidados básicos de enfermería.

\section{La Atención especializada}

La Atención especializada es, en definitiva, el conjunto de medios humanos y materiales del sistema de salud, puestos a disposición de la población para atender los problemas sanitarios de mayor complejidad y que, por ello mismo, superan las posibilidades de la Atención primaria.

Al igual que la Atención primaria, la Atención especializada se presta en régimen ambulatorio y de urgencias, pero a diferencia de aquélla sólo la Atención especializada ofrece la asistencia en régimen de internamiento. La Atención especializada incluye asistencia en régimen domiciliario, la hospitalización y la rehabilitación.

Si la estructura física fundamental de la Atención primaria es el Centro de Salud, la de la especializada es el hospital, aunque hay otros centros no hospitalarios, como los centros de especialidades, a los que también nos podemos referir. Es función de los poderes públicos establecer los criterios de coordinación previstos entre ambos niveles asistenciales, atendiendo a la complejidad de los servicios prestados en cada uno de ellos.

Son objetivos de la Atención especializada:

a) Ofrecer a la población los medios técnicos y humanos de diagnóstico y tratamiento y rehabilitación que por su nivel de especialización no pueden resolverse en el nivel de Atención primaria. 
b) Posibilitar la hospitalización de los pacientes que lo precisen.

c) Atender las urgencias y emergencias que requieran cuidados de este nivel.

d) Prestar asistencia ambulatoria especializada.

e) Al igual que en la Atención primaria: promoción de la salud, prevención de las enfermedades, educación sanitaria de la población.

f) Poner sus centros e instituciones a disposición de la investigación y docencia en materia de salud.

g) Formación de profesionales sanitarios.

La Atención especializada se caracteriza actualmente por:

a) Ofrecer una cobertura sanitaria totalizadora, ya que en su seno se agotan todas las posibilidades del sistema de salud.

b) Acoger los recursos humanos más cualificados en cada área por su alta especialización.

c) Acoger los medios materiales y técnicos más sofisticados y costosos y por ello, más valorados por la población.

d) La integración de los recursos hospitalarios y extrahospitalarios en una estructura única: los Centros de Especialidades que actúan a modo de consultas externas «desplazadas» del hospital, y la «jerarquización» de los médicos.

e) La adopción de modernas técnicas de gestión.

f) La descentralización y la coordinación con el nivel de Atención primaria.

Son fines de la Asistencia especializada:

a) Ofrecer a la población los medios técnicos y humanos de diagnóstico, tratamiento y rehabilitación adecuados que, por su especialización o características, no puedan resolverse en el nivel de la Atención primaria.

b) Posibilitar el internamiento en régimen de hospitalización a los pacientes que lo precisen.

c) Participar en la atención de las urgencias, asumiendo las que superen los niveles de la Asistencia primaria.

d) Prestar la asistencia en régimen de consultas externas que requieran la atención especializada de la población, en su correspondiente ámbito territorial, sin perjuicio de lo establecido para los equipos de Atención primaria.

e) Participar, con el resto del dispositivo sanitario, en la prevención de las enfermedades y promoción de la salud.

f) Colaborar en la formación de los recursos humanos y en las investigaciones de salud.

De modo informativo, entre la legislación vigente actual deben tenerse en cuenta:

a) Ley 16/2003, de 28 de mayo, de Cohesión y Calidad del Sistema Nacional de Salud, establece en su artículo 13 el contenido de las prestaciones de atención especializada. 
b) Real Decreto 521/1987, de 15 de abril, por el que se aprueba el Reglamento sobre estructura, organización y funcionamiento de los hospitales gestionados por el Instituto Nacional de la Salud.

c) Decreto 74/2007, de 18 de mayo, del Consell por el que se aprueba el Reglamento sobre estructura, organización y funcionamiento de la atención sanitaria en la Comunidad Valenciana.

\section{El proceso de cuidar y la relación con el paciente}

\subsection{Definición de la enfermería profesional}

La American Nurses Association (ANA) define la enfermería como la protección, el fomento y la optimización del estado de salud y las capacidades del individuo, la prevención de la enfermedad y las lesiones, el alivio del sufrimiento a través del diagnóstico y el tratamiento de las respuestas humanas, y la defensa de la asistencia a los individuos, las familias, las comunidades y las poblaciones.

La política de la ANA identifica seis rasgos fundamentales de la enfermería profesional. Estas características son:

a) Creación de una relación humanitaria que potencie la salud y su recuperación.

b) Atención al abanico de experiencias y respuestas humanas a la salud y la enfermedad en el entorno físico-social.

c) Integración de datos objetivos con conocimientos adquiridos mediante el reconocimiento de la experiencia subjetiva de un paciente o un grupo.

d) Aplicación de datos científicos a los procesos diagnósticos y terapéuticos, mediante la utilización de enjuiciamiento y pensamiento crítico.

e) Profundización de los conocimientos profesionales de enfermería por medio de la educación continuada.

f) Influencia en las políticas sociales y de salud pública a favor de la justicia social.

\subsection{Asunción del papel del profesional de enfermería}

Las acciones que llevamos a cabo ante un paciente, tanto las verbales como las no verbales, influyen en los sentimientos y la concepción de este sobre el nivel de competencia que se muestra, el papel de la enfermería en la asistencia sanitaria y la adaptación global del paciente al centro sanitario. La asunción de un papel profesional implica que debemos comportarnos como un profesional. Así, la observación de las normas establecidas nos ayudará a transmitir la competencia que queremos mostrar como profesionales de enfermería, no solamente a los pacientes 
sino también a los compañeros y otros profesionales. Escuetas normas a seguir durante los laboratorios y durante las prácticas clínicas son:

a) Ir arreglado con atuendo limpio y respetar el código de vestimenta de la facultad o institución.

b) Mantener el cabello aseado, recogido, retirado de la nuca y llevar las uñas cortas. Utilizar esmalte de uñas transparente sin color. No se permite la utilización de uñas sintéticas dado que pueden albergar bacterias.

c) Hablar correctamente, sin jerga ni términos inadecuados.

d) Relacionarse con los pacientes como personas valiosas merecedoras de respeto y consideración. Dirigirse a ellos por su nombre, no usar apodos.

e) No hablar en tono condescendiente con los pacientes. Recordar que el paciente conoce mejor que nadie su organismo, sus sentimientos y sus respuestas. Escuchar y prestar atención a lo que relata sobre sí mismo o los sentimientos subyacentes que no está expresando.

f) Mantener un papel profesional en todo momento.

g) Actuar como una herramienta terapéutica de asistencia y curación. Aprovechar el lenguaje corporal para reforzar la comunicación verbal honesta.

h) Aceptar la responsabilidad y rendir cuentas del comportamiento llevado a cabo, actuación profesional y los servicios de enfermería que hay que prestar. Si se desconoce en un momento dado qué se espera de nosotros, preguntar a otros profesionales, compañeros y la enfermera de referencia. Nuestra responsabilidad consiste en prestar cuidados de enfermería de manera fiable, honesta y digna de confianza.

i) Mantener en secreto la información sobre el paciente. No hablar sobre el mismo en público.

\subsection{Prestación de cuidados al paciente}

Durante el desarrollo de esta asignatura veremos distintos procedimientos con los que la constante relación con el paciente es fundamental y, por ello, es necesario establecer un esquema general de asistencia antes de integrar los cuidados; para lograrlo hay que tener en cuenta:

a) Aplicar medidas higiénicas en las manos.

b) Recoger el material necesario para llevar a cabo los cuidados que vamos a prestar en el momento al paciente.

c) Comprobar e identificar correctamente al paciente. Presentarse y explicar los cuidados que vamos a brindarle.

d) Efectuar la valoración de enfermería.

e) Registrar los hallazgos conforme se realice la exploración y anotarlos.

f) Determinar las constantes vitales, si así lo indica la política de la unidad.

g) Llevar guantes, realizar todas las intervenciones de enfermería y anotar los hallazgos inmediatamente después de finalizar.

h) Al administrar la medicación prescrita, registrar la actividad y observar si aparecen signos de efectos secundarios o hallazgos inusuales. 
i) Aplicar técnicas de comunicación fluidas.

j) Despedirse del paciente.

k) Realizar la higiene de manos después de asistir al paciente y antes de abandonar la unidad de enfermería. 


\section{CAPITULO 2}

\section{Las etapas del proceso de cuidar}

\section{Introducción}

En este punto trataremos de aproximarnos al máximo, desde la teoría, a la práctica enfermera. Así, tal y como ya hemos visto, hablar de práctica no significa en modo alguno dejar de lado la teoría, sino todo lo contrario (disciplina vs. práctica enfermera). De esta forma, trataremos de establecer el puente entre la «forma de pensar» y la «forma de hacer»y aunar ambos en los que definiremos como proceso de cuidar.

Además, hay que tener en cuenta que las distintas acciones que comporta el proceso de cuidar requieren de un soporte metodológico que permita mantener un orden entre dichas acciones, garantizando la consecución de la meta u objetivo que nos proponemos en dicho proceso. Otra de las ventajas que nos aporta la utilización de un determinado método es la posibilidad de poder justificar, probar y evaluar el proceso de cuidar.

Por tanto, podemos afirmar que el ejercicio profesional de la enfermería requiere de un instrumento metodológico que nos ayude a llevar a cabo el proceso de cuidar, ordenando y cohesionando las acciones que dicho proceso comporta, a la vez que nos permite dejar constancia de las acciones realizadas, posibilitando su evaluación y permitiendo que el fin perseguido pueda ser alcanzado.

\section{El proceso de cuidar}

Tomando como puntos de partida el significado de los términos proceso y cuidar, trataremos de mostrar el alcance de lo que denominaremos proceso de cuidar. A continuación y, considerando que es a partir del reconocimiento de este proceso cuando se inicia el desarrollo disciplinar de la enfermería, nos referiremos al proceso de cuidar en enfermería.

Según la Real Academia Española, el vocablo proceso se puede definir como: «acción de ir hacia delante, un conjunto de fases sucesivas de un fenómeno natural», $\mathrm{y}$ es precisamente esta acepción la que impregna el proceso de cuidar en enfermería. Por tanto, el término proceso se refiere a: 
a) Sucesión de acciones.

b) Dirección hacia delante de las acciones.

c) Acciones que quedarán vinculadas entre sí por el objetivo que persiguen.

d) Acciones que pueden no tener fin.

e) Acciones de pensar y acciones de ejecutar.

Conociendo la dirección concreta del proceso de cuidar, podemos esbozar que la expresión proceso de cuidar en enfermería recoge la forma de pensar y la forma de hacer de los profesionales de enfermería. Esta forma de pensar y de hacer se personalizará cuando esté dirigida a un sujeto concreto (entendido como persona, familia o comunidad). Así el proceso de cuidar en enfermería quedaría definido como el ejercicio de las posibilidades o facultades propias de la profesión de enfermería. Significa una forma de pensar propia en torno al ser humano, a su salud, al entorno y al cuidado, y una forma de hacer condicionada por los resultados de la acción de pensar (figura 1).

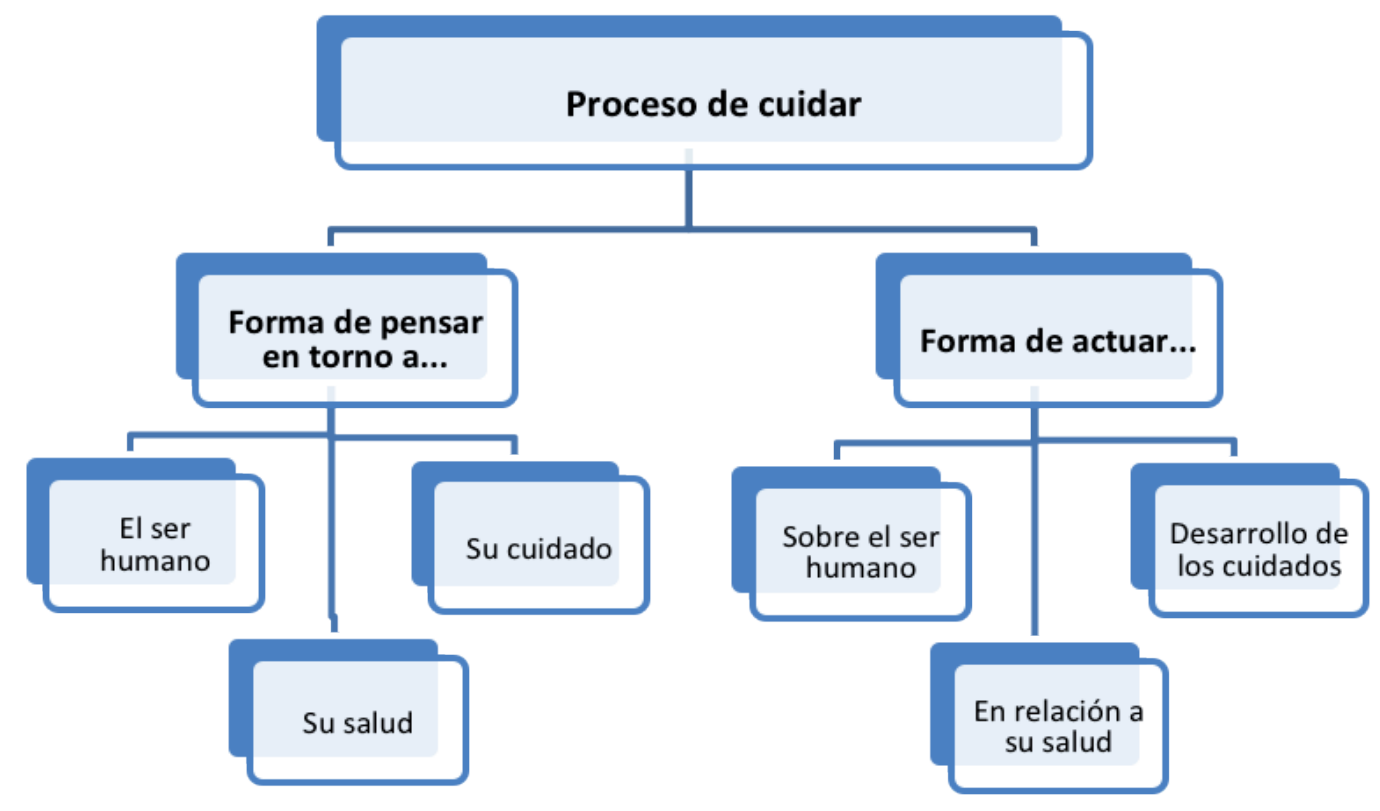

Figura 1. El proceso de cuidar. Benavent, 2009

Teniendo en cuenta lo establecido anteriormente, es fácil observar la enorme complejidad que implica el proceso de cuidar. Al definir el término proceso hemos visto que se impregnaba de características como proyectar hacia delante y no tener fin. Si a esto le añadimos la continuidad, variedad y diversidad que exige la acción de cuidar, este término se complica.

Cuando hablamos de proceso de cuidar estamos identificando una secuencia de acciones que podríamos señalar cuando comienza, pero cuyo fin no se dará hasta que no concluya el proceso de vida misma. Los seres humanos llevamos a cabo, para nosotros mismos y para los demás, un proceso de cuidar que se prolonga desde el nacimiento hasta la muerte y que está en continua variación. Pero, el proceso de cuidar como acción profesional queda vinculada a las enfermeras exigiéndoles un compromiso que va más allá de la mera realización de una serie de acciones de 
cuidados aprendidas como parte de las costumbres culturales de un grupo humano y sin más base que la tradición. Este compromiso alcanza al desarrollo disciplinar por cuanto se hace necesario:

a) Definir qué son y cómo son esas acciones de cuidados que encierra el proceso de cuidar.

b) Establecer la relación entre dichos cuidados y la especificidad de la acción del profesional de enfermería.

c) Identificar, describir y analizar un instrumento que haga posible el proceso de cuidar profesionalmente.

\subsection{Acciones que comporta el proceso de cuidar}

El profesional de enfermería, responsabilizado del proceso de cuidar, debe estar capacitado para llevar a cabo una serie de actividades. Estas actividades, marcadas por la definición que se ha presentado sobre el proceso de cuidar, son:

a) Identificar la necesidad del cuidado: considerando las variables individuales, grupales y culturales que modifican esta necesidad. Esto supone para El profesional de enfermería un ejercicio complejo, puesto que le obliga a dotarse de la información que le permita identificar el efecto de las variables en cada suceso o situación concreta y a tener conocimiento del efecto que las distintas culturas tienen sobre la manifestación de la necesidad de cuidados.

b) Identificar el tipo de cuidados requeridos: para dar respuesta a esa necesidad detectada. Para llevar a cabo esta actividad, el profesional de enfermería, además de necesitar un conocimiento técnico acerca de los tipos de acciones que le permitirán satisfacer la necesidad identificada, deberá conocer si el sujeto ya ha realizado acciones encaminadas a satisfacer esta necesidad, qué tipo de acciones son y determinar el valor real que tienen en esa situación y el valor entendido como significado para el sujeto.

c) Identificar la capacidad del sujeto para llevar a cabo dicho cuidado: el profesional cuando cuida no puede ni debe olvidar que está entrando en el ámbito de autonomía del sujeto. Esto exige que coincidamos en las propuestas de enfermeras como Henderson u Orem cuando se refieren a que el sujeto debe ser autónomo en el menor tiempo posible, debiendo participar al máximo nivel de sus posibilidades en el proceso de cuidados. Para ello, la enfermera debe determinar las posibilidades de participación del sujeto en su proceso de cuidados (tanto físicos como mentales), su actitud e interés en la participación y finalmente la aceptación explícita.

d) Identificar la manera en que podremos satisfacer dicho cuidado: esto es la manera en que vamos a llevar a cabo la acción de cuidar. Concretar las tareas a realizar, determinar el tiempo que cada una de estas tareas exige, y determinar el material y/o instrumentos que necesitamos.

e) Determinar la delegación de acciones: el compromiso que las enfermeras asumimos de hacer participar al sujeto en su proceso de cuidados nos obliga a identificar cuál o cuáles de las acciones necesarias deberemos llevar a cabo 
personalmente, y cuál o cuáles aquellas que podremos delegar en el propio sujeto. Pero la delegación no solo es posible hacerla en el sujeto, sino que también la enfermera podrá traspasar algunas de las acciones programadas entre el personal técnico y cuidadores informales que componen el equipo de cuidados.

f) Considerar el carácter ético que tiene el proceso de cuidar: los valores que condicionan la necesidad de cuidado dotan de carácter ético al proceso de cuidar.

g) Ejecutar las acciones concretas de cuidado: la ejecución es la muestra del hacer y la práctica de la enfermería profesional, y requiere de la realización de una serie de técnicas variadas en cuanto a su complejidad que no son el fin del proceso de cuidar.

h) Evaluar los resultados: El proceso de cuidar, como secuencia de acciones dirigidas a un fin, exige de la evaluación de los resultados que dichas acciones producen en la dirección del fin que se persigue. Considerando además que el proceso no tiene fin siempre, esta evaluación no debe entenderse como un punto y aparte, sino como un punto y seguido.

El proceso exige una secuencia de acciones encadenadas, cohesionadas e interdependientes que respondan a un fin y que no tendrán final: el fin es conseguir el máximo nivel de bienestar de las personas a las que cuidamos y además es sin final, porque hasta el último momento de nuestra vida los seres humanos necesitamos cuidados.

La exigencia de que exista esta conexión en las acciones que comporta el proceso de cuidar, de no perder la meta de este proceso, y de consolidar el proceso de cuidar como la esencia de la disciplina enfermera obliga a la utilización de un instrumento metodológico que permita garantizar todo ello.

\subsection{La necesidad de un instrumento metodológico para el proceso de cuidar}

Solo la utilización de una metodología nos permitirá llevar a cabo estas acciones, transformar el conocimiento común en conocimiento científico, posibilitando la consolidación de la actividad de cuidar como actividad profesional. Este será uno de los argumentos que justificarán la necesidad de utilizar el proceso de cuidados enfermero.

Al no utilizar una metodología concreta corremos el riesgo de perder información, obtener una información inexacta, incluir juicios de valor, perder la objetividad de la información y no mantener la secuencia de dicha información en el desarrollo de la historia. Además, no nos sirve un documento cualquiera para recoger la información, sino que este debe tener una estructura que permita alcanzar el objetivo de los cuidados, un orden que favorezca su utilización y una flexibilidad que permita a la enfermera adaptarlo a la diversidad a la que debe atender. 
Un joven estudiante de la Universitat Jaume I tiene 21 años y obtuvo una beca Erasmus para ir a cursar el último año de sus estudios en una universidad portuguesa. Inició su estancia en noviembre y a finales del mismo mes su padre sufre un infarto cerebral y muere. Su madre le llama a Portugal pero le dice que no es necesario que venga. Él como están próximas las vacaciones decide venir. En enero vuelve a Portugal y mantiene comunicación telefónica con su madre. Un mes después decide ponerse a trabajar de repartidor para poder enviar algo de dinero a su madre y conoce a una persona con quien establece muy buenas relaciones y acaban decidiendo vivir juntos. Su madre se encuentra muy sola y él decide llevársela a Portugal. Cuando la madre llega se instala a vivir con ellos, las relaciones se hacen muy dificiles y la madre decide volver a España.

Al carecer de un instrumento metodológico para la recogida de datos de la historia que acabamos de contar, se producen los siguientes cambios en la historia. Así pues, normalmente, el estudiante pasa a transformarse en un estudiante de enfermería; las circunstancias del fallecimiento del padre se modifican; las vacaciones que se aproximan pasan a ser, sin duda, las de Navidad; el hijo acaba siendo hijo único; el trabajo de repartidor acaba concretándose en repartidor de pizzas u otros; la persona a quien conoce es una chica y suele mantener una relación amorosa con ella; por último, la dificultad en las relaciones se achaca a una mala relación entre la madre y la chica con la que vive su hijo.

Por lo tanto, podemos observar de forma directa que, si no se usa un instrumento metodológico:

a) Se ha perdido información.

b) La información que queda es inexacta.

c) Se han incluido juicios de valor.

d) La información ha perdido objetividad.

e) No se ha mantenido la secuencia en el desarrollo de la historia, lo cual hace difícil retener la información recibida.

Si trasladamos este ejercicio a una situación de cuidados donde la información a transmitir puede estar referida a varios sujetos, si esta información no está escrita, recogida en el momento en que se ha observado y si el objetivo de nuestra actuación no está claramente identificado y definido, no nos deberá extrañar que adjudiquemos la información de una persona a otra diferente, que olvidemos aspectos importantes y que señalemos como importante solo aquello que desde nuestra percepción y perspectiva particular consideramos fundamental.

Esta pequeña reflexión pone de manifiesto la necesidad de recoger, utilizando un documento escrito, el resultado de nuestras acciones de cuidados. Ese documento escrito, además, deberá tener: 
a) Una estructura que permita alcanzar los objetivos de cuidados.

b) Un orden que favorezca su utilización.

c) Una flexibilidad que permita a la enfermera adaptarlo a la diversidad a la que debe atender.

\section{Valoración: instrumentos a utilizar}

La valoración del paciente es la primera etapa del proceso de cuidar, al que, de ahora en adelante vamos a determinar a través del método enfermero. El paralelismo que mantienen dicho proceso y el método científico nos permite identificar de manera inmediata las características de esta etapa y su finalidad: identificar las respuestas del sujeto ante una determinada situación o problema de salud.

Podemos identificar en esta etapa seis niveles de recogida de datos a través de las cuales llegamos a alcanzar el objetivo propuesto. Estos seis niveles los podemos describir como:

1. Entrevista/anamnesis.

2. Exploración:

a) Física de cabeza a pies, focalizando por aparatos y sistemas.

b) Exploración neurológica.

3. Uso de herramientas de valoración biopsicosocial (test y encuestas):

a) Actividades básicas de la vida diaria: Barthel/Katz.

b) Riesgo de úlceras por presión: Norton/Braden.

c) Alteración cognitiva: Pfeiffer.

d) Riesgo de desnutrición: NSI.

e) Riesgo de exclusión social: APGAR familiar.

f) Riesgo de caídas: Morse

4. Realización de pruebas diagnósticas y terapéuticas:

a) Toma de constantes.

b) Toma de muestras.

c) Diagnóstico por imagen.

5. Valoración específica de procesos asistenciales.

6. Valoración específica de patologías.

Tratar seis niveles distintos de recogida de datos, al inicio del proceso de cuidar a través del método enfermero, no es un capricho casual. Debemos ser conscientes de que no conocemos al nuevo usuario o paciente que se nos presenta y, por tanto, tenemos que indagar y valorar en todo aquello que pueda afectar a su proceso de salud-enfermedad, así, deberemos realizar una valoración lo más completa posible que incluya cada uno de los aspectos que nosotros consideramos relevantes reflejar y cada uno de los aspectos que el paciente considere importantes remarcar sobre su propio proceso.

Es importante señalar que las actividades que el profesional de enfermería lleva a cabo durante esta etapa son actividades que se realizarán a lo largo de todo el método 
enfermero, lo que nos permite remarcar la afirmación de que la interdependencia existe entre las etapas. Esta característica de la valoración significa la confirmación de que las actividades que llevamos a cabo a lo largo de las etapas del proceso no se producen en un momento temporal concreto y aislado sino que se extienden a lo largo de todo el proceso.

Por lo tanto, la valoración se utilizará para detectar un problema durante todas las fases, para obtener información sobre la respuesta del cliente a las acciones de la enfermera y, en la etapa de la evaluación, para comprobar si los objetivos han estado conseguidos. Kozier, Erb y Olivieri (1993) afirman que: «La valoración es un proceso continuado que la enfermera realiza en cada una de las etapas del proceso de atención de enfermería».

La valoración nos permitirá obtener información que no solo nos ayudará a identificar problemas, sino que también nos mostrará cuáles son los cuidados que el sujeto se da a sí mismo y cómo dichos cuidados están incidiendo en su salud y bienestar.

Un carácter más amplio tiene la definición de valoración que proponen Benavent, Ferrer i Francisco (2009) al afirmar que es «un método sistemático de recogida de datos que consiste en la apreciación del sujeto con la finalidad de identificar las respuestas que manifiesta en relación con las diversas circunstancias que le afectan». Las respuestas a las que se refieren los autores pueden indicarnos la existencia de un problema, la presencia de un factor etiológico, o bien describirnos una situación de salud.

\section{Planificación de los cuidados}

Esta etapa puede definirse como la agrupación de datos para establecer un juicio clínico sobre el problema o afección del paciente o, dicho de otro modo, para establecer un diagnóstico.

Además, esta etapa incluye la formulación de objetivos mensurables, realistas y centrados en el paciente, que permitan proporcionar una atención personalizada y los procedimientos que permitirán alcanzar los objetivos propuestos.

Identificar tanto los objetivos como los procedimientos a seguir para alcanzarlos, implica, de forma explícita la planificación de actividades para la consecución de objetivos, de esta forma, esta etapa lleva de forma intrínseca la planificación del método enfermero en función de las respuestas que el paciente haya ofrecido en la etapa de valoración.

Diferentes autores definen la planificación como:

a) «Es el momento en que se determinará cómo brindar los cuidados de enfermería de forma organizada, individualizada y orientada a los objetivos». Alfaro, 2003. 
b) «Implica el desarrollo de estrategias diseñadas para reforzar las respuestas saludables del sujeto o evitar, reducir o corregir las respuestas insanas». Iyer, Taptich y Bernocchi-Losey (1997).

c) «El establecimiento de un plan de acción, en prever las etapas de su realización, las acciones que se han de llevar a cabo, los medios que hay que emplear y las precauciones que hay que adoptar, en pocas palabras, en pensar y organizar una estrategia de cuidados bien definida». M. Phaneuf, 1999.

Dentro de la etapa de diagnóstico que estamos tratando, desarrollaremos por tanto:

1. Planificación:

a) Guías y vías clínicas de cuidados

b) Según la dependencia

c) Cuidados técnicos

2. Respuestas humanas ante problemas de salud:
a) Alimentación
b) Higiene
c) Eliminación
d) Movilidad
e) Respiración
f) Comunicación
g) Seguridad
h) Sexualidad/reproducción

3. Dependencias en cuidados básicos en función del resultado ofrecido por Barthel:
a) Comida
b) Arreglo
c) Vestido
d) Baño/ducha
e) Deposición
f) Micción
g) Ir al retrete
h) Transferencia
i) Deambulación
j) Subir y bajar escaleras

4. Problemas específicos por grupos de procesos asistenciales.

5. Problemas específicos por patologías.

6. Situaciones de riesgo en cuidados básicos y específicos. 


\section{Etapa de intervención}

La etapa de intervención, dentro del método científico, correspondería a la etapa de tratamiento de enfermería en el correspondiente método enfermero.

Podemos definir esta etapa como el momento en el que la enfermera lleva a cabo las actividades programadas en la etapa de planificación o, como afirma Alfaro (2003): «Es poner en acción las estrategias enumeradas en el plan de atención; es la acción de enfermería que permite llegar al resultado deseado de los objetivos del cliente».

Así, podemos observar que las intervenciones de enfermería son «cualquier tratamiento, basado en el criterio clínico y los conocimientos que el personal de enfermería lleva a cabo para mejorar la respuesta del paciente» (Bulechek, Butcher y Dochterman, 2008).

Las intervenciones de enfermería sirven para:

a) Controlar el estado de salud.

b) Evitar, solucionar o controlar un problema.

c) Ayudar en las actividades de la vida diaria.

d) Promover una salud óptima y la independencia.

De este modo, determinamos que los procedimientos a llevar a cabo en esta etapa de intervención son:

1. Procedimientos generales en cuidados básicos:

a) Mantenimiento de la máxima autonomía posible del paciente.

b) Supliéndola solo cuando sea necesario.

c) Enseñanza de autocuidados a paciente y cuidador.

2. Procedimientos específicos por grupos de procesos asistenciales dirigidos a solucionar los problemas, aumentar la independencia y fomentar los autocuidados.

3. Procedimientos específicos por patologías dirigidos a solucionar los problemas, aumentar la independencia y fomentar los autocuidados.

4. Procedimientos dirigidos a eliminar los peligros o disminuir el riesgo de cuidados básicos y específicos. 


\section{Evaluación de los cuidados}

De acuerdo con Craven y Himle (1996), la evaluación de los cuidados consiste en «juzgar la eficacia de la atención de enfermería a la hora de alcanzar los objetivos y resultados del paciente en función de cómo responde este ante las intervenciones». El propósito de la evaluación es establecer criterios sobre la evolución del paciente, analizar la eficacia de los cuidados de enfermería, revisar las posibles áreas de colaboración con otros profesionales de la atención sanitaria y la derivación a dicho profesionales, y controlar la calidad de la atención de enfermería y su efecto en el paciente (Alfaro-LeFevre). El personal de enfermería valora tanto los factores favorables para alcanzar dichos objetivos como los obstáculos, considerando que «los objetivos pueden alcanzarse por completo, parcialmente o no lograrse; además, pueden aparecer nuevos problemas por el camino», tal y como afirma Alfaro-LeFevre (1996), ya que la evaluación debe ser una acción continua y formal que está presente a lo largo de todo el proceso del método enfermero, así es parte integral de cada una de las etapas vistas hasta ahora.

Concretamente, en atención especializada, para evaluar el trabajo llevado a cabo, valoraremos:

a) Indicadores generales hospitalarios: estancia media, estancia media ajustada, mortalidad, recaídas, índice de frecuentación, etc.

b) Indicadores hospitalarios de calidad de los servicios de enfermería: UPP, caídas, infección nosocomial, nivel de dependencia, desnutrición, complicaciones del catéter vesical, etc.

c) Indicadores especificos en servicios especiales: UCI, urgencias y quirófano. 


\section{CAPITULO 3}

\section{Los cuidados básicos: definiciones}

\section{Introducción}

El origen de los cuidados básicos de enfermería se encuentra en el origen de la propia humanidad, es decir, en las necesidades de alimentación, higiene, eliminación o seguridad que el ser humano tiene como tal y que se ven afectadas, o alteradas, en caso de enfermedad.

Desde la prehistoria han existido diferentes grupos de personas que han asumido la cobertura de estas necesidades en las personas enfermas o con incapacidades. La evolución de estos colectivos han llevado a la profesionalización del cuidado, cuyo máximo exponente en la actualidad es la enfermería.

El objetivo de este tema es conocer el concepto de cuidados básicos, identificándolos como parte fundamental del cuidado y responsabilidad de los profesionales de enfermería.

\section{Definición de cuidados básicos de enfermería}

El concepto de cuidados básicos de enfermería ha sido fuente de debate durante muchos años. Por una parte, al observar diferentes teorías y modelos de enfermería desarrolladas por autoras de prestigio como F. Nightingale (1980), V. Henderson (1978), D. Orem (citada por Crisp et al., 2009) o N. Roper (1983), los cuidados básicos aparecen como una parte fundamental de la enfermería (tabla 1). Por otra parte, en la práctica asistencial los profesionales eluden esta responsabilidad, delegando estas tareas en otros colectivos con menor nivel académico, y la investigación en enfermería explora la eficacia de procedimientos técnicos, relegando los cuidados básicos a un segundo plano.

\begin{tabular}{c|cccc}
\hline Cuidado básico & F. Nightingale & V. Henderson & D. Orem & N. Roper \\
\hline Seguridad & $\checkmark$ & $\checkmark$ & $\checkmark$ & $\checkmark$ \\
Comunicación & $\mathbf{X}$ & $\checkmark$ & $\checkmark$ & $\checkmark$ \\
\hline
\end{tabular}




\begin{tabular}{c|cccc}
\hline Cuidado básico & F. Nightingale & V. Henderson & D. Orem & N. Roper \\
Respiración & X & $\checkmark$ & $\checkmark$ & $\checkmark$ \\
Alimentación & $\checkmark$ & $\checkmark$ & $\checkmark$ & $\checkmark$ \\
\hline Eliminación & X & $\checkmark$ & $\checkmark$ & $\checkmark$ \\
Higiene & $\checkmark$ & $\checkmark$ & $\mathbf{X}$ & $\checkmark$ \\
Sueño y descanso & $\checkmark$ & $\checkmark$ & $\checkmark$ & $\checkmark$ \\
Temperatura & $\mathbf{X}$ & $\checkmark$ & $\mathbf{X}$ & $\checkmark$ \\
Ejercicio y movilidad & $\mathbf{X}$ & $\checkmark$ & $\checkmark$ & $\checkmark$ \\
Sexualidad & $\mathbf{X}$ & $\mathbf{X}$ & $\mathbf{X}$ & $\checkmark$ \\
\hline
\end{tabular}

Tabla 1. Cuidados básicos reflejados por diferentes autoras. Adaptado de Kitson et al., 2010

Vestirse, asearse, comer o ir al baño son actividades de la vida diaria, cotidianas y habituales, que las personas ejecutan de modo independiente, sabiendo cómo hacerlo y las posibles consecuencias de no hacerlo correctamente. En otras palabras, puede decirse que los cuidados básicos forman parte de un conocimiento tácito que se transmite de generación en generación. Pero, ¿qué ocurre cuando una persona se ve afectada por un problema de salud? ¿mantiene ese nivel de independencia para ejecutar todos o algunos de esos autocuidados?, o por el contrario ¿va a necesitar la ayuda de otros para ello?

Talens y Casabona aportan que los cuidados básicos (2013) de enfermería deben entenderse como aquellas acciones/actividades generales y comunes que realizan las enfermeras sobre cualquier individuo que se encuentre ingresado en una unidad hospitalaria, con independencia del problema de salud que motivó su ingreso. Son acciones para las que estar capacitadas por sus conocimientos de enfermería y legitimadas por su titulación en enfermería.

Siguiendo a Kitson et al. (2010) los cuidados básicos de enfermería pueden definirse como los cuidados que requiere cualquier persona, sea cual sea su diagnóstico médico y complementando el tratamiento médico prescrito. Además hay que tener en cuenta que estos cuidados son aplicables en cualquier medio: el hogar, el hospital, la escuela, etc. Por lo tanto, aplicar los cuidados básicos de enfermería consiste en atender al individuo, sano o enfermo, en la ejecución de aquellas actividades que contribuyen a su salud o al restablecimiento de la misma; teniendo en cuenta que siempre debemos dirigir a la persona hacia el mayor grado de independencia posible.

\subsection{Los cuidados básicos durante la hospitalización y la visión de las enfermeras}

Los cuidados de enfermería durante la hospitalización proporcionan seguridad a los pacientes y familiares, aseguran una calidad asistencial en los procedimientos derivados de la patología y son responsabilidad de los profesionales de enfermería. 
Los cuidados pueden clasificarse en cuidados directos y cuidados indirectos:

1. Los cuidados indirectos son aquellos relacionados con el entorno del paciente y cuestiones organizativas como comunicación con otras unidades, gestión de traslados, relaciones con la atención primaria de salud, actividades multidisciplinares, sesiones clínicas, etc.

2. Los cuidados directos son aquellos que se realizan directamente sobre los pacientes. A su vez, se dividen en:

a) Cuidados técnicos: en general, se asocian a las enfermedades que motivaron el ingreso y su tratamiento, e implican la realización de procedimientos instrumentales

b) Cuidados especificos relacionados con la hospitalización: son responsabilidad de los servicios de enfermería, están orientados hacia la seguridad de las personas y se relacionan con la pérdida de autonomía. Requieren de procedimientos y técnicas específicas dirigidas a la cobertura de los cuidados básicos y la prevención de efectos adversos (úlceras por presión, caídas, adherencia al tratamiento, etc.).

Pero ¿qué visión tienen las enfermeras de los cuidados en los servicios de hospitalización? Talens Belén y Casabona Martinez (2013) concluyen en su estudio que:

Entre las enfermeras asistenciales está presente una ambigüedad conceptual en torno al significado de los cuidados de Enfermería. Reducir la práctica clínica y asistencial a la mera ejecución de técnicas y actividades conduce a una percepción distorsionada de los cuidados de Enfermería, en plena oposición a su naturaleza holista.

La naturaleza de los cuidados de Enfermería ha de estar presente en todas las acciones, actividades y técnicas que la enfermera dirige al paciente, como marca de identidad enfermera. Integrar tales actividades y técnicas como ente constitutivo de los cuidados de Enfermería precisa de la existencia de interrelación enfermera-paciente, la cual permite establecer e identificar las necesidades de los pacientes en todas sus dimensiones, con el fin de contribuir a satisfacerlas. El juicio clínico, lo posibilitan conocimientos procedentes de la ciencia biomédica y de las humanidades, que permita el pensamiento y criterio reflexivo. Finalmente, tales acciones y técnicas han de ser autonomía y competencia profesional de la enfermera.

Supeditar la Enfermería a la mera ejecución de técnicas supone una amenaza para los propios fundamentos y principios de la profesión y disciplina enfermera. A día de hoy, técnicas realizadas recientemente por enfermeras, son realizadas legítimamente por otros estamentos profesionales. Para que una técnica sea autónoma de Enfermería y no pueda ser reclamada por otro estamento profesional ha de estar integrada en los cuidados de Enfermería.

Como hemos visto, a pesar de los esfuerzos de las principales teóricas por articular el cuerpo de conocimientos propio de la enfermería a partir de los cuidados básicos, pero no parece que los profesionales asuman esta responsabilidad. La formación en enfermería se ha llevado a cabo durante mucho tiempo desde una perspectiva técnica (centrada en la capacidad de ejecutar procedimientos), biomédica (centrada en la patología y no en la persona) y subordinada a otros profesionales. Este hecho, unido a otros como la delegación de tareas o las rutinas de trabajo, hace que los nuevos profesionales, con una formación más amplia basada en los fundamentos del cuidado, se vean engullidos por un sistema productivo basado 
en la división de tareas que dificulta el desarrollo de un cuerpo de conocimientos propio.

Kitson, Athlin y Conroy (2014) afirman que la enfermería debe explorar los cuidados básicos como aspectos fundamentales de la atención al paciente, de una manera sistemática, conceptualmente coherente y científica, y que para ello se debe hacer frente a los siguientes desafíos:

a) La necesidad de pensar de una forma integrada acerca de los cuidados básicos desde el punto de vista conceptual, metodológico y práctico.

b) La tensión continua en la práctica de enfermería entre un enfoque despersonalizado y mecanicista de los cuidados básicos.

c) La necesidad de coherencia en torno a la comprensión y el manejo de la dinámica de la relación enfermera-paciente o encuentro.

d) La necesidad de un enfoque sistemático de los cuidados básicos que combine las dimensiones físicas, psicosociales y relacionales en los entornos asistenciales.

\section{Responsabilidad legal}

A nivel internacional, son varios los informes que ponen en evidencia la calidad de los cuidados que reciben los pacientes en los hospitales (Francis, 2013), los efectos adversos ligados a la hospitalización (Kohm et al., 1999; Ministerio de Sanidad y Consumo, 2006) o plantean una serie de medidas para mejorar la calidad de los cuidados (Institute of Medicine, 2010; Garling, 2008). En todos estos informes se observa la presencia de los cuidados básicos, de un modo más o menos directo, como un aspecto fundamental de los cuidados de enfermería y su relación con la calidad de la asistencia, en cuanto a satisfacción y seguridad de los pacientes.

Existen sobrados motivos para afirmar que los profesionales de enfermería tienen una responsabilidad para con los cuidados básicos de las personas que atienden, aunque estos se deleguen en otros profesionales, pero ¿qué dice la legislación al respecto?

En España, la Ley 44/2003, de 21 de noviembre, de Ordenación de las Profesiones Sanitarias expone en su artículo 7 que:

1. Corresponde, en general, a los Diplomados sanitarios, dentro del ámbito de actuación para que les faculta su correspondiente título, la prestación personal de los cuidados o los servicios propios de su competencia profesional en las distintas fases del proceso de atención de salud, sin menoscabo de la competencia, responsabilidad y autonomía propias de los distintos profesionales que intervienen en tal proceso.

2. Sin perjuicio de las funciones que, de acuerdo con su titulación y competencia específica corresponda desarrollar a cada profesional sanitario, ni de las que puedan desarrollar otros profesionales, son funciones de cada una de las profesiones sanitarias de nivel Diplomado las siguientes: 
a) Enfermeros: corresponde a los Diplomados universitarios en Enfermería la dirección, evaluación y prestación de los cuidados de Enfermería orientados a la promoción, mantenimiento y recuperación de la salud, así como a la prevención de enfermedades y discapacidades.

Por otra parte, la Orden CIN/2134/2008, de 3 de julio, por la que se establecen los requisitos para la verificación de los títulos universitarios oficiales que habiliten para el ejercicio de la profesión de enfermero, establece las competencias que deben ser adquiridas; entre ellas, pueden destacarse las siguientes:

a) Identificar, integrar y relacionar el concepto de salud y los cuidados, desde una perspectiva histórica, para comprender la evolución del cuidado de enfermería.

b) Aplicar el proceso de enfermería para proporcionar y garantizar el bienestar la calidad y seguridad a las personas atendidas.

c) Dirigir, evaluar y prestar los cuidados integrales de enfermería al individuo, la familia y la comunidad.

d) Conocer las alteraciones de salud del adulto, identificando las manifestaciones que aparecen en sus distintas fases. Identificar las necesidades de cuidado derivadas de los problemas de salud. Analizar los datos recogidos en la valoración, priorizar los problemas del paciente adulto, establecer y ejecutar el plan de cuidados y realizar su evaluación. Realizar las técnicas y procedimientos de cuidados de enfermería, estableciendo una relación terapéutica con los enfermos y familiares. Seleccionar las intervenciones encaminadas a tratar o prevenir los problemas derivados de las desviaciones de salud. Tener una actitud cooperativa con los diferentes miembros del equipo.

En ambos textos se describe la responsabilidad de los profesionales de enfermería con respecto a la valoración, planificación, ejecución y evaluación de los cuidados. Es evidente que al hablar de cuidados se incluyen tanto los cuidados básicos como los derivados de la realización de técnicas más complejas. El hecho de que los cuidados básicos se deleguen a otros miembros del equipo de cuidados (auxiliares de enfermería, celadores, etc.) no significa que no sean responsabilidad de enfermería. 


\section{CAPITULO 4 \\ Cuidados básicos basados en la evidencia}

\section{Introducción}

Se define la investigación científica como un intento de incrementar la suma de lo que se conoce, usualmente referido como cuerpo de conocimientos, mediante el descubrimiento de nuevos hechos y relaciones a través de un proceso de indagación sistemática y científica. Una definición más exhaustiva es la de Kerlinger (1975): «La investigación científica es una investigación sistemática, controlada, empírica y crítica, de proposiciones hipotéticas sobre las supuestas relaciones que existen entre fenómenos naturales». Esta definición aporta sobre la anterior la presencia de dos notas características de la investigación científica, como son su carácter crítico, antidogmático y el control que preside todo su proceso para excluir el mayor número de explicaciones rivales. Sin embargo, no está exenta de problemas, el principal: excluye la investigación con fines exploratorios, descriptivos, predictivos y evaluativos.

Es llamativo conocer que el término investigar en enfermería es un concepto que no se define con frecuencia, de forma que muchos textos de investigación en enfermería pasan de largo ante este punto. Aun así, podemos encontrar diversas definiciones desde el año 1965. Estas definiciones van añadiendo características a medida que se va desarrollando dicho concepto de investigación en enfermería, aspectos como por ejemplo la salud, la promoción y la calidad de vida o la práctica enfermera que pone especial énfasis en la educación y la gestión. En el año 1992 Notter y Hott realizaron la siguiente definición: «Investigación sistemática de la práctica de la enfermería y del efecto de su práctica en el cuidado del paciente, de la familia o la comunidad». Esta definición aporta por sí misma la connotación reseñada de la práctica enfermera, sin distinción desglosada de dicha práctica. Por lo tanto, se entiende que cualquier actividad de enfermería, sea de la índole que sea, incluida la educación y la gestión o administración, se incluye comúnmente en el término general de investigación en enfermería.

Talbot, en el año 1995 describe el concepto de investigación en enfermería como crear y mantener una sólida base científica para la práctica de la enfermería. Esto se logra mediante la generación y validación de conocimiento que promueva mejores resultados en los cuidados de los pacientes. En esta definición podemos añadir, de forma distintiva al resto, la referencia al método científico como método para crear dicha base para la práctica enfermera. 
Tres son las cuestiones más relevantes que se extraen de estas definiciones. En primer lugar, la investigación en enfermería debe dirigirse a cuestiones relevantes para los profesionales y debe desarrollar un cuerpo único de conocimientos para la práctica de enfermería. En segundo lugar, se encuentra la diferenciación del foco de la investigación, iniciada por Notter y Hott, e implícita en la mayoría de las definiciones con distinto grado de importancia. Por un lado, encontraríamos la investigación centrada en cuestiones relacionadas con la educación, administración, servicios de salud, etc., que repercuten indirectamente en la práctica de enfermería. Y por otro lado, encontramos la investigación relacionada directamente con la práctica de enfermería, que estudiaría la mejora de los resultados en los cuidados del paciente, familia o comunidad. En tercer lugar, la dimensión interdisciplinaria de la investigación queda reflejada de manera explícita, ya que existen aspectos del cuidado del paciente que están relacionados con otras disciplinas.

De esta forma, podemos distinguir dos prioridades básicas de la investigación en enfermería:

a) Necesidad de desarrollar conocimiento para sostener la práctica.

b) Necesidad de salvar la separación entre la práctica y la investigación; de forma que los hallazgos de la investigación sean canalizados a la práctica.

\section{Etapas del proceso de investigación}

Llegados a este punto, conocer las etapas del proceso de investigación se hace sustancial. Así, al desarrollar una investigación, las etapas que componen la misma son:

a) Fase conceptual: formularíamos y delimitaríamos el problema que queremos tratar. Realizaríamos una revisión de la literatura, crearíamos el marco teórico sobre el que vamos a trabajar y formularíamos los objetivos, preguntas o hipótesis.

b) Fase de diseño y planificación: en esta segunda fase estableceríamos lo que se conoce como plan metodológico. En él se especificaría el diseño de investigación; la población y muestra que van a formar parte de nuestro estudio; las variables que vamos a tratar y considerar para el estudio; los métodos a emplear para la obtención de datos (por ejemplo si vamos a usar una encuesta) y revisar el plan y ejecutar un estudio piloto si es necesario.

c) Fase empírica: en esta etapa es donde se pondría en marcha todo lo establecido en la segunda fase. De esta forma, aquí se llevaría a cabo la recogida de datos y, además, se revisaría y prepararían los datos para su análisis.

d) Fase analítica: tras preparar los datos para su análisis, se explotarían los mismos para intentar extraer el máximo partido de ellos, dando también 
interpretación a los resultados obtenidos y elaborando aportaciones propias a los mismos. Este proceso se llevaría a cabo en esta fase.

e) Fase de diseminación: en esta fase se lleva a cabo la comunicación de los resultados, tras conocerse, pueden ser usados en la práctica si son de tal relevancia que impliquen cambios notorios en la misma. Esta es la fase donde vamos a centrar nuestra atención durante esta exposición, debido a que nuestro objetivo hoy aquí es aplicar la investigación a través de la PBE y para aplicar dicha investigación deberemos conocer previamente cómo se disemina o difunde y cómo acceder a la misma.

No podemos proseguir, por tanto, sin definir la utilización misma de la investigación, dando por entendido que se trata de un proceso complejo con rasgos políticos, organizacionales, socioeconómicos y actitudinales, por el que se incorporan los hallazgos o innovaciones a la práctica. Como se puede apreciar en esta definición, la utilización de la investigación no viene delimitada únicamente por lo que podríamos denominar coloquialmente como «tener ganas» (ganas por parte del profesional de buscar, de averiguar, de preocuparse, de indagar) sino que esta utilización viene determinada por una serie de factores en los que ahondaremos y profundizaremos, para tratar de ser más conscientes de las variables que nos rodean y que favorecen o dificultan la llegada de la investigación a la práctica diaria en enfermería.

En este proceso complejo del que tratamos, tenemos que ser conscientes que hay autoras como Christine Hancock, secretaria general del Royal College of Nursing of The United Kingdom, que en el año 1993 vertía sus opiniones acerca de la relevancia y la utilidad de investigar en enfermería y aportaban que «el progreso se desplomará si la profesión no se renueva ni se fortalece continuamente con nuevo conocimiento y nuevas ideas derivadas de la investigación». Así, observando y analizando lo que diferentes autores aportan al respecto, podemos resumir que todas estas declaraciones inciden en:

a) la importancia fundamental de la investigación para el desarrollo de una profesión autónoma,

b) la necesidad de ejercer una práctica (incluida la gestión y la educación) fundamentada científicamente y validada por la investigación,

c) la necesidad de que los hallazgos de la investigación sean diseminados y utilizados,

d) algunos autores enfatizan que la investigación no debe contemplarse como algo extraordinario o un lujo, por si quedase todavía alguna duda. Existe, por consiguiente, un elevado grado de acuerdo sobre la relevancia de la investigación y la finalidad de la misma.

Por desgracia, la incorporación de la investigación a la práctica clínica, depende de muchos factores, unos podremos controlarlos de forma individual y otros no. Pasamos ahora a ahondar en esos determinantes de la utilización de la investigación. En diversos estudios se determinan que las características organizacionales explican entre un 80 y un $90 \%$ del total de la varianza, mientras que los factores 
ambientales contribuyen entre un 5 y un $10 \%$, y las características individuales sólo entre el 1 y el $3 \%$. Otra conclusión general, a través de estudios, es que los efectos de muchas de estas variables son inestables, lo que sugiere la importancia del contexto y por tanto la limitada validez externa de los hallazgos.

Entre las características individuales, las más estudiadas son: la edad, el género, la educación, la ocupación, el estatus de empleo, la autoridad dentro de la organización para implementar el cambio, el contacto con consultores, el entrenamiento en habilidades de lectura crítica, la asistencia a conferencias, el nivel de lectura de revistas, área de experiencia, implicación en actividades de investigación, formación en técnicas de investigación, etc. Por el contrario, entre las variables individuales no relacionadas con el uso de la investigación están: el ámbito de experiencia, la edad, el género y las habilidades de valoración crítica.

En cuanto a las características organizacionales, vienen referidas a las distintas unidades organizativas de la asistencia sanitaria (un servicio, un hospital, la administración general sanitaria, etc.). Entre las características que se han estudiado son: tamaño de la organización, urbano frente a rural, diversidad de tareas, niveles de jerarquía, acceso a literatura actual y relevante, centralización de la toma de decisiones, cultura, falta de apoyo de los gestores, formalización de las reglas, colegas, recursos financieros, clima de investigación en la organización, valor de la investigación en la organización, entrenamiento del personal, dependencia interorganizacional y mecanismos que favorecen el flujo de la información. Podemos determinar que casi todas las variables organizacionales estudiadas se han asociado con el uso de la investigación en al menos un estudio, pero las que más sistemáticamente lo han hecho son: el tamaño de la organización, la centralización de la toma de decisiones, el apoyo administrativo y el clima de investigación.

Por último, las características ambientales han sido las menos estudiadas en la literatura de enfermería. Entre estas figuran: urbanización, regulaciones y legislación, recursos financieros locales, densidad de población, edad de la organización y estructura reticular (network embeddedness). De entre estas últimas, urbanización y estructura reticular se han asociado significativamente con el uso de la investigación.

\section{Práctica basada en la evidencia}

La expresión medicina basada en la evidencia (MBE) fue acuñada en la Facultad de Medicina de la Universidad de McMaster, Canadá, en los años ochenta para referirse a una estrategia de aprendizaje clínico que ya llevaba desarrollándose una década en dicha facultad. La siguiente definición: «El uso consciente, explícito y juicioso de la mejor evidencia actual para la toma decisiones sobre el cuidado de los pacientes. Implica integrar la maestría clínica con la mejor evidencia externa derivada de la investigación sistemática», fue realizada por Sackett, Rosenberg, Gray, Haines y Richardson (1996). Esta añade que la MBE implica rastrear la mejor evidencia externa que dé respuesta a nuestras preguntas clínicas. 
En cuanto al motivo crucial del surgimiento de la MBE podemos encontrar que los mismos autores que definen la MBE exponen como sus razones:

a) Surgen continuamente nuevas evidencias relevantes para la clínica.

b) Es difícil acceder, localizar y obtener la información clínica relevante.

c) Como consecuencia de los dos primeros puntos, el conocimiento y la práctica clínica se vuelven obsoletos.

d) La educación continua tradicional no logra mejorar el rendimiento clínico.

e) La práctica de la MBE puede mejorar la práctica clínica y mantener actualizados a los profesionales.

Estos cinco puntos pueden resumirse en una idea: la MBE es una propuesta dirigida a salvar la separación entre la práctica y la investigación (research-practice gap). Y un supuesto que parece indiscutible es que la práctica debe estar basada en la más actual, fiable y válida evidencia procedente de la investigación.

Pero esta exposición de motivos no es suficiente para explicar el surgimiento de la MBE y, aún menos, su éxito. Éxito en cuanto a la velocidad de propagación e influencia en la política y asistencia sanitaria, particularmente en el Reino Unido y Canadá; a su rápida extensión internacional, y también a su contagio sobre otras disciplinas de la salud, como enfermería, odontología, salud pública, fisioterapia, salud mental; e incluso saltando a otras disciplinas fuera del ámbito de la salud, como la educación, la administración de los recursos humanos y el trabajo social disciplinas con un denominador común: su orientación a los servicios humanos. Por ello, este término de MBE ha evolucionado de forma forzosa a un término más general que puede abarcar todas estas disciplinas, acuñándose el término definitivo como práctica basada en la evidencia ( $\mathrm{PBE})$.

\section{Pregunta clínica estructurada}

Para conseguir tomar decisiones relativas al cuidado o atención de los pacientes en la práctica clínica, es necesaria una serie de elementos que configuren de forma robusta estas decisiones. Estas decisiones consecutivamente son:

a) En primer lugar, se formula una pregunta clínica referida a un problema de un paciente. La pregunta debe ser específica, detallándose cuatro componentes (I) el tipo de paciente o problema de interés, (II) la intervención clínica, (III) una intervención con la que comparar (cuando dicha comparación sea pertinente) y (IV) el resultado clínico de interés. Las preguntas clínicas pueden surgir desde cualquier área de la práctica clínica (prevención, tratamiento, pronóstico, etiología, etc.).

b) El segundo paso es encontrar las mejores evidencias disponibles. Para ello el profesional debe tener habilidades de búsqueda efectiva y un fácil acceso a las bases de datos bibliográficos. Hay dos tipos de bases de datos disponi- 
bles. Unas son bibliográficas y permiten identificar la literatura relevante. El otro tipo de bases de datos aportan directamente los documentos primarios o secundarios de interés.

c) El siguiente paso es la valoración de las evidencias. Dos son las cuestiones a valorar: la validez de las evidencias y su utilidad clínica.

d) En cuarto lugar, aplicar los resultados obtenidos a la práctica clínica y actuar de acuerdo con la evidencia. Entre las cuestiones que el clínico debe considerar para aplicar la evidencia están: (I) el paciente, ¿en qué grado es similar a los de la población del estudio o estudios?, (II) ¿cuáles son los beneficios y daños probables para el paciente?, (III) la intervención, o el diagnóstico, etc., ¿está disponible en el contexto de la práctica clínica? y (IV), los valores y las preferencias del paciente ¿cómo influyen en la decisión?

e) Por último, la evaluación de la actuación basada en la evidencia. Esta evaluación irá dirigida a dos áreas: evaluación de los resultados en los pacientes y la evaluación de la actuación profesional.

Vamos a centrarnos en el primer punto descrito. Así, en cuanto a la formulación de la pregunta clínica, debe ser estructurada de forma correcta para encontrar la relevancia investigadora esperada. Así, los componentes de la pregunta son:

(P) Problema o situación o pacientes

(I) Intervención

(C) Comparación de Intervención (si procede)

(O) «Outcomes», resultados o efectos

De forma sucinta los tipos o categorías de pregunta clínica estructuradas puede ser: intervención, daño, pronóstico y diagnóstico.

\section{Búsqueda de la mejor evidencia}

La búsqueda de la mejor evidencia en el apartado eminentemente práctico posee una serie de guías que orientan y explican cómo avanzar en la nombrada búsqueda, por ello se recomienda la lectura de guías como:

http://ebevidencia.com/archivos/2701 


\section{CAPÍTULO 5 \\ Cuidados básicos \\ en la alimentación}

\section{Introducción}

La nutrición es uno de los pilares fundamentales para la salud. Cada día más estudios de investigación ponen de manifiesto la relación entre una alimentación deficitaria o incorrecta y la aparición de ciertas patologías. El dicho popular «somos lo que comemos» nos lleva a la conclusión de la importancia de la alimentación y sus aspectos relacionados (hábitos, entorno, etc.), que tienen el mismo interés que el resto de cuidados de enfermería.

Por lo tanto, la nutrición es vital para la vida y la salud. Nutrientes importantes se encuentran en los alimentos y son necesarios para las funciones corporales. El régimen alimentario de una persona debe variar en contenido para proporcionar todos los nutrientes esenciales. La nutrición inadecuada puede disminuir gravemente el nivel de bienestar de una persona.

Durante este tema trataremos de revisar las competencias necesarias para la atención de pacientes con necesidades nutricionales. Por la influencia significativa que desempeña la nutrición adecuada en la conservación de salud y la prevención de las enfermedades, el enfermero debe integrar la valoración nutricional a los cuidados de su paciente. La recolección continua de los datos a través de diversos métodos como la historia clínica, exploración física y análisis de los exámenes de laboratorio pueden proporcionar información pertinente para dirigir el plan de atención de enfermería.

\section{Valoración nutricional}

El National Institute for Health and Clinical Excellence (NICE, 2006) recomienda que «el cribado de desnutrición debe ser realizado en todos los pacientes ingresados» y que «deber ser repetido semanalmente». En España, sólo el 18 \% de los hospitales realizan el cribado nutricional de forma sistemática, a pesar de que en algunos estudios, la prevalencia de desnutrición en pacientes hospitalizados asciende en ocasiones hasta el 50 \% (Martín Peña et al., 2005).

La valoración nutricional es aquella que permite conocer si los pacientes presentan estados carenciales o de exceso de determinados nutrientes. Realizar una valoración 
temprana del riesgo de desnutrición al ingreso del paciente permite establecer medidas que pueden ayudar a disminuir complicaciones asociadas como infecciones, lesiones por presión, retrasos en la cicatrización de las heridas, e incluso disminuir días de estancias (Leandro Merhi et al., 2007).

Uno de los principales problemas a la hora realizar esta valoración reside en la falta de una herramienta válida y sencilla que permita establecer, de forma fehaciente, si existe riesgo de desnutrición o no, en los pacientes hospitalizados. Otros problemas relacionados con la valoración del riesgo de desnutrición son la falta de formación de los profesionales de la salud o la presión asistencial. Se propone un método multidimensional de valoración del riesgo de desnutrición basado en tres herramientas. Por ello, debe considerarse el uso de diferentes métodos (Consellería de Bienestar Social, 2004):

a) Factores que pueden estar afectando a la alimentación (tabla 2): en la tabla 2 se recogen determinados factores que pueden afectar al estado nutricional de una persona y que deberán ser tenidos en cuenta en una primera valoración y a lo largo de la relación terapéutica mantenida con los pacientes. La mayoría de estos factores no son modificables desde la atención especializada, pero es conveniente que se reflejen en la historia del paciente para asegurar la continuidad asistencial.

\section{Factores que pueden afectar al estado nutricional}



Tabla 2. Factores que pueden afectar el estado nutricional. Fuente: Elaboración propia

b) Signos y síntomas clínicos: las alteraciones nutricionales provocan modificaciones en nuestro organismo que pueden ser observadas durante la exploración física o detectadas a través de la entrevista. Estas alteraciones pueden observarse en la tabla 3.

Este método resulta sencillo de aplicar, pero debe manejarse con mucho cuidado, ya que muchos de estos signos y síntomas pueden ser provocados por enfermedades, de modo que la alteración nutricional sería una consecuencia de una enfermedad, y no un problema de salud en sí misma.

c) Valores antropométricos: la Organización Mundial de la Salud recomienda que, para la valoración nutricional de adultos, se emplee el Índice de Masa Corporal (IMC) o índice de Quetelet. Este índice se obtiene dividiendo el peso actual en kilos por la estatura en metros al cuadrado: $\mathrm{IMC}=$ peso $(\mathrm{kg}) /$ talla $\left(\mathrm{m}^{2}\right)$. 


\begin{tabular}{|c|c|c|}
\hline $\begin{array}{l}\text { Área } \\
\text { corporal }\end{array}$ & Signo de buen estado & Signo de mal estado \\
\hline $\begin{array}{l}\text { Aspecto } \\
\text { general }\end{array}$ & Alerta, buena respuesta & Indiferente, apático caquéctico \\
\hline $\begin{array}{l}\text { Vitalidad } \\
\text { general }\end{array}$ & Fortaleza, energía duerme bien, vigoroso & $\begin{array}{l}\text { Se fatiga con facilidad, sin energía, se } \\
\text { duerme con facilidad, parece cansado }\end{array}$ \\
\hline Peso & $\begin{array}{l}\text { Normal para la talla, para la edad y para } \\
\text { la constitución corporal }\end{array}$ & Sobrepeso o déficit de peso \\
\hline Cabello & $\begin{array}{l}\text { Brillante, lustroso, firme, no se cae con } \\
\text { facilidad, cuero cabelludo sano }\end{array}$ & $\begin{array}{l}\text { Seco, frágil, pérdida del color, se } \\
\text { desprende con facilidad, delgado y escaso }\end{array}$ \\
\hline Cara & $\begin{array}{l}\text { Color de la piel uniforme, aspecto } \\
\text { saludable }\end{array}$ & $\begin{array}{l}\text { Color oscuro sobre los carrillos y por } \\
\text { debajo de los ojos, descamación cutánea, } \\
\text { edema facial, piel pálida }\end{array}$ \\
\hline Ojos & $\begin{array}{l}\text { Brillantes, claros, húmedos, sin úlceras } \\
\text { en los bordes de los párpados, mucosas } \\
\text { húmedas y de color rosado, no hay vasos } \\
\text { sanguíneos prominentes }\end{array}$ & $\begin{array}{l}\text { Mucosas oculares pálidas, xeroftalmía, } \\
\text { aumento de vascularización, xantelasma, } \\
\text { córnea cicatrizada u opaca }\end{array}$ \\
\hline Labios & $\begin{array}{l}\text { Color rosado, lisos, húmedos, sin grietas } \\
\text { ni inflamaciones }\end{array}$ & $\begin{array}{l}\text { Hinchados y voluminosos, lesiones en los } \\
\text { vértices de la boca o fisuras o cicatrices }\end{array}$ \\
\hline Lengua & Rojo intenso, papilas presentes & $\begin{array}{l}\text { Aspecto liso, de color rojo o brillante o } \\
\text { violáceo, hinchada, hipertrofia o atrofia }\end{array}$ \\
\hline Dientes & $\begin{array}{l}\text { Rectos, sin caries, sin dolor, brillantes, } \\
\text { sin cambios de coloración, mandíbula } \\
\text { con buena forma }\end{array}$ & $\begin{array}{l}\text { Caries dental, aspecto manchado, } \\
\text { posición inapropiada, falta de piezas }\end{array}$ \\
\hline Encías & $\begin{array}{l}\text { Firmes, de color rosado, sin hinchazón o } \\
\text { hemorragia }\end{array}$ & $\begin{array}{l}\text { Aumentadas de volumen, sangran con } \\
\text { facilidad, eritema marginal, retracción } \\
\text { gingival, hinchazón e inflamación }\end{array}$ \\
\hline Glándulas & $\begin{array}{l}\text { No hay aumento de tamaño de tiroides, } \\
\text { ni hinchazón en la cara }\end{array}$ & $\begin{array}{l}\text { Aumento de tamaño de la tiroides, aumento } \\
\text { del tamaño de las glándulas parótidas }\end{array}$ \\
\hline Piel & $\begin{array}{l}\text { Lisa, con buena coloración, ligeramente } \\
\text { húmeda, sin exantemas, hinchazón o } \\
\text { anomalías de color }\end{array}$ & $\begin{array}{l}\text { Rugosa, seca, con descamación, } \\
\text { hinchada, pálida, pigmentada, falta de } \\
\text { grasa subcutánea, depósitos adiposos, } \\
\text { equimosis, petequias }\end{array}$ \\
\hline Uñas & Firmes, rosadas & $\begin{array}{l}\text { En forma de cuchara (coiloniquia), } \\
\text { frágiles, pálidas, irregulares }\end{array}$ \\
\hline Esqueleto & Buena postura, sin malformaciones & $\begin{array}{l}\text { Mala postura, arqueamiento de las piernas, } \\
\text { omóplatos prominentes, deformidad del } \\
\text { tórax a nivel del diafragma }\end{array}$ \\
\hline Músculos & $\begin{array}{l}\text { Bien desarrollados, firmes, con buen tono, } \\
\text { algo de grasa por debajo de la piel }\end{array}$ & $\begin{array}{l}\text { Flácidos, tono inadecuado, desarrollo } \\
\text { inadecuado, dificultad para la marcha }\end{array}$ \\
\hline Extremidades & No hay dolor & Débiles y dolorosas, edema \\
\hline Abdomen & Plano & Distendido \\
\hline $\begin{array}{l}\text { Sistema } \\
\text { nervioso }\end{array}$ & $\begin{array}{l}\text { Reflejos normales, estabilidad } \\
\text { psicológica }\end{array}$ & $\begin{array}{l}\text { Disminución o pérdida de reflejos, } \\
\text { confusión mental, depresión, trastornos } \\
\text { sensoriales, debilidad motora, parestesias }\end{array}$ \\
\hline $\begin{array}{l}\text { Aparato } \\
\text { cardiovascular }\end{array}$ & $\begin{array}{l}\text { Frecuencia cardiaca y ritmo normales, sin } \\
\text { soplos, presión arterial normal para la edad }\end{array}$ & Cardiomegalia, taquicardia, hipertensión \\
\hline Tubo digestivo & Sin órganos o tumoraciones palpables & Hepatoesplenomegalia \\
\hline
\end{tabular}

Tabla 3. Observaciones clínicas para la valoración nutricional. Fuente: Lynn, 2012 
Un peso saludable para un individuo es aquel que se encuentra en un rango correspondiente al IMC para la talla correspondiente, entre 18,5 y 24,9 (tabla 4). Por otro lado, se ha demostrado que índices inferiores a 20 son indicativos de malnutrición y se asocian con un aumento significativo en la mortalidad en diferentes tipos de pacientes (Muñoz, 2009). Aunque diversos estudios muestran que la sensibilidad del IMC a la hora de detectar riesgo de desnutrición es inferior a la de otros instrumentos (Baccaro y Sánchez, 2009), su uso sigue estando recomendado por su facilidad a la hora de aplicarse (FELANFE, 2009).

\begin{tabular}{lll}
\hline \multicolumn{1}{c}{ Valor IMC } & \multicolumn{1}{c}{ Clasificación } & \multicolumn{1}{c}{ Riesgo asociado } \\
\hline$<\mathbf{1 6 , 0 0}$ & Delgadez severa & Muy Severo \\
$\mathbf{1 6 , 0 0}-\mathbf{1 6 , 9 9}$ & Delgadez moderada & Severo \\
\hline $\mathbf{1 7 , 0 0}-\mathbf{1 8 , 4 9}$ & Delgadez no muy pronunciada & Moderado \\
$\mathbf{1 8 , 5}-\mathbf{2 4 , 9 9}$ & Normal & No se modifica \\
$\mathbf{2 5 , 0 0}-\mathbf{2 9 , 9 9}$ & Sobrepeso & Incrementado \\
$\mathbf{3 0 , 0 0}-\mathbf{3 4 , 9 9}$ & Obeso tipo I & Moderado \\
$\mathbf{3 5 , 0 0}-\mathbf{3 9 , 9 9}$ & Obeso tipo II & Severo \\
$\mathbf{2 4 0 , 0 0}$ & Obeso tipo IIII & Muy Severo \\
\hline
\end{tabular}

Tabla 4. Valores del ImC. Fuente: Adaptado de fELAnPE, 2009

d) Indicadores analíticos: Existen diferentes determinaciones analíticas que se utilizan para conocer el estado nutricional del paciente. Los valores de estas deben ser valorados en conjunto y nunca de forma aislada ya que determinadas patologías pueden producir valores similares de alguna determinación o alterar los resultados (tabla 5).

\begin{tabular}{|c|c|c|c|}
\hline $\begin{array}{l}\text { Parámetro } \\
\text { bioquímico }\end{array}$ & Valores & Disminución & Aumento \\
\hline Hemoglobina & $\begin{array}{l}\text { Hombres } 13,8-17,2 \\
\text { Mujeres } 12,1-15,1\end{array}$ & Anemia & Deshidratación \\
\hline Hematocrito & $\begin{array}{l}\text { Hombres 40,7-50,3\% } \\
\text { Mujeres 36,1-44,3\% }\end{array}$ & Anemia & Deshidratación \\
\hline $\begin{array}{l}\text { Albúmina } \\
\text { sérica }\end{array}$ & $4,0-5,0 \mathrm{~g} / \mathrm{dl}$ & $\begin{array}{l}\text { Desnutrición, } \\
\text { malabsorción proteica, } \\
\text { Dieta pobre en proteínas }\end{array}$ & $\begin{array}{l}\text { Deshidratación } \\
\text { Dieta rica en proteínas }\end{array}$ \\
\hline Transferrina & $\begin{array}{l}\text { Hombres } 215-360 \mathrm{mg} / \mathrm{dl} \\
\text { Mujeres } 245-370 \mathrm{mg} / \mathrm{dl}\end{array}$ & $\begin{array}{l}\text { Anemia hemolítica, } \\
\text { deficiencia de proteínas }\end{array}$ & Anemia ferropénica \\
\hline $\begin{array}{l}\text { Nitrógeno } \\
\text { ureico } \\
\text { sanguíneo }\end{array}$ & 6 a $20 \mathrm{mg} / \mathrm{dl}$ & $\begin{array}{l}\text { Desnutrición, hidratación } \\
\text { excesiva }\end{array}$ & $\begin{array}{l}\text { Inanición, alto } \\
\text { consumo de proteínas, } \\
\text { deshidratación grave }\end{array}$ \\
\hline Creatinina & $\begin{array}{l}\text { Hombres } 0.7-1.3 \mathrm{mg} / \mathrm{dl} \\
\text { Mujeres } 0.6-1.1 \mathrm{mg} / \mathrm{dl}\end{array}$ & $\begin{array}{l}\text { Reducción en la masa } \\
\text { muscular, desnutrición } \\
\text { grave }\end{array}$ & Deshidratación \\
\hline
\end{tabular}

Tabla 5. Datos bioquímicos con implicaciones nutricionales. Fuente: MedlinePlus 
e) Escalas de valoración del riesgo de desnutrición: En la literatura pueden encontrarse diferentes escalas para medir el riesgo de desnutrición (FELANFE, 2009). Una de las escalas más sencilla, propuesta para su utilización en población anciana ambulatoria, es el cuestionario: «Conozca su salud nutricional» («Determine your nutritional Health») (Consellería de Bienestar Social, 2004). Este formulario fue desarrollado y distribuido por la Nutritional Screening Initiative (NSI) en 1990. Contiene diez preguntas referidas a la cantidad y el tipo de ingesta, a las limitaciones para la compra o preparación de la misma e incluye el consumo de medicamentos y la presencia de ganancia o pérdida involuntaria de peso en el tiempo (tabla 6). Aunque esta escala se propuso y se utiliza en el ámbito de la atención primaria, gran parte de los pacientes que ingresan en las unidades de hospitalización médico-quirúrgica provienen de sus domicilios, por lo que su alimentación está directamente relacionada con los ítems que refleja esta escala.

\begin{tabular}{|c|c|c|c|c|}
\hline PREGUNTAS & \multicolumn{4}{|c|}{ PUNTUACIÓN } \\
\hline $\begin{array}{l}\text { ¿Ha tenido una enfermedad o afección que le ha hecho cambiar el } \\
\text { tipo y/o cantidad de alimento que come? }\end{array}$ & $\mathrm{Si}$ & 2 & No & 0 \\
\hline ¿Toma menos de dos comidas al día? & $\mathrm{Si}$ & 3 & No & 0 \\
\hline ¿Come poca fruta, vegetales o productos lácteos? & $\mathrm{Si}$ & 2 & No & 0 \\
\hline ¿Toma más de tres vasos de cerveza, licor o vino, casi a diario? & $\mathrm{Si}$ & 2 & No & 0 \\
\hline ¿Tiene problemas dentales que hacen difícil comer? & $\mathrm{Si}$ & 2 & No & 0 \\
\hline ¿Le falta suficiente dinero para comprar la comida que necesita? & $\mathrm{Si}$ & 4 & No & 0 \\
\hline ¿Come sólo la mayoría de las veces? & $\mathrm{Si}$ & 1 & No & 0 \\
\hline ¿Toma a diario tres o más fármacos recetados por usted mismo? & $\mathrm{Si}$ & 1 & No & 0 \\
\hline ¿Ha perdido o ganado $5 \mathrm{~kg}$ de peso en los últimos seis meses? & $\mathrm{Si}$ & 2 & No & 0 \\
\hline $\begin{array}{l}\text { ¿Tiene dificultad física para comprar, cocinar y/o comer por mí } \\
\text { mismo? }\end{array}$ & $\mathrm{Si}$ & 2 & No & 0 \\
\hline \multicolumn{5}{|l|}{ PUNTUACIÓN TOTAL } \\
\hline \multicolumn{5}{|c|}{$\begin{array}{l}\text { INTERPRETACIÓN: } \\
0 \text { a 2: Bueno: Reevaluar el estado nutricional al alta del paciente. } \\
3 \text { a 5: Riesgo nutricional moderado: Tomar medidas para mejorar los hábitos alimen- } \\
\text { tarios y el estilo de vida: control de las comidas, estímulo de la alimentación. Valora- } \\
\text { ción de determinaciones analíticas. Reevaluar el estado nutricional al alta del paciente. } \\
6 \text { o más: Riesgo nutricional alto: Valorar resultados analíticos. Valorar interconsulta con } \\
\text { servicio de nutrición y dietética. Reevaluar el estado nutricional al alta del paciente. }\end{array}$} \\
\hline
\end{tabular}

Tabla 6. Encuesta «Determine your nutritional Health». Fuente fELANFE, 2009

El cuestionario, aplicado de forma aislada, solamente puede utilizarse como indicador de alto, medio o bajo riesgo de desnutrición, pero su realización de forma 
temprana por el profesional de enfermería que realiza la valoración permite establecer el nivel de riesgo y tomar las medidas oportunas, como vigilancia de las comidas o poner en conocimiento del servicio de nutrición del centro la situación del paciente. Cuando los resultados del cuestionario indican un riesgo nutricional alto, se propone un estudio nutricional más profundo, mediante la aplicación de otros instrumentos y de determinaciones analíticas como los niveles de albúmina y de colesterol total, entre otros.

La valoración nutricional de los pacientes, unida al problema de salud que ha motivado el ingreso hospitalario, determinará si es necesario llevar a cabo alguna modificación específica en los hábitos alimentarios.

\section{Tipos de dietas}

El diccionario de la Real Academia Española define dieta como «conjunto de sustancias que regularmente se ingieren como alimento», sin considerar las necesidades energéticas o de nutrientes de las personas. Los problemas de salud que requieren de hospitalización obligan a monitorizar la dieta de los pacientes, y en ocasiones es necesario realizar modificaciones sobre su dieta.

Estas modificaciones de la dieta pueden tener un objetivo preventivo (prevenir la aparición de determinados problemas relacionados con la alimentación) o terapéutico (modificación de la dieta que se realiza cuando ya existe un problema de salud). De este modo, las dietas pueden clasificarse en terapéuticas o preventivas, y a su vez pueden clasificarse según el tipo de modificaciones: energéticas, de nutrientes, de textura y de consistencia.

\subsection{Con modificaciones energéticas}

En caso de que sea preciso controlar, tanto por exceso o por defecto, el aporte calórico, hablaremos de dietas hiper o hipocalóricas.

1. Dieta hipocalórica: toda restricción del aporte calórico a una persona se realizará después de un estudio individualizado. Aunque depende del criterio médico, no son recomendables dietas con aporte inferior a $1000 \mathrm{kcal} /$ día. Además debe mantenerse siempre el aporte y equilibrio entre nutrientes. Están indicadas en situaciones de obesidad o sobrepeso.

2. Dieta hipercalórica: se trata de una dieta, en principio basal, donde los nutrientes que aportan energía se encontrarían aumentados. Estas dietas están indicadas fundamentalmente en pacientes críticos, que por su patología tienen el metabolismo elevado y requieren de un mayor aporte de nutrientes, así como en pacientes anoréxicos o desnutridos. 


\subsection{Con modificaciones de nutrientes}

1. De hidratos de carbono: a diferencia de la dieta hipocalórica, esta dieta tiene como objetivo realizar una restricción parcial o selectiva de algún tipo de hidrato de carbono en concreto y no una disminución del aporte calórico. Está indicada en los pacientes diabéticos o cuando existan problemas de absorción a nivel intestinal. También en aquellos casos en los que exista una alteración en la degradación de alguna sustancia como ocurre en el caso de la intolerancia a la lactosa, que da lugar a la aparición de síntomas gastrointestinales.

2. De proteínas:

a) Hipoproteica: Se caracteriza porque se disminuye el aporte de proteínas. Está indicada en situaciones de insuficiencia renal y hepática.

b) Sin gluten: el gluten es una proteína presente en el trigo, la cebada y el centeno. Este tipo de dieta se prescribe a los pacientes diagnosticados de enfermedad celíaca.

c) Hiperproteica: se caracteriza por un aumento del aporte de proteínas. Indicada en pacientes desnutridos y críticos, estos últimos, además de precisar un mayor aporte de energía por tener un metabolismo elevado, tienen una mayor destrucción celular y parece que un mayor aporte de proteínas puede ayudar a regenerar el tejido destruido (Langer y Astrid, 2014).

3. De lípidos: baja en triglicéridos y/o colesterol. Se reduce el aporte de alimentos ricos en estas sustancias en pacientes con problemas de hiperlipidemias y/o hipercolesterolemia.

4. De minerales: destacan principalmente las dirigidas a controlar los niveles de sodio y potasio.

a) Baja en sodio: la sal de mesa es la principal fuente de sodio en la dieta europea. Los alimentos más ricos en sodio son los de origen animal (carne, huevos y lácteos). El sodio retiene agua en el organismo y está contraindicado en pacientes con hipertensión arterial.

b) Baja en potasio: el objetivo de esta dieta baja en potasio es controlar la hiperpotasemia, sobre todo en pacientes con insuficiencia renal. Alimentos ricos en potasio, y por tanto, desaconsejados, son quesos, embutidos, bollería industrial, plátanos, cerezas, sopas de sobre, frutos secos, chocolate y tomate en lata.

5. Otras: cualquier dieta con modificación de nutrientes destinada a la prevención de patologías o el tratamiento de ellas, como por ejemplo, dietas laxantes (con aumento de fibra y líquidos) y dietas astringentes (con disminución de fibra y grasas). 


\subsection{Modificaciones de la textura y consistencia}

También llamadas dietas progresivas. En el ciclo salud-enfermedad de una persona, esta pasa por distintos estadios en donde tanto el contenido como la forma de administración de la alimentación varía en función de la situación del paciente. Así, por ejemplo, a un paciente recién sometido a una intervención quirúrgica bajo anestesia general no se le daría una dieta con alimentos sólidos, sin haber tolerado antes una dieta líquida o blanda, puesto que es posible que su aparato digestivo aún no esté preparado. Las dietas progresivas pueden proporcionar un aporte completo o parcial de nutrientes y energía. En caso de que fuese parcial, habría que proporcionar suplementos para cubrir las carencias de la dieta.

Existen varios tipos de dietas con modificación de la textura o consistencia: dieta líquida, semisólida y blanda.

1. Absoluta: se elimina el aporte de cualquier tipo de alimento y líquido por vía oral. Está indicada en el preoperatorio y postoperatorio inmediato. En determinadas intervenciones quirúrgicas sobre el aparato digestivo, la dieta absoluta puede prolongarse durante varios días. En caso necesario, es posible administrar los nutrientes por vía parenteral.

2. Dieta líquida: está indicada en fases de recuperación de íleo paralítico, en cuadros de diarrea, para la preparación de exploraciones intestinales (gastroscopias, colonoscopías, etc.), en las fases de tránsito entre la nutrición parenteral y alimentación oral o en pacientes con problemas de masticación, deglución o digestión secundarios a alteraciones fisiológicas o mecánicas.

3. Dieta semisólida o triturada (blanda mecánica): es una dieta en la que la textura de los alimentos es de tipo puré. Su objetivo es asegurar la ingesta en aquellos pacientes con alteraciones en la masticación y/o deglución.

4. Dieta blanda y dieta de fácil masticación: ambas dietas están indicadas en la fase de tránsito de la dieta líquida o semisólida a la basal.

a) Dieta blanda: es una dieta donde los alimentos se presentan enteros, pero con poco aceite y condimentos, sometidos a cocción con el fin de facilitar su digestión.

b) Dieta blanda de fácil masticación: se diferencia de la dieta blanda exclusivamente en la textura de los alimentos. Esta dieta está encaminada a conseguir el mínimo esfuerzo para la masticación.

A la hora de confeccionar una dieta individualizada, se tendrán en cuenta las modificaciones energéticas, de nutrientes y de textura. Su combinación puede dar lugar a múltiples tipos de dietas. 


\section{Interacción entre los medicamentos y los nutrientes}

Las interacciones entre medicamentos y alimentos no se detectan con tanta facilidad como las interacciones entre unos medicamentos y otros, sin embargo su frecuencia potencial es mucho mayor, ya que los alimentos son, con gran diferencia, las sustancias que más se asocian con la administración de medicamentos.

Una interacción entre un nutriente y un fármaco puede definirse como:

a) La modificación de los efectos de los nutrientes por la administración anterior o simultánea de un medicamento.

b) La modificación de los efectos de un medicamento por la administración anterior o simultánea de un nutriente.

En toda interacción hay, pues, un fármaco o nutriente cuya acción es modificada y otro u otros que actúan como precipitantes o desencadenantes de la interacción. En algunos casos es bidireccional. En la tabla 7 se muestran algunas de estas interacciones y cuáles son las recomendaciones para evitarlas.

\section{Procedimiento de ayuda en la alimentación oral}

Las bandejas de comida llegan a la unidad en unos carros térmicos o en propias bandejas térmicas, identificadas, cada una de ellas, con el número de habitación del paciente y un código asignado según la dieta.

Algunas personas precisan asistencia al comer: ancianos, discapacitados (por ejemplo, pacientes invidentes, tetrapléjicos, etc.), aquellos que deban permanecer en decúbito supino, etc.

\begin{tabular}{|ccc|}
\hline Fármaco & Tipo de interacción & Recomendación \\
\hline $\begin{array}{c}\text { Anticoagulantes } \\
\text { orales }\end{array}$ & $\begin{array}{c}\text { Alimentos ricos en vi- } \\
\text { tamina K antagonizan } \\
\text { su efecto }\end{array}$ & $\begin{array}{c}\text { Dieta sin comer grandes cantidades de } \\
\text { estos alimentos (brécol, coles, espinacas, } \\
\text { lechuga...) }\end{array}$ \\
\hline Atenolol & $\begin{array}{c}\text { Los alimentos actúan } \\
\text { como barrera física }\end{array}$ & Tomar con el estómago vacío \\
\hline Azitromicina & $\begin{array}{c}\text { Disminuye } \\
\text { la absorción }\end{array}$ & Separar la ingesta del fármaco 2 h \\
\hline Captopril & $\begin{array}{c}\text { Puede disminuir la } \\
\text { absorción }\end{array}$ & Tomar con el estómago vacío \\
\hline
\end{tabular}




\begin{tabular}{|c|c|c|}
\hline Fármaco & Tipo de interacción & Recomendación \\
\hline Digoxina & $\begin{array}{l}\text { Los alimentos ricos en } \\
\text { fibra y pectina se unen } \\
\text { al fármaco }\end{array}$ & $\begin{array}{l}\text { No tomarlo con alimentos ricos en fibra } \\
\text { y a la misma hora en relación con las } \\
\text { comidas }\end{array}$ \\
\hline Eritromicina & $\begin{array}{l}\text { Disminuye } \\
\text { la absorción }\end{array}$ & Separar la ingesta del fármaco $2 \mathrm{~h}$ \\
\hline Fluorquinolonas & $\begin{array}{l}\text { Disminuye } \\
\text { la absorción }\end{array}$ & Separar la ingesta del fármaco $2 \mathrm{~h}$ \\
\hline Isoniazida & $\begin{array}{l}\text { Puede retrasar y dismi- } \\
\text { nuir la absorción }\end{array}$ & Separar la ingesta del fármaco $2 \mathrm{~h}$ \\
\hline IMAO & $\begin{array}{l}\text { Crisis hipertensivas } \\
\text { si se toman alimentos } \\
\text { con alto contenido en } \\
\text { tiramina }\end{array}$ & $\begin{array}{l}\text { Evitar: quesos, escabeches, conservas, } \\
\text { ahumados o vino tinto }\end{array}$ \\
\hline Levodopa & $\begin{array}{l}\text { Los aa inhiben } \\
\text { la absorción }\end{array}$ & No tomar con proteínas \\
\hline Paracetamol & $\begin{array}{l}\text { Los alimentos ricos } \\
\text { en pectina retrasan la } \\
\text { absorción }\end{array}$ & Tomar con el estómago vacío si se tolera \\
\hline Penicilina oral & $\begin{array}{l}\text { Disminuye } \\
\text { la absorción }\end{array}$ & Separar la ingesta del fármaco $2 \mathrm{~h}$ \\
\hline
\end{tabular}

Tabla 7. Interacciones fármacos-alimentos. Fuente: San Miguel Samano y Sánchez Méndez, 2011

\subsection{Consideraciones generales de ayuda en la alimentación oral}

Entre las consideraciones generales que debemos tener presentes y que nos servirán tanto para los pacientes que asistimos con la labor de alimentarse como para los totalmente independientes en esta área podemos distinguir:

1. Respetar los horarios de las comidas sin que existan interferencias por visitas (médicas u otras).

2. Asegurarse que las condiciones de higiene de la habitación son las adecuadas antes de pasar con la bandeja:

a) Vigilar los olores.

b) Que haya una buena iluminación.

c) Que el mobiliario destinado a depositar la bandeja de comida esté limpio y despejado de objetos.

3. Confirmar el tipo de dieta prescrito, así como las posibles restricciones por razones médicas, de índole cultural o social (cerdo en los musulmanes, ternera en los hindúes, etc.), o de preferencias o gustos del paciente. 
4. Verificar si el paciente es diabético y si precisa control glucémico previo a la ingestión de alimentos. Verificar que el paciente no tenga programado algún estudio diagnóstico o de laboratorio que pudiera influir en los alimentos que va a consumir.

5. Comprobar que el interior de la bandeja corresponde con la dieta pautada y que dispone de los utensilios necesarios, cubiertos, servilleta, etc.

6. Se repartirán las bandejas de comida en primer lugar a los pacientes que no precisen de ayuda para comer, cuidando de que estos tengan todo a su alcance, y después las de los pacientes que sí que la precisen.

7. Al finalizar la comida se retirarán las bandejas de las habitaciones, depositándolas en el carro de nuevo, para que el personal de cocina lo retire todo de la unidad.

8. Se comprobará la cantidad de comida ingerida por cada paciente y se anotará en su gráfica para cumplimentar el balance, así como cualquier incidencia.

\subsection{Asistencia a un paciente con la comida}

En especial, las personas muy jóvenes o personas de edad avanzada, como aquellas con artritis en las manos, pueden tener ciertas dificultades para abrir frascos de jugo, por ejemplo. También, los pacientes con parálisis de las manos o con demencia avanzada pueden ser incapaces de alimentarse por sí mismos. Para ellos es necesario que el enfermero proporcione la asistencia necesaria. Esta competencia con frecuencia se delegará a las auxiliares de enfermería. Sin embargo, el enfermero es responsable de la valoración inicial y continua de las complicaciones potenciales para el paciente relacionadas con la alimentación. Antes de delegar esta actividad, es fundamental que el enfermero se asegure de que el auxiliar de enfermería está capacitado para observar cualquier dificultad en la deglución y que conoce las precauciones para la bronco-aspiración.

\subsection{Procedimiento}

\subsubsection{Material necesario}

Bandeja con la comida, toalla, vaso, cubiertos, mesa de cama, dieta prescrita, cañitas flexibles, servilletas, empapador y registros de enfermería para dejar constancia de la actividad al finalizar.

\subsubsection{Identificación de resultados esperados y planificación}

El resultado esperado se logra cuando se ayuda al paciente con la alimentación y este consume del 50 al $60 \%$ del contenido de la bandeja de alimentos. Otro resultado que se podría lograr es que el paciente no presente bronco-aspiración durante la comida. Además, el resultado deseado se logra cuando el paciente expresa que el consumo de alimentos es apropiado. 


\subsubsection{Ejecución}

1. Tener en cuenta las consideraciones generales de ayuda en la alimentación oral.

2. Lavarse las manos.

3. Explicar al paciente el procedimiento que vamos a seguir.

4. Valorar el nivel de conciencia del paciente e identificar alguna limitación física, de la agudeza visual o auditiva. Si el paciente utiliza dispositivos auxiliares para la audición, anteojos o dentadura, se le proporcionarán según sea necesario.

5. Lavar las manos del paciente o ayudar en este procedimiento, según el caso.

6. Ayudar al paciente a colocarse en una posición cómoda: sentado en una silla o en la cama o elevar el cabecero de la cama $90^{\circ}$, según el caso.

7. Colocar un empapador o toalla sobre el paciente, si así lo desea.

8. Si es posible, sentarse frente al paciente mientras consume los alimentos.

9. Ayudar al paciente en función de sus necesidades (cortar la carne, abrir la tapa de los recipientes, etc.). Si el paciente puede, se le pide que sostenga los alimentos con sus manos y se alimente tanto como sea posible.

10. Conversar con el paciente durante este procedimiento. La conversación convierte la comida en un momento más placentero y favorece la relajación.

11. Dar tiempo suficiente al paciente para que mastique e ingiera los alimentos. El paciente podría necesitar reposo por periodos breves durante la alimentación.

12. Proporcionar bebida a lo largo de la comida.

13. Cuando se complete el consumo de alimentos, retirar la bandeja de la habitación, poniendo atención a la cantidad y tipo de alimentos consumidos. Observar también el volumen de líquidos ingeridos. Retirar la mesa de cama.

14. Ayudar al paciente en el lavado de manos y la higiene bucal si así lo desea.

15. Retirar el empapador o toalla si se utilizó para la protección del paciente.

16. Colocar la cama en una posición cómoda para el paciente.

17. Elevar la barandilla lateral si se hubiera bajado anteriormente.

18. Lavarse las manos.

19. Registrar la actividad y la cantidad de alimentos y líquidos ingeridos.

\subsubsection{Consideraciones especiales}

Para pacientes con artritis en las manos, se cuenta con utensilios especiales con mangos modificados, que facilitan sostener los cubiertos. Los pacientes con trastornos visuales pueden guiarse para que se alimenten con el uso de un patrón como «las manecillas del reloj». Para pacientes con disfagia, se sugieren bocados pequeños de alimentos, se recomienda que el paciente no hable mientras deglute y que intente deglutir dos veces después de cada bocado. La utilización de una pajita potencia el riesgo de aspiración, ya que el paciente disfágico controla en menor medida la cantidad de líquidos que debe ingerir. En pacientes con hemiplejía se debe insistir en que mastiquen por el lado no afecto. 
Se debe tener en cuenta que los pacientes con sensibilidad al látex pueden desarrollar reacciones alérgicas de carácter grave frente a ciertas proteínas de origen vegetal. Algunos alimentos presentan reactividad cruzada con el látex (aguacate, plátano, papaya, avellana, kiwi, patata y tomate). Los pacientes alérgicos a estos alimentos pueden serlo también al látex y viceversa.

\subsubsection{Situaciones inesperadas e intervenciones relacionadas}

a) El paciente comenta que no desea comer nada de lo que se encuentra en la bandeja de alimentos: se revisan con él los motivos por los que no desea comer nada de lo que se encuentra en la bandeja. Se valoran los factores psicológicos que pudieran tener impacto en la nutrición. En ocasiones se encuentra desnutrición en personas de edad avanzada con depresión. En conjunto se crea un plan para atender la falta de consumo de alimentos.

b) El paciente comenta que siente náuseas y no desea comer: se retira la bandeja de alimentos de la habitación. Se revisa con el paciente la importancia de consumir pequeñas cantidades de alimentos o de líquidos, como galletas saladas o bebidas carbonatadas, si la dieta del paciente lo permite. Se administran fármacos antieméticos si están prescritos (si no lo están, se solicita una consulta) y se pide que intente consumir pequeñas cantidades de alimento después de que haya tenido efecto el medicamento. 


\section{CAPITULO 6}

\section{Cuidados básicos en la movilidad}

\section{Introducción}

La capacidad de moverse tiene estrecha relación con la satisfacción del resto de las necesidades humanas básicas. El ejercicio regular contribuye al funcionamiento saludable de cada sistema corporal. Por el contrario, la falta de ejercicio y la inmovilidad afectan en forma negativa todos los aparatos y sistemas. De esta forma, la enfermería debe favorecer la actividad y el ejercicio para brindar el bienestar, prevenir la enfermedad y restablecer la salud.

En este apartado trataremos varios puntos referentes a la movilidad de los pacientes. En primer lugar y antes de iniciar la manipulación de pacientes trataremos de nuestra propia higiene postural, debido a que la carencia de la misma o la inadecuación de nuestros movimientos provoca, a largo plazo, un malestar que es causa de incapacidades temporales y dificultades que acarrean problemas no sólo en nuestra vida profesional, sino también personal.

Tras tratar este apartado, describiremos las posiciones más frecuentes de los pacientes encamados, su movilización (tanto si son parcialmente dependientes, como si son totalmente dependientes) y cómo realizar transferencias de un paciente. Además, debemos tener en cuenta de que todo ello se encuentra englobado dentro del marco propio de la seguridad del propio paciente y, por supuesto, entre otras cosas, está dirigido a prevenir las úlceras por presión o úlceras por decúbito.

\section{Higiene postural}

La higiene es la rama de la medicina que tiene por objeto la conservación de la salud y la prevención de enfermedades. La higiene postural es el estudio de la profilaxis y de la corrección de las posturas incorrectas en las actividades (cotidianas y profesionales) del individuo. Analiza las posturas habituales, tales como estar sentado frente al ordenador, estudiando o cualquier otra postura que se mantenga durante largos períodos de tiempo, y dicta una serie de normas que debemos adoptar para que esa postura no nos produzca fatiga ni lesiones.

El personal de enfermería, en su trabajo diario, tiene que manipular cargas con bastante frecuencia o movilizar enfermos. Estas cargas suponen un riesgo de lesiones dorso-lumbares muy elevado si no se realizan correctamente. 
La manipulación manual de toda carga que pese más de tres kilos puede suponer riesgo dorso-lumbar, puesto que, aunque parezca una carga pequeña, manipulada con unas malas condiciones ergonómicas (alejada del cuerpo, con giros de tronco, con un centro de gravedad desplazado o poco estable, etc.), podría generar un impacto que hay que evitar.

La mecánica corporal es el uso apropiado de nuestro sistema músculo-esquelético con el fin de evitar lesiones, al realizar las actividades profesionales o de nuestra vida diaria. Esta mecánica corporal tiene unas normas o recomendaciones cuyo fin es evitar la fatiga y las lesiones a corto y largo plazo y está relacionada, sobre todo, con el ámbito laboral.

\subsection{La espalda}

\subsubsection{La columna vertebral}

Entre las funciones que realiza la columna vertebral encontramos que: sirve como elemento de sostén para el cráneo; proporciona protección a la médula espinal; permite desplazarse en posición de pie sin perder el equilibrio, por lo tanto, proporciona estabilidad; y da flexibilidad a los movimientos, permitiendo que sean en todas direcciones.

Anatómicamente, conocemos que la columna está compuesta por: 7 vértebras cervicales, 12 torácicas, 5 vértebras lumbares, el sacro y el coxis. Entre las vértebras se encuentran los discos intervertebrales que le dan mayor flexibilidad. Por último, como característica, de frente la columna aparenta ser rectilínea, pero vista desde un eje lateral se aprecian sus curvaturas. Estas curvaturas normales o fisiológicas del eje cráneo-caudal (figura 2) se llaman:

a) Lordosis cervical

b) Cifosis dorsal

c) Lordosis lumbar

d) Curva sacra

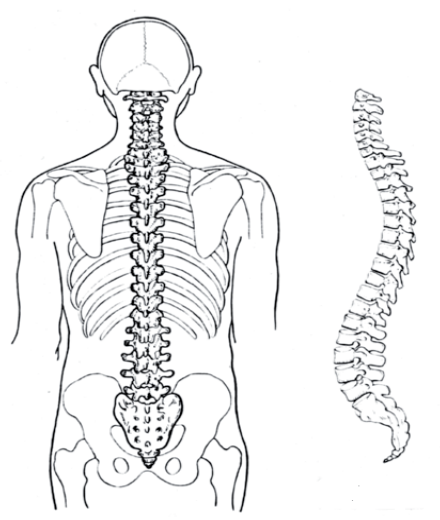

Figura 2. Columna vertebral. Fuente: Google Imágenes. Imagen libre 


\subsubsection{Vértebras y articulaciones vertebrales}

Todas las vértebras, estructuralmente, están formadas por dos elementos básicos: cuerpo vertebral y sus apófisis. Las apófisis son las prolongaciones óseas que forman articulaciones entre las diferentes vértebras y permiten su movimiento. Las vértebras se articulan unas con otras y ello permite el movimiento, pero debemos saber que no todas las articulaciones vertebrales tienen la misma movilidad, ya que las vértebras torácicas o dorsales son menos móviles. Las articulaciones entre las vértebras lumbares permiten movimientos más amplios, exceptuando el que se produce hacia atrás, que es más limitado (figura 3 ).

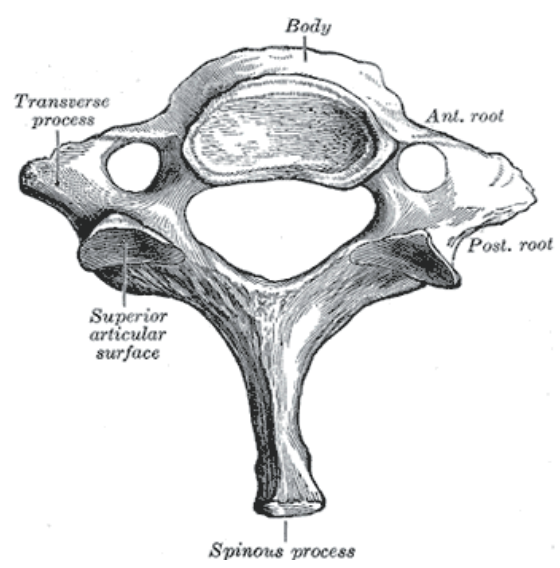

Figura 3. Vértebra. Fuente: Google imágenes. Imagen libre

Las vértebras soportan dos terceras partes del peso del cuerpo y sobre ellas recae gran parte de los movimientos que realizamos. Así, los cuidadores tienen que proteger esta zona para prevenir las lumbalgias, dado que esta lesión puede llegar a ser muy incapacitante. Todas estas articulaciones están recubiertas de ligamentos que las protegen y fijan dando estabilidad.

\subsubsection{El disco intervertebral}

El disco intervertebral se sitúa entre los cuerpos vertebrales, amortiguando las presiones que recaen sobre la columna. Tiene la forma de almohadilla y está formado por cartílago, y en su centro se encuentra el núcleo que amortigua las presiones. $\mathrm{Su}$ desplazamiento o salida puede provocar hernias discales (figura 4).

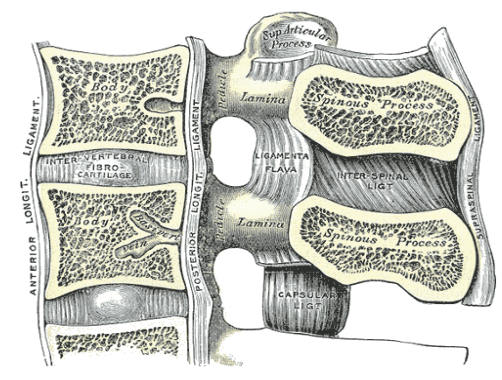

Figura 4. Disco intervertebral. Fuente: Google imágenes. Imagen libre 


\subsubsection{La postura}

Es la forma en que cada uno coloca su cuerpo y lo mantiene para que no caiga por la atracción de la gravedad. La postura corporal correcta sería aquella en la que se cumplen una serie de normas que aseguran una buena distribución del peso del cuerpo y que facilitan el esfuerzo de los músculos, para sostenerlo o para realizar una acción.

La postura corporal deficiente puede desencadenarse por una mala colocación, al trasladar a la persona en situación de dependencia, también por la colocación incorrecta en las propias tareas del día a día. Las malas posturas corporales están relacionadas con la aparición del dolor de espalda y también con dolores y molestias de las articulaciones de las extremidades.

El entorno psicosocial en que se desarrolla la actividad también influye en la postura. Existe una interrelación entre la postura y el estado psíquico individual, el estrés, y la percepción del dolor y de la fatiga. Además, las alteraciones posturales pueden estar provocadas por los elementos del entorno cuando están mal situados (silla, mesa...), son inadecuados (temperatura ambiental, luminosidad...), la falta de ergonomía, y todo ello obliga a forzar o modificar las condiciones biomecánicas correctas (figura 5).



Figura 5. La postura. Fuente: Google imágenes. Imagen libre

\subsection{Normas biomecánicas}

Las normas biomecánicas son normas básicas en las que el cuidador se debe basar para la realización de las movilizaciones y transferencias de la persona en situación de dependencia y en las actividades de la vida diaria, tanto las propias y como las de la persona a la que ayuda. Se pueden resumir estas normas biomecánicas en:

a) Planificar el trabajo a realizar y la distancia a recorrer si estuviésemos cargando una carga.

b) Despejar el camino a recorrer, si lo hubiera. 
c) Colocar bien los pies: apoyados firmemente en el suelo, de manera estable, separados ligeramente uno de otro y más adelantado el pie en dirección al movimiento.

d) Mantener la espalda recta.

e) Flexionar las piernas.

f) Aproximar el cuerpo de la persona a la que se está ayudando. Cuando hay que mover a una persona en situación de dependencia, se debe mantener su cuerpo muy cerca del propio cuerpo, así se reparte mejor la carga.

g) Seguridad en el agarre. El cuidador debe sujetar firmemente a la persona en situación de dependencia para evitar caídas.

h) Ampliar la base de sustentación del cuidador. Los pies de la persona que ayuda deben estar separados para aumentar el equilibrio, dirigiendo una de las puntas de los pies en la dirección del movimiento y la otra ligeramente flexionada para realizar el desplazamiento con las piernas y no forzar la espalda.

i) Sincronizar movimientos. Se debe crear un contrapeso al trasladar a la persona, realizando los movimientos al mismo tiempo, persona en situación de dependencia y persona cuidadora. Así se reduce su peso a menos de la mitad.

\subsection{Higiene postural en la vida diaria}

Mantener una adecuada higiene postural en la vida cotidiana y en el trabajo es adecuado para evitar problemas de salud relacionados. En este apartado veremos cómo hacerlo a través de actividades de la vida cotidiana:

1. Levantarse de la cama: Cualquier persona que todavía conserva cierta independencia en esta tarea debería considerar las siguientes normas.

a) Nunca sentarse directamente en la cama

b) Colóquese de lado lo más cerca posible del borde de la cama.

c) Saque las piernas fuera de la cama, a la vez que con ayuda del codo que queda más cercano al canto de la cama se apoya para ayudar a incorporar el tronco.

d) Con ayuda del otro brazo terminar de incorporar el tronco hasta quedar sentado en el borde de la cama.

e) Para las personas en situación de dependencia en ocasiones es necesario hacerlo despacio o esperar unos minutos antes de levantarse para evitar mareos y posibles caídas.

2. Aseo personal: Se debe evitar la inclinación de tronco hacia delante con extensión de rodillas, ya que esta postura resulta muy perjudicial para la espalda, para ello:

a) Frente al lavabo, si se necesita inclinarse hacia delante, mantenga siempre las rodillas algo flexionadas a la vez que una de las piernas está por delante de la otra (en posición de dar un paso). Además, puede ir alternando una pierna con otra.

b) Mientras dure el aseo en el lavabo: se puede apoyar las manos sobre el lavabo para descargar el peso que se ejerce sobre la espalda. 
c) Si se está duchando: mantenga la espalda recta, sin inclinación hacia delante y flexione ligeramente las rodillas, mirando hacia el lugar donde está colocada la ducha. Así evitará una hiperlordosis en la columna vertebral.

d) Lavarse la cabeza: si lo hace mientras se ducha puede estar forzando su columna. Lo correcto para lavarla sería hacerlo fuera de la bañera, de rodillas e introduciendo la cabeza en ella. Pero esta posición no pueden realizarla muchas personas a determinadas edades, entonces el lavado de cabeza será mejor hacerlo dentro de la bañera con una pierna más adelantada que la otra y siempre manteniendo la espalda lo más recta posible, sin sobrecargarla.

3. Vestido: A la hora de vestirse se intentarán evitar los desequilibrios. Para ello, no se vista la parte inferior de pie y sin apoyo en la columna. Podría caerse.

a) La mejor posición para el vestido de la parte inferior es sentado y luego, levantarse para acabar de colocar la prenda.

b) Si no existe la posibilidad de una silla en la habitación donde se viste, puede hacerse estando sentado en la cama, pero si tiene una buena estabilidad y equilibrio.

c) Cuando se está de pie hay que buscar un apoyo fijo para su espalda, como la pared. Esto evitará que se incline la espalda hacia delante sobrecargándola.

4. Cómo permanecer sentado: Es una de las posturas más frecuentes de la vida diaria. Hay que tener en cuenta que se requiere de un mobiliario adecuado para poder tener una correcta posición en esta postura. La altura de la silla debe ser lo suficientemente baja como para poder apoyar los pies en el suelo; el respaldo debe dejar apoyar correctamente la zona lumbar, ya que esta zona es la que más suele sufrir si se está mal sentado; por último, la silla debería tener reposabrazos para apoyar y ayudar a mantener la posición. La forma correcta para permanecer sentado sería:

a) Siéntese lo más atrás posible, apoyando la espalda contra el respaldo.

b) Evite realizar torsiones sobre la columna. No gire los hombros sin dejar que giren en el mismo sentido las caderas. A veces, desde sentado se quieren coger cosas que están al lado. Si para cogerlas se hace torsión de la columna, se favorece la aparición de lesiones que pueden provocar la aparición de dolor.

c) Evite las posturas prolongadas. Vaya cambiando de postura, ande cada 50 minutos para evitar lesiones en la zona glútea y sacra.

5. Cómo cargar pesos: No se debe inclinar el tronco con las piernas en extensión, ni girar con el peso separado de su cuerpo. Además:

a) Mantenga la espalda recta.

b) Flexione las rodillas y caderas.

c) Sujete a la persona o el peso que esté transfiriendo lo más cerca posible de su cuerpo.

d) Mientras realiza el esfuerzo de elevación del peso, pase sus piernas de flexión a extensión. Evite realizar este esfuerzo con la espalda inclinada hacia delante. 
e) No eleve el peso que transporte por encima del pecho.

f) Traslade a la persona lo más cerca posible de su cuerpo, desplazándose usted con las rodillas ligeramente flexionadas para no sobrecargar la columna.

\section{Posiciones de los pacientes encamados}

Los pacientes que están encamados pueden adoptar diversas posiciones en función de si se trata de parte de un plan de cambios posturales, de realizar alguna de las diversas técnicas de exploración médica que se pueden llevar a cabo, de facilitar intervenciones quirúrgicas o, simplemente, de buscar la mayor comodidad posible para el paciente.

Las posiciones más habituales en las que podemos colocar a un paciente se han dividido clásicamente en no quirúrgicas y quirúrgicas, aunque en cualquiera de ellas se pueden realizar determinadas técnicas quirúrgicas.

\subsection{Posiciones para estancia en la cama y cambios posturales no quirúrgicos}

Estas posiciones, aunque se pueden usar para técnicas quirúrgicas y exploraciones, se emplean habitualmente para la estancia del paciente en la cama durante largos períodos de tiempo. Para ello se intenta planificar un plan de cuidados en el que se procura que la presión producida en ciertos puntos, debido a la postura, no llegue a producir lesiones. Además, se busca el mayor confort para el paciente. Todo ello es lo que se conoce como plan de cambios posturales.

Estos cambios deben ser planificados por el equipo de enfermería siguiendo las necesidades del paciente y teniendo en cuenta las limitaciones propias de su patología. El objetivo fundamental del plan de cambios posturales es limitar el tiempo que una zona concreta del cuerpo se encuentra comprimida debido al peso del propio cuerpo, pues esta presión produce una reducción de la circulación sanguínea y, por lo tanto, anoxia en los tejidos, facilitando la aparición de necrosis hística y úlceras.

El tiempo aconsejado para que un paciente esté en una misma posición es de dos o tres horas como máximo, para evitar las posibles complicaciones nombradas. Este será el tiempo que tendremos en cuenta a la hora de planificar un plan de cambios posturales.

\subsubsection{Decúbito supino o dorsal}

En esta posición el paciente está acostado sobre su espalda, los miembros extendidos en una posición cómoda y con las manos en pronación. 
En el caso de un plan de cambios posturales en el que el paciente pase en la misma posición un tiempo prolongado, se pueden poner apoyos y descargas para conseguir una buena alineación corporal y reducir la presión en zonas de riesgo. Para estos apoyos, normalmente, se hará uso de almohadas y toallas, las cuales en esta posición se dispondrán en:

a) Una almohada debajo de cuello y de los hombros, para evitar la hiperextensión del cuello y reducir la presión en la zona occipital.

b) Una pequeña almohada o toalla enrollada en la zona lumbar para decargar la zona y mantener la curvatura lumbar.

c) Una toalla enrollada debajo del borde de las caderas y los muslos, para evitar la rotación externa del fémur.

d) Una pequeña almohada debajo del hueco poplíteo, para disminuir la tensión en las piernas.

e) Una pequeña almohada, debaja del tercio inferior de las piernas, para evitar la presión en los talones.

f) Un tope en la planta de los pies para mantenerlos en posición fisiológica $\left(90^{\circ}\right)$ y evitar así el pie equino.

Esta posición está indicada: como posición de encamado; como parte de un plan de cambios posturales; para la exploración del tórax, abdomen y miembros; y en postoperatorios (figura 6).
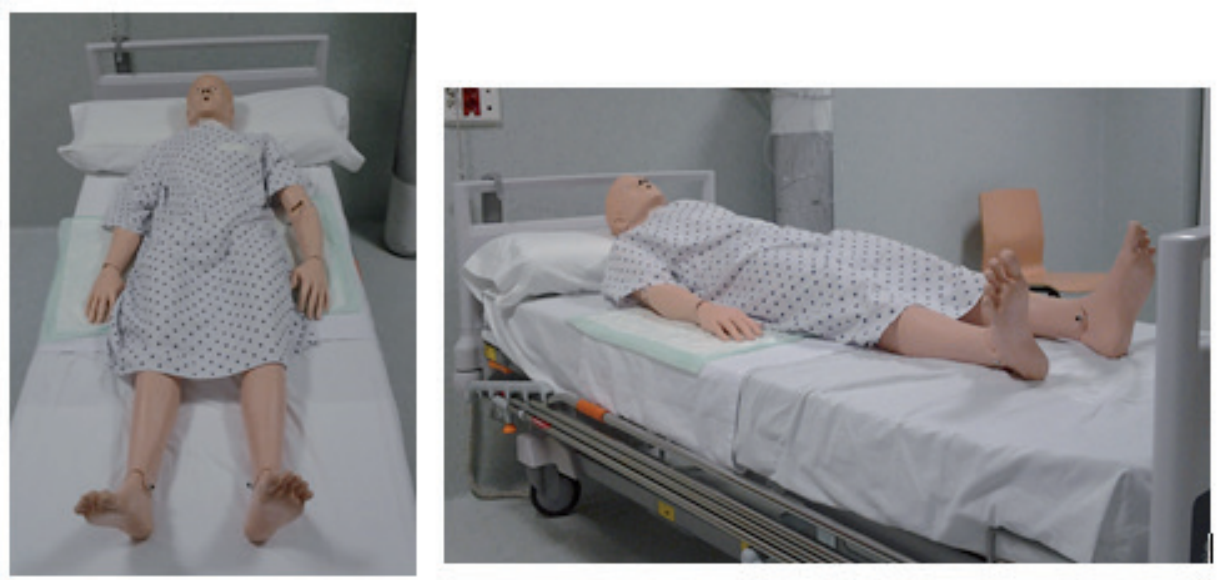

Figura 6. Decúbito supino o dorsal. Fuente: Elaboración propia

\subsubsection{Decúbito lateral derecho o izquierdo}

El paciente está acostado sobre un lateral; la pierna inferior está extendida y la superior ligeramente adelantada y flexionada; el hombro inferior levemente adelantado, para que no se cargue el peso sobre él, y con el brazo extendido o flexionado; por último, el brazo superior adelantado y en flexión para que no apoye sobre el tórax. 
Como apoyos y descargas se pondrían:

a) Una almohada debajo de la cabeza, para mantenerla alineada.

b) Una almohada doblada debajo del brazo superior para mantenerlo alineado y fuera del tórax.

c) Una almohada en la espalda para mantener la alineación del cuerpo.

d) Una almohada debajo de la pierna superior para mantenerla alineada.

Esta posición está recomendada como posición de encamado y como parte de un plan de cambios posturales; para la administración de enemas (decúbito lateral izquierdo) y medicaciones vía rectal; para la higiene del paciente encamado; para hacer la cama estando ocupada; y para fisioterapia respiratoria (figura 7).


Figura 7. Decúbito lateral. Fuente: Elaboración propia

\subsubsection{Decúbito prono o ventral}

El paciente está tumbado sobre su tórax y abdomen con la cabeza hacia un lado y las piernas estiradas. Los brazos pueden estar estirados a lo largo del cuerpo o flexionados por los codos con las palmas de las manos hacia abajo.

Como apoyo y descargas se colocan:

a) Una almohada debajo de la cabeza y de los hombros para disminuir la presión en la cara y en el tórax, facilitando la respiración y disminuyendo la presión en las mamas en el caso de mujeres.

b) Una almohada debajo de las caderas y el abdomen, para alinear la columna, disminuyendo la curvatura lumbar.

c) Un pequeño cojín debajo del tercio inferior de los muslos para disminuir la presión en las rodillas. Una almohada debajo de los tobillos para evitar el pie equino.

Aunque esta postura no es muy habitual verla en el ámbito hospitalario, se debe conocer que esta postura está indicada como parte de un plan de cambios posturales; en la cirugía dorsal; en exploraciones de espalda y para proporcionar masajes. 

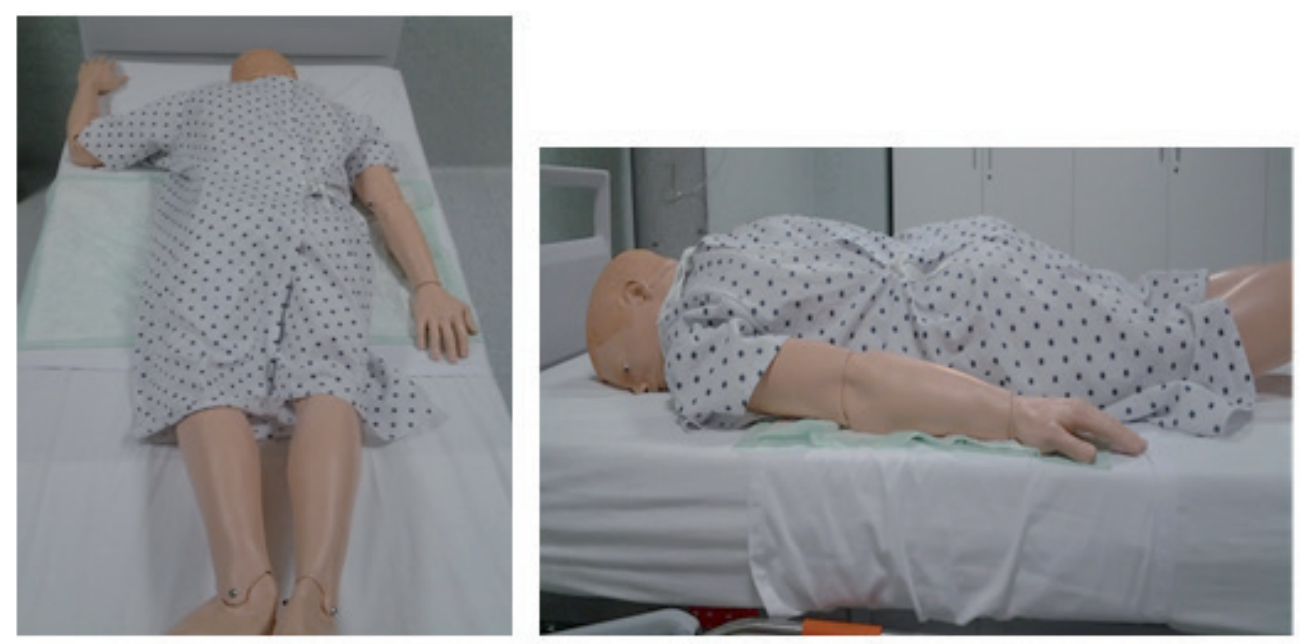

Figura 8. Decúbito prono. Fuente: Elaboración propia

\subsubsection{Sims, semiprona o posición inglesa}

Es una posición intermedia entre el decúbito lateral y el decúbito prono en la que el paciente está tumbado a unos $45^{\circ}$ entre estas dos posturas y se apoya sobre el lateral del tórax y la parte anterior de la cadera. El brazo inferior se encuentra extendido hacia atrás con la palma de la mano hacia arriba, y el brazo superior en flexión con la palma de la mano hacia delante y ligeramente separado del cuerpo. La pierna inferior está estirada o en ligera flexión y la pierna superior en flexión más adelantada que la inferior.

Como apoyos y descargar se colocan:

a) Una almohada debajo de la cabeza para que el cuello esté perfectamente alineado.

b) Una almohada debajo del hombro y el brazo superior, para que el tórax no se vaya hacia prono y el brazo esté alineado con el cuerpo.

c) Una almohada debajo de la cadera y la pierna superior, para que la cadera no descienda hacia prono y la pierna superior esté alineada.

Se recomienda usar esta posición en pacientes inconscientes, dado que se considera la posición de seguridad; para la administración de medicamentos vía rectal; para el sondaje y examen rectal y como parte de un plan de cambios posturales.

\subsubsection{Fowler}

El paciente se encuentra en decúbito supino con la cabecera de la cama elevada a $45^{\circ}$, los brazos pueden estar sobre el abdomen o a los lados, encima de una almohada, y las piernas extendidas en ligera flexión. Esta es la posición en la que el paciente pasa la mayor parte del tiempo si no hay contraindicación. 
Como apoyos y descargas se colocan:

a) Una almohada debajo de la cabeza para aumentar la comodidad del paciente.

b) Un cojín debajo de cada brazo para que estén ligermente elevados y reducir así la tensión en los hombros, evitando los edemas.

c) Una almohada debajo de las rodillas para disminuir la tensión en los músculos de la pierna.

Esta posición está indicada en pacientes con problemas respiratorios o cardíacos, ya que favorece la ventilación; o como parte de un plan de cambios posturales, para que el paciente pueda comer, beber, leer, etc.; también para exploraciones de tórax o cara; y para la administración de medicación por vía oral y en postoperatorios.

Existen dos variaciones sobre esta posición que son la posición de semi-Fowler, en la que la elevación del cabecero de la cama es de unos $30^{\circ}$, en vez de los $45^{\circ}$ de la posición originaria; y la Fowler alta, en la que el cabecero de la cama está cercano, a los $90^{\circ}$ situando al paciente en una posición sentada (figura 9).

\subsection{Posiciones de exploración, tratamientos médicos o quirúrgicos}

Las posiciones quirúrgicas se emplean fundamentalmente para exploraciones médicas o para facilitar el acceso quirúrgico, nunca como parte de un plan de cambios posturales. Por lo tanto, una vez terminada la exploración, se deberá posicionar al paciente en cualquiera de las posiciones vistas anteriormente. Puesto que la tensión y la presión realizadas se producen durante un corto período de tiempo, no hay riesgo de que se produzcan lesiones, por lo que habitualmente no es necesario utilizar almohadas en estas posiciones.

Las posiciones que pasaremos a tratar son ginecológica o de litotomía, Trendelenburg, anti-Trendelenburg, genupectoral, Roser o Proetz y posición para punción lumbar.

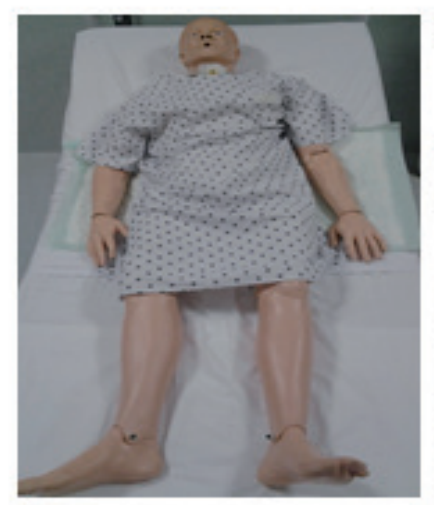

Posición semi-Fowler

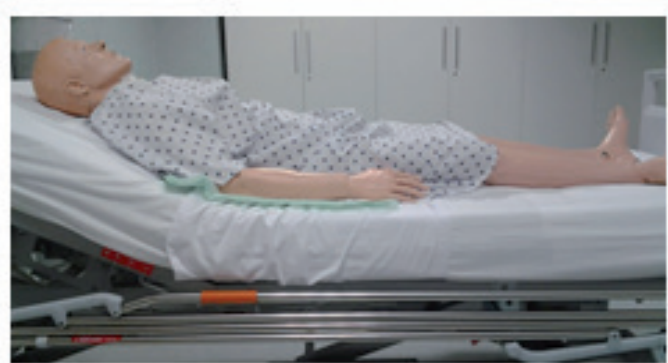




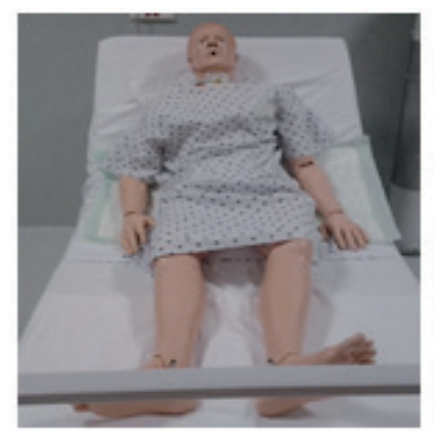

Posición de Fowler
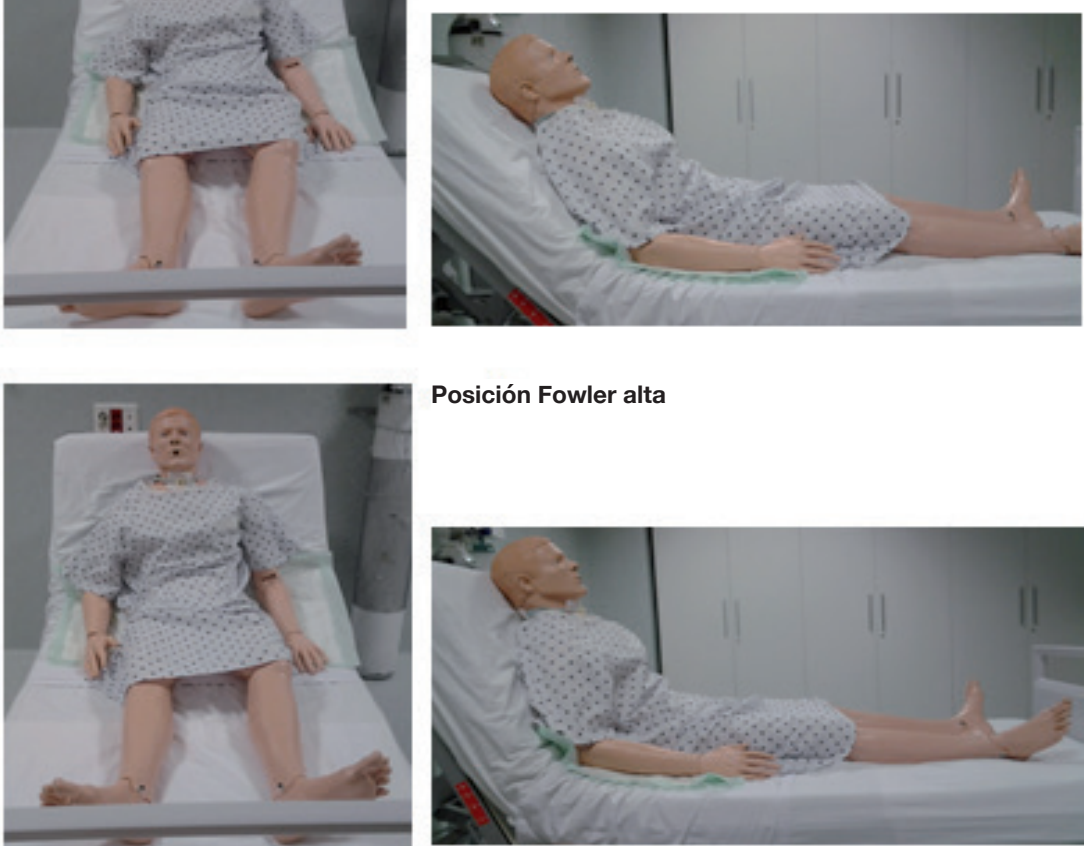

Posición Fowler alta

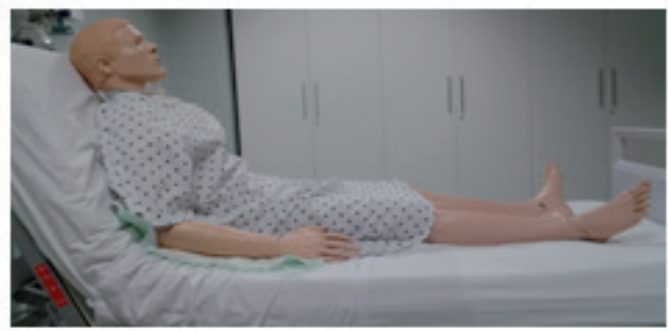

Figura 9. Posiciones semi-Fowler, Fowler y Fowler alta. Fuente: elaboración propia

\subsubsection{Ginecológica o de litotomía}

Para colocar a la paciente en esta posición, partimos de un decúbito supino, habitualmente con las manos sobre el abdomen, aunque la paciente puede ponerlas donde le sea más cómodo, siempre que no interfiera con la exploración que se va a realizar. Si contamos con una mesa ginecológica, las piernas se flexionarán por la cadera y las rodillas, separadas entre sí y se sujetan en unos soportes denominados estribos, para que la paciente descanse las piernas en ellos ypueda mantener la postura. Si la paciente está en una cama normal, las piernas se hallarán separadas y flexionadas, con los pies apoyados en la cama.

Esta postura está indicada en exploraciones o intervenciones ginecológicas; en exploraciones de embarazadas y partos; en exploraciones rectales y vesicales y en el sondaje vesical en la mujer y para el lavado genital de la misma.

\subsubsection{Trendelenburg}

Para realizar esta posición, pondremos al paciente en decúbito supino y levantaremos los pies de la cama de manera que el paciente quede en un plano inclinado con la cabeza más baja que los pies. Una variante de esta posición es situar al paciente con las rodillas flexionadas en el borde de la cama, dejando las piernas colgando a este nivel para que el paciente no se resbale hacia abajo. 
Esta posición está recomendada en situaciones en las que necesitemos mejorar la circulación sanguínea en el cerebro, como en las pilotimias o síncopes; para drenaje de secreciones bronquiales y en cirugías de órganos pélvicos y para que el paquete abdominal se desplace hacia el tórax y permita mejor el acceso quirúrgico (figura 10).

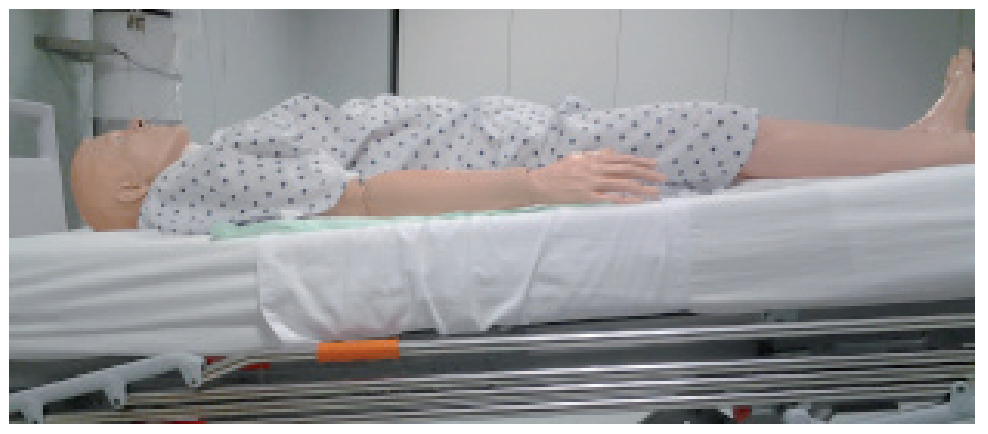

Figura 10. Posición Trendelenburg. Fuente: Elaboración propia

\subsubsection{Anti-Tredelenburg, Trendelenburg inversa o de Morestin}

En esta posición el paciente se sitúa en decúbito supino, en un plano inclinado, con la cabeza más alta que los pies, es decir, con la posición contraria al Trendelenburg. Esta posición está indicada para evitar problemas de reflujo gástrico; en pacientes con problemas respiratorios en los que no pueda usarse la posición Fowler y en ciertas intervenciones quirúrgicas (figura 11).

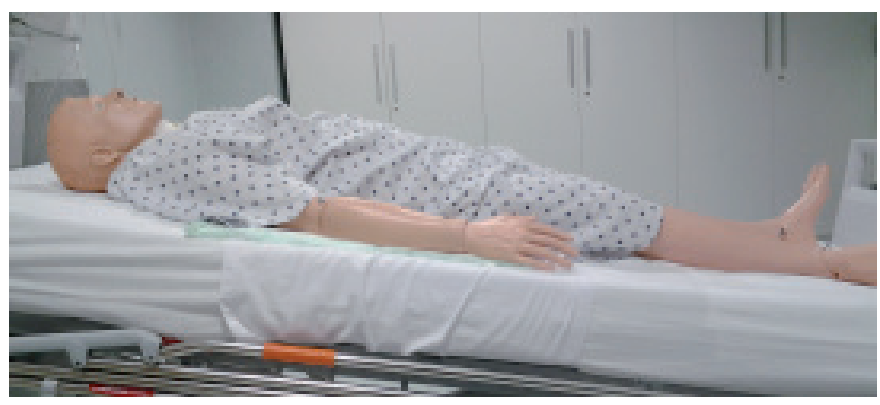

Figura 11. Posición anti-Trendelenburg. Fuente: Elaboración propia

\subsubsection{Genupectoral o mahometana}

En esta posición, el paciente se apoya sobre sus rodillas manteniendo el pecho sobre la cama y la cabeza ladeada. Los brazos se colocan como resulte más cómodo. Es muy importante tener en cuenta la intimidad del paciente, así como mantenerle de esta forma el menor tiempo posible, dado que el paciente puede sentirse humi1lado. Esta posición es idónea en exploracioens de recto y colon; en cirugía de la zona rectal y en curas de fístulas rectales. 


\subsubsection{Roser o Proetz}

Colocamos al paciente en decúbito supino con la cabeza colgando, sobresaliendo por el borde superior de la cama. Si no se puede quitar el cabecero de la cama, se pone al paciente en oblicuo, siguiendo la diagonal de la cama, con la cabeza sobresaliendo por un lateral. Esta posicion se utiliza para realizar una intubación endotraqueal al paciente, en exploraciones faríngeas, en ciertas intervenciones quirúrgicas como en la de bocio y para lavar el pelo a pacientes encamados (figura 12).



Figura 12. Posición de Roser o Proetz. Fuente: Elaboración propia

\subsubsection{Posición para realizar una punción lumbar}

Existen dos posibilidades para esta posición:

a) El paciente se coloca sentado en el borde de una camilla, con la columna vertebral lo más flexionada posible, de manera que la cabeza quede lo más cerca de las rodillas que se pueda y así conseguir que se abran bien los espacios intervertebrales. Además, el paciente puede pasar sus brazos debajo de las rodillas para ayudar en la flexión.

b) El paciente se sitúa tumbado en la cama en decúbito lateral, adoptando una posición fetal, con la espalda en el borde de la cama para permitirle al médico llevar a cabo cómodamente la punción.

Esta posición se adopta para la recogida de líquido cefalorraquídeo y para administrar anestesia epidural.


Figura 13. Posición de punción lumbar. Fuente: Elaboración propia 


\subsubsection{Posición de Kraske}

Es una modificación de la posición prona. La mesa quirúrgica se flexiona en un ángulo que puede ser moderado o severo, según el abordaje quirúrgico que sea necesario. Hay que almohadillar muy bien las zonas de la cresta ilíaca y la cadera, ya que la mesa se angula en dicha zona. Esta posición se utiliza para procedimientos quirúrgicos en la zona rectal y coccígea. Debido a la postura descendente se produce un estancamiento venoso de la zona cefálica y caudal. Por ello, es muy importante regresar al paciente a la posición horizontal, de esta forma se evitarán problemas secundarios.

\subsubsection{Posición renal}

Una variante de la posición lateral es la posición renal. El paciente se coloca en posición lateral, pero de modo que la región renal coincida con la división de la mesa de operaciones. Se flexiona ligeramente la mesa al nivel de la cresta ilíaca, para que el elevador del cuerpo se pueda subir tanto como se desee, para aumentar el espacio entre las costillas inferiores y la cresta ilíaca. Se colocará una correa sobre la cadera para estabilizar al paciente. El brazo de arriba se apoya en un soporte de brazos. La pierna de abajo está más flexionada que la de arriba, situando una almohada entre las mismas. Esta posición se emplea sobre todo en intervenciones de riñón, ya que se consigue elevar el punto quirúrgico.

\section{Efectos de la inmovilidad en el cuerpo}

La inmovilidad de los pacientes tiene ciertos efectos adversos. Las consecuencias de estos efectos adversos pueden medirse de forma clara a través de ciertos signos físicos pero, es de conocer, que la inmovilidad en sí misma tiene también ciertos efectos a nivel psicológico que muchas veces son más complicados de determinar. Los principales efectos adversos de la inmovilidad pueden detallarse en:

a) Disminución de la fuerza y tono musculares, disminución del tamaño de los músculos.

b) Disminución de la movilidad y flexibilidad articulares.

c) Limitación de la fortaleza e intolerancia a la actividad.

d) Desmineralización ósea.

e) Falta de coordinación y alteración de la marcha.

f) Disminución del esfuerzo respiratorio e incremento de las secreciones respiratorias con atelectasias y congestión respiratoria.

g) Incremento de la carga de trabajo al corazón, hipotensión ortostática, trombosis venosa.

h) Alteración de la circulación y maceración cutánea.

i) Disminución del apetito, estreñimiento.

j) Estasis urinaria, infección.

k) Alteración de los patrones del sueño, dolor, depresión, ira, ansiedad. 
Autores como Griffiths (2012) determinan, a través de una revisión narrativa, que los efectos adversos del paciente asociados a la inmovilidad y el manejo deficiente de los mismos están relacionados con:

a) La necesidad que nace en el paciente de conocer los analgésicos que pueden serle administrados antes de iniciar la movilización.

b) La atención que requiere el paciente en relación a su confort.

c) El dominio que tiene el paciente con los dispositivos de ayuda a la movilidad, incluso la aceptación de estos dispositivos.

d) El miedo psicológico a caer que tienen los pacientes.

e) La necesidad que tiene el paciente para evitar daños tisulares relacionados con la inmovilidad.

\section{Plan de cambios posturales}

Las personas en situación de dependencia pueden estar largos periodos de tiempo con un gran sedentarismo e incluso inmovilismo, por lo que hay que proteger las zonas de riesgo en donde se pueden provocar úlceras por decúbito, estas zonas de riesgo se extienden, sobre todo, en las zonas de prominencias óseas. Se cree que los cambios posturales son necesarios para prevenir la aparición de úlceras por presión y que, además, ayudan a mejorar la función cardiovascular y respiratoria y evitan la rigidez articular y la flacidez muscular. Una reciente revisión realizada por la Cochrane (2014) resume que las pruebas para apoyar la administración del cambio de posición para prevenir las úlceras de decúbito tienen un volumen pequeño y de baja calidad, y aún no se conoce si posiciones o frecuencias particulares de cambio de posición reducen su aparición. Es importante resaltar que esta falta de pruebas acerca de la efectividad del cambio de posición, o de qué régimen de cambio de posición es el mejor, no significa que el cambio de posición no sea eficaz; y ante la falta de evidencia al respecto, seguiremos llevando a cabo esta práctica de la forma habitual. Así, los expertos recomiendan que si la persona se encuentra en situación de dependencia:

a) Si puede colaborar y está encamada durante todo el día, se deben realizar los cambios posturales cada hora.

b) Si puede realizarlos de forma autónoma, hay que pedirle que los realice más a menudo.

c) Si no puede colaborar, hay que hacerlos cada 2-3 horas.

d) Hay que tener cuidado al hacer los cambios posturales, ya que se pueden provocar úlceras por el roce o hematomas por golpes. Recordar que nunca hay que arrastrar a la persona sobre la cama.

e) Mantener la cama limpia, seca y sin arrugas.

f) Se debe airear la habitación.

g) Mantener la alineación corporal.

h) Distribuir bien el peso de la persona con la ayuda de almohadas y/o protecciones. 
i) Dar siempre estabilidad y equilibrio a la persona en situación de dependencia.

j) Utilizar productos de apoyo que amortigüen las zonas de presión: colchones de aire; almohadones; protectores locales, sobretodo en talones y tobillos.

Teniendo en cuenta todo lo visto hasta ahora en lo referente al cuidado básico de la movilidad, conocemos que hay que conservar la higiene postural tanto de la persona a la que cuidamos como la nuestra propia. Además, se han visto las posiciones que pueden adoptar los pacientes en la cama y las protecciones que debemos ofrecer para evitar la escoriación de la piel, entre ellas el plan de cambios posturales.

Para poder llevar a cabo este plan de cambios posturales, debemos conocer cómo movilizar a los pacientes, debido a que existen técnicas determinadas para no dañar al paciente, ni dañarnos nosotros mismo con el esfuerzo de movilizar a un paciente.

\section{Movilización de los pacientes}

Los pacientes hospitalizados presentan diversos grados de dependencia para todas sus funciones y actividades de la vida diaria. En función de ese grado de dependencia, podemos clasificar a los pacientes en: pacientes autónomos que son los que realizan sus actividades diarias sin necesidad de ninguna ayuda; pacientes que colaboran que son los que, bien porque no pueden o bien porque su patología así lo aconseja, necesitan ayuda para realizar sus actividades diarias; y, por último, los pacientes dependientes o pacientes que no colaboran, que son los pacientes que no pueden ni siquiera ayudar para realizar sus actividades diarias $\mathrm{y}$, por lo tanto, necesitan que el personal de enfermería les asista totalmente.

Entre las situaciones en las que los pacientes precisan más ayuda está su propia movilización. El cambio de postura es una de las situaciones que más problemas les causan, por lo que el personal de enfermería debe conocer la manera de movilizarles en función de su grado de dependencia, de la forma más cómoda posible para ambos y cuidando de que no se produzcan lesiones en ninguno de los dos.

Aspectos generales a tener en cuenta antes de movilizar al paciente:

1. Mantener al paciente bien alineado y protegerlo de lesiones durante el desplazamiento.

2. Realizar una valoración del paciente conociendo su diagnóstico médico del paciente, la capacidad que posee y cualquier movimiento y posición final que no esté permitido.

3. Valorar la capacidad del paciente para colaborar con los movimientos planificados. Debe pedirse que colabore en su propia transferencia.

4. Asegurarse de que haya personal suficiente para desplazar al paciente con seguridad.

5. Planificar de manera cuidadosa lo que se llevará a cabo antes de desplazar o elevar a un paciente. El enfermero puede lesionar al paciente o a sí mismo si 
no se realiza una planificación adecuada. Si es necesario, solicite el apoyo de otro enfermero. Esto reduce el esfuerzo de todas las personas involucradas. Comunique el plan al personal y al paciente, para asegurar movimientos coordinados.

6. Explicar al paciente lo que desea hacer. A continuación, use la capacidad del paciente para colaborar en la tarea. Esta técnica a menudo disminuye el esfuerzo necesario y la posibilidad de lesiones al personal de enfermería.

7. Si el paciente sufre dolor, se administran los analgésicos prescritos en cantidad suficiente y antes de la transferencia, para permitir que el paciente colabore con comodidad en el desplazamiento. Además deberemos tener en cuenta dejar pasar un tiempo prudencial para que estos analgésicos hayan surtido efecto.

8. Se eleva la cama, como sea necesario, de forma que la altura de trabajo sea cómoda y segura para el enfermero.

9. Se activan los frenos de la cama, de la silla de ruedas o de la camilla (en transferencias), de forma que no se deslicen mientras se desplaza al paciente.

10. Tener en cuenta los principios de la mecánica corporal vistos en este tema.

11. Dar sostén adecuado al cuerpo del paciente. Evitar sujetarlo y sostenerlo de las extremidades mediante los músculos.

12. Siempre que sea posible, se utilizan dispositivos para reducir la fricción.

13. Mueva su cuerpo y el del paciente en un movimiento suave, rítmico. Los movimientos irregulares tienden a aplicar esfuerzo adicional a los músculos y articulaciones y son incómodos para el paciente.

14. Lavarse las manos y colocarse guantes.

15. Proteger y prever el recorrido de los elementos y accesorios que tenga el paciente (sondas, drenajes, sistemas de perfusión, etc.) antes de la movilización, despejándolo de obstáculos.

16. Si la técnica de movilización la va a realizar más de una persona, siempre habrá una que la dirija, dé las órdenes y coordine los movimientos previamente pactados para aunar esfuerzos y sincronizar movimientos.

\subsection{Movilizar al paciente hacia el cabecero de la cama}

Es frecuente que los pacientes se deslicen hacia los pies de la cama, sobre todo si están en determinadas posiciones que favorecen este movimiento, como lo es la posición de Fowler. Para volver a colocar al paciente en una posición adecuada, hay que seguir los siguientes pasos:

Paciente que colabora:

1. Seguir los aspectos generales de movilización de pacientes.

2. Colocar la cama en horizontal si no hay contraindicaciones.

3. Retirar la almohada y colocarla en posición vertical en el cabecero, para evitar que el paciente se golpee en la cabeza, si se realiza el movimiento con mucho ímpetu.

4. Pedirle al paciente que flexione las rodillas apoyando los pies en la cama y que, si es posible, coloque las manos en el cabecero de la cama. 
5. Con la espalda recta, pasar el brazo más próximo al cabecero por debajo de los hombros, sujetando el cuello del paciente, y el otro por debajo del hombro del paciente más próximo a nosotros, mientras el paciente se sujeta a nuestro hombro con ese mismo brazo pasándolo bajo nuestra axila. Tendremos las piernas flexionadas y realizaremos el movimiento cambiando el peso de la pierna de atrás, que tendrá el pie en dirección a la cama, a la pierna de delante, que tendrá el pie en dirección al movimiento.

6. Pactar con el paciente una señal para realizar el movimiento, como por ejemplo contar hasta tres. Tras la señal, el paciente levantará la cadera apoyando con fuerza los pies y tirará de los brazos hacia arriba, mientras nosotros le ayudamos con el movimiento hacia el cabecero.

7. Colocar la almohada bajo la cabeza del paciente y ordenar la ropa de cama.

8. Anotar la técnica y sus incidencias en la hoja de registro correspondiente.

Paciente que no colabora:

Si el paciente no colabora, la técnica puede hacerse de dos formas, siempre con dos personas:

1. Seguir los tres pasos de la técnica anterior.

2. Una persona se situará a cada lado de la cama, en la misma posición de movimiento que en la técnica anterior, o bien cada uno con un brazo bajo los hombros y el otro bajo la cadera del paciente.

Existen dos posibilidades de realizar esta técnica:

Posibilidad A, sin entremetida:

1. Si el paciente no puede por sí mismo, flexionarle las rodillas apoyando los pies en la cama, para no tener que arrastrarlas en la movilización y reducir el rozamiento y el esfuerzo.

2. Cada persona pasará un brazo por debajo de los hombros para sujetar el cuello del paciente y el otro bajo la cadera, como en la técnica anterior.

3. Pactar una señal para coordinar el movimiento entre las dos personas y desplazar al paciente hacia arriba, hasta la posición adecuada, con un movimiento igual a la técnica anterior.

Posibilidad B, con entremetida:

1. Pasar bajo la espalda del paciente una entremetida que abarque desde la cabeza hasta los muslos.

2. Sujetar firmemente la entremetida por los extremos, lo más próximo posible al paciente.

3. A la señal pactada, tirar de la entremetida hasta colocar al paciente en la posición adecuada con un movimiento igual a la técnica anterior.

4. Sea cual sea la técnica elegida, al finalizar dicha técnica colocar la almohada y arreglar la cama. 
5. Registrar la técnica (hora de la realización y posición final en la que queda el paciente).

6. Anotar las incidencias si las hubiera.

\subsection{Movilizar a un paciente al borde de la cama}

En ciertas situaciones, y muchas veces como paso previo a otras movilizaciones, es necesario mover a los pacientes hasta el borde de la cama. Para realizar esta parte de la movilización de un paciente podemos encontrarnos con los diferentes tipos de paciente, en función del grado de dependencia que se ha expuesto anteriormente, en base a ello realizaremos los procedimientos siguientes (figura 14).

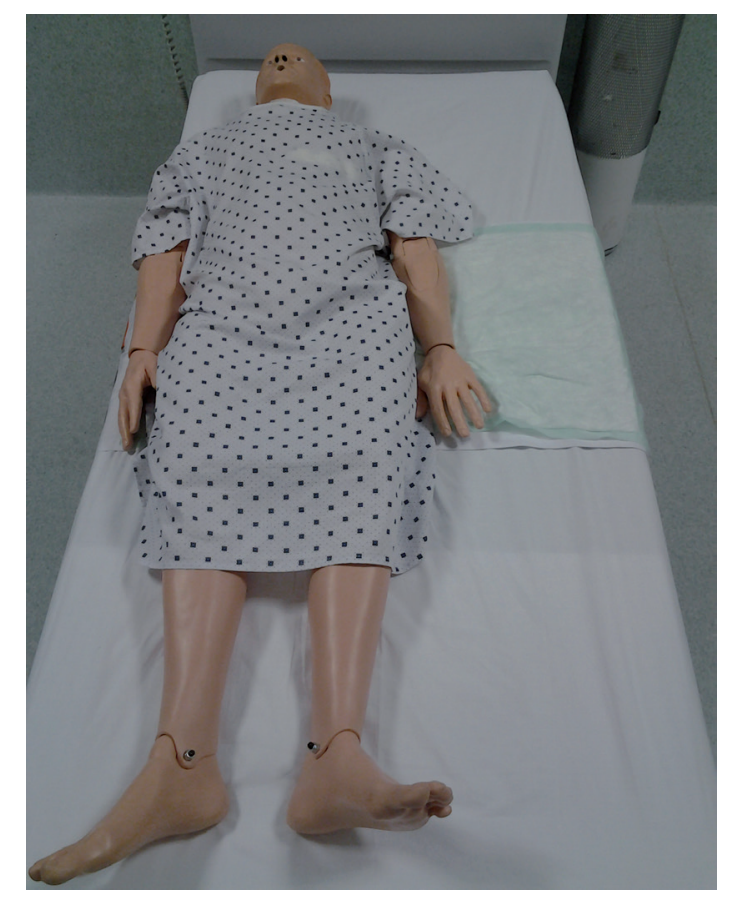

Figura 14. Paciente al borde de la cama. Fuente: Elaboración propia

\subsubsection{Paciente que colabora}

1. Seguir las indicaciones generales de las técnicas de movilización de pacientes.

2. Situarse al lado del paciente hacia donde lo vamos a mover.

3. Adelantar una pierna haciendo tope con la cama para evitar una caída si el paciente se pasa de brusquedad en el movimiento.

4. Pasar los brazos en la misma posición que para subirlo hacia el cabecero.

5. Pedirle al paciente que apoye los pies en la cama para realizar el movimiento.

6. Pactar una señal para iniciar el movimiento $y$, en ese momento, con la ayuda del paciente, traerlo hacia nosotros cambiando el peso de la pierna más adelantada a la de atrás, para realizar el movimiento con las piernas y no con la espalda. 
7. Si hay que separarse del paciente dejándolo en esta posición, ponerle la barandilla de la cama.

8. Arreglar la cama.

9. Registrar la técnica.

10. Anotar las incidencias si las hubiera.

\subsubsection{Paciente que no colabora y una sola persona}

La técnica es igual a la del paciente que colabora, pero al tener que realizar nosotros todo el esfuerzo la haremos en tres tiempos para repartir la carga en cada movimiento y reducir el riesgo de lesión.

1. Seguir las indicaciones generales de las técnicas de movilización de pacientes.

2. Primero pasaremos los brazos debajo de las piernas, haciendo tracción con estas hasta el borde de la cama.

3. En segundo lugar, pasaremos los brazos debajo de la cadera y moveremos esta, alineándola con las piernas.

4. Por último, pasaremos ambos brazos debajo de la espalda, el cuello y los hombros del paciente y moveremos la cabeza y el tórax, hasta dejar al paciente alineado en el lado de la cama elegido.

Este método de tres tiempos es más cómodo que el método clásico de dos tiempos (cabeza y tórax primero, y cadera y piernas después). Además, resulta más seguro al cargar menos peso en cada fase y dejar para el final el tórax, pues este permanece en el centro de la cama hasta el final. Todo ello, sin suponer apenas pérdida de tiempo.

\subsubsection{Paciente que no colabora y dos personas}

La técnica es igual a la de mover el paciente al cabecero de la cama, tanto con entremetida como sin ella, pero en lugar de mover el paciente hacia arriba, se le mueve hacia el lado elegido. La persona que tira hacia sí del paciente fijará al borde de la cama la rodilla de la pierna adelantada, para evitar accidentes y que el paciente se caiga.

\subsection{Movilizar a un paciente de decúbito supino a decúbito lateral}

Este cambio de posición de un paciente es uno de los procedimientos más usados en la práctica hospitalaria. Para realizar esta técnica, vamos a tener que mover al paciente al borde de la cama del lado contrario al que le vamos a girar, de forma que, al finalizar la movilización, este quede en el centro de la cama y no haya riesgo de caída. Aun así, es imprescindible colocar la barandilla de la cama antes de dejar al paciente en esta posición. 
Para realizar esta técnica, apenas hay diferencia entre que el paciente colabore o no, pues no se trata de arrastrar al paciente sino de hacerle rodar sobre sí mismo. Por tanto, la única diferencia estriba en que, si el paciente colabora, puede apoyarse en nuestro hombro para ayudar en el movimiento.

\subsubsection{Técnica con una sola persona}

1. Seguir los pasos generales de movilización de pacientes.

2. Retirar la ropa de la cama sin descubrir al enfermo.

3. Mover al paciente al lado contrario al que se le va a girar, según la técnica descrita anteriormente y dejar puesta la barandilla de ese lado, antes de cambiar de lado de la cama para realizar el giro, para evitar accidentes.

4. Situarnos al lado de la cama en el que vamos a girar al paciente.

5. Separar ligeramente el brazo del paciente que luego quedará en la parte inferior, para que no quede bajo el cuerpo al realizar el movimiento. Cruzar el brazo contrario sobre el tórax del paciente.

6. Estirar la pierna más cercana a nosotros y flexionar la pierna más alejada o bien cruzarla sobre la otra.

7. Colocarnos con una pierna más adelantada que otra y, con la espalda recta, situar una mano por detrás del hombro más lejano y la otra detrás de la cadera más lejana.

8. Manteniendo la espalda recta, y mediante un cambio de peso de nuestra pierna más próxima a la cama a la pierna más alejada, girar con suavidad al paciente hacia nosotros, teniendo en cuenta que no debe quedar muy cercano al borde de la cama, para evitar que se caiga al realizar algún movimiento.

9. Colocar la barandilla de la cama.

10. Si la movilización se realiza para un cambio postural, pedirle al paciente que se agarre a la barandilla mientras colocamos las almohadas, según se vio en el apartado de posiciones de pacientes encamados.

11. Si el hombro inferior del paciente queda debajo del cuerpo, tirar ligeramente de él para sacarlo un poco sin deshacer la postura.

12. Arreglar la cama y registrar la técnica.

\subsubsection{Técnica con dos personas sin entremetida:}

La técnica es exactamente igual, pero la segunda persona ayuda en el movimiento desde el otro lado de la cama y coloca los apoyos y almohadas, mientras la primera persona mantiene la postura si el paciente no puede colaborar.

\subsubsection{Técnica con dos personas con entremetida:}

La técnica es igual hasta que tenemos al paciente con la pierna más alejada de nosotros flexionada. Entonces, en lugar de sujetar al paciente por el hombro y la 
cadera, la persona del lado contrario nos acercará la parte de la entremetida de su lado para que nosotros, sujetando la entremetida de los extremos, tiremos de ella para hacer girar al paciente mientras la otra persona nos ayuda en el movimiento. Una vez posicionado el paciente, y antes de colocar las almohadas, volvemos a poner la entremetida en su sitio estirándola bien para que no tenga arrugas. A partir de este punto se siguen los pasos del protocolo anterior.

\subsection{Mover a un paciente a Sims o decúbito prono}

Aunque no muy frecuentemente, en determinadas situaciones clínicas, y a veces formando parte de un plan de cambios posturales, es necesario colocar a los pacientes en posición de Sims o en decúbito prono. La mayor complicación de esta movilización es que cualquier vía, drenaje o sonda que pueda tener puesto el paciente tiene que pasar de un lado a otro de la cama, junto con el giro del paciente, con los riesgos de desinserción que ello conlleva.

Por ello, en caso de que el paciente tenga insertado alguno de estos elementos, serán necesarias por lo menos tres personas para realizar esta técnica correctamente: dos para realizar la movilización y una para vigilar y cuidar de las vías, etc., mientras se realiza la movilización.

Para realizar cualquiera de estas movilizaciones, habitualmente se parte de la posición de decúbito lateral para después decantarse por una de las siguientes dos opciones, en función de las vías que tenga el paciente. O bien colocar el brazo inferior hacia arriba de manera que, al rotar, el cuerpo no pase por encima del brazo en ningún momento. En este caso, las dos personas continúan rotando al paciente desde la posición de decúbito lateral hasta Sims o prono, y se colocan las almohadas y apoyos según convenga. $\mathrm{O}$ bien, pegar el brazo inferior al cuerpo para que este rote por encima del brazo. En esta posición, la persona que está a la espalda del paciente pasa una mano bajo la cintura del paciente hasta sujetar el brazo inferior del mismo y, en ese momento, tira del brazo del paciente para que este quede por detrás, mientras la otra persona tira del paciente para hacerlo girar y lo fija en la posición deseada, sin que caiga de golpe boca abajo sobre la cama. Al finalizar este paso, sólo nos quedaría colocar las almohadas y apoyos, asegurarnos de que el paciente está cómodo, arreglar la cama y registrar la técnica.

\subsection{Transferencias}

Por último, en lo que se refiere a movilizaciones, se tratarán las técnicas de transferencias de pacientes, con las que cambiaremos a los pacientes del lugar en el que se encuentre ubicado hacia otro que, tal vez, nos sea más necesario, como por ejemplo, una silla de ruedas. 


\subsubsection{Levantar a un paciente de la cama al sillón o silla de ruedas}

La inmovilización y el estar encamado por largo periodos de tiempo tienen de forma inherente un proceso de sucesión de complicaciones que son evitables. Por lo tanto, siempre que el estado de salud del paciente lo permita, se iniciará un plan para levantarlo aunque sólo sea para estar en un sillón, lo que le va a permitir que esté más cómodo.

Para realizar esta técnica, podemos encontrarnos con un paciente que sea capaz de colaborar y quiera hacerlo, o bien un paciente que por su estado de salud, su patología o involuntariedad, no pueda colaborar.

\section{Paciente que colabora:}

Para considerar que el paciente colabora, este tiene que ser capaz de mantenerse de pie y dar algunos pasos.

La técnica se llevará acabo de la siguiente manera:

1. Seguir las indicaciones generales de movilización de pacientes.

2. Colocar el sillón al lado de la cabecera o de los pies de la cama. Si es una silla de ruedas, estará frenada. Prepararemos las zapatillas y la bata del paciente si fuera necesario.

3. Indicamos al paciente que se acerque al borde de la cama y, si no puede, le acercaremos nosotros según la técnica descrita.

4. Colocar la barandilla de la cama y subir el cabecero hasta posición de Fowler, lo más alto posible.

5. Bajar la barandilla de la cama.

6. Situarnos en el borde de la cama a la altura de la cadera del paciente, con la espalda recta, el pie cercano a la cabecera dirigido hacia esta y el posterior en dirección a la cama.

7. Con un brazo extendido, lo pasamos por detrás de los hombros del paciente y sujetamos el cuello y hombros. Con este brazo no haremos fuerza y únicamente servirá para acompañar el movimiento y evitar que el paciente caiga de espaldas sobre la cama.

8. Con el otro brazo sujetaremos al paciente por la rodilla más alejada.

9. En esta posición, tiramos de las rodillas mientras nos separamos ligeramente para dejar paso a las piernas del paciente, que en ese momento están bajando. Mientras hacemos esto, mantenemos los hombros y el cuello del paciente, para que no se caiga hacia atrás.

10. El paciente debe quedar sentado al borde de la cama, están sus piernas entre las nuestras. En este momento, nos aseguraremos de que el paciente se encuentra bien y no se marea, sobre todo si es la primera vez que se levanta, después de algún tiempo encamado. Si se marea o no se encuentra bien, haremos justo el movimiento contrario para volver a tumbarle en la cama.

11. Una vez hemos comprobado que no se marea, le ponemos las zapatillas y la bata. 
12. Sujetamos al paciente por las axilas y le indicamos que se agarre a nuestros hombros, nunca al cuello.

13. Manteniendo nuestras piernas por fuera de las del paciente, le animamos a que se ponga de pie.

14. Giramos hacia el lado del sillón o silla de ruedas, moviendo los pies sin rotar el tronco.

15. Durante todo este proceso, estaremos pendientes de si le flaquean las piernas al paciente. De ser así, con una ligera flexión de nuestras rodillas contactaremos con las del paciente, para bloquearlas y evitar la flexión de estas, y por tanto la caída.

16. Cuando esté alineado con el sofá o silla de ruedas, le indicamos al paciente que descienda suavemente sujetándose a nosotros hasta quedar sentado.

17. Colocamos las almohadas necesarias para que mantenga la postura y esté cómodo.

18. Cubrimos al paciente con una sábana o manta doblada por la mitad.

19. Nos aseguramos de que se encuentra bien.

20. Arreglamos la cama.

21. Registramos la técnica y las incidencias.

Para que el paciente se suba de nuevo a la cama, realizaremos la misma técnica en sentido inverso. Cuando el paciente esté de pie de espaldas a la cama, le aproximaremos el sillón para que apoye un pie en él, para darse impulso mientras nosotros le ayudamos en el movimiento.

\section{Paciente que no colabora:}

Esta técnica debe realizarse por, al menos, dos personas, en función del tamaño y el peso del paciente:

1. Seguir las indicaciones generales de movilización de pacientes.

2. Acercamos al paciente al borde de la cama según el protocolo anterior.

3. Mientras una persona vigila que el paciente no se caiga, el otro coloca, a la altura de la cadera del paciente, el sillón o silla de ruedas en el lado de la cama donde le vamos a levantar y sube el cabecero de la cama a posición de Fowler.

4. Una persona se sitúa detrás del respaldo del sillón, al lado del paciente, y sujeta a este por debajo de las axilas. El otro se sitúa frente al primero, a la altura de las rodillas del paciente, sujetándole por las mismas.

5. Se le indica al paciente que ponga las manos sobre su pecho y, en un movimiento coordinado, las dos personas bajan con suavidad al paciente de la cama al sillón o silla de ruedas.

6. Si disponemos de grúa, la usaremos siguiendo estrictamente sus instrucciones de uso según marca y modelo.

7. Terminamos la técnica igual que el protocolo anterior.

Para que el paciente se suba de nuevo a la cama, realizaremos la misma técnica en sentido inverso. 


\subsubsection{Cambio del paciente de la cama a una camilla u otra cama}

Es frecuente que el paciente, al ingreso o cuando tiene que ir a otros servicios del hospital, tenga que cambiar de cama o pasarse a una camilla. Es una técnica sencilla aunque no exenta de riesgos. Sea cual sea el caso, primero deberán seguirse las normas generales de movilización de pacientes, y a partir de este punto:

1. Situar la cama o camilla pegada a lo largo de uno de los dos lados de la cama del paciente.

2. Proceder a la retirada de la ropa que cubra al enfermo.

a) Si el enfermo colabora, se trasladará él mismo con ayuda de una persona, que se colocará junto al lateral de la cama vacía hacia donde hay que pasar al paciente.

b) Si el enfermo no colabora, son necesarias al menos dos personas, situándose una al lado de la cama del paciente y otra al lado de la cama hacia donde se le pasará.

3. Ambos pasarán sus brazos bajo la cadera y los hombros del paciente.

4. Con un movimiento coordinado, las personas acercarán al paciente al borde de la cama y, en un segundo tiempo, lo pasarán a la nueva cama o camilla.

5. Esta técnica se puede realizar del mismo modo con la ayuda de una entremetida para pasar al paciente, sujetando esta a la altura de la cadera y los hombros, lo más próximo posible al paciente.

6. Si se dispone de una tercera persona, esta se situará entre los cabeceros, sujetando y controlando la cabeza del paciente.

7. Acomodar al paciente en la cama o camilla nueva.

8. Registrar la técnica.

Es importante tener la cama frenada y hacer cierta presión sobre la misma, con nuestra pierna más cercana a la cama o camilla, para que no se separen las camas durante la realización de la técnica y realizar el movimiento con la espalda recta. La persona situada en el borde de la cama hacia donde se movilizará al paciente controlará que no se caiga de la cama en caso de un movimiento descontrolado. 


\section{CAPITULO 7}

\section{Cuidados básicos \\ en el sueño y el descanso}

\section{Introducción}

Dormir es una necesidad básica de los seres humanos. El sueño nocturno y los pequeños descansos diurnos permiten a las personas recuperar sus energías. Cuando dormimos no somos conscientes del mundo que nos rodea, pero durante este periodo de tiempo ocurren gran cantidad de procesos fisiológicos que son esenciales para mantenernos saludables.

En las personas que padecen un proceso de enfermedad, la necesidad de descanso y sueño aumenta ya que implica un gasto extra de energía. Además, el ritmo de trabajo de los hospitales y sus condiciones ambientales (ruido, iluminación, temperatura, etc.) dificultan el descanso de los pacientes.

Los objetivos de este tema son definir el sueño y descanso, como parte fundamental de los cuidados de enfermería, conocer los factores que afectan al adecuado descanso de los pacientes, describir los métodos de valoración del sueño y establecer los cuidados de enfermería para asegurar un adecuado descanso.

\section{Descanso y sueño. Conceptos}

El descanso y el sueño son esenciales para la salud y básicos para la calidad de vida. Sin sueño ni descanso nuestra capacidad de concentración y de participar en las actividades cotidianas disminuye, a la vez que aumenta la irritabilidad. A continuación definiremos estos conceptos.

\subsection{El descanso}

El diccionario de la Real Academia Española define descansar como «cesar en el trabajo, reparar las fuerzas con la quietud»o «tener algún alivio en las preocupaciones». Descansar supone disminuir la actividad física y mental, que permite a las personas prepararse para continuar con sus actividades cotidianas, pero para descansar se requiere tranquilidad y silencio que permitan liberar la ansiedad y relajar el cuerpo.

Descansar puede implicar el sueño, o no. Cada persona tiene una necesidad de descanso y hábitos para descansar, otorgándole un significado diferente. A pesar de 
ello, existen seis situaciones que la mayoría de personas asocian a un inadecuado descanso y que los profesionales de enfermería deben tener en cuenta:

a) Pierden el control de la situación.

b) Se sienten rechazadas.

c) No entienden lo que está pasando.

d) Presentan molestias e irritaciones.

e) Se sienten dependientes para realizar actividades básicas.

f) Se sienten inseguras. No saben si recibirán ayuda cuando la necesiten.

\subsection{El sueño}

El sueño puede considerarse un proceso universal (común en todas las personas) que conlleva una alteración de la conciencia y del estado funcional (disminución de la actividad física), que ocurre de forma cíclica (se repite periódicamente) y es reversible (ante estímulos externos o al finalizar el proceso).

\subsubsection{Funciones del sueño}

La Sociedad Española de Medicina Oral del Sueño afirma en su página web que en la actualidad no puede afirmarse cuál es la finalidad fisiológica del sueño, aunque existen varias teorías al respecto:

a) Conservación de la energía: durante el sueño disminuye la actividad física $\mathrm{y}$, por tanto, el consumo de $\mathrm{O}_{2}$ y nutrientes, lo que permite que el organismo recupere sus reservas de energía, como un mecanismo de homeostasis similar a la hibernación.

b) Función reparadora: la falta de sueño produce irritabilidad, disminución del rendimiento intelectual, problemas de memoria y agotamiento. Los que apoya esta teoría, afirman que el sueño sirve para restablecer la actividad física y cerebral del organismo.

c) Función de protección: Desde un punto de vista preventivo, se podría decir que el sueño permite al organismo prepararse para la actividad física y mental en el siguiente ciclo de vigilia. Esta teoría está ligada a la anterior, aunque con otro punto de vista.

d) Consolidación de la memoria: durante la fase REM del sueño, se ha detectado una mayor actividad cerebral en las áreas de la memoria y las emociones.

\subsubsection{Fases del sueño}

Los ritmos circadianos de nuestro organismo son los que determinan el ciclo vigilia-sueño, a través la interacción de diferentes sistemas neuroquímicos del SNC y la producción y liberación de hormonas, afectando a diferentes aparatos y sistemas de nuestro organismo. A su vez, el sueño consta de dos etapas: 
a) Sueño no REM (NREM): Es lo que se conoce como sueño reparador y está dividido en cuatro etapas progresivas, desde que estamos despiertos hasta el sueño profundo.

1. FASE I y II: la persona empieza a adormilarse y alcanza un sueño ligero. Las dos etapas suelen durar alrededor de 30 minutos y es fácil despertar a la persona con estímulos externos.

2. FASE III y IV: las funciones vitales empiezan a disminuir y aumenta el nivel de relajación muscular hasta llegar al sueño más profundo. Estas dos etapas suele durar entre 30 y 60 minutos.

b) Sueño REM (Rapid Eye Movement): Durante esta fase la persona continua profundamente dormida, aunque el cerebro permanece activo durante unos 10-20 minutos. En ella, se produce una pérdida del tono muscular, movimientos rápidos de los ojos, cambios en la tensión arterial y la frecuencia cardiaca.

Estas etapas siguen un patrón cíclico, con una duración entre 70 y 110 minutos, de modo que en un periodo de 7-8 horas de descanso, se repiten entre 4 y 6 veces. El sueño suele interrumpirse tras la fase REM, y en caso de no sea así, el ciclo debe volver a empezar desde la primera fase NREM, dificultando que el sueño cumpla con sus funciones (figura 15).

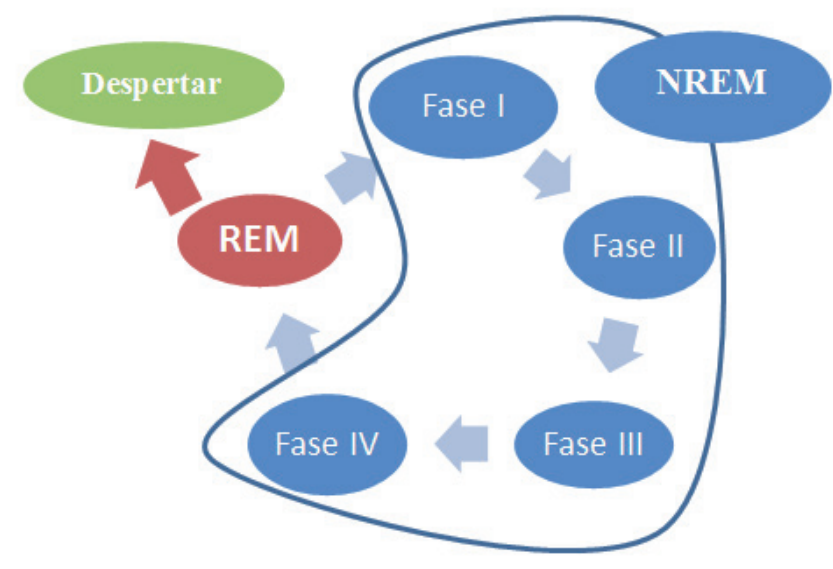

Figura 15. Etapas del sueño. Fuente: Elaboración propia

\subsubsection{Factores que afectan la calidad del sueño}

Las necesidades de sueño varían en cada persona en función de diferentes factores como la edad, las condiciones ambientales o las rutinas de trabajo. En general podemos clasificar estos factores como:

1. Factores psicológicos: la ansiedad, la depresión o el estrés alteran la liberación de hormonas como la adrenalina y provocan alteraciones de las fases REM Y NREM. 
2. Factores socioculturales: los estilos de vida, la alimentación, el consumo de determinadas sustancias como alcohol o tabaco, o los ritmos de trabajo (trabajo a turnos, periodos de exámenes, etc.) producen alteraciones del ciclo vigilia-sueño, afectando a la calidad del sueño.

3. Factores ambientales: ventilación, iluminación, olores, ruido, tener o no compañero o el tipo de cama son factores que pueden afectar a la calidad del sueño.

4. Factores biofisiológicos: las necesidades de sueño varían en función de determinados factores como la edad (tabla 8), y se pueden verse alterados por otros como realizar ejercicio físico, la alimentación, el estado de salud (dolor crónico), presencia de terminadas patologías (enfermedad respiratoria, úlcera gástrica, etc.) o el consumo de medicamentos (diuréticos, antidepresivos, betabloqueantes, etc.).

\begin{tabular}{lc}
\hline & Horas de sueño \\
\hline Neonatos & 16 \\
Lactantes & 14 \\
Preescolar & 12 \\
Escolares & $8-12$ \\
Adolescentes & $8-9$ \\
Adulto & $6-8$ \\
Edad avanzada & $4-8$ \\
\hline
\end{tabular}

Tabla 8. Horas de sueño según edad. Fuente: Elaboración propia

\section{La hospitalización y su repercusión en el sueño}

La hospitalización supone en sí misma una alteración de los ritmos circadianos, asociándose a una alteración de un sueño que no es protector ni reparador. La calidad del sueño influye en una mejor y rápida recuperación de la causa que motiva los ingresos hospitalarios (Aguilera, Díaz y Sánchez, 2012).

La alteración del sueño en los pacientes hospitalizados tiene consecuencias psicológicas y físicas, tal y como han observado Young et al. (2008) en su trabajo. Por una parte, puede aumentar los niveles de ansiedad, modificando el estado de ánimo y el humor, e incluso provocar delirium. Por otra parte, puede elevar la tensión arterial, alterar la ventilación, el sistema inmunitario o la diabetes mellitus. Además, las alteraciones del sueño se asocian a un mayor riesgo de caídas en el anciano (Stone et al., 2008) y peor calidad de vida (Léger et al., 2012).

Los pacientes hospitalizados son más propensos que la población general a padecer trastornos del sueño, principalmente el insomnio agudo (dificultad para iniciar 
y mantener el sueño). Mientas que la prevalencia de insomnio en la población general oscila entre el 10 y el $30 \%$, Vico-Romero et al. (2014), han observado una prevalencia global de insomnio del $42 \%$ al estudiar una muestra de 299 pacientes en el Hospital de Mataró, coincidiendo con los resultados obtenidos en otros estudios internacionales, en los que la prevalencia de insomnio oscila entre $30 \mathrm{y}$ $45 \%$ (Venlateshiah y Collop, 2012; Meissner et al., 1998), pudiendo aumentar en determinadas patologías como los accidentes cerebro-vasculares hasta el $78 \%$ (Pasic et al., 2011). En este punto, cabe preguntarse qué factores son lo que alteran el sueño de los pacientes ingresados en los hospitales.

\subsection{Factores que influyen en la calidad del sueño durante la hospitalización}

Existen varios estudios que han tratado de conocer qué factores son lo que realmente más afectan a la calidad del sueño en los pacientes hospitalizados. De acuerdo con Aguilera, Díaz y Sánchez (2009), podemos resumirlos del siguiente modo:

a) La existencia de una patología previa de sueño.

b) El consumo habitual de sedantes.

c) El nivel de ansiedad de los pacientes durante la hospitalización.

d) Variables ambientales en la sala de atención, entre los que se encuentran ruidos molestos, iluminación inadecuada, falta de comodidad del inmobiliario, etc.

e) La causa de la hospitalización que incide en la presencia de alteraciones del sueño, especialmente en aquellas patologías que se cursan con dolor desde moderado a severo.

Otros estudios realizados por profesionales de enfermería añaden a esta lista otros factores como la presencia de pirosis o reflujo gastroesofágico, incapacidad funcional al ingreso y sensación de sobrecarga para el cuidador, que provocan elevados niveles de angustia (Vico-Romero et al., 2014). Albella Vallverdú et al. (2013) encontraron que el 43,2 \% de pacientes que eran portadores de algún tipo de dispositivo presentaban bastantes o muchas molestias para dormir, además de que al $12,4 \%$ le habían despertado las enfermeras durante su actividad, presentando dificultades para volverse a dormir el 53,1\%.

Los factores que afectan a la calidad del sueño durante la hospitalización también se han estudiado desde la perspectiva de los profesionales en nuestro entorno (Medina Cordero, Feria Lorenzo y Oscoz Muñoa, 2009), coincidiendo en gran parte con los factores reportados por los pacientes (tabla 9).

Parece evidente que durante la hospitalización, los pacientes se ven sometidos a nuevas reglas y horarios, que pueden no coincidir con los de su reloj biológico, sin olvidar que no están allí voluntariamente, sino por una enfermedad o problema de salud que les genera ansiedad, en el mejor de los casos. Por otra parte, los 
ritmos de trabajo, las condiciones de la habitación, los compañeros de habitación, las visitas de familiares, etc., son factores con un elevado potencial para alterar el ritmo de vigilia-descanso y la calidad del sueño. El profesional de enfermería debe minimizar dichos factores para que los pacientes no modifiquen su patrón habitual de sueño y de esta manera facilitar el descanso nocturno.

\begin{tabular}{|c|c|c|}
\hline Grupos & Factores & Profesionales* \\
\hline \multirow{3}{*}{ Enfermedad } & Molestias & $>80 \%$ \\
\hline & Aparatos, sondas, vías, oxígeno & $>80 \%$ \\
\hline & Dolor & $>80 \%$ \\
\hline \multirow{6}{*}{$\begin{array}{l}\text { Organización de los } \\
\text { cuidados }\end{array}$} & Actuaciones de enfermería & $>80 \%$ \\
\hline & Horario de los tratamientos & $>80 \%$ \\
\hline & Horario de los cuidados & $>80 \%$ \\
\hline & Exceso de familiares & $>80 \%$ \\
\hline & Toma de constantes & $60-80 \%$ \\
\hline & Actuaciones del personal de limpieza & $<60 \%$ \\
\hline \multirow{4}{*}{ Estructura/dotación } & Falta de intimidad & $>80 \%$ \\
\hline & Compañero de habitación & $>80 \%$ \\
\hline & Características de la cama & $60-80 \%$ \\
\hline & Cercanía al control & $60-80 \%$ \\
\hline \multirow{6}{*}{ Ambiente } & Murmullos en los pasillos & $>80 \%$ \\
\hline & Luces de la habitación & $>80 \%$ \\
\hline & Ruidos de las puertas & $>80 \%$ \\
\hline & Luces del pasillo & $60-80 \%$ \\
\hline & Sonido de los timbres & $60-80 \%$ \\
\hline & Frío/calor & $60-80 \%$ \\
\hline Social/Familiar & Preocupaciones laborales, familiares, etc. & $>80 \%$ \\
\hline Personal & Pijama/camisón & $<40 \%$ \\
\hline
\end{tabular}

Tabla 9. Factores que afectan al sueño según los profesionales de enfermería.

Fuente: Medina Cordero, 2009

Medina Cordero, Feria Lorenzo y Oscoz Muñoa (2009) afirman, en su estudio sobre los conocimientos del sueño y cuidados en profesionales de enfermería, que «enfermería considera el descanso como un proceso de vital importancia dentro del concepto salud-enfermedad», aunque concluyen que «el abordaje de los cuidados básicos en el descanso es primordial desde el punto de vista enfermero, y la formación básica en este sentido ha de acometerse, desde el punto de vista institucional». El primer paso para establecer los cuidados requeridos por los pacientes para mejorar la calidad del sueño consiste en hacer una valoración de este. 


\section{Valoración del sueño}

En el caso de las unidades de hospitalización, la valoración de la calidad del sueño permitirá a los profesionales de enfermería detectar qué pacientes no descansan de forma adecuada y qué factores son los que alteran la calidad del sueño, para establecer intervenciones en ese sentido. Es importante tener presente que hay mucha variabilidad en las necesidades de sueño y descanso entre las personas.

La valoración de la calidad del sueño puede realizarse de forma subjetiva, a través de la entrevista con el paciente, la observación de determinados signos y síntomas y el uso de índices o cuestionarios; o bien de forma objetiva, a través de pruebas diagnósticas más complejas, como la polisomnografía, que se realizan por indicación médica.

\section{a) Entrevista, signos y sintomas y escalas para valorar la calidad del sueño}

Durante la entrevista con el paciente podemos obtener información muy relevante sobre su estado de ánimo, nivel de descanso o calidad del sueño. Para ello, es necesario que se orienten las preguntas de la entrevista hacia (Bello, 2010):

1. La cantidad y calidad del sueño y del descanso deben evaluarse sobre la base de:

a) Edad.

b) Los patrones usuales de descanso y sueño y su posible modificación durante el ingreso hospitalario:

I. Cantidad de horas, tiempo de conciliación, siestas diurnas, despertares nocturnos y posibilidad de conciliar el sueño nuevamente.

II. Calidad del sueño y si está deteriorada, pesadillas, uso de medios para facilitar el sueño (lectura, radio, etc.).

III. Condiciones del entorno que dificultan el sueño (ruido, iluminación, temperatura, adaptación de la cama, colchón, almohada o ropa).

c) El estado de salud:

I. Esta información también puede obtenerse de la historia clínica. Problemas de incontinencia, hipertiroidismo, trastornos del sueño previos, enfermedades de salud mental, consumos de sustancias (tabaco, alcohol, drogas) o medicación que puede alterar el ciclo del sueño (tabla 10).

d) El nivel de tensión actual.

I. Nivel de ansiedad.

II. Nivel de dolor.

III. Problemas familiares, preocupación por la enfermedad o por los procedimientos a realizar, miedo por el desenlace, etc. Esta información debe obtenerse con cautela, ya que puede estar relacionada con aspectos personales o familiares del paciente. 
2. Observar a los pacientes para buscar signos y síntomas de privación del sueño:

a) Cambios en el comportamiento: dificultad de concentración, confusión, irritabilidad, apatía.

b) Signos físicos: nistagmus leve, temblor de manos, ptosis parpebral, enrojecimiento de la esclerótica, expresión vacía, ojeras, bostezos frecuentes, cambios en la postura, cefaleas.

c) Quejas verbales de no sentirse bien descansado.

3. Escalas para medir la calidad del sueño: Existen diferentes escalas para medir la calidad del sueño, aunque deben utilizarse con cautela en pacientes con deterioro cognitivo o que consumen sustancias o fármacos que pueden alterar el ciclo del sueño. Entre ellas encontramos:

a) Subjective Evaluation of Sleep Tool.

b) Índice de la calidad del sueño de Pittsburg.

c) Escala Atenas de Insomio (validada por Nenclares y Jiménez, 2005).

d) Cuestionario de Oviedo del sueño (disponible en URL: http://www.juntade andalucia.es/servicioandaluzdesalud/library/plantillas/externa.asp?pag=/ contenidos/gestioncalidad/CuestEnf/PT5_CuestOviedo_Suenio.pdf).

\begin{tabular}{|l|l|}
\hline \multicolumn{1}{|c|}{ Fármaco } & \multicolumn{1}{c|}{ Efecto } \\
\hline $\begin{array}{l}\text { Antidepresivos } \\
\text { y estimulantes }\end{array}$ & Suprimen el sueño REM. \\
\hline Betabloqueantes & Pueden causar pesadillas e insomnio. \\
\hline Cafeína & Impide el sueño. \\
\hline Digoxina & Puede provocar pesadillas. \\
\hline Diuréticos & Causan nicturia. \\
\hline Hipnóticos & Causan tolerancia e interfieren en estados más profundos de sueño. \\
\hline Narcóticos & Suprimen la fase REM y aumentan la somnolencia. \\
\hline
\end{tabular}

Tabla 10. Fármacos que pueden alterar el ciclo del sueño. Fuente: Lynn, 2012

b) Pruebas diagnósticas:

1. Polisomnografía: Consiste en medir la actividad cerebral y muscular durante el periodo de sueño del paciente. Para ello se conecta al paciente a una serie de electrodos. 


\section{Cuidados para favorecer la calidad del sueño}

A pesar de que Enfermería considera que un adecuado reposo es necesario durante la hospitalización, se conoce qué factores son los que afectan principalmente a la calidad del sueño y las consecuencias de que los pacientes no descansen adecuadamente, pero existe poca evidencia, centrada en las unidades de hospitalización, sobre cuáles serían las mejores intervenciones de enfermería para mejorar la calidad del sueño de los pacientes.

Según Medina Cordero et al. (2009), para los profesionales de enfermería, los procedimientos que favorecen el sueño son principalmente el control del dolor, seguido del control de los estímulos ambientales, crear un entorno seguro y otras que podrían agruparse como higiene del sueño. El protocolo sobre cuidados para propiciar el reposo y el sueño del enfermo del Hospital Gregorio Marañón (2010) establece que estos procedimientos son:

1. Promover medidas de confort:

a) Adecuar la ropa de cama a las necesidades del paciente.

b) Vestir al paciente con ropa cómoda.

c) Cuando el paciente sea dependiente, asegurarse de que esté limpio, seco y sin arrugas en las sábanas.

d) Colocar a los pacientes adecuadamente para favorecer la relajación muscular, proporcionando dispositivos de apoyo y protegiendo las zonas de presión, asegurándose que el paciente está cómodo (si el paciente está consciente y orientado preguntarle directamente).

e) En pacientes con dolor, administrar la analgesia pautada por el médico, si es posible, 30 minutos antes de acostarse.

f) En pacientes con problemas respiratorios, administrar los medicamentos broncodilatadores prescritos por el médico, si es posible al menos una hora antes de irse a dormir, si no está contraindicado, y colocar al paciente en una posición que favorezca la ventilación según sus necesidades (posición Fowler o semi-Fowler).

2. Crear un ambiente que haga sentirse al paciente seguro:

a) Situar la cama en la posición más baja posible, después de la realización de cualquier procedimiento.

b) Emplear barras laterales si está indicado, o el paciente lo pide.

c) Colocar, si se puede, el timbre de llamada de forma que no se desplace, dejándolo al alcance del paciente (ejemplo: sujetándolo a la almohada o barandilla).

d) Dejar al alcance de la mano del paciente lo que pueda necesitar durante la noche (luz, servilletas, vaso con agua, botella de orina, etc.).

e) Explicar al paciente portador de sistemas intravenosos, drenajes u otros dispositivos, como moverse y colocarse en la cama para que estos funcionen adecuadamente. 
f) Proporcionar una longitud de tubo (sueros, drenajes, oxígeno, etc.) suficiente, para que el paciente pueda moverse con comodidad y seguridad.

g) Mantener despejado el acceso al cuarto de baño, con el fin de evitar caídas.

h) Siempre que sea posible y el paciente esté de acuerdo, recomendar que le acompañe un familiar, si esto favorece el sentirse seguro.

3. Crear un ambiente relajado:

a) Si el paciente está de acuerdo, cerrar las cortinas o persianas de las ventanas si las hubiese, cuando se le acueste, para evitar que entre luz de la calle.

b) Correr las cortinas entre pacientes si así lo requieren, para preservar su intimidad.

c) Apagar la luz de la habitación, utilizando la luz testigo. Cuando se requiera entrar, utilizar la luz del aseo entreabriendo la puerta. Encender la luz de la cabecera cuando sea imprescindible, y la general sólo si la situación lo requiere.

d) Cerrar la puerta de la habitación si al paciente no le importa, tras crear un ambiente seguro, para favorecer la intimidad, disminuir ruidos y luz. Si el paciente requiere una estrecha vigilancia, valorar dejar la puerta abierta parcial o totalmente, primando siempre la seguridad.

e) Cumplir horarios de televisores y radios con sonido ambiente. Recomendar a los pacientes el uso de dispositivos de escucha individual.

f) Suspender las llamadas sonoras de teléfono móvil (cuando este se permita), dentro de la habitación, en el mismo horario que la televisión y la radio.

g) Mantener el volumen de conversación lo más bajo posible, tanto con los pacientes como entre profesionales.

h) El personal debe utilizar el calzado suministrado en el Hospital, o en su defecto con suela de goma, para que el ruido al caminar esté amortiguado.

i) Los horarios de medicación, siempre que sea factible, estarán adaptados para interrumpir lo menos posible el sueño, al menos en seis horas consecutivas.

j) Apagar las luces de los pasillos cuando no sean imprescindibles, y aquellas que no sea posible apagar y puedan llegar a alguna habitación con pacientes, atenuarlas lo máximo posible. 


\section{CAPITULO 8}

\section{Cuidados básicos \\ en la eliminación}

\section{Introducción}

Según la Real Academia Española, dentro de la rama médica, la palabra eliminación significa «dicho del organismo: expeler una sustancia». Por lo tanto, vamos a definir la eliminación como la necesidad que tiene el organismo de deshacerse de las sustancias perjudiciales e inútiles que resultan del metabolismo.

Hay que tener en cuenta que la excreción de deshechos se produce principalmente por la orina y las heces, aunque también existen otras vías de eliminación como la sudoración y la respiración. La eliminación tiene una gran importancia para la vida, ya que con ella mantenemos el equilibrio de líquidos y sustancias del medio interno, y al eliminar las sustancias de deshecho mantenemos un funcionamiento adecuado de los diferentes órganos.

En este tema trataremos especialmente la eliminación urinaria y fecal, aplicando los cuidados básicos de utilización de botella y cuña. Además, se realizarán las correctas mediciones de diuresis para poder realizar un correcto balance del equilibrio de líquidos, hecho de fundamental importancia en determinadas unidades como las renales, las digestivas y las de quemados.

\section{Tipos de eliminación}

\subsection{Eliminación intestinal}

Mediante la eliminación intestinal se expulsa al exterior las sustancias que no pueden ser reabsorbidas por la sangre y que no son asimilables por el organismo. El conjunto de sustancias que se eliminan constituyen las heces, estas están formadas por residuos alimentarios, secreciones, células descamadas de los intestinos y bacterias.

\subsection{Eliminación urinaria}

La sangre filtra a través del riñón sustancias innecesarias para el organismo tales como la urea, el exceso de agua y electrolitos, glucosa, aminoácidos, ácido úrico 
y creatinina; manteniendo así el equilibrio hidro-electrolítico del cuerpo. Esta sustancia eliminada es la orina.

\subsection{Eliminación en la respiración}

A través de la respiración se eliminan productos como el dióxido de carbono y vapor de agua sobrante. En un día, un adulto puede excretar a través de la respiración de 300 a $400 \mathrm{ml}$ de agua.

\subsection{Eliminación en la sudoración}

La sudoración tiene un importante papel en la termorregulación del organismo. Además, a través de ella se eliminan agua, electrolitos (sodio, cloro y potasio) y otros productos de excreción como la urea.

Además de ello, cierta cantidad de agua se elimina por difusión a través de la piel (transpiración insensible). Si se mantiene la integridad de la piel, la pérdida diaria de agua pasa desapercibida y oscila alrededor de $500 \mathrm{cc} /$ día. Si se produce pérdida de la continuidad de la piel, como en las quemaduras, estas pérdidas se incrementan considerablemente.

\section{Factores que afectan a la micción}

Numerosos factores afectan a la cantidad y calidad de la orina producida por el cuerpo y la forma en que esta se excreta.

1. Efectos del envejecimiento:

a) Disminución de la capacidad de los riñones para concentrar la orina, lo que puede ocasionar nicturia.

b) Disminución del tono muscular vesical, lo que puede reducir la capacidad de la vejiga para retener la orina, ocasionando aumento en la frecuencia de micciones.

c) Disminución de la capacidad contráctil de la vejiga que ocasiona retención urinaria y estasis que incrementan el riesgo de infecciones de vías urinarias.

d) Problemas neuromusculares, problemas articulares degenerativos, alternación en el proceso de pensamiento y debilidad son trastornos que pueden interferir con el control voluntario de la micción y la capacidad para llegar a tiempo al retrete.

2. Consumo de alimentos y líquidos:

a) La deshidratación incrementa la reabsorción de líquidos en los riñones ocasionando disminución en la producción de orina, la cual queda más concentrada. 
b) La sobrecarga de líquidos ocasiona la excreción de grandes cantidades de orina diluida.

c) El consumo de bebidas que contienen cafeína ocasiona incremento en la producción de orina por su efecto diurético.

d) El consumo de bebidas alcohólicas incrementa la producción de orina por la inhibición de la liberación de hormona antidiurética.

e) El consumo de alimentos con grandes cantidades de agua puede incrementar la producción de orina.

f) El consumo de alimentos y bebidas ricas en sodio ocasiona disminución de la formación de orina porque el sodio y el agua se reabsorben y ocurre retención de estos.

g) La ingestión de ciertos alimentos (por ejemplo espárragos, cebolla, remolacha) puede ocasionar alteraciones en el olor o color de la orina.

3. Variables psicológicas:

a) Las variables individuales, familiares y socioculturales pueden influir en los hábitos de micción.

b) Los pacientes pueden percibir la micción como un acto personal y privado. La necesidad de pedir ayuda puede ocasionar incomodidad o ansiedad.

c) La tensión emocional puede causar la salida de pequeñas cantidades de orina a intervalos más frecuentes.

d) La tensión emocional puede ocasionar dificultades para vaciar la vejiga por sus efectos en la relajación de los músculos perineales y el esfínter ureteral externo.

4. Actividad y tono muscular:

a) El ejercicio regular incrementa el metabolismo y la producción y eliminación óptima de orina.

b) Los periodos prolongados de inmovilidad pueden ocasionar mal control de la micción y estasis urinaria por disminución del tono vesical y del esfínter.

c) El uso de catéteres a permanencia produce pérdida del tono vesical, porque los músculos vesicales ya no están expuestos a la distensión ocasionada por el llenado de la vejiga con orina.

d) Los embarazos, la atrofia muscular relacionada con los cambios hormonales de la menopausia y el daño muscular relacionado con traumatismos ocasionan disminución del tono muscular.

5. Trastornos patológicos:

a) Las anomalías congénitas del aparato urinario, la enfermedad poloquísitica renal, infección de vías urinarias, cálculos urinarios (renales), hipertensión, diabetes mellitus, gota y ciertas colagenopatías ocasionan alteración de la calidad y cantidad de la orina.

b) Las enfermedades que reducen la actividad física o producen debilidad generalizada (por ejemplo artritis, enfermedad de Parkinson, artropatía degenerativa) pueden interferir con el uso del retrete.

c) Los déficits cognitivos y trastornos psiquiátricos pueden interferir con la capacidad o deseo de controlar la micción voluntaria. 
d) La fiebre y diaforesis (sudoración profusa) favorecen la conservación de líquidos corporales.

e) Otros trastornos patológicos, como la insuficiencia cardíaca congestiva, pueden ocasionar retención de líquidos y disminución de la diuresis.

f) Las altas concentraciones de glucosa sanguínea, como las que ocurren con la diabetes mellitus, pueden ocasionar incremento del gasto urinario por diuresis osmótica.

6. Medicamentos:

a) El abuso de analgésicos como ácido acetil salicílico o ibuprofeno puede causar daño renal (nefrotoxicidad).

b) Algunos antibióticos como la gentamicina pueden causar daño renal.

c) El uso de diuréticos puede ocasionar incremento moderado o intenso en la producción y excreción de orina diluida, al impedir que el agua y ciertos electrolitos se reabsorban en los túbulos renales.

d) El uso de medicamentos colinérgicos puede ocasionar incremento de la micción por estimulación de la contracción del músculo detrusor.

e) Algunos analgésicos y tranquilizantes interfieren con la micción de la orina, por la disminución de la eficacia de los reflejos neutrales para la micción por la supresión del sistema nervioso central.

f) El uso de ciertos fármacos puede producir cambios en el color de la orina. Los anticoagulantes pueden ocasionar hematuria o un color rosado o rojizo. Los diuréticos pueden hacer más claro el color de la orina, que presenta un amarillo pálido. La amitriptilina y las vitaminas del complejo B pueden causar orina verdosa o verde-azulosa. La levodopa y el hierro inyectable pueden producir orina de color pardo u oscuro.

\section{Factores que afectan a la eliminación intestinal}

a) Movilidad: el movimiento y ejercicio ayudan a movilizar las heces a través del intestino.

b) Dieta: los alimentos altos en fibras ayudan a conservar el movimiento de las heces por el intestino. Un consumo alto de líquidos contribuye a que las heces no se endurezcan. El líquido adecuado también ayuda a las fibras a mantener las heces blandas y abultadas, y previene la deshidratación, que es un factor contribuyente del estreñimiento.

c) Medicamentos: los antibióticos y laxantes pueden determinar que las heces sean más blandas y frecuentes. Los diuréticos pueden conducir a desecación, endurecimiento y deposición menos frecuente de heces.

d) Derivaciones intestinales: de manera usual, las ileostomías descargan heces líquidas, de mal olor. Las colostomías suelen evacuar heces pastosas, formadas. 


\section{Manejo del orinal tipo botella}

La botella es un recipiente ovoideo con una cara plana graduada, para medir su contenido, y un cuello ancho, alargado y más elevado que se emplea para la micción del hombre (figura 16).

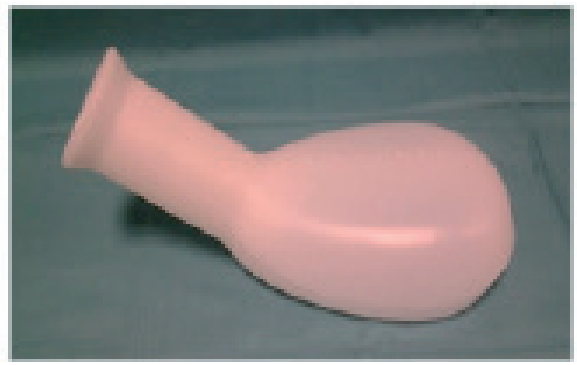

Figura 16. Botella. Fuente: Elaboración propia

En esta técnica pretendemos facilitar la eliminación urinaria en el paciente varón. Así, aprenderemos a colocar y retirar un dispositivo (en este caso la botella) en el pene del paciente para depositar la orina, cuando el paciente no puede hacer uso por sí mismo del inodoro, debido a limitaciones en la movilidad, enfermedades neurológicas, psiquiátricas, etc. El procedimiento a seguir según la Guía de Actuación de Enfermería: Manual de procedimientos editada por la Conselleria de Sanitat de la Generalitat Valenciana es:

1. Colocarse los guantes.

2. Preparar el material y trasladarlo a la habitación del paciente.

3. Preservar la intimidad del paciente.

4. Informar al paciente.

5. Solicitar la colaboración del paciente y familia.

6. Ayudar al paciente para que adopte una posición adecuada.

7. Colocar empapador si el paciente está encamado.

8. Proporcionar la botella y, en caso de necesitar ayuda, colocar la botella entre las piernas del paciente e introducir el pene.

9. Retirar la botella al finalizar la micción y llevarla al sitio destinado para su limpieza.

10. Facilitar el papel higiénico o ayudar en la limpieza de los genitales.

11. Ayudar o proporcionar material para higiene de las manos.

12. Dejar al paciente en una posición cómoda y adecuada con acceso fácil al timbre y a sus objetos personales.

13. Verter la orina en el recipiente graduado y medir, si se precisa.

14. Desechar en el wC.

15. Realizar limpieza y desinfección de la botella.

16. Recoger el material.

17. Retirarse los guantes.

18. Realizar lavado de manos. 
19. Registrar en la documentación de enfermería diuresis y características de la orina, fecha y hora, incidencias y respuesta del paciente.

Observaciones: En pacientes pediátricos, ancianos y personas discapacitadas, sujetar la botella hasta que se realice la micción, para evitar el derrame.

\section{Manejo del orinal tipo cuña}

En este apartado aprenderemos a colocar y retirar un dispositivo (cuña) para que la paciente pueda llevar a cabo tanto la eliminación urinaria (mujeres) como fecal, cuando el paciente no puede hacer uso por sí mismo del inodoro, debido a limitaciones en la movilidad, enfermedades neurológicas, psiquiátricas, etc.

Así, como objetivos, podríamos delimitar la facilitación de la eliminación fecal y/o urinaria del paciente encamado, además de educar al paciente y familia en el manejo de la cuña (figura 17). La cuña es un recipiente plano cuya parte anterior es muy delgada y que se ensancha por la posterior, donde se sitúa el asa de sujeción. Se usa para la micción de la mujer y la defecación, así como para la higiene genital, tanto del hombre como de la mujer.

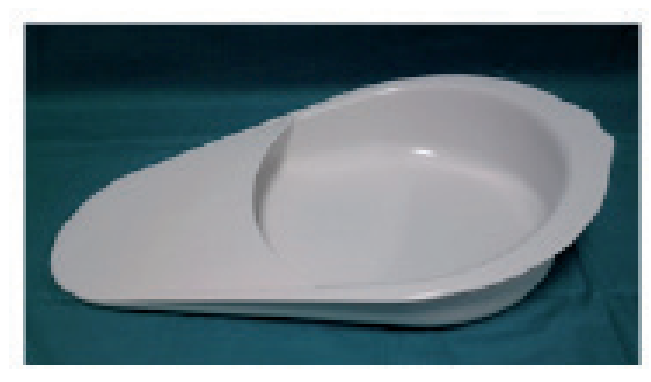

Figura 17. Orinal tipo cuña. Fuente: Elaboración propia

Esta técnica se trata de un procedimiento muy frecuente en pacientes encamados, ya que permite la micción y defecación en la propia cama cuando el paciente, por motivo de su enfermedad, no puede o no debe levantarse. Se realiza entre una o dos personas, dependiendo del grado de movilidad del paciente.

1. Realizar lavado de manos.

2. Preparar el material y trasladarlo a la habitación del paciente.

3. Colocarse los guantes.

4. Preservar la intimidad del paciente.

5. Informar al paciente.

6. Solicitar la colaboración del paciente y familia.

7. Ofrecer la botella si es un varón. 
a) Paciente con movilidad:

1. Colocar al paciente en decúbito supino con la cabecera de la cama elevada.

2. Retirar ropa de la cama.

3. Pedir al paciente que flexione las rodillas y levante las caderas.

4. Introducir cuña bajo los glúteos y asegurarse que está bien centrada.

b) Paciente sin movilidad:

1. Colocar la cama del paciente en posición horizontal.

2. Retirar la ropa de cama.

3. Colocar al paciente en decúbito lateral.

4. Colocar la cuña bajo las nalgas.

5. Girar al paciente sobre su espalda con la cuña colocada en las nalgas.

6. Comprobar que la cuña está centrada bajo el paciente.

7. Elevar cabecera para su comodidad sino está contraindicado.

8. Cubrir al paciente con la sábana superior.

9. Proporcionar el papel higiénico.

10. Dar tiempo necesario e informar al paciente que nos avise al finalizar.

11. Retirarse los guantes.

12. Realizar lavado de manos.

13. Colocarse los guantes desechables no estériles.

14. Retirar la cuña y trasladarla al sitio destinado para la limpieza.

15. Ayudar en la higiene de los genitales.

16. Cambiar empapador si precisa y dejar la ropa de la cama bien colocada.

17. Proporcionar material para la higiene de las manos.

18. Dejar al paciente en una posición cómoda y con fácil acceso al timbre y objetos personales.

19. Verter la orina en un recipiente graduado y medir, si se precisa.

20. Desechar en el wC.

21. Realizar limpieza y desinfección de la cuña.

22. Recoger el material.

23. Retirar los guantes.

24. Realizar lavado de manos.

25. Registrar en la documentación de enfermería el procedimiento, fecha y hora, incidencias y respuesta del paciente.

\section{Medición de la diuresis}

La medición de la diuresis podríamos definirla como la cuantificación y valoración de la cantidad de orina eliminada por el paciente en un periodo de tiempo determinado.

Los objetivos pretendidos con esta técnica son dos. Por un lado, deseamos cuantificar la cantidad de orina eliminada por el paciente, pero, además, queremos determinar las características físicas de la orina: color, olor, presencia de sangre u otros elementos anormales. 
Procedimiento:

1. Informar al paciente sobre la necesidad del control de diuresis y explicarle que no realice micciones en el wC, sino que orine en la botella o cuña.

2. Realizar el lavado de manos.

3. Preservar la intimidad del paciente.

4. Solicitar la colaboración del paciente y familia.

5. Colocarse los guantes no estériles.

6. Verter la orina en el recipiente graduado y medir.

7. Desechar en el wC.

8. Recoger el material.

9. Retirar los guantes.

10. Realizar el lavado de manos.

11. Registrar en la documentación de enfermería cantidad de orina, aspecto, olor, fecha y hora, incidencias y respuesta del paciente.

Observaciones: las personas que no controlan esfínteres (niños y ancianos generalmente), se medirá por el sistema de doble pesada:

a) Pesamos el pañal seco.

b) Pesamos el pañal mojado.

c) Restamos el valor del primero al segundo.

d) Registramos.

En pacientes con sondaje vesical:

a) Medir la diuresis cuando la bolsa de drenaje esté a 2/3 del total, para evitar la tracción sobre el catéter por el peso de la bolsa.

b) Observar directamente en la bolsa la cantidad de orina y vaciar la bolsa, utilizando la válvula de drenaje.

c) Anotar la cantidad de orina en la gráfica.

\section{Balance del equilibrio de líquidos}

El organismo mantiene un delicado equilibrio hidroelectrolítico y acido-básico. Esta homeostasis depende de varios procesos fisiológicos que regulan la entrada y salida de líquidos, y el desplazamiento del agua y las sustancias disueltas en ella entre los compartimentos del organismo. Casi todas las enfermedades pueden constituir una amenaza para este equilibrio, debido a que las altas temperaturas o una intensa actividad pueden afectar al equilibrio si no se mantiene una correcta ingesta de aguas y sales. El contenido líquido o acuoso del organismo humano es del 40-60\% de su peso total. Además, hay que conocer que la cantidad de agua que tiene el organismo varía con:

a) La edad: El porcentaje de agua desciende con la edad.

b) El sexo: Las mujeres tienen una cantidad de agua inferior que los hombres. 
c) La grasa corporal: Los obesos tienen un menor contenido de agua por kilogramo de peso que los delgados.

De forma general, los líquidos se obtienen a partir del consumo de bebidas (1500 ml) y a partir de los alimentos $(1000 \mathrm{ml})$ principalmente. Pero en caso de hospitalización, la entrada de líquidos también es debida a las perfusiones y deben ser tenidas en cuenta. La cuantificación de las pérdidas insensibles por el organismo también deben ser tenidas en cuenta y estas se generalizan en: la difusión de la piel $(350 \mathrm{ml})$, por la transpiración cutánea $(100 \mathrm{ml})$ y por los pulmones $(350 \mathrm{ml})$ generalmente.

Así, el balance del equilibrio de líquidos es un cálculo de suma importancia, por lo tanto conocer cómo realizarlo y su fiel reflejo de enfermería puede ser determinante para ciertas patologías y pacientes. A través del balance del equilibrio de líquidos conoceremos la cantidad de líquidos administrados (ingeridos e intravenosos) y eliminados por el paciente, en un tiempo determinado, para la valoración del equilibrio hidroelectrolítico.

Procedimiento:

1. Preservar la intimidad del paciente.

2. Informar al paciente.

3. Solicitar la colaboración del paciente y familia.

4. Determinar la cantidad, tipo de ingesta de líquidos y los hábitos de eliminación.

5. Identificar posibles factores de riesgo de desequilibro de líquidos (hipertermia, terapia diurética, patologías renales, insuficiencia cardíaca, infección, poliuria, diarrea, etc.).

6. Medir y registrar todas las entradas de líquido: con las comidas, con la medicación oral, líquidos parenterales, intravenoso, hemoderivados, etc.

7. Medir y registrar todas las salidas: orina, drenajes, deposiciones líquidas, sudor, vómitos, aspiración gástrica, etc.

8. Pesar al paciente para valorar pérdidas insensibles, si su estado lo permite cada 24 horas.

9. Añadir como salidas las pérdidas insensibles. Estas se calcularán según la siguiente fórmula:

$$
P 1=\frac{\text { Peso } \times \text { número de horas }}{2}
$$

10. Restar las salidas a las entradas y anotar en la gráfica. Al cerrar el balance, contabilizar la cantidad perfundida y la que queda por perfundir.

11. Anotar fecha y hora de comienzo y finalización del control.

Observaciones:

Además de todo el proceso anterior hay que valorar el estado de piel y mucosas, el color de la orina, y valorar la aparición de edemas. Como norma general, el balance se hará en un tiempo de 24 horas, salvo criterio del facultativo. 


\section{CAPÍTULO 9 \\ Cuidados básicos en la higiene}

\section{Introducción}

V. Henderson y otras autoras encuadran la higiene dentro de las necesidades básicas de las personas. De hecho, Maslow establece como prioritarias las necesidades fisiológicas, dentro de las cuales están la necesidad de termorregulación y la necesidad de eliminación, funciones ambas en las que la piel tiene especial importancia, por lo que es imprescindible que esta se mantenga en buen estado. Si a todo esto sumamos la función de barrera y protección que tiene la piel, vemos que la higiene, como medio imprescindible para mantenerla en buen estado, es una actividad básica y fundamental que habrá que incluir en nuestro plan de cuidados, cuando el paciente tenga disminuidas o anuladas las facultades para realizar estas actividades por sí mismo. En este tema se tratarán los procedimientos de cuidados relacionados con la higiene, más habituales en las unidades de hospitalización.

\section{Consideraciones generales en la higiene}

Es importante remarcar en este cuidado básico, debido a su intimidad, que el enfermero que asiste a los pacientes con actividades básicas de higiene debe respetar las preferencias individuales del paciente y proporcionar sólo las medidas de atención que el paciente no puede proporcionarse a sí mismo.

Además, mediante la higiene obtenemos una serie de beneficios para nuestros pacientes, tanto físicos como psicológicos:

1. Beneficios físicos:

a) Mantener la piel en buen estado para cumplir su función de barrera a través de:

- Conservar su integridad, sin lesiones ni heridas.

- Mantener su manto ácido y así evitar la contaminación por cualquier microorganismo no habitual.

- Facilitar la descamación de células muertas.

- Evitar el aumento excesivo de microorganismos.

- Facilitar la eliminación de sustancias de deshecho.

b) Aprovechar el momento de la higiene para valorar el estado de la piel:

- Valoración física de la piel: coloración, turgencia, etc.

- Vigilar la aparición de indicios de úlceras.

- Descubrir precozmente lesiones cutáneas.

- Evaluar la evolución de úlceras y lesiones establecidas. 
c) Realizar actividades que mejoren el estado de salud del paciente:

- Utilizar la temperatura del agua para ayudar a subir o bajar la temperatura del paciente, según se necesite.

- Realizar técnicas básicas de masaje durante la higiene para mejorar la circulación y ayudar a drenar el acúmulo de líquidos en la piel (edemas).

- Movilizar las diversas articulaciones para prevenir rigideces.

- Favorecer el descanso del paciente, manteniendo la cama y al propio paciente en perfecto estado.

\section{Beneficios psicológicos:}

- Mejorar la autoestima del paciente al evitar el mal olor.

- Aumentar la sensación de bienestar.

- Favorecer la relación y comunicación del paciente con el equipo de enfermería.

- Transmitir técnicas de autocuidado, permitiendo que el paciente participe en su higiene en la medida de lo posible.

Antes de realizar cualquier técnica de higiene, es imprescindible que tengamos en cuenta una serie de consideraciones:

a) Valorar el tipo de técnica a realizar en función del grado de dependencia y las necesidades higiénicas del paciente.

b) Conocer el estado de salud del paciente y cualquier aspecto que implique una modificación de las actividades habituales.

c) Mantener la intimidad del paciente:

1. Usando elementos de separación con el resto de los pacientes, como biombos y cortinas.

2. Asegurándonos de que la puerta está cerrada y no se puede ver al paciente desde otra estancia del hospital a través de las ventanas.

3. Asegurándonos de tener todo el material preparado antes de empezar para no tener que salir durante la realización de la técnica.

4. Se invitará a salir a los familiares que pueda haber en ese momento.

d) Realizarla siempre que sea necesario y como mínimo una vez al día.

e) Colaborar, si es posible, entre dos personas, con el fin de facilitar la movilización y aumentar la seguridad del paciente. Si no es posible, se usará siempre la barandilla del lado contrario a donde esté la persona realizando la higiene.

f) Solicitar la colaboración del paciente.

g) Evitar las corrientes de aire.

h) Descubrir únicamente la parte del paciente sobre que la que estemos actuando, manteniendo el resto del cuerpo cubierto con una toalla o sábana para evitar que se enfríe y mantener su intimidad.

i) Mantener una temperatura adecuada en la habitación (entre 22 y $24{ }^{\circ} \mathrm{C}$ ).

j) Utilizar jabones adecuados para mantener el $\mathrm{pH}$ de la piel (figura 18). 


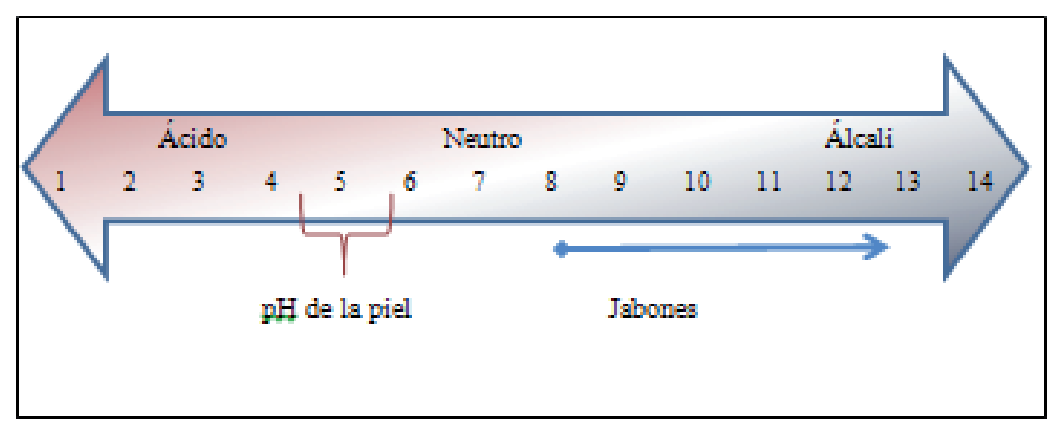

Figura 18. Valores del pH. Fuente: Elaboración propia

k) Mantener la temperatura del agua según el gusto del paciente. Si el paciente no puede opinar, se mantendrá uno o dos grados por encima de la temperatura corporal, para que tenga una sensación agradable, salvo que haya indicación terapéutica de lo contrario.

l) Seguir un orden establecido, el cual, salvo contraindicación, será de limpio a sucio y de arriba hacia abajo.

m) Cuidar especialmente las sondas o sueros que pueda tener puesto el paciente para evitar su desinserción.

\section{Hacer una cama vacía}

En este apartado vamos a tratar el conjunto de actividades que realiza el personal de enfermería encaminadas a mantener un correcto aseo e higiene de la cama del paciente.

Hay que tener en cuenta que hay que preparar la cama en condiciones de higiene y comodidad para el paciente, evitando arrugas y pliegues en la cama que pueden llevarnos a ciertas complicaciones en los pacientes encamados.

Procedimiento:

1. Realizar el lavado de manos.

2. Preparar el material y trasladarlo a la habitación

3. Colocarse los guantes.

4. Colocar la cama en posición horizontal.

5. Retirar la ropa de la cama sucia, depositándola en la bolsa de ropa sucia.

6. Colocar la funda de colchón y sobre ella la sábana bajera, extendiéndola y ajustándola a las cuatro esquinas de forma que no tenga arrugas.

7. Realizar el pliegue en mitra.

8. Extender la sábana encimera, con el dobladillo hacia arriba y plegando las esquinas inferiores.

9. Colocar colcha y manta siguiendo el mismo procedimiento que la sábana encimera. 
10. Colocar funda de almohada.

11. Recoger el material.

12. Retirar los guantes.

13. Realizar el lavado de manos.

14. Anotar el procedimiento en los registros de enfermería.


Figura 19. Pliegue en mitra. Fuente: Elaboración propia

Observaciones:

a) No dejar la ropa de cama limpia sobre ninguna superficie sucia ni en el suelo, ello prevendrá posibles infecciones.

b) No airear la ropa de cama.

c) Frenar la cama antes de empezar el procedimiento.

\section{Hacer una cama ocupada}

Tanto la definición como los objetivos de este procedimiento son exactamente los mismos que los del procedimiento anterior, pero, esta vez, tendremos en cuenta que el paciente encamado no podrá, por diversos motivos, levantarse de la cama y hay que realizar dicho procedimiento con el paciente en la cama. Para ello:

Procedimiento:

1. Realizar el lavado de manos.

2. Preparar el material y trasladarlo a la habitación del paciente.

3. Preservar la intimidad del paciente.

4. Informar al paciente para obtener su colaboración y consentimiento.

5. Realizar la técnica lo menos lesivamente posible.

6. Mantener una temperatura adecuada $25-26{ }^{\circ} \mathrm{C}$.

7. Evitar corrientes de aire.

8. Proteger al paciente de las caídas.

9. Colocarse los guantes.

10. Colocar la cama en posición horizontal (si el paciente lo tolera) y retirar las almohadas. 
11. Realizar la higiene del paciente encamado.

12. Aflojar la ropa de la cama.

13. Dejar al enfermo tapado con la sábana superior y ayudarle a ponerse en decúbito lateral, procurando evitar desconexiones de los aparatos o sondas y colocarse frente a él para sujetarle.

14. Enrollar la ropa sucia de abajo a lo largo, junto a la espalda del paciente, y colocar la ropa limpia en esa mitad de la cama.

15. Colocar la sábana bajera limpia enrollándola hasta el centro de la cama y fijando las dos esquinas.

16. Colocar la entremetida y poner empapadores si es necesario.

17. Volver al paciente hacia el lado limpio, retirando la sábana sucia, entremetida y empapadores. Depositar la ropa sucia en las bolsas destinadas a tal fin.

18. Estirar la sábana y entremetida evitando arrugas, remeterlas por debajo del colchón y efectuar doblez en las dos esquinas.

19. Extender la sábana encimera limpia sobre el paciente.

20. Colocar colcha y manta, si se precisa.

21. Doblar la parte superior de la sábana por encima de la colcha.

22. Remeter con holgura la sábana encimera y colcha en los pies de la cama para evitar decúbitos y posturas inadecuadas.

23. Colocar las almohadas necesarias para que el enfermo esté cómodo.

24. Dejar al paciente en una postura cómoda.

25. Recoger el material.

26. Retirar los guantes.

27. Realizar el lavado de manos.

28. Registrar en la documentación de enfermería: procedimiento, fecha y hora, motivo, incidencias y respuesta del paciente.

Observaciones:

a) La cama del enfermo se cambiará en su totalidad diariamente después del baño. Además, se cambiará siempre que se moje o se manche.

b) Evitar introducir el carro de la ropa limpia en la habitación del enfermo. Introducir sólo la bolsa donde se va a depositar la ropa sucia, sólo en el caso de que esta sea individual.

\section{Aseo en ducha o bañera}

El aseo general es el que se realiza sobre toda la superficie corporal. Debe llevarse a cabo diariamente, generalmente por la mañana, antes del cambio de ropa de cama. Si el paciente es independiente o mínimamente dependiente, lo hará él mismo, con o sin nuestra ayuda según lo necesite. Cuando el paciente no pueda levantarse, bien porque no pueda o porque su patología lo desaconseje, se realizará en la cama.

La técnica de aseo en ducha o bañera es la técnica de aseo que se usa cuando el paciente es autosuficiente o requiere mínima ayuda. Así, se trata del conjunto de 
actividades de supervisión y evaluación, que realiza la enfermera, y de las medidas higiénicas que lleva a cabo el paciente para preservar su piel limpia y en buen estado.

Los objetivos de este procedimiento son los mismos que en cualquier técnica de higiene: prevenir alteraciones en la piel, prevenir infecciones, contribuir al bienestar físico y psíquico del paciente y estimular la circulación sanguínea.

Procedimiento:

1. Preservar la intimidad del paciente.

2. Informar al paciente.

3. Observar el estado de higiene y valorar la frecuencia habitual de higiene general.

4. Explorar los factores culturales que puedan estar influenciando en las creencias sobre el significado, frecuencia y forma de llevar a cabo la higiene.

5. Comunicar al paciente la necesidad del baño y cómo ha de llevarse a cabo, teniendo en cuenta las creencias y valores culturales detectados con anterioridad sobre la higiene.

6. Proporcionar todo el material necesario para la higiene.

7. Indicar al paciente que no cierre por dentro el aseo por si la enfermera ha de ayudarle. Señalar el timbre del aseo y explicarle su funcionamiento por si requiere ayuda.

8. Evaluar si las medidas higiénicas llevadas a cabo por el paciente han sido efectivas.

9. Registrar en la documentación de enfermería incidencias y respuesta del paciente.

Observaciones:

a) Si el paciente no puede realizar su higiene de forma independiente, se le prestará la ayuda necesaria para: desvestirse, bañarse y aplicarse crema, vestirse y acomodarse.

b) Vigilar las medidas de seguridad, sobre todo si el suelo está mojado.

c) La higiene puede realizarse de pie o sentado en una silla de baño, si el paciente no necesita.

\section{Aseo del paciente encamado}

Esta técnica de aseo es la técnica que se emplea en los pacientes que por su estado no pueden levantarse de la cama, aunque conserven su movilidad. Se considera la higiene del paciente en cama como el conjunto de medidas higiénicas que realiza la enfermera cuando el paciente presenta limitación para realizar su propia higiene y requiere estar encamado. 
Los objetivos relacionados con este procedimiento son:

a) Mantener limpia y en buen estado la piel y sus anejos.

b) Prevenir alteraciones de la piel e infecciones.

c) Contribuir al bienestar físico y psíquico del paciente.

d) Proporcionar al paciente el aseo necesario para satisfacer las necesidades de higiene y comodidad.

e) Educar al paciente y familia en los cuidados de higiene.

Procedimiento:

1. Explicar al paciente que es la hora del baño y pedir su colaboración.

2. Ofrecer la cuña o la botella antes de iniciar el aseo.

3. Situar el material necesario de manera que esté a nuestro alcance.

4. Lavarse las manos y ponerse los guantes.

5. Colocar al paciente en decúbito supino.

6. Desvestir al paciente y cubrirlo con la sábana o con una toalla para preservar su intimidad.

7. Iniciar el lavado por la cara con agua sin usar jabón.

8. Continuar con un orden descendente: cuello, hombro, axilas, manos, tórax abdomen, piernas y pies.

9. Colocar al paciente en decúbito lateral para el lavado y secado de la espalda. Aplicar crema hidratante masajeando a la vez.

10. Posicionar de nuevo en decúbito supino y lavar la zona genital.

11. Enjabonar, aclarar y secar a fondo, realizando toques suaves con la toalla sin arrastrarla por la piel. Evitar enjabonar en exceso.

12. Al asear insistir en los espacios interdigitales, debajo de los pechos (en caso de mujeres), en la zona umbilical y en los pliegues inguinales.

13. Cambiar la ropa de cama.

14. Vestir al paciente con pijama o camisón.

15. Peinarlo y dejar al paciente en una posición cómoda.

Observaciones:

a) Para mayor comodidad podemos emplear una toalla a modo de manopla.

b) Realizar la higiene del enfermo una vez al día y siempre que sea necesario porque se haya ensuciado.

c) Descubrir únicamente la zona sobre la que se está actuando.

d) Cambiar el agua y la esponja tantas veces como sea necesario.

e) En pacientes con miembro superior inmovilizado o con acceso vascular, se les desvestirá comenzando por el brazo libre. Para vestirlos, hay que comenzar por el brazo portador de la vía.

f) Si el paciente lleva una infusión intravenosa, para quitarle la bata hospitalaria se procederá de la siguiente forma:

a. Extraer completamente la manga del brazo sin la infusión y llevarla hasta el tubo conectado al brazo con la infusión.

b. Sujetar el recipiente por encima del brazo del paciente, tirar de la manga hacia arriba sobre el recipiente para quitar la bata usada. 
c. Colocar la manga de la bata limpia del brazo con la infusión sobre el recipiente, como si fuera una prolongación del brazo del paciente y pase el recipiente por el puño de la manga.

d. Volver a colocar el recipiente. Deslizar cuidadosamente la bata sobre el tubo y la mano del paciente.

e. Deslizar el brazo y el tubo por la manga, procurando no tirar del tubo.

f. Ayudar al paciente a colocarse la otra manga.

g. Comprobar que la velocidad de goteo de la infusión es la adecuada.

\section{Aseo del cabello}

Las técnicas de aseo parcial pueden realizarse junto al aseo general o bien por separado, puesto que su frecuencia variará dependiendo de las necesidades del paciente. Cuando el paciente pueda, las realizará por sí mismo y, si no, supliremos esta necesidad.

En cuanto al aseo del cabello, los pacientes encamados necesitan realizar la higiene del cabello al menos una vez a la semana, para evitar la suciedad y mejorar el confort. Así adoptaremos un conjunto de medidas higiénicas, que realiza la enfermera, para mantener la higiene del cabello en un paciente encamado, con los objetivos de: proporcionar al paciente encamado el aseo necesario para mantener la higiene del pelo y cuero cabelludo, proporcionar bienestar al paciente, evitar la proliferación de parásitos y activar la circulación sanguínea del cuero cabelludo.

\section{Procedimiento:}

1. Realizar el lavado de manos y preparar el material.

2. Preservar la intimidad del paciente al mismo tiempo que lo informamos de la técnica que nos disponemos a realizar.

3. Informar y solicitar la colaboración del paciente y la familia.

4. Mantener una temperatura ambiente adecuada y evitar las corrientes de aire.

5. Proteger al paciente de caídas.

6. Colocarse los guantes.

7. Poner la cama en posición horizontal y al paciente en decúbito supino.

8. Retirar el cabezal de la cama.

9. Colocar al paciente en el borde de la cama en posición de Roser.

10. Colocar el empapador debajo de los hombros del paciente.

11. Poner una toalla alrededor del cuello y las torundas de algodón taponando los oídos.

12. Colocar la palangana o lavacabezas debajo de la cabeza del paciente, sobre una silla.

13. La temperatura del agua de la jarra ha de ser de $35-37^{\circ} \mathrm{C}$. Proceder al lavado.

14. Secar bien con una toalla. Peinar y secar con un secador de mano.

15. Retirar las torundas de algodón de los oídos.

16. Dejar al paciente en una posición cómoda. 
17. Recoger el material, realizar el lavado de manos y registrar en la documentación de enfermería: el procedimiento, motivo, fecha y hora, incidencias y respuesta del paciente.

Observaciones:

a) El lavado de cabeza con palangana, debido a la posición de Roser, está contraindicado en algunos casos:

a. Aumento de la presión intracraneal.

b. Pérdida de líquido cefalorraquídeo.

c. Incisiones abiertas en cuero cabelludo.

d. Lesiones cervicales.

e. Traqueotomía.

f. Dificultad respiratoria.

b) Si detectamos alguno de estos casos en el que la posición de Roser está contraindicada, podemos limpiar el cabello por mechones, con gasas empapadas en agua, a los enfermos a quienes no se les puede lavar la cabeza en la cama mediante el procedimiento habitual.

\section{Higiene bucal}

Una higiene oral deficiente lleva implícita problemas de salud tales como caries, enfermedad periodontal, etc. Los pacientes necesitan un control estricto de la higiene oral para prevenir enfermedades, aumentar el bienestar, mantener la mucosa en buenas condiciones y evitar contaminaciones de la vía respiratoria en pacientes intubados.

Como norma general, se realiza después de las comidas. En pacientes inconscientes o que no puedan comer, dependerá del protocolo de la unidad. Siempre que un paciente pueda colaborar, hay que procurar que realice sus cuidados en la medida que se lo permitan sus posibilidades.

Consideraremos la higiene de la boca como el conjunto de medidas higiénicas que realiza el personal de enfermería en la cavidad bucal, cuando el paciente tiene limitación para realizar su propia higiene.

Podemos diferenciar cuatro procedimientos:

1. Valorar la autonomía del paciente y fomentar el autocuidado.

2. En pacientes autónomos: informar y facilitar el material necesario.

3. En pacientes conscientes que precisan ayuda:

a) Realizar lavado de manos.

b) Preparar el material

c) Preservar la intimidad del paciente.

d) Informar al paciente. 
e) Solicitar la colaboración del paciente y familia.

f) Colocarse guantes y mascarilla.

g) Colocar al paciente sentado o semiincorporado.

h) Cubrir tórax con toalla o empapador.

i) Cepillar dientes, lengua y encías.

j) Enjuagar primero con agua limpia y luego con colutorio.

k) Aplicar bálsamo labial hidratante en labios.

4. En pacientes inconscientes:

a) Posición con la cabeza ladeada.

b) Enrollar una gasa alrededor de unas pinzas y empapar con un antiséptico.

c) Limpiar la cavidad oral. Cambiar la gasa a menudo.

d) Aclarar la boca con agua (jeringa 10 c.c.) y aspirar.

e) Secar los labios.

f) Aplicar bálsamo labial hidratante en los labios.

5. En pacientes con prótesis dental: retirar dentadura y enjuagarla con agua tibia y cepillarla. Dejarla en recipiente con agua.

6. Dejar al paciente en una posición cómoda.

7. Recoger el material.

8. Retirar guantes y mascarilla.

9. Realizar lavado de manos.

10. Registrar en la documentación de enfermería: el procedimiento, motivo, fecha y hora, incidencias y respuesta del paciente.

Observaciones:

a) Indicar al enfermo la importancia de mantener una higiene correcta de la boca y estimularle a que lo realice después de cada comida.

b) Si un paciente inconsciente muerde el cepillo dental no hay que extraerlo por la fuerza. Hay que esperar a que el paciente relaje la boca antes de retirar el cepillo y continuar con el cuidado de la cavidad bucal.

\section{Higiene de los ojos}

Esta técnica va dirigida a realizar cuidados de los ojos en enfermos con reflejo corneal disminuido, disminución del volumen de lágrimas o ausencia de movimientos automáticos de los párpados.

A través de esta técnica proporcionaremos el aseo necesario para mantener los ojos limpios y húmedos, evitando la irritación, infecciones, edemas palpebrales y erosiones corneales.

Procedimiento:

1. Realizar lavado de manos.

2. Preparar el material.

3. Preservar la intimidad del paciente. 
4. Informar al paciente.

5. Solicitar la colaboración del paciente y familia.

6. Si el paciente está inconsciente colocarlo en posición decúbito supino o semi-Fowler. Si el paciente está consciente en posición Fowler.

7. Colocarse los guantes.

8. Cargar las jeringas con solución salina fisiológica.

9. Humedecer una gasa con solución salina y limpiar del ángulo interno al externo de cada ojo, hasta que quede limpio de secreciones. Utilizar una gasa distinta para cada párpado y para cada ojo. Todo esto realizarlo con los párpados cerrados.

10. Posteriormente, abrir los párpados del paciente con los dedos índice y pulgar de una mano y con la otra se instila solución salina fisiológica, desde el lado opuesto del lagrimal. Utilizar una jeringa estéril para cada ojo. Mantener siempre la cabeza ladeada del lado del ojo que se está lavando.

11. Secar con una gasa estéril cada ojo.

12. Cerrar suavemente los párpados.

13. Dejar al paciente en una posición cómoda.

14. Recoger el material.

15. Retirarse los guantes.

16. Realizar lavado de manos.

17. Registrar en la documentación de enfermería: procedimiento, motivo, fecha y hora, incidencias y respuesta del paciente.

Observaciones:

a) Evitar durante el procedimiento la luz directa sobre los ojos del paciente.

b) En pacientes inconscientes, aplicar crema epitelizante tras la limpieza. Dejar los ojos tapados con gasas húmedas de solución salina, renovar la gasa cada 2 horas o cuando se seque. La higiene completa de los ojos en estos pacientes se recomienda cada ocho horas.

\subsection{Extracción de lentes de contacto}

Tal vez, no imaginemos realizar esta técnica en estos instantes, puesto que vamos a trabajar con pacientes que, de llevar lentes de contacto, teóricamente, podrán quitárselas ellos solos. Pero supongamos que estamos en la planta y uno de nuestros pacientes, al que conocemos que es usuario de dichas lentes, cae inconsciente por algún motivo, por ejemplo una baja de tensión. En estos momentos deberemos saber actuar y atender al individuo en su totalidad.

Procedimiento:

1. Ponerse guantes no estériles.

2. Se retrae el párpado inferior con una mano. Utilizando la punta de los dedos pulgar e índice, se sujeta la lente con un movimiento de pellizco de la mano contralateral, desplazando la lente de contacto hacia la porción inferior de la esclerótica. 
3. Utilizando la punta de los dedos índice y pulgar, se sujeta la lente de contacto, con un movimiento suave de pellizco se retira.

4. Se colocan las lentes en un contenedor indicado para tal uso con antiséptico adecuado.

5. Se retira los guantes.

6. Realizar el lavado de manos.

7. Anotar la técnica.

\section{Higiene de los pies}

En esta técnica se describirán los cuidados encaminados a mantener los pies en perfecto estado. Los objetivos por tanto serán los siguientes:

a) Conservar o restablecer una buena higiene de los pies.

b) Prevenir las complicaciones del reposo prolongado en cama: UPP, pie equino, etc.

c) Prevenir infecciones.

d) Estimular la circulación sanguínea.

e) Fomentar la comodidad del enfermo.

Procedimiento:

1. Informar al paciente para obtener su colaboración y consentimiento.

2. Preservar en todo momento la intimidad del paciente.

3. Realizar la técnica lo menos lesivamente posible.

4. Examinar el estado de los pies en enfermos independientes.

5. En enfermos encamados, realizar los cuidados de los pies durante el baño:

a) Retirar los vendajes y/o apósitos y examinar los pies.

b) Sumergirlos en la palangana con agua y lavarlos bien.

c) Secar poniendo especial atención en los espacios interdigitales para evitar que queden húmedos.

d) Cortar las uñas en línea recta y con bordes lisos.

e) Curar heridas si existen.

f) Masajear los pies con crema hidratante o vaselina.

6. En enfermos con movilidad muy limitada, proteger talones y maléolos para evitar la aparición de UPP. Proceder del siguiente modo:

a) Masajear bien con vaselina.

b) Vendar con venda de algodón sin apretar, cubriendo el talón y maléolos.

c) Vendar por encima con venda de malla.

d) Es preferible la utilización de taloneras. Actualmente existen diferentes modelos comercializados.

7. Registrar la técnica en la gráfica del paciente.

Observaciones:

a) Colocar un estribo en el pie o base inferior de la cama, para que las extremidades conserven su posición funcional y evitar el pie equino. 


\section{Higiene de los genitales}

La higiene de los genitales se define como el conjunto de medidas que realiza el personal de enfermería para conservar, limpia y en buen estado, la piel de la zona perineal, cuando el paciente tiene limitación para realizar su propia higiene.

El objetivo de esta técnica es mantener limpios los genitales del paciente para cubrir las necesidades de higiene, a la vez que prevenir infecciones urinarias y ulceraciones. Además, se contribuye a proporcionar al paciente una sensación de bienestar y comodidad.

Se realiza siempre al final del aseo general, después de las deposiciones y cada vez que sea necesario.

Procedimiento:

1. Explicarle al paciente la técnica que vamos a realizar y pedir su colaboración.

2. Lavarse las manos y ponerse los guantes.

3. Colocar al paciente en posición ginecológica de encamado si es mujer y en decúbito supino con piernas separadas si es hombre.

4. Dejar al descubierto la zona genital, cubriendo el resto del cuerpo.

5. Colocar un empapador debajo de los glúteos y colocar la cuña.

6. Verter agua templada sobre los genitales.

7. Realizar la higiene genital en función del sexo:

7.1. Higiene genital masculina:

a) Lavar primero el pene y los testículos. Enjuagar.

b) Si el paciente no está circuncidado, retraer el prepucio del pene y lavar el glande realizando movimientos circulares desde el meato hacia fuera. Enjuagar. Subir de nuevo el prepucio a su posición para evitar edema de glande.

c) Aclarar con abundante agua y secar suavemente.

d) Si no se ha hecho la higiene general, colocar al paciente en posición decúbito lateral y proceder al lavado y secado de la zona perianal: ano y pliegue interglúteo.

e) Aplicar solución antiséptica si el paciente presenta sonda vesical o heridas.

7.2. Higiene genital femenina:

a) Enjabonar y lavar la zona genital en el siguiente orden: pubis, zona interna de los muslos, meato urinario, labios menores, labios mayores, hendidura vulvar, ano y pliegue interglúteo.

b) Separar los labios mayores con una mano y con la otra lavar de arriba abajo y de dentro hacia fuera, utilizando esponja o torundas para cada maniobra. Prestar especial atención a los pliegues que hay entre los labios mayores y menores.

c) Aclarar con abundante agua y secar suavemente.

d) Si no se ha hecho la higiene general, colocar a la paciente en posición decúbito lateral y proceder al lavado y secado de la zona perianal: 
desde la hendidura vulvar hasta el ano y pliegue interglúteo, con un solo movimiento.

e) Aplicar antiséptico en caso de sonda vesical o heridas.

8. Colocar pañal si se precisa.

9. Dejar al paciente en posición cómoda.

10. Recoger el material

11. Retirarse los guantes.

12. Realizar el lavado de manos.

13. Registrar en la documentación de enfermería: el procedimiento, fecha y hora, motivo, incidencias y respuesta del paciente.

\section{Cuidado de las uñas}

La higiene de las uñas es un aspecto más de la higiene habitual que hay que cuidar, sobre todo teniendo en cuenta que debajo de ellas se acumula la suciedad y, por tanto, los microorganismos con mayor facilidad. Los pacientes pueden tener dificultad para su cuidado, sobre todo en los pies, por lo que tendremos que suplir esta carencia cuando sea necesario.

Procedimiento:

1. Realizar lavado higiénico de manos.

2. Preparar el material.

3. Preservar la intimidad del paciente.

4. Informar al paciente.

5. Solicitar la colaboración del paciente y familia.

6. Preparar agua en una palangana a $30-32{ }^{\circ} \mathrm{C}$.

7. Proteger la cama con el empapador.

8. Colocarse los guantes no estériles.

Pies:

1. Lavar los pies con agua y jabón, sumergirlos para reblandecer durezas o si tienen mucha suciedad.

2. Enjuagar con agua a chorro.

3. Secar bien, sobre todo los espacios interdigitales con una toalla.

4. Valorar estado de los pies: durezas, úlceras, deformidades, temperatura y coloración, edemas y pulsos periféricos.

5. Realizar cuidados específicos si presenta úlceras por presión.

6. Limar durezas con suavidad.

7. Cortar uñas en línea recta.

8. Aplicar crema hidratante con un suave masaje.

Manos:

1. Sumergir las manos en agua unos dos minutos como máximo para evitar maceraciones. 
2. Cortar uñas de forma ovalada, dejando sobresalir como mínimo de la base de la uña 10-15 mm. Valorar la decisión del paciente.

3. Retirar restos de suciedad dentro de las uñas.

4. Aplicar crema hidratante.

9. Dejar al paciente en una posición adecuada.

10. Recoger el material.

11. Retirar los guantes.

12. Lavarse las manos.

13. Registrar en la documentación de enfermería: procedimiento, motivo, fecha y hora, incidencias y respuesta del paciente 


\section{CAPÍTULO 10}

\section{Cuidados básicos en la comunicación}

\section{Definición}

Según el diccionario de la Real Academia Española, el término comunicación proviene del latín y se refiere a:

a) Acción y efecto de comunicar o comunicarse.

b) Trato, correspondencia entre dos o más personas.

c) Transmisión de señales mediante un código común al emisor y al receptor.

d) Unión que se establece entre ciertas cosas, tales como mares, pueblos, casas o habitaciones, mediante pasos, crujías, escaleras, vías, canales, cables y otros recursos.

e) Cada uno de estos medios de unión entre dichas cosas.

f) Papel escrito en que se comunica algo oficialmente.

g) Escrito sobre un tema determinado que el autor presenta a un congreso o reunión de especialistas para su conocimiento y discusión.

h) Figura que consiste en consultar la persona que habla el parecer de aquella o aquellas a quienes se dirige, amigas o contrarias, manifestándose convencida de que no puede ser distinto del suyo propio.

Aguilar, Boltà, Gahete y Saz (2009) realizan la siguiente reflexión: la palabra comunicación proviene del latín communis que significa común. Tanto el latín como los idiomas romances han conservado el especial significado de un término griego, el de koinoonia, que significa a la vez comunicación y comunidad. También en castellano el radical «común» es compartido por los términos comunicación y comunidad. Ello indica, como punto etimológico, la estrecha relación entre «comunicarse» $\mathrm{y}$ «estar en comunidad». En pocas palabras, se «está en comunidad» porque «se pone algo en común» a través de la «comunicación».

La comunicación se suele definir como un intercambio de información entre dos o más personas, pero no debemos olvidar que el objetivo de la comunicación es provocar una respuesta, con lo cual no únicamente es un mero intercambio sino que es un proceso en el cual se debe producir un retorno continuo de la información, para que sea procesada por los participantes de dicho proceso.

Miller define comunicación como: «Es un mensaje a un receptor con la intención consciente de afectar a su conducta posterior». Entendemos que la forma en que a las personas les llega la información influye en su posterior manera de actuar, o 
también que una persona bien informada se siente considerada, valorada y respetada, y por tanto es posible que su conducta sea de colaboración y de integración al equipo. Apoya esta idea el concepto definido por Shanon y Weaver (1949) ya que postulan que comunicación es «todo aquello que sucede entre dos o más mentes. Dado que la conducta es aquello que perciben los demás, toda conducta es comunicación y toda comunicación produce conductas».

Otros autores consideran que comunicar es «el proceso por medio del cual el individuo transmite estímulos para modificar el comportamiento de otros» (Houland). Esto quiere decir que el proceso de comunicar implica entendimiento entre personas, como abogan Davis y Newston (1986) definiendo comunicación como «la transferencia de información y el entendimiento entre dos personas». También el proceso de comunicación implica relación ya que Johnson (1985) consideraba la comunicación como «un medio para que una persona envie un mensaje a otra, a la espera de respuesta». Esta relación se da a través de unos canales por los que se envía un mensaje de un emisor a un receptor, que serían elementos indispensables para que exista comunicación.

Según Cibanal y Arce (2000), «la comunicación es la capacidad que posee un individuo o un grupo para transmitir sus ideas y sus sentimientos a otros individuos o grupos, sin olvidar recibir las ideas y sentimientos de otros individuos o grupos».

\section{Niveles de comunicación}

Cibanal define que cuando nos comunicamos tenemos la impresión de que nuestra comunicación es nítida, sin embargo observamos cómo nuestro interlocutor ha captado, comprendido o interpretado cosas distintas. Si queremos ser eficaces es necesario tener en cuenta:

a) Definir de forma muy concreta los comportamientos o las actitudes que queremos cambiar o mejorar.

b) Observar nuestro comportamiento.

c) Practicar.

Entre las dificultades que estos autores exponen que ocurren de forma más frecuente y que se deben evitar son:

a) Evitar hacernos reproches: Una vez que he programado lo que quiero cambiar hay que mantener una actitud de experimentador.

b) Evitar la creencia irracional de que no puedo o soy incapaz de cambiar: Hay que mantenerse abiertos al cambio.

c) Evitar culpabilizar a los otros de no poder conseguir lo que nos proponemos: Es una constante el no querer asumir nuestra responsabilidad.

d) Evitar las explicaciones fáciles de nuestros comportamientos: hay que tener una actitud escéptica y cuestionarnos sobre la causa de dichos sentimientos y comportamientos. 
e) Ser muy concretos en la definición de nuestras dificultades: De la manera más precisa posible, para saber exactamente lo que queremos cambiar de nuestro comportamiento. Para ello nos puede ayudar:

I. Hacer una parrilla de las situaciones y personas que quiero cambiar.

II. Anotar regularmente nuestras observaciones.

III. Anotar lo que físicamente siento.

IV. Anotar lo que pienso y lo que me digo a mí mismo.

v. Anotar los resultados y las consecuencias.

VI. Anotar qué otros comportamientos me gustaría tener hacia el futuro.

VII. Anotar nuestras observaciones de forma sistemática.

\section{Factores que influyen en la comunicación}

Aguilar, Boltà, Gahete y Saz (2009) realizan una diferenciación entre las barreras internas y externas de la comunicación. Entre estas barreras internas de la comunicación destacan:

a) Diferencias culturales o de género entre el emisor y el receptor: Debido a que vivimos en una sociedad plural, las diferencias culturales y de género en nuestra actitud frente a ciertas cosas, gestos y tiempos pueden hacer el proceso de comunicación más complicado.

b) No escuchar: El receptor no está interesado en lo que se está comunicando, no presta atención y solo escucha lo que quiere oír e ignora las señales no verbales.

c) Juicios: Los estereotipos, prejuicios e ideas preconcebidas sobre el emisor o la información que se está intercambiando bloquean el significado de la información.

d) Suposiciones: Suponer que la otra persona o personas piensan lo mismo que el emisor sobre el contenido de lo que se está comunicando.

e) Historial de la relación: Pensar en cómo acabaron las conversaciones previas con la misma persona o en la relación que se tiene con esa persona puede afectar a su manera de enfrentarse a conversaciones venideras.

f) Factor educativo personal: Las experiencias acumuladas durante la infancia nos permiten construir nuestra manera de comprender la realidad y también frente a los hechos. Construimos nuestro marco de referencia, que constituye uno de los aspectos más importantes de nuestra personalidad. Cada persona posee un marco de referencia único y tiende a emitir e interpretar los mensajes en función de los parámetros que lo caracterizan.

g) Deficiente redacción del mensaje: Si el mensaje ya sea escrito u oral no contiene todos los datos de lo que se quiere expresar, el resultado esperado es una falta de comprensión del mismo.

h) Incongruencia entre el contenido y la intención: Si deseamos comunicar un mensaje, debemos asegurar que el contenido y la intención con que se comunica sean coherentes. La información que no sea específica o clara o que no esté relacionada con lo que se está comunicando puede constituir una barrera para la comunicación eficaz. 
i) Falta de claridad: Los mensajes que son confusos debido a la utilización inapropiada del lenguaje, resultante de la utilización de un vocabulario inadecuado, una pobre selección de palabras, utilización de palabras vacías, de frases mal construidas, con una organización de ideas inadecuada dificultan la comunicación. Hablar rápido o muy lento, no remarcar las ideas o informes pobremente expresados llevan a una transmisión inadecuada. La elección de palabras o imágenes usadas para comunicar afectan a la comprensión. No todo el mundo entiende igual los distintos términos y palabras.

j) Descuidos u omisiones: Puede ser que el mensaje esté constituido correctamente, siendo claro y coherente, pero no lo entregamos a la persona a la que iba dirigido.

k) Filtración: Si el emisor no tiene toda la información, o no informa sobre los hechos que conoce, transmite un mensaje distorsionado o filtrado. El filtro, tanto si es intencionado como si no, implica una selección del que se comunica basada en perjuicios. La filtración es la manipulación de la información del emisor para que sea vista más favorablemente por el receptor. No es posible la información objetiva. En una organización vertical, cuanto más vertical más posibilidad de filtración hay.

Siguiendo las mismas autoras, entre las barreras externas de la comunicación se encuentran:

a) Ruido: Se entiende como ruido, en el proceso de comunicación, las perturbaciones que provocan que el mensaje sea inteligible en parte o en su totalidad. El ruido puede llegar a ser parte de la información, deteriorarla o destruirla. Un ejemplo podría ser el ruido de la calle, de teléfonos, de faxes, etc. que impide entender el significado del mensaje.

b) Señales no verbales: Si las señales no verbales como gestos faciales, el contacto visual, la apariencia, no complementan lo que se está comunicando, el significado puede verse distorsionado.

c) Medio o canal de comunicación inadecuado: Seleccionar el medio erróneo, como podría ser enviar una carta formal para pedir a una persona que se reúna con otra persona en cinco minutos, puede conducir a malentendidos.

d) Presión de tiempo: Tratar de comunicar un asunto importante bajo presión de tiempo constituirá una barrera tanto para el emisor como para el receptor.

Cibanal y Arce (2000) no distinguen en su libro si los factores que influyen en la comunicación pertenecen a una entidad externa o interna de la persona, pero realizando un escrutinio de estos factores se puede determinar que destacan que la amplia mayoría de estos factores pertenecen al ámbito interno. Asimismo, destacan los siguientes factores:

a) La percepción: La imagen que uno se hace del mundo y del otro es un elemento esencial en la comunicación. Así conocemos que existen filtros fisiológicos que nos influyen a la hora de ver la realidad, como los sentidos, debido a ello sabemos que la percepción es selectiva. Siempre se verá una parte de un todo y, por ello, no se debe aislar el fenómeno de su contexto. 
b) Valores y creencias: Los valores están muy relacionados con la autoestima e influyen enormemente en la comunicación porque tratamos de imponerlos. Los profesionales de la salud deben llegar a saber abordar y resolver estos conflictos de valores. En cuanto a las creencias, también los profesionales de la salud poseemos ideas irracionales o estereotipos sobre ciertas personas o situaciones. De esta forma, tendemos a considerar solamente como adecuado aquello que entra dentro de nuestros valores y creencias.

c) Aspectos sociales: Cada sociedad y cada cultura suministra a sus miembros su propia explicación sobre las estructuras y el significado que le da a las cosas. De esta forma, las ideas sociales confieren de manera importante el estilo personal de comunicación y de interacción de una persona con otra. Si los profesionales no conocen estos aspectos sociales de los pacientes, les resultará difícil saber el sentido que ellos dan al mensaje que reciben.

d) Aspectos culturales: La significación del lenguaje en los asuntos humanos se deriva del modo como funciona dentro de las pautas de las relaciones culturales. Además, la evaluación de las pautas de la vida cultural nos hace comprender las formas en que estas se expresan en el discurso o la comunicación, y nos permite apreciar que la cultura es mantenida gracias a la comunicación.

e) Aspectos familiares: El proceso que conduce a percibir «la manera en que las cosas son» se construye desde el nacimiento a través del consenso. El proceso de búsqueda y retención del consenso es lo que otorga a la realidad un cierto grado de estabilidad colectiva y, por tanto, individual. La familia sería el sistema intermedio entro lo individual, lo natural, lo privado y lo que pertenece a lo público, cultural y lo social, y se entiende como una instancia de socialización.

f) Aspectos individuales: El observador, con sus limitaciones, supuestos y prejuicios, organiza lo observado. Así, creamos el mundo que percibimos, no porque no exista una realidad externa, sino porque seleccionamos y remodelamos la realidad que vemos, para conformarla a nuestras creencias acerca de la clase de mundo en el que vivimos (Bateson, 1991). Desde una perspectiva ética, se admite el nexo necesario entre el observador y lo observado, y ello nos conduce a examinar cómo participa el observador en lo observado.

g) Otros aspectos: Se pueden considerar los filtros de la filosofía de vida, las creencias, la religión o las situaciones personales, nuestras relaciones, nuestro cansancio, nuestras preocupaciones, ansiedades, miedos, depresiones, etc.

\section{Tipos de comunicación}

De forma general, los autores dividen la comunicación en dos tipos: la comunicación verbal y la comunicación no verbal. La comunicación verbal se refiere a la transmisión de un mensaje mediante la utilización de la palabra hablada o escrita, puede ser directa (oral) o indirecta (informes, boletines, programas, rumores). Aguilar, Boltà, Gahete y Saz (2009) destacan que para realizar una comunicación verbal eficaz se han de tener en cuenta unos principios: 
a) Simplicidad: El mensaje ha de estar construido con palabras de fácil comprensión, realizando estructuras que se adapten al campo estructural del receptor y que no den pie a interpretaciones erróneas. También el mensaje ha de estar condensado, dicho coloquialmente «ir al grano», con el objetivo de no distraer o perder la atención del receptor. A la realización de largas explicaciones y la utilización de temas inadecuados se le llama sobrecomunicación. No debemos caer en el otro lado que sería la subcomunicación, es decir, que con el afán de reducir el mensaje con la finalidad de simplificarlo lo estructuremos de forma incompleta y dificultemos su interpretación.

b) Claridad: Se ha de transmitir lo que se pretende transmitir, sin dar lugar a interpretaciones erróneas. Para conseguir una comunicación congruente debe haber concordancia entre el mensaje hablado y el mensaje no verbal transmitido. La finalidad es que el receptor sepa el qué, cómo, por qué, cuándo, quién y dónde.

c) Momento y pertinencia: Para conseguir una correcta transmisión y recepción del mensaje es importante que el tiempo en el que se realiza sea apropiado, con la finalidad de asegurar que se escucha.

d) Adaptabilidad: Se ha de modificar o modular el lenguaje hablado en función de las señales (gestos, lenguaje no verbal) procedentes del receptor. En este aspecto se intenta conseguir variar los estímulos del momento, a medida que se produce la comunicación mediante el feedback recibido del receptor; por tanto, hay que evitar los mensajes rutinarios o automáticos.

e) Credibilidad: La validez de una creencia, la confianza que inspira el emisor puede ser el aspecto más importante de la comunicación. Para conseguir credibilidad se ha de conocer el tema objeto de la comunicación, de esta manera se sustenta la solidez del mensaje; además ha de existir una actitud de confianza y seguridad con lo que transmitimos, sino no se creará un clima de seguridad y credibilidad. Es importante recalcar que no hay que caer en el autoritarismo o el narcisismo intentando recalcar la credibilidad del mensaje, para evitarlo hay que potenciar el aspecto constructivo del mensaje.

La comunicación no verbal es el lenguaje corporal y los sentimientos que el emisor experimenta en el curso de la comunicación. Así, cuando nos comunicamos expresamos nuestra actitud hacia el asunto o mensaje objeto de la comunicación. Según Cibanal y Arce (2000) la comunicación no verbal supone la captación de las señales sutiles que complementan e ilustran aspectos de la interacción verbal, y a menudo proporcionan mensajes y expresan sentimientos que no están sujetos al análisis directo consciente de quienes interactúan. Según estos autores, este tipo de comunicación es importante en el campo de la salud, principalmente en dos ámbitos:

a) La sensibilidad: La enfermedad crea en el paciente un estado de fuerte ansiedad que se acompaña de incertidumbre, la cual le lleva a buscar en el medio ambiente indicios que le indiquen cuál es la situación real de su salud o enfermedad. En función de ello, el paciente se crea unas expectativas acerca de la gravedad de su propia enfermedad, del interés que el profesional de la salud tiene por él, etc. 
b) La expresividad: Dado el gran número de emociones de diferentes clases que se suelen experimentar, suele ser habitual que el paciente experimente un aumento considerable de su capacidad de expresividad por vía no verbal.

Aguilar, Boltà, Gahete y Saz (2009) destacan que la comunicación no verbal se realiza a través de elementos como:

a) El tono de voz: Es uno de nuestros medios principales de expresión, pero tenemos sobre él menos control de lo que pensamos. Sin querer, a través del tono, transmitimos nuestros sentimientos. Por ejemplo, hacia una persona por la cual sentimos aversión nos es difícil mostrar un tono amable.

b) La mirada: Es otro importante medio de expresión de nuestros sentimientos. Mediante la mirada podemos transmitir amabilidad, desconfianza, rencor... No solamente la mirada es importante, también lo es la forma de mirar; hay personas que son incapaces de mirar los ojos del otro, esto nos dice que es una persona desconfiada o en la que no puedes confiar.

c) La apariencia física: Otro medio de comunicar cómo somos. En la manera de vestir o cuidarnos, damos información al otro de cómo somos o pensamos.

d) La postura y la marcha: Dan información sobre el grado de autoconcepto, estado de humor o de salud. Con la postura que iniciamos al comunicar, estamos enviando mensajes al otro de nuestra postura psíquica. Por ejemplo, en una reunión, quien se sienta alejado y mal sentado en la silla indica que el tema no le interesa excesivamente.

e) La expresión facial (gestos) y la expresión corporal: La parte de nuestro cuerpo más expresiva es la cara. Los músculos que envuelven los ojos y la boca son muy expresivos, pueden llegar a controlarse pero comúnmente son espontáneos. Las emociones que podemos transmitir son: alegría, tristeza, sorpresa, descontento, miedo y rabia. Al igual que nuestra cara habla por sí sola, también lo hacemos con nuestro cuerpo (manos, brazos...) y transmitimos cómo nos sentimos ante el mensaje que emitimos.

Dentro de la comunicación no verbal podemos incluir una situación que, cuando sucede, muchas veces incomoda tanto al profesional como al paciente, hablamos de los silencios. Aguilar, Boltà, Gahete y Saz (2009) destacan cuatro tipos de silencios:

a) Silencio de «no atención»: La persona no mira al que habla y finge estar absorta en otra actividad como leer, hacer algo manual o simplemente mirar fijamente hacia otro lado como por ejemplo la ventana.

b) Silencio de bienvenida: La persona reconoce la presencia del otro con un simple movimiento de ceja o de la boca, pero no dice nada. Este silencio hace que el otro se sienta incluido.

c) Silencio por miedo: La persona se muestra inquieta, angustiada, quiere hablar pero tiene miedo a hacerlo.

d) Silencio reflexivo: La expresión facial y corporal nos dicen que, aunque en silencio, la persona medita con atención lo que se le está diciendo o se le ha dicho. 
Según Cibanal y Arce (2000), los silencios pueden interpretarse como pausas, siendo importante tener en cuenta las pausas e ir intercalándolas con paráfrasis que indiquen que se está escuchando. El silencio es como una parte de la comunicación que uno tiene consigo mismo. Entre sus significados se encuentra el silencio de poder, el rechazo de comunicación y la escucha activa. Si existe alguna duda del tipo de silencio que se está transmitiendo, hay que clarificarlo con el paciente. Además, estos autores distinguen también elementos y actitudes que se muestran a través de la comunicación no verbal, entre las que destacan:

a) La mirada: Uno de los elementos de la comunicación no verbal que más información aporta. Entre sus funciones está la regulación del flujo de la comunicación, la obtención de un feedback, la expresión de las emociones o la comunicación de la naturaleza de la relación. Se aconseja que la mirada sea regulada (de dos a tres segundos). Mirar a menudo con poca intensidad y duración. Si tenemos dificultad para mirar podemos entrenarnos mediante un ejercicio de relajación y, cuando estemos relajados, visualizar a esas personas y comprobar que las miramos a los ojos. También se puede mirar a la frente, la barbilla, la boca o las mejillas.

b) Entre los elementos acústicos encontramos:

a. La voz: Tiene la capacidad de transmitir información acerca de los estados emocionales del que habla. Debemos esforzarnos por encontrar el volumen adecuado, dando énfasis a lo que decimos.

b. Fluidez verbal: Si hablamos muy deprisa, nuestro interlocutor tendrá dificultad para seguirnos. Si hablamos lentamente o dudando, perdemos el interés de nuestro interlocutor.

c. Tono: Empleemos diferentes tonos de voz para expresar los diversos sentimientos o emociones que tengamos. El tono muestra la calidad de la voz.

c) Expresión facial y gestos: La sonrisa en los hombres es importante para producir una impresión favorable (Shrout, 2006). Hay que tener en cuenta que la expresión facial esté en consonancia con lo que sentimos. Si no podemos tener esta consonancia, lo más sencillo es explicar a nuestro interlocutor lo que nos pasa, para que así no interprete de forma negativa.

d) Ocupación del espacio: Según Cibanal y Arce (2000) el sentido del yo se desplaza dentro de una especie de burbuja privada, que representa la cantidad de espacio que siente que debe haber entre él y los otros. La forma más sencilla de actuar a este respecto, es clarificar la distancia con el paciente.

e) El tacto: Existen diferentes clases de tacto (funcional o profesional, cortés o social, amigable y tacto íntimo). Además, este tacto también actúa en función de la edad y las culturas. Indica proximidad cuando este es recíproco. Por el contrario, cuando se da en una sola dirección indica poder. En nuestra profesión, a menudo, tenemos que tocar a los pacientes, incluso en sus partes más íntimas, hay que pedirles permiso y explicarles por qué lo hacemos.

f) El olfato: Algunas enfermedades y tratamientos pueden actuar directamente para producir en el paciente olores desagradables, mientras que otros afectan al olor del paciente a través de acciones sobre la región gastrointestinal. También los profesionales de la salud pueden ser asociados a olores particu- 
lares. Los olores tienen a menudo un enorme poder para evocar la memoria de tiempos y lugares ya olvidados. No está de más preguntar al paciente si le molestan los olores o le evocan sentimientos negativos, ya que esto permite clarificar ciertas reacciones o comportamientos que a veces nos pueden extrañar.

g) Apariencia física general: Está constituida por mi constitución y mi cuerpo. La sociedad de consumo da mucha importancia a la apariencia y la manipula según imposiciones sociales. Es nuestra tarjeta de visita. Anime a sus colegas a que le hagan observaciones sobre su apariencia física. Este aspecto es muy personal, según las situaciones, usted debe, con la ayuda de sus colegas o amigos descubrir lo que le ayude a expresar lo que es o quiere ser.

\section{Actitudes del receptor}

Cibanal y Arce definen ciertas actitudes que debe poseer un receptor a la hora de comunicarse. Entre estas actitudes se expresan:

a) Escucha activa: Tipo de respuesta verbal que contiene algún mensaje real que refleja el mensaje del paciente. Durante esta, el profesional permanece en silencio.

b) Feedback: Es la actitud de devolver al paciente lo que este le acaba de decir, tanto el contenido como el sentimiento o la demanda. Se trata de decírselo tal cual el receptor lo haya captado.

c) Empatía: Es la capacidad de comprender correctamente lo que experimenta nuestro interlocutor.

d) Respeto o aceptación incondicional del paciente: La concepción del otro se basa en una información insuficiente de lo que hace o nosotros captamos de él.

e) Autenticidad: Supone que uno es él mismo cuando lo que dice está acorde con sus sentimientos. Ser sincero y honrado consigo mismo.

f) Concreción: Ser capaces de ser concretos y específicos en lo que hablamos. Pedir al paciente que nos ponga ejemplos o que nos hable en primera persona. También que nos clarifique lo que siente cuando nos está exponiendo su problema o situación.

g) Confrontación: Capacidad de poner de manifiesto las contradicciones entre lo que el paciente dice y lo que hace; entre su comportamiento verbal y el que no lo es.

h) Inmediatez: Capacidad del profesional de puntualizar los sentimientos, las reacciones y las palabras que el paciente expresa y que remiten a situaciones exteriores a la relación de ayuda. 


\section{Habilidades, estrategias y gestos de los profesionales de enfermería}

López González (2005), en su estudio, destaca que sólo el 33 \% de los profesionales de enfermería que entrevistó habían recibido formación sobre la comunicación interpersonal en el trabajo a lo largo de su vida laboral. Además, al $94 \%$ de los profesionales les hubiera gustado tener más conocimientos acerca de la comunicación interpersonal, y sólo al $6 \%$ no les interesaba ser más diestros en este tema. Por último, el $82 \%$ de los participantes habían sido testigos de errores en la ejecución de su trabajo por una incorrecta comunicación. En el $55 \%$ de los casos el error tuvo consecuencias, siendo el paciente el afectado en todos los casos. La segunda encuesta valorada en el estudio del mismo autor revelaba que el test de comunicación verbal mostraba que el $24 \%$ de los sujetos del estudio presentaban una inadecuada comunicación verbal. Por último, en el tercer test analizado, que pertenece al examen del oyente, el $12 \%$ presentaban déficit en el hábito de escuchar y, aunque el $70 \%$ fueron calificados como buenos oyentes, sólo el $18 \%$ de ellos llegaron a ser oyentes excelentes. Así, en el test de comprensión de contenidos verbales, el $39 \%$ de los encuestados presentaba mala comprensión de contenidos verbales y tan sólo un $6 \%$ tenía una excelente comprensión.

Para ello, es importante destacar qué dice la literatura acerca de las habilidades que facilitará que el personal de enfermería se comunique con sus pacientes y con los familiares. De esta forma, Ramón-García, Segura-Sánchez, Palanca-Cruz y Román-López (2011) destacan en un estudio realizado que entre las habilidades encontradas en la literatura para la comunicación en salud destacan: la empatía, la cordialidad, la educación, el respeto y escuchar activamente.

Siguiendo los mismos autores, entre las estrategias para facilitar la comprensión y recordar los mensajes de salud se encuentran: comunicar la información de forma veraz, inteligible, clara, sencilla, concisa, concreta, evitando los tecnicismos y con un vocabulario accesible. Una estrategia para que los familiares recuerden los mensajes consiste en ejemplificar los mensajes de salud cercanos al individuo, para que así pueda recordarlos en un futuro. Otra estrategia consiste en la utilización de una expresión oral clara, directa, evitando ambigüedades y suspicacias. Así se podrá facilitar la compresión a los familiares empleando expresiones adecuadas al contexto sociocultural de los mismos para que estas sean entendidas. Además se han de analizar las ideas antes de comunicarlas y valorar el propósito del mensaje. Ofrecer al comunicarnos frases sencillas y concretas. Utilización de un lenguaje sencillo adaptado al nivel sociocultural de los familiares. Repetir los conceptos claves para que sean comprendidos y recordados con facilidad por los receptores. Otra estrategia consiste en la observación realizada a los familiares para poder realizar mediante esta acción una explicación o repetición de forma diferente, en caso de no ser entendido el contenido de la información. Otra estrategia que influye en la comunicación verbal consiste en escoger un ritmo adecuado para hablar, el cual no deberá de ser ni muy rápido ni muy lento. Y en cuanto al tono de voz empleado se ha de utilizar uno adecuado, ya que un volumen muy alto condiciona 
cierto rechazo e impresiona agresivamente por parte del receptor y, en cambio, un volumen muy bajo impide ser comprendido y aparenta inseguridad y temor. Por último para facilitar la comprensión se ha de asegurar la retroalimentación con el interlocutor mediante la realización de un feedback. Estas actitudes coinciden con las mostradas por otras autoras en su estudio, como el estudio realizado por Landete Belda (2012). 


\section{CAPÍTULO 11}

\section{Cuidados básicos \\ en el confort y la seguridad}

\section{Introducción}

Según el diccionario de la Real Academia Española (RAE), se puede definir el confort como «aquello que produce bienestar y comodidades»; la comodidad es necesaria para vivir a gusto y con descanso. Por otro lado, la RAE define seguridad como «cualidad de seguro»; es decir, aquello que está libre y exento de todo peligro, daño o riesgo. Por lo tanto, podemos deducir que ambos términos deben estar presentes en el ámbito hospitalario.

Aunando los términos confort y seguridad, podemos reflexionar que uno no puede darse sin la presencia del otro en el ambiente sanitario, es decir, son complementarios. De tal forma que, por mucho confort que se le ofrezca a un paciente, si este no se siente en un ambiente seguro, no podrá sentirse confortable.

Así, el confort es una necesidad importante y asegura la comodidad del paciente; es una de las principales responsabilidades de la enfermería. Proporcionar comodidad puede ser tan simple como eliminar arrugas de la cama del paciente, ofrecerle la mano para que se sostenga o colaborar con sus necesidades de higiene. A menudo, proporcionar comodidad incluye el alivio del dolor.

En este tema trataremos aspectos bastantes amplios de la enfermería y algunos que están directamente relacionados con indicadores hospitalarios de seguridad y confort. Así, los puntos a tratar serán los siguientes:

a) Promoción de la comodidad del paciente.

b) La habitación del paciente.

c) Asepsia, infección nosocomial y manejo de la infección.

d) Lavado de manos.

e) Prevención de las caídas.

f) Prevención y tratamiento de las úlceras por presión.

g) Sujeción.

h) Dolor.

Antes de adentrarnos en el análisis de cada uno de estos puntos, mencionar que creemos que el dolor debe tener su tema especial, debido a la relevancia del mismo y presencia en múltiples procesos, por ello debe ser tratado de forma más profunda y se abordará más adelante. 


\section{La habitación del paciente}

La unidad de enfermería es el conjunto de departamentos y recursos materiales relacionados con el personal de enfermería, que se disponen para promocionar los cuidados necesarios a los pacientes ingresados en un centro hospitalario.

La unidad de paciente (figura 20) es el conjunto formado por el espacio de la habitación, el mobiliario y el material que utiliza el paciente durante su estancia en el centro hospitalario. Por lo tanto, el número de unidades de paciente será igual al número de camas que tenga el hospital. Aunque el número de camas por habitación varía de un hospital a otro, siendo en la gran mayoría de dos o tres camas; aunque la tendencia actual que se está siguiendo para las nuevas construcciones es realizar habitaciones individuales. La situación idónea es poder disponer en cada planta de habitaciones individuales y de habitaciones compartidas, para utilizar una u otra modalidad en función de las características de los pacientes.

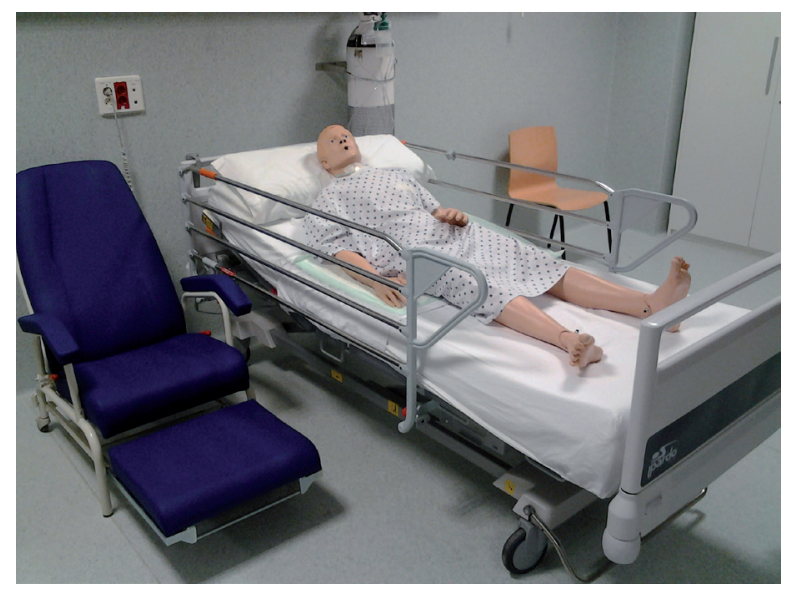

Figura 20. Unidad de paciente. Fuente: Elaboración propia

En las habitaciones con varias camas, cada unidad puede aislarse mediante biombos o cortinas, para asegurar y respetar la intimidad del paciente. En las habitaciones individuales, se considera «unidad del paciente» a todo el contenido y el espacio físico de la propia habitación.

En los hospitales donde se carezca de estas últimas, las habitaciones individuales deben preservarse para el aislamiento de los pacientes que presenten gravedad en su estado general, patologías infectocontagiosas, pacientes operados con riesgo de ser contagiados, inmunodeprimidos o pacientes con algún tipo de alteración psíquica, entre otros.

\subsection{Características de la unidad del paciente tipo}

La patología y la edad del paciente son factores determinantes que hay que tener en cuenta en la organización y disposición del paciente. Las medidas de la habitación dependen del número de camas. Las dimensiones aproximadas son las siguientes: 
a) Habitaciones individuales ( 1 cama): las medidas deben ser de unos $10 \mathrm{~m}^{2}$.

b) Habitaciones dobles ( 2 camas): las medidas deben ser de unos $14 \mathrm{~m}^{2}$.

c) Habitaciones triples (3 camas): las medidas deben ser de unos $18-20 \mathrm{~m}^{2}$.

El número máximo de camas por habitación no debe ser superior a cuatro. Algunas características comunes en las habitaciones son (figura 21):

a) Espacio de 1,20 metros entre la cama y las paredes, o entre camas si hay más de una.

b) Altura de las paredes de 2,50 metros.

c) Disponer de un baño completo (lavabo, ducha y váter), de fácil acceso y adaptado para discapacidades físicas en caso necesario.

d) Paredes pintadas con colores claros, sin brillo.

e) Puertas amplias para permitir el paso de camas.

f) Mobiliario complementario, como sillón/cama para acompañante y armario

g) Disponer de luz natural y sistema de ventilación.

h) Sistema de comunicación interna con el personal de la unidad accesible para el paciente.

i) Tomas de oxígeno y sistema de vacío ubicado en la cabecera de la cama del paciente.

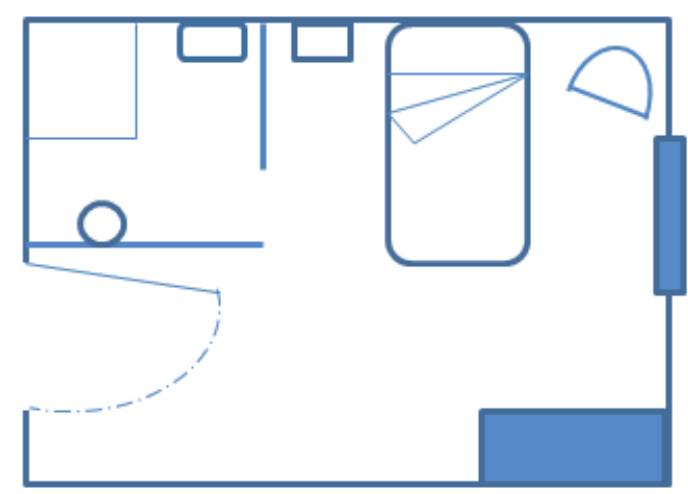

Figura 21. Modelo de habitación individual. Fuente: Elaboración propia

\subsection{Otros tipos de unidad del paciente}

Cada unidad hospitalaria se diseña teniendo en cuenta el tipo de pacientes que va a acoger. Las unidades de geriatría, por ejemplo, o de pacientes con algún tipo de dependencia física deben disponer de aseos adaptados a su discapacidad, es decir, que lleven planto de ducha (en lugar de bañera), con suelo antideslizante y asideros en la pared. También estarán provistos de barras o asideros de sujeción para facilitar el uso de inodoro, sin que haya riesgo para los pacientes.

a) Unidad de pediatría: Debe diseñarse y decorarse con colores y motivos que llamen la atención del niño y resulten alegres y atractivos (por ejemplo, escenas de dibujos animados en sus paredes). 
b) Unidad de geriatría: En el caso de pacientes dependientes de una silla de ruedas o de otros dispositivos de ayuda, las habitaciones deben disponer de mayor espacio y de un acceso adecuado a la habitación y al baño, para que puedan pasar sillas de ruedas, carros, camillas, grúas, etc.

c) Unidades con características especiales: En estos casos, debido a las características especiales de los pacientes, hay que adaptar todo o parte del equipamiento $\mathrm{y}$, además, se debe disponer de otro tipo de utensilios, equipo y aparatos diferentes, que son necesarios para proporcionar los cuidados adecuados a estos pacientes.

\subsection{Condiciones ambientales}

El entorno que rodea al paciente tiene una notable influencia sobre la respuesta de este al tratamiento que está recibiendo. En general, las habitaciones tienen que ser espaciosas, tranquilas y soleadas, y deben mantenerse limpias, aireadas y ordenadas, para evitar la aparición de problemas psíquicos o patológicos (infecciones por ejemplo).

El estado de ánimo del paciente puede verse afectado como consecuencia de las características ambientales, por lo tanto la limpieza y la seguridad son dos factores importantes que favorecen y facilitan el proceso de curación del paciente.

Las habitaciones hospitalarias deben reunir una serie de condiciones ambientales que van a repercutir, de manera directa, en el estado de salud y en la evolución del paciente. Las condiciones ambientales que mayor repercusión tienen sobre el paciente son las atmosféricas, la iluminación, la insonorización y la limpieza.

Las condiciones atmosféricas con una mayor incidencia sobre el paciente son:

a) Temperatura: La temperatura de la unidad de hospitalización debe estar entre 20-22 ${ }^{\circ} \mathrm{C}$, aunque puede variar en las diferentes zonas del hospital. Así, en los pasillos estará entre $20-21{ }^{\circ} \mathrm{C}$, en las consultas externas entre $21-23^{\circ} \mathrm{C}$, en los quirófanos entre $20-25^{\circ} \mathrm{C}$, etc. La temperatura se regula mediante termómetros o termostatos que se disponen en las unidades de los pacientes, los pasillos, las dependencias especiales, etc. Muchos hospitales disponen de circuitos cerrados de ventilación, que llevan un sistema automático de control de la temperatura. Es importante que se realice un correcto mantenimiento y limpieza de los sistemas de control de la temperatura, para evitar la contaminación de los sistemas de refrigeración, sobre todo por legionella.

b) Humedad: Los valores del grado de humedad que se consideran óptimos oscilan entre el 40 y el $60 \%$. Se controla mediante el uso de higrómetros que se colocan en la unidad del paciente, los pasillos y las dependencias especiales. En algunos estados patológicos, como ciertas afecciones respiratorias, un grado de humedad relativa bajo (10 al $20 \%)$ resulta más cómodo para el paciente. Además, el descenso del grado de humedad favorece, generalmente, la diseminación de los microorganismos que afectan al sistema 
respiratorio. El aumento del grado de humedad agrava las enfermedades que afectan al corazón y al sistema circulatorio.

c) Ventilación y pureza del aire: La ventilación se realiza, normalmente, abriendo las ventanas y la puerta durante cortos espacios de tiempo. Para renovar el aire de la habitación es suficiente con abrir la ventana durante 10-15 minutos. Siempre que sea posible, se lleva a cabo durante los procedimientos de cambio de ropa de cama y limpieza de la habitación. Para ventilar la habitación se evitarán las corrientes de aire, es recomendable el empleo de biombos para evitar que el aire llegue de forma directa al paciente. En los hospitales modernos, con circuito cerrado de aire acondicionado o sistemas de climatización, no deben abrirse las ventanas de las habitaciones para ventilar, pues el aire está en constante renovación y, si se abriera la ventana, se producirían descompensaciones en el circuito del aire. Las impurezas habituales que se encuentran en el aire son gases, partículas de polvo y microorganismos. Las enfermedades respiratorias pueden diseminarse mediante estas impurezas al estornudar, hablar o toser. En las habitaciones debe protegerse a los pacientes contra las infecciones aplicando técnicas de aislamiento, liberación del polvo, buena ventilación y amplio espacio entre las camas.

Las condiciones de iluminación repercuten de manera directa en el bienestar y en la evolución de la enfermedad del paciente. La iluminación en los centros sanitarios puede ser de dos tipos:

a) Luz natural: Es la producida por los rayos solares; por sus propiedades curativas, desinfectantes, térmicas, etc., es la más indicada para el cuidado y la recuperación de los enfermos. Algunos especialistas opinan que una habitación está bien iluminada si tiene un espacio de ventanas igual, en superficie, a casi la cuarta parte del suelo. Además, la luz directa del sol es eficaz para aumentar la resistencia a las enfermedades. Se ha demostrado su valor terapéutico, especialmente para reducir la susceptibilidad a enfermedades como el raquitismo y la tuberculosis. Además de su importancia como factor esencial de salud, la luz solar aporta iluminación natural a las habitaciones, que influye positivamente en el estado de ánimo de los pacientes.

b) Luz artificial: Está diseñada de forma que pueda ser utilizada según las necesidades. Puede adaptarse para que proporcione luz indirecta, como luz de foco directo para el examen del paciente, luz para leer o luz de menor intensidad.

La habitación debe disponer de un sistema eléctrico de comunicación con el control de enfermería, colocado en la cabecera de la cama y que, normalmente, lleva un piloto para que sea visible en la oscuridad. Cuando el paciente lo activa, se enciende una luz o un sonido en el control de enfermería, que se identifica como una llamada en demanda de ayuda.

Las condiciones de insonorización también revisten gran importancia. Los investigadores han demostrado que el ruido ambiental, expresado en decibelios, produce fatiga física y trastornos nerviosos o emocionales (contaminación sonora). El ruido que se genera en el entorno hospitalario puede provenir del exterior o del interior: 
a) Ruido exterior: Se produce, generalmente, como consecuencia de las actividades de la calle que, además, pueden llevar asociada la producción de vibraciones. Estos ruidos pueden paliarse mediante sistemas de aislamiento colocados en las ventanas, con el fin de disminuir la influencia de estos factores sobre el estado emocional del paciente.

b) Ruido interior: Se produce como consecuencia del tránsito de personas en los pasillos y de la actividad laboral del propio centro sanitario. Para evitar la producción de ruidos es importante que el personal sanitario cumpla y haga cumplir las siguientes normas:

1. Respetar los carteles de recomendación de «Silencio».

2. Hablar en tono moderado y evitar risas llamativas y escandalosas.

3. Moderar el volumen de la televisión y la radio de las habitaciones.

4. Controlar la utilización de los teléfonos móviles.

5. Abrir y cerrar las puertas con cuidado, evitando golpes.

6. Desplazar el mobiliario suavemente y sin arrastrarlo.

7. Utilizar calzado de suela flexible o de goma para evitar desplazamientos ruidosos.

8. Realizar el transporte de las camas, sillas de ruedas, carros, pies de gotero, etc., con cuidado, evitando golpear las paredes, los muebles o las puertas.

Para favorecer la comodidad del paciente, además de las condiciones atmosféricas de iluminación y de insonorización, hay que tener en cuenta la importancia que tiene el mantener la unidad de hospitalización en condiciones óptimas de limpieza e higiene.

Las condiciones de higiene y limpieza repercuten seriamente en la evolución del paciente. La acumulación de eliminaciones del paciente (orina, vómitos, exudados, heces, etc.) en un ambiente semicerrado o cerrado da lugar a que se produzcan olores desagradables, que repercuten en el propio paciente, en el personal sanitario, en otros pacientes y en las visitas.

Todo ello hace que el entorno resulte incómodo y, desde el punto de vista sanitario, crea una posible e importante fuente de infección, que hace necesaria la limpieza y eliminación de la suciedad para evitar el riesgo de que se produzcan infecciones hospitalarias.

Si el personal de enfermería considera que la habitación del paciente no reúne las condiciones de higiene adecuadas avisará al personal de limpieza, para que friegue el suelo y limpie los muebles y así evitar la diseminación de microorganismos.

Cuando se da de alta al paciente, debe realizarse una limpieza más exhaustiva de la unidad, y de todo el material que tenga que ser utilizado; y es necesario desinfectarlo y esterilizarlo. Al realizar la limpieza de la habitación, hay que tener en cuenta lo siguiente:

a) Debe hacerse diariamente y siempre que sea necesario.

b) Hay que preparar con antelación todo el material necesario. 
c) Siempre que sea posible, se debe realizar con las ventanas abiertas, pero hay que evitar las corrientes de aire.

d) No olvidar que uno de los mejores desinfectantes es la lejía, aunque, actualmente, existen compuestos comerciales preparados que no necesitan aclarado y son muy potentes contra la proliferación de microorganismos.

\section{Promoción de la comodidad}

El dolor es una de las principales causas de incomodidad y, a su vez, la incomodidad genera malestar en los pacientes, disminuyendo su confort. Existen diferentes intervenciones destinadas a disminución del dolor y/o promoción de la comodidad, que podemos agrupar en administración de analgésicos, apoyo emocional, medidas de comodidad y métodos no farmacológicos.

Los métodos no farmacológicos pueden disminuir los componentes emocionales que arrastran tanto la incomodidad como el dolor, fortaleciendo la capacidad de afrontamiento, brindar al paciente el sentido de control, contribuir al alivio del dolor, disminuir la fatiga y favorecer el sueño.

La aplicación de los métodos no farmacológicos enumerados a continuación debe valorarse individualmente en cada paciente, sin considerar el orden propuesto como un orden de prioridad en su selección. No todos los métodos expuestos a continuación son apropiados para todos los pacientes.

En primer lugar, es necesario revisar la historia del paciente y el plan de atención de enfermería, en busca de información sobre su estado y las contraindicaciones a la hora de seleccionar el método más indicado. Se debe preguntar al paciente acerca de si sufre alergias o intolerancias conocidas, valorar el nivel de comodidad y el dolor utilizando una herramienta de valoración apropiada, identificar las características del dolor y síntoma relacionados (cefalea o inquietud), preguntar al paciente cuáles son las intervenciones que han tenido éxito o no en el pasado para favorecer su comodidad, valorar signos vitales y verificar los registros de administración de medicamentos para conocer la hora en que se suministró el último analgésico. Por último, es fundamental valorar las creencias culturales relacionadas con el dolor y la respuesta del paciente a intervenciones particulares, para valorar la eficacia y la presencia de efectos adversos.

El resultado esperado se logra cuando el paciente experimenta alivio de sus molestias sin efectos adversos. Otros resultados apropiados incluyen disminución de la ansiedad y mejor relajación; aumento de la capacidad para participar en actividades cotidianas o expresar comprensión y satisfacción con el plan terapéutico.

Como ya se ha mencionado, este procedimiento no tiene un plan secuencial, sino que se valorará e intervendrá según la evolución y la aportación específica de cada paciente. Así, podemos distinguir: 
1. Ajustar el entorno del paciente para favorecer la comodidad:

a) Ajustar la temperatura de la habitación con base en las preferencias del paciente.

b) Reducir la intensidad de la luz, pero se permite que exista luz adecuada de acuerdo con las preferencias del paciente.

c) Reducir el ruido innecesario. Se evitan las conversaciones cerca de la habitación del paciente.

d) Cerrar las cortinas o la puerta de la habitación, siempre que sea posible.

2. Evitar interrupciones innecesarias de los periodos de descanso coordinando las actividades a realizar en el paciente para realizarlas en conjunto.

3. Ayudar al paciente a cambiar de posición con frecuencia; a mantenerse en posición cómoda, con buena alineación corporal y soporte para las extremidades. Se eleva la cabecera de la cama según sea apropiado.

4. Proporcionar higiene bucal según sea necesario para mantener la boca y las mucosas limpias y húmedas, con frecuencia de cada una a dos horas. Esto es de especial importancia en pacientes que no pueden beber líquidos y que no tienen permitido el consumo de líquidos por vía oral.

5. Asegurar la disponibilidad de líquidos apropiados para beber, a menos que esté contraindicado. Se asegura que el paciente cuente con agua a su alcance.

6. Eliminar situaciones físicas que pueden causar incomodidad:

a) Cambio de apósitos y ropa de cama sucia o húmeda.

b) Eliminar arrugas en la ropa de la cama.

c) Asegurar que el paciente no se apoye en sondas, tubos, alambres o cualquier otro equipo.

7. Ayudar en deambulación y la movilidad con el arco de movimientos activos o pasivos, según sea apropiado.

8. Valorar necesidades espirituales del paciente relacionadas con la experiencia dolorosa. Se puede preguntar si desea la visita de algún consejero espiritual.

9. Considerar el uso de la distracción ofreciendo libros, televisión, música, vídeos o cualquier otro objeto/actividad de interés para el paciente de acuerdo con la edad.

10. Considerar el uso de la imaginación guiada:

a) Se ayuda al paciente a identificar una escena o experiencia que este describa como feliz, placentera o tranquilizadora.

b) Se pide al paciente que inicie con varios minutos de respiración dirigida, relajación o meditación.

c) Se ayuda al paciente a concentrarse en una imagen tranquilizadora, placentera.

d) Si está indicado, se lee una descripción de la escena identificada o de la experiencia, utilizando una voz suave y tranquilizadora.

e) Se pide al paciente que se concentre en los detalles de la imagen, como intensidad, sonidos, olores, sabores, tacto.

11. Considerar el uso de actividades de relajación, como la relajación muscular progresiva:

a) Se pide al paciente que adquiera una posición cómoda.

b) Se pide al paciente que dirija su atención a un grupo muscular en particular. Se inicia con los músculos de la mandíbula y después se continúa con los del cuello, hombros, porción proximal y distal de los brazos, manos, abdomen, nalgas, muslos, piernas y pies. 
c) Se pide al paciente que contraiga un grupo muscular y observe la sensación que producen los músculos contraídos. Después de cinco a siete segundos se le pide que los relaje a la vez y se concentre en el estado de relajación, observando la diferencia en la sensación en los músculos cuando están contraídos y relajados.

d) Se pide al paciente que continúe contrayendo y relajando cada grupo muscular hasta que se abarque la totalidad del cuerpo.

e) Se pide al paciente que practique al menos dos veces al día unos diez minutos y después lo utilice como tratamiento según sea necesario.

Otro procedimiento que también podemos emplear es la técnica del masaje. El masaje tiene muchos beneficios, lo que incluye relajación general e incremento de la circulación. Un masaje en la espalda puede incorporarse en el baño del paciente, como parte de los cuidados antes de ir a la cama por la noche o en cualquier momento para favorecer su comodidad. Algunos enfermeros no brindan masajes a los pacientes porque piensan que no tienen tiempo suficiente.

Sin embargo, proporcionar un masaje en la espalda da la oportunidad para que el enfermero observe la piel en busca de signos de maceración. Mejora la circulación, disminuye el dolor, los síntomas de angustia y ansiedad, mejora la calidad del sueño y también proporciona un mecanismo de comunicación con el paciente a través del tacto.

Algunos pacientes consideran dicho masaje como un lujo y pueden estar reticentes a aceptarlo, por lo que debe comunicarse la importancia y utilidad del procedimiento. Un masaje en la espalda eficaz debe durar de cuatro a seis minutos. Por lo general se utiliza crema; debe calentarse antes de aplicarla. El enfermero debe conocer el diagnóstico médico del paciente cuando se considere proporcionar un masaje. Tales masajes están contraindicados, por ejemplo, cuando el paciente se sometió a cirugía de la espalda o tiene fracturas costales. El paciente se coloca en decúbito prono o, si esto está contraindicado, en decúbito lateral.

Hay que recordar que, para comodidad y protección del propio enfermero, se debe elevar la cama a una altura de trabajo cómoda, por lo común a la altura de los codos del cuidador y se baja una barandilla lateral. Durante el masaje se va variando la presión ejercida para favorecer la circulación y la relajación.

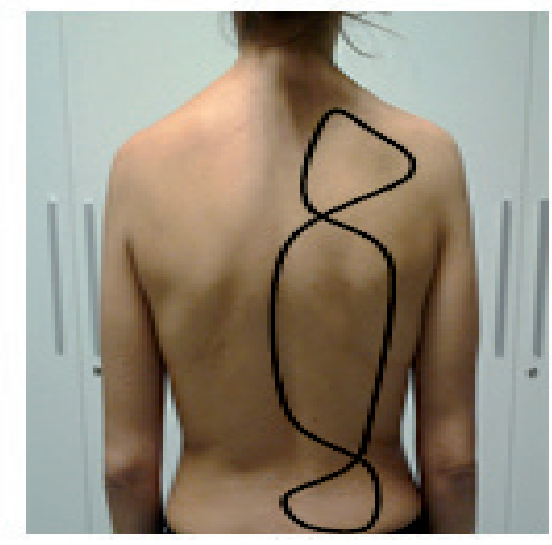

Figura 22. Dirección del masaje. Fuente: Elaboración propia 
En nuestro país, concretamente elaborados por el Servicio Andaluz de Salud de la Junta de Andalucía, existen protocolos dirigidos exclusivamente hacia el manejo ambiental de la situación del paciente, con el fin de obtener mayor confort y seguridad. A continuación se exponen dichos protocolos para mayor comprensión:

1. Manejo ambiental. Confort: consiste en la manipulación del entorno físico del paciente para crearle un ambiente seguro:

a) Identificar las necesidades de seguridad del paciente, según la función física, cognoscitiva y el historial de conducta.

b) Eliminar factores ambientales de peligro (alfombras o mantas flojas muebles u objetos peligrosos).

c) Colocar los objetos de uso frecuente al alcance del paciente.

d) Acompañar al paciente en las actividades realizadas fuera de la sala, si procede.

e) Disponer de camas limpias y cómodas, con un colchón adaptado a las necesidades del paciente y de altura regulable.

f) Disponer medidas de seguridad mediante barandillas laterales o el acolchamiento de barandillas, si procede.

g) Colocar el interruptor de posición de la cama al alcance del paciente.

h) Disponer de dispositivos de adaptación (banco de escalera o barandillas), si procede.

i) Colocar los muebles en la habitación de manera que se acomode mejor a las discapacidades del paciente o de la familia.

j) Facilitar una sonda suficientemente larga que permita libertad de movimientos, si procede.

k) Proporcionar una habitación individual, si está indicado.

l) Controlar los estímulos ambientales como temperatura, corrientes, iluminación o ruidos, si procede.

$m$ ) Individualizar las restricciones de visitas para que se adapten a las necesidades del paciente o de la familia o ser querido.

n) Individualizar la rutina diaria de forma que se adapte a las necesidades del paciente.

o) Traer objetos del hogar que le resulten familiares al paciente.

p) Mantener una coherencia en cuanto a la asignación de personal con el tiempo.

q) Valorar el riesgo de caídas.

r) Establecer medios inmediatos y continuos de llamada a los cuidadores y permitir que el paciente y la familia sepan que se les responderá inmediatamente.

s) Permitir que la familia o ser querido se queden con el paciente.

t) Educar al paciente y a la familia acerca de los cambios y precauciones, de forma que no interrumpan inadvertidamente el ambiente planificado.

u) Proporcionar a la familia información sobre la composición de un ambiente hogareño seguro para el paciente.

v) Proporcionar ambientadores, si es necesario.

2. Manejo ambiental. Seguridad: consiste en vigilar y actuar sobre el ambiente físico para fomentar la seguridad del paciente. 
a) Todo paciente con más de 65 años debe tener hecha la escala de riesgo de caídas múltiples, para validar el riesgo de caídas

b) Determinar las necesidades de seguridad, según la dependencia del paciente tanto física como psíquica, y el historial de conductas al respecto.

c) Identificar los riesgos: se actuará según el mapa de riesgos de la unidad.

d) Identificar los factores que puedan mejorar la motivación de la conducta.

e) Todo paciente con riesgo de caídas o de lesión debe de tener vigilancia de seguridad y pautado el grado de vigilancia.

f) Determinar el contexto sociocultural de la conducta sanitaria.

g) Determinar el conocimiento actual y las conductas de estilo de vida.

h) Modificar el ambiente para reducir riesgos: colocar el sillón del lado de levantarse, evitar ducharse solo si tiene riesgo de caídas, etc.

i) Disponer de dispositivos de adaptación: barandillas, colchón, etc.

j) Utilizar dispositivos de protección para limitar la movilidad si procede.

k) Educación al paciente/cuidadora del alto riesgo y el manejo.

Ambos protocolos son complementarios, además, teniendo en cuenta la exposición de mejora de confort en los pacientes expuesto al principio del punto, podemos determinar un protocolo que fomente la seguridad y el confort de forma completa a cualquier paciente.

\section{Asepsia, infección nosocomial y manejo de la infección}

Los profesionales de enfermería y otros trabajadores de la salud desempeñan un papel clave para reducir la propagación de la enfermedad, minimizar las complicaciones y disminuir los resultados adversos para sus pacientes. Al limitar la diseminación de microorganismos se logra romper la cadena de trasmisión-infección. La práctica de la asepsia incluye todas las actividades para prevenir la infección o romper la cadena de infección. La asepsia médica o técnica de limpieza consiste en procedimientos y prácticas que reducen el número y la transferencia de agentes patógenos. La asepsia quirúrgica, o técnica estéril, incluye prácticas que sirven para contar con objetos y zonas libres de microorganismos y mantenerlos de igual modo.

A continuación se revisan los procedimientos que ayudan a prevenir la propagación de la infección, incluyendo la higiene de manos y la técnica de esterilización. La higiene de manos constituye la forma más eficaz para ayudar a prevenir la diseminación de microorganismos. Está demostrado que una mejora en el cumplimiento de la higiene de las manos reduce las tasas globales de infección en los centros sanitarios (CDC, 2002).

Las precauciones básicas y las precauciones para evitar la transmisión son otra parte importante de la protección de los pacientes y de los profesionales de la salud, para prevenir que la infección se propague. 


\section{Limpieza}

La limpieza se define como el proceso de separación, por medios mecánicos y/o físicos, de la suciedad depositada en las superficies inertes, que constituyen un soporte físico y nutritivo del microorganismo en el que el mismo puede desarrollarse con capacidades reproductivas.

El objetivo de la limpieza es la eliminación física de materia orgánica y de los microorganismos existentes en el medio hospitalario, para evitar posteriores contaminaciones, aunque la misma no asegura la destrucción de los mismos. Además de esto, la limpieza evita las incrustaciones en el material, de modo que evita que este se estropee.

El agente básico de la limpieza es el detergente. Los detergentes son sustancias producidas por células vivas, todos estos productos contienen necesariamente en su formulación tensoactivos (catalizadores), que tienen el poder de acelerar reacciones químicas en bajas concentraciones, cuya finalidad es limpiar por medio de la tensión superficial del agua, así como de dispersión y suspensión de suciedad. Están compuestos por enzimas, surfactantes y solubles. Su uso está indicado en periodos cortos como de 1 a 15 minutos, y son clasificados dependiendo del tipo de substrato que se quiere afectar. Según las recomendaciones internacionales, la elección debe darse en los detergentes enzimáticos neutros, que evitan el daño y la corrosión.

Cronológicamente, la limpieza es un paso previo a la desinfección y esterilización, por lo que constituye un factor de importancia prioritaria. Por lo tanto, la limpieza debe ser realizada en todo material médico hospitalario contaminado, precediendo al proceso de desinfección o esterilización.

La limpieza generalmente comprende:

a) Una acción mecánica: como frotar, cepillar, lavar con agua bajo presión o uso de aire comprimido.

b) Una acción química: detergente, detergente enzimático y agua que son usados para inhibir y eliminar a los microbios, residuo orgánico y el polvo.

c) El calor (agua caliente) mejora las propiedades de disolución del agua, el detergente y las enzimas.

\section{Desinfección}

La desinfección es un proceso por el cual se destruye la mayoría de los microorganismos patógenos ubicados sobre un objeto inanimado, pero este proceso no asegura la total destrucción de los microorganismos, como las esporas. Sobre esta definición podemos diferenciar dos conceptos:

a) Antisepsia: básicamente el proceso de antisepsia es el mismo que el de desinfección, la gran diferencia entre ambos conceptos deriva de la superficie 
sobre la que se aplica. En la desinfección, el desinfectante a utilizar se distribuye sobre zonas u objetos inanimados, mientras que en la antisepsia se aplica sobre superficies animadas (como, por ejemplo, la piel de una persona).

b) Esterilización: en el proceso de esterilización se destruyen todas las formas de microorganismos existentes sobre un material, así como sus formas de resistencia (sus esporas). Por lo tanto, un objeto desinfectado nunca podrá considerarse estéril.

Existen diferentes métodos de antisepsia, dependiendo de que su mecanismo de acción sea físico o químico (figura 23). Tal vez el método más habitual de antisepsia sea el uso de antisépticos químicos (tabla 11).

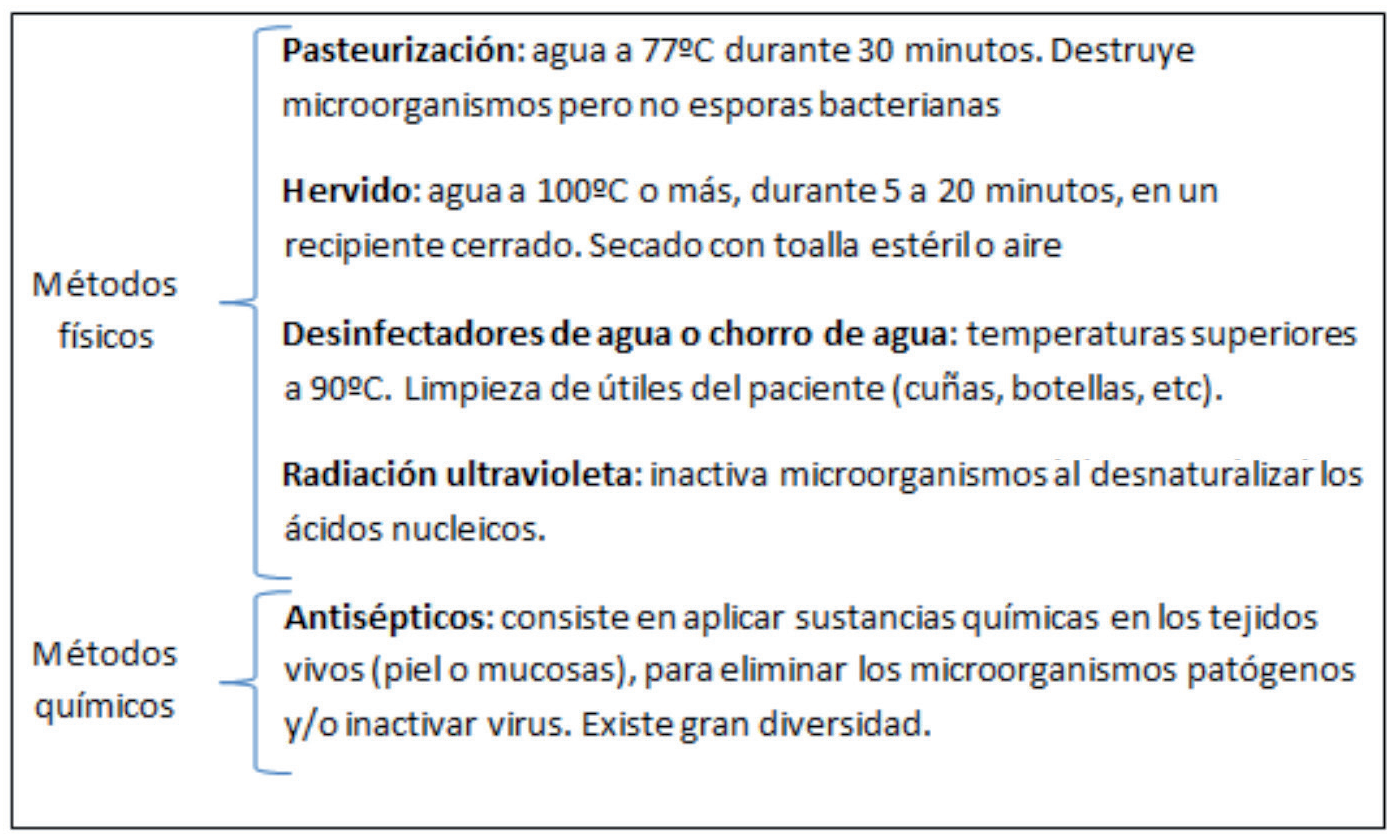

Figura 23. Métodos de antisepsia. Fuente: Elaboración propia 


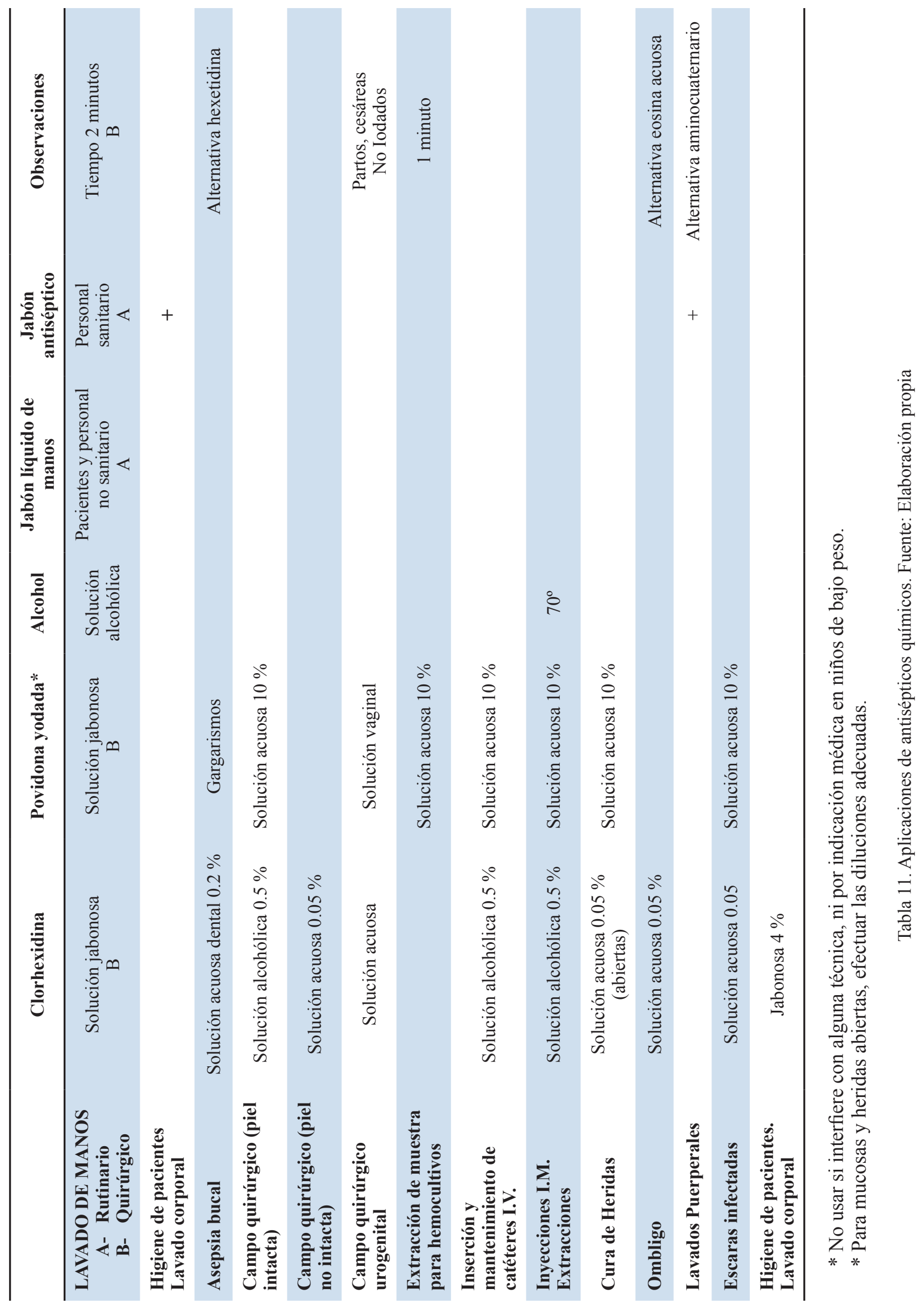




\subsection{Esterilización}

Una vez se haya visto que los materiales que nos han llegado al servicio de esterilización están en óptimas condiciones, podemos proceder al empaquetamiento de los mismos. El empaquetar cada artículo tiene como finalidad permitir la esterilización del material, asegurar la esterilización antes y en el momento de uso y además favorecer la transferencia del contenido con técnica aséptica. Los paquetes seleccionados para introducir el material en ellos y posteriormente esterilizarlos deben:

a) Ser compatible con el método de esterilización y resistir las condiciones físicas.

b) Permitir la penetración y remoción del agente esterilizante.

c) Mantener la integridad del paquete.

d) Resistir la humedad o roturas.

e) Ser flexible, facilitando su manipulación.

f) Proteger el contenido del paquete contra daños físicos.

g) Ser libre de residuos tóxicos como colorante o almidón.

h) Evitar la liberación de fibras o partículas.

i) Ser barrera microbiana.

j) Ser compatible con las dimensiones, peso y configuración del artículo.

Todo paquete debe quedar sellado, ser hermético y disponer en una zona visible tanto la fecha de esterilización como la fecha de caducidad o vida de anaquel. La vida de anaquel se define como el tiempo durante el cual un paquete estéril se mantiene como tal, cuando está almacenado. Esta vida depende de muchos factores (figura 24):

a) Tipo y espesor del material de empaque: los paquetes que ofrecen mayor resistencia a la contaminación son los de plástico sellado al calor y los de plástico y papel.

b) Manipulación excesiva.

c) Condiciones ambientales: temperaturas excesivas pueden originar transpiración y la humedad puede conducir bacterias.

d) El cierre del paquete: estos deben estar sellados.

e) Los paquetes están comercialmente preparados y esterilizados pueden considerarse estériles, hasta la fecha de vencimiento impresa en el paquete.

f) El sistema de almacenamiento determina la vida de anaquel.

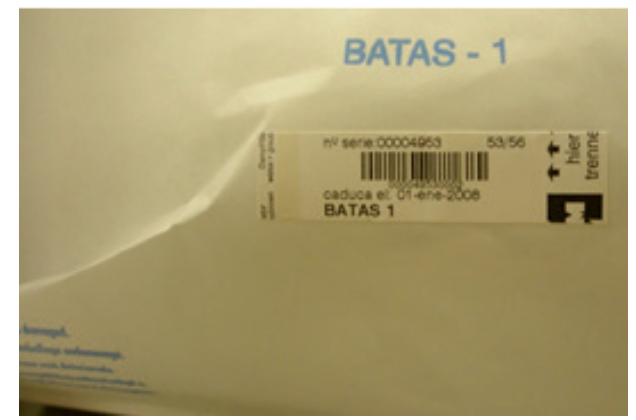

Figura 24. Paquete de esterilización. Fuente: Elaboración propia 


\subsubsection{Controles físicos, químicos y biológicos}

En estos momentos disponemos de un paquete, el cual está a punto de ser esterilizado. Para poder asegurarnos que nuestro proceso de esterilización es correcto se hace uso de los controles físicos, químicos y biológicos.

a) Controles físicos: elementos incorporados en el aparato esterilizador, como termómetros, manómetros de presión, sensores de carga, válvulas o sistemas de registro que permiten visualizar si el equipo ha alcanzado los parámetros exigidos para el proceso. Deben ser calibrados periódicamente para garantizar la información que proporcionan.

b) Controles químicos: existen de diversos tipos:

a. Cinta de Minnesota: Cinta adhesiva impregnada con tinta termoquímica, que cambia de color cuando es expuesta a temperatura. Su finalidad de uso es demostrar que el artículo fue expuesto al proceso de esterilización y distinguir entre artículos procesados y no procesados.

b. Test de Bowie Dick: Es un método para evaluar la eficacia del sistema de vacío del autoclave de prevacío, cuya finalidad consiste en demostrar la ausencia de aire u otros gases no condensados en la cámara de esterilización, que puedan impedir la rápida y uniforme penetración del vapor en el interior de la carga. En una prueba correcta, el indicador habrá virado hacia un tono negro de manera uniforme y en toda su extensión. Una prueba incorrecta se manifiesta por un color más tenue que el indicado por el fabricante o por la aparición de manchas o zonas de distinto color o densidad.

c. Control multiparamétrico: Consiste en una tira de papel impregnado con tinta termocrómica, que cambia de color cuando ha sido expuesta a las condiciones mínimas (tiempo, temperatura) necesarias del método. Este tipo de indicador se introduce dentro de las cajas a esterilizar, para proporcionarnos información sobre si la temperatura que se ha llegado a alcanzar dentro de la misma es la correcta y necesaria para el ciclo de esterilización.

c) Controles biológicos: son dispositivos inoculados con esporas de microorganismos caracterizados por su alta resistencia. Generalmente se utilizan las del bacilo Subtilis y bacilo Stearothermophilus, debido a que son los que más alta resistencia se les conoce. Los controles biológicos son en la actualidad el mejor medio disponible para confirmar la esterilización de un artículo o para determinar la eficiencia de un proceso de esterilización. Están diseñados para confirmar la presencia o ausencia de microorganismos viables después del proceso de esterilización.

\subsubsection{Servicio de esterilización}

La función del servicio de esterilización es proporcionar a todos los servicios del hospital el material esterilizado en óptimas condiciones para ser utilizado. El funcionamiento de este servicio puede considerarse en forma centralizada o descentralizada, según el criterio que exista en cada institución. 
El área de esterilización consta de tres zonas perfectamente definidas y en donde se realizan actividades específicas (figura 25).



Figura 25. Modelo de servicio de esterilización. Fuente: Elaboración propia

\subsection{Precauciones y medidas para la prevención de infecciones en la atención sanitaria}

El proceso de esterilización del material se lleva a cabo en servicios específicos y es fundamental para la prevención de infecciones, pero también es necesario que los profesionales de enfermería, y el resto del equipo asistencial, apliquen una serie de medidas generales de prevención y detección precoz de la infección, con el objetivo de minimizar el riesgo de desarrollar una infección nosocomial y educar al paciente y familia en las medidas de prevención de la infección. En la figura 26 se observan las medidas generales propuestas por la Conselleria de Salut de la Generalitat Valenciana.

Por otra parte, las medidas para la prevención de infecciones pueden clasificarse en tres niveles. El primer nivel hace referencia a las precauciones estándar relacionadas con el lavado de manos, la gestión de residuos y el uso de equipos de protección personal (guantes, bata, etc.). En el segundo nivel se encuentran las medidas de precaución según el tipo de transmisión (aislamiento), y en el tercer nivel encontramos medidas relacionadas con la educación de pacientes y familiares. 


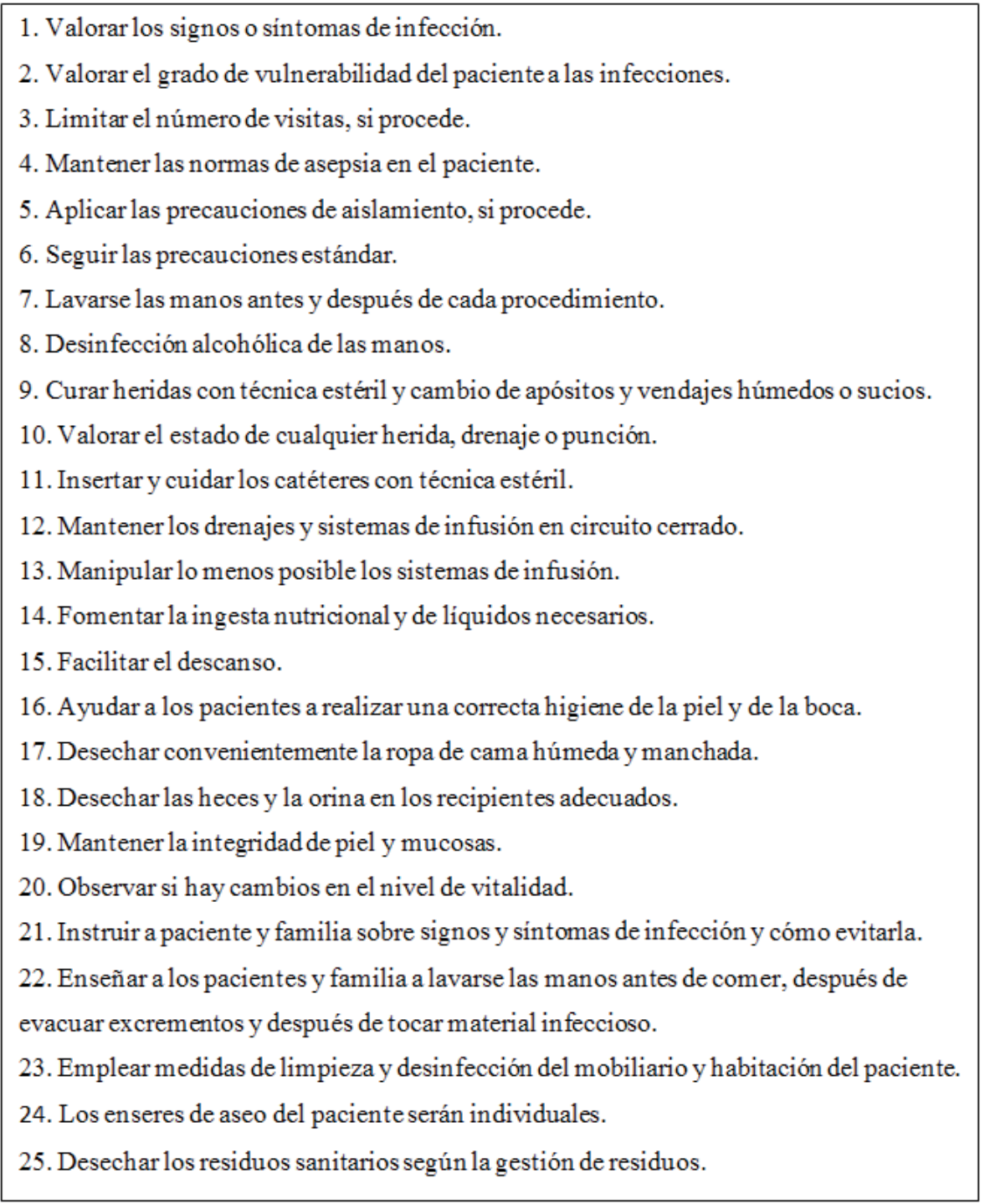

Figura 26. Medidas generales para la prevención de infecciones de la Generalitat Valenciana. Fuente: Conselleria de Sanitat, Generalitat Valenciana, 2007

\subsubsection{Precauciones estándar}

Estas precauciones de primer nivel se definen como las medidas a adoptar por el personal sanitario ante cualquier paciente hospitalizado, independientemente de la patología que padezca, siempre que vaya a entrar en contacto con sangre o fluidos corporales, excepto el sudor, piel no intacta y membranas mucosas; con el fin de prevenir la transmisión de patógenos que se vehiculizan a través de la sangre o fluidos corporales, piel no intacta y membranas mucosas mediante la interposición de barreras adecuadas. Entre estas precauciones estándar encontramos:

1. Informar a paciente y familia de las medidas adoptadas y su fundamento.

2. Usar guantes si hay riesgo de contacto con mucosas o fluidos corporales.

3. No circular con guantes. Retirarlos tras el contacto con un paciente. 
4. Lavarse las manos antes y después de la asistencia al paciente y al ponerse o quitarse los guantes. Usar guantes no exime de la necesidad de descontaminación de las manos.

5. Usar mascarilla, gafas y bata siempre que exista riesgo de salpicadura y cambiar inmediatamente si se manchan.

6. En caso de salpicadura de sangre o fluidos en mucosas, lavar abundantemente con suero salino (o agua y jabón) y aplicar antiséptico. Si la salpicadura se produce en los ojos, aplicar un colirio antiséptico.

7. No manipular agujas ni material cortante o punzante tras su utilización. Hay que depositarlo en los contenedores para material de riesgo biológico.

8. Las muestras de laboratorio de sangre o líquidos corporales deben remitirse al laboratorio en recipientes cerrados.

9. Si existe derramamiento de sangre o líquidos corporales sobre la piel del personal (intacta o no): lavar inmediatamente con agua y jabón y usar antiséptico (clorhexidina y solución yodada).

10. La eliminación de los residuos hospitalarios se hará de acuerdo a la política de gestión de residuos con riesgo biológico.

A continuación se exponen el lavado de manos, como medida de primer nivel, y el aislamiento como medida de segundo nivel, debido a su relevancia y frecuencia de uso.

\subsection{Lavado de manos: tipos y procedimientos}

Las manos son la principal fuente de transmisión de microorganismos. Por tanto, la higiene de las manos es la medida más importante de eficacia probada para evitar la trasmisión de enfermedades infecciosas. De acuerdo con la OMS, existen cinco momentos para la higiene de las manos para los profesionales sanitarios (figura 27):

a) Antes del contacto con cada paciente.

b) Antes de realizar una tarea limpia/aséptica

c) Después del riesgo de exposición a líquidos corporales.

d) Después de tocar al paciente.

e) Después del contacto con el entorno del paciente.

Además hay que tener en cuenta que el uso de guantes no elimina la necesidad de efectuar la higiene de manos, ni viceversa. Tampoco es conveniente llevar uñas naturales que excedan de los $5 \mathrm{~mm}$ o uñas artificiales al tener contacto directo con el paciente. También se recomiendan las lociones o cremas para manos, a fin de hidratar y proteger la piel de la aparición de dermatitis irritante relacionada con la higiene de las manos. Existen varios tipos de lavado de manos. 


\section{Sus 5 Momentos}

\section{para la Higiene de las Manos}

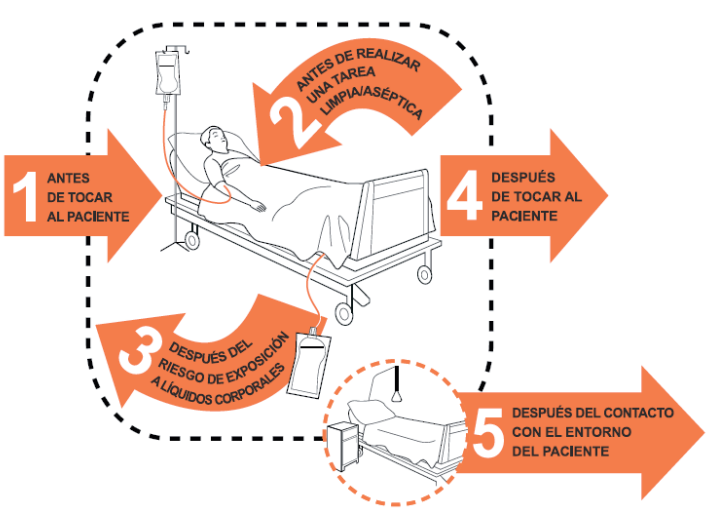

Figura 27. Momentos para la higiene de manos según la OMS. Fuente: oMS

\subsubsection{Lavado de manos higiénico}

El lavado de las manos con agua y jabón sigue siendo el mejor método para su descontaminación y es necesario realizarlo antes de aplicar soluciones hidroalcohólicas, si las manos están sucias y después de usar el inodoro.

Este procedimiento es una medida higiénica que persigue eliminar el mayor número posible de microorganismos patógenos de las manos, mediante la técnica de lavado de manos con agua, jabón y antiséptico; con el fin de prevenir la propagación y transmisión de microorganismos patógenos, disminuir la flora bacteriana de las manos antes de un procedimiento y disminuir la prevalencia de la infección nosocomial en los centros sanitarios. En la figura 28 se observa el procedimiento descrito por la oms (figura 28). 


\section{¿Cómo lavarse las manos?}

¡Lávese las manos solo cuando estén visiblemente sucias! Si no, utilice la solución alcohólica

(1) Duración de todo el procedimiento: 40-60 segundos

0

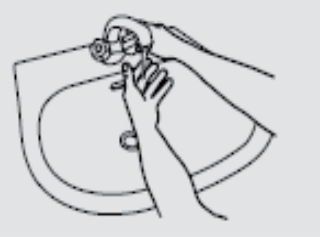

Mójese las manos con agua;
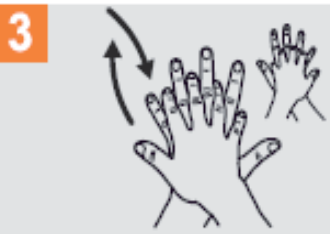

Frótese la palma de la mano derecha contra el dorso de la mano izquierda entrelazando los dedos y viceversa;

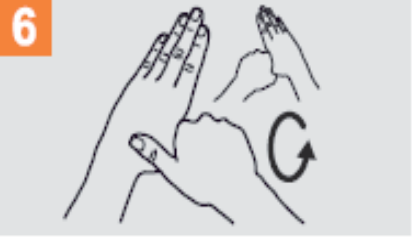

Frótese con un movimiento de rotación el pulgar izquierdo, atrapándolo con la palma de la mano derecha y viceversa;


Séquese con una toalla desechable;
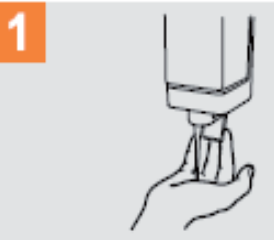

Deposite en la palma de la mano una cantidad de jabón suficiente para cubrir todas las superficies de las manos;



Frótese las palmas de las manos entre si, con los dedos entrelazados;

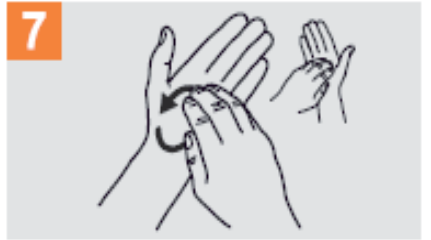

Frótese la punta de los dedos de la mano derecha contra la palma de la mano izquierda, haciendo un movimiento de rotación y viceversa;


Sírvase de la toalla para cerrar el grifo;



Frótese las palmas de las manos entre si;

5

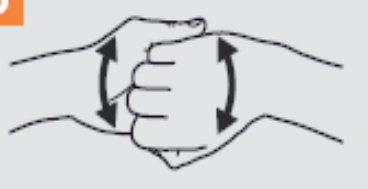

Frótese el dorso de los dedos de una mano con la palma de la mano opuesta, agarrándose los dedos;

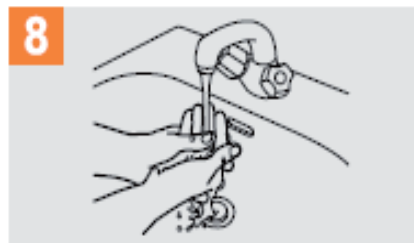

Enjuáguese las manos con agua;
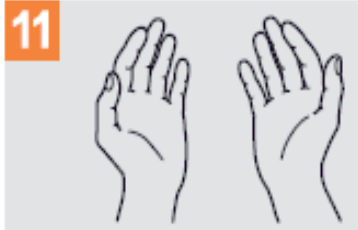

Sus manos son seguras,

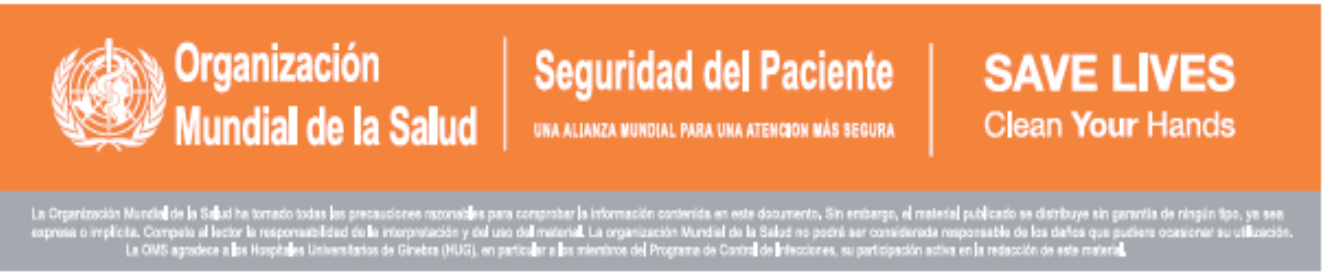

Figura 28. Cartel de lavado de manos de la oms. Fuente: oms 


\subsubsection{Lavado de manos con solución alcohólica}

El lavado de manos con soluciones alcohólicas es el medio habitual preferente para desinfectar las manos, cuando estas no están visiblemente sucias. Es más rápido, más eficaz y mejor tolerado por las manos que lavarlas con agua y jabón (figura 29).

\section{¿Cómo desinfectarse las manos?}

¡Desinféctese las manos por higiene! Lávese las manos solo cuando estén visiblemente sucias

(1) Duración de todo el procedimiento: $20-30$ segundos

1 a

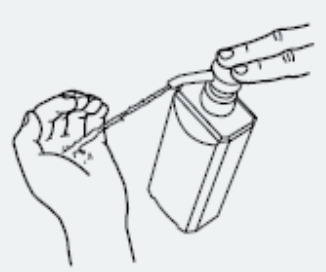

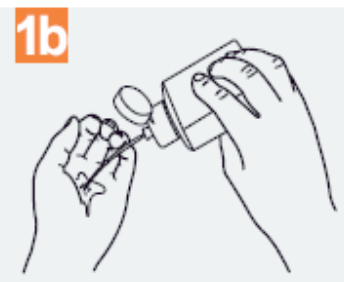

Deposite en la palma de la mano una dosis de producto suficiente para cubrir todas las superficies;

3

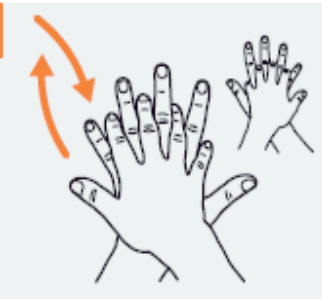

Frótese la palma de la mano derecha contra el dorso de la mano izquierda entrelazando los dedos y viceversa;

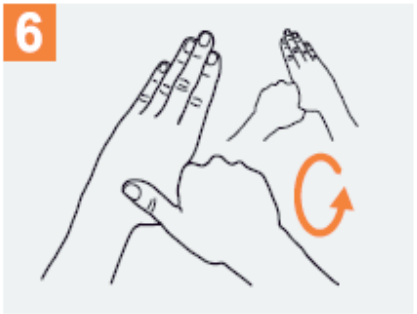

Frótese con un movimiento de rotación el pulgar izquierdo, atrapándolo con la palma de la mano derecha y viceversa;

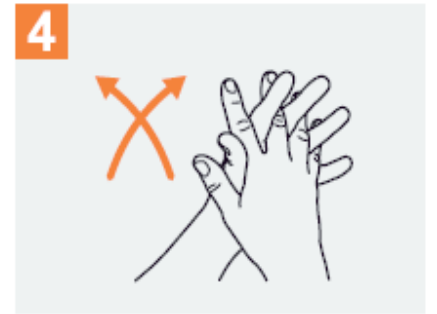

Frótese las palmas de las manos entre sí, con los dedos entrelazados;

\section{7}

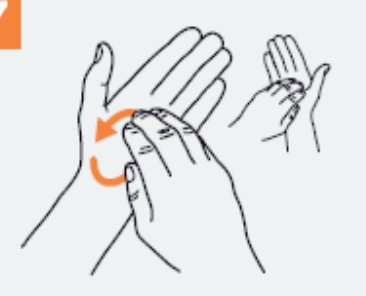

Frótese la punta de los dedos de la mano derecha contra la palma de la mano izquierda, haciendo un movimiento de rotación y viceversa;
2

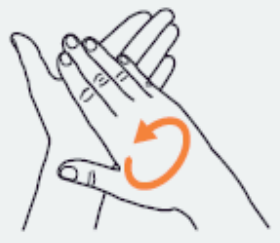

Frótese las palmas de las manos entre si;

5

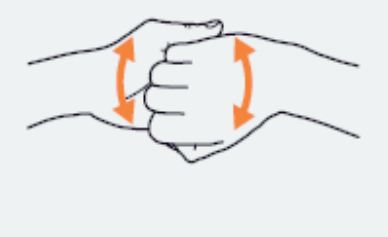

Frótese el dorso de los dedos de una mano con la palma de la mano opuesta, agarrándose los dedos;

8

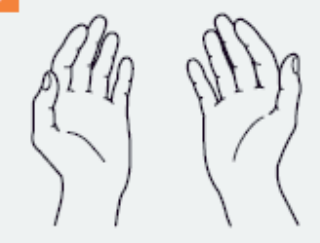

Una vez secas, sus manos son seguras.

Figura 29. Cartel sobre el uso de solución alcohólica de la oms. Fuente: OMS

La mayoría de antisépticos de manos en base alcohólica contienen isopropanol. La actividad antimicrobiana de los alcoholes se atribuye a su capacidad de desnaturalizar las proteínas. Soluciones de alcohol con concentraciones del $60 \%$ al $95 \%$ 
son las más eficaces y concentraciones más altas son menos potentes, porque las proteínas no se desnaturalizan fácilmente en ausencia de agua. Los alcoholes tienen excelente actividad germicida in vitro contra bacterias gram-positivas y gramnegativas, incluyendo patógenos multiresistentes, Mycobacterium tuberculosis, y varios hongos.

Ciertos virus con envoltura son sensibles a los alcoholes (VIH, Herpesvirus, Influenza, VRS). Los alcoholes tienen actividad muy pobre contra las esporas bacterianas. $\mathrm{Su}$ efectividad una vez aplicados, es rápida pero no tienen ninguna actividad residual apreciable (efecto remanente). El uso de alcoholes no es apropiado cuando las manos están visiblemente sucias o contaminadas con materiales proteicos.

Los productos en base alcohólica para la frotación de manos, previstos para el uso sanitario, están disponibles en soluciones de baja viscosidad, geles y espumas, que incorporan emolientes, humectantes $u$ otros agentes dermoprotectores que evitan la sequedad de la piel.

Los alcoholes son inflamables y en este sentido es necesario tomar las medidas de precaución oportunas, tanto en su uso como en su almacenaje, debiéndose seguir las recomendaciones del fabricante.

Para asegurar su eficacia, el producto deberá haber superado como mínimo las normas UNE-EN 1040 (evaluación de actividad bactericida básica de los antisépticos y desinfectantes químicos); UNE-EN 1500 (tratamiento higiénico de las manos por fricción) y la UNE-EN 12791 (desinfectantes para el lavado quirúrgico de manos).

\subsubsection{Lavado de manos quirúrgico}

El lavado quirúrgico de manos es aquel proceso realizado antes de cualquier intervención quirúrgica, para eliminar el mayor número de microorganismos patógenos de manos y antebrazos, a través de un lavado mecánico y de desinfección con productos químicos.

Los objetivos de este tipo de lavados son disminuir la flora resistente de las manos y antebrazos y prevenir las infecciones nosocomiales. Al tratarse de un lavado más sofisticado y con un objetivo muy definido dirigido a eliminar y controlar la mayor parte posible de microorganismos se compone de varios pasos:

1. La duración del lavado: 2-5 minutos, dependiendo de las instrucciones del fabricante del producto utilizado.

2. Preparación para el lavado quirúrgico:

a) Mantener las uñas cortas y retirar esmalte de uñas.

b) Retirar toda la joyería (los anillos, los relojes de pulsera, las pulseras) antes de entrar en la sala de operaciones.

c) Lavar manos, brazos y codos con un jabón no antiséptico, antes de entrar en el área de la sala de operaciones o si las manos están visiblemente sucias. 
d) Limpiar la zona subungular con limpiaúñas.

e) Los cepillos de uñas no deberían ser usados, ya que pueden dañar la piel y pueden facilitar el derramamiento de celdas. Los cepillos de uñas, si se usan, deben ser estériles y de uso único, de una vez.

3. Preparación quirúrgica de las manos con un jabón antiséptico:

a) Mojarse las manos.

b) Poner una cantidad de jabón suficiente para cubrir toda la superficie de las manos.

c) Comenzar a contar el tiempo del procedimiento. Frotar cada lado de cada dedo, entre los dedos, la parta de atrás y la parte delantera de la mano durante dos minutos.

d) Proceder a frotar los antebrazos, manteniendo la mano más alta que el brazo en todo momento. Esto ayuda a evitar una nueva contaminación de las manos e impide que agua y jabón sean colonizados por bacterias que contaminan las manos.

e) Lavar cada lado del brazo desde la muñeca hasta el codo durante un minuto.

f) Repetir el proceso en la otra mano, conservando las manos por encima de los codos en todo momento.

g) Enjuagar las manos y brazos, haciéndolos pasar por el agua en una dirección sólo, de la punta de los dedos hasta el codo.

h) Con las manos por encima de los codos séquese las manos y brazos con una toalla o paño estéril. Utilizar una toalla para cada brazo.

i) En todo momento durante el procedimiento, se debe tener cuidado de no salpicarse la indumentaria quirúrgica.

j) Cuando se utilice la desinfección alcohólica de manos:

- Antes de aplicar la solución con alcohol, realizar un prelavado de antebrazos y manos con un jabón normal y secar las manos y antebrazos completamente.

- Después aplicar la solución alcohólica, hasta que manos y antebrazos queden secos completamente.

\subsection{Preparación de un campo estéril}

Un campo estéril se crea para obtener un sitio de trabajo quirúrgicamente aséptico. Debe considerarse área restringida. Puede usarse una compresa estéril para establecer un campo estéril o extender un área de trabajo estéril. La compresa debe ser a prueba de agua por un lado, el que se apoya sobre la superficie de trabajo. Después de establecido el campo estéril, pueden incorporarse otros elementos estériles necesarios, como soluciones. Los artículos y las manos enguantadas estériles son los únicos objetos permitidos en el campo.

Para iniciar la importancia de este procedimiento, pasaremos a describir primeramente los principios básicos de la asepsia quirúrgica: 
a) Sólo un objeto estéril puede tocar otro objeto estéril. Si uno sin esterilizar toca uno esterilizado se habrá producido la contaminación de este último.

b) Abrir los paquetes estériles de forma que la primera solapa de la envoltura apunte hacia el extremo más alejado del trabajador, para evitar la posibilidad de que la superficie estéril toque la ropa no estéril. El exterior del envase estéril se considera contaminado.

c) Evitar derramar cualquier solución sobre el paño o papel que se utilizará como campo para objetos esterilizados. La humedad penetra en la tela o papel estéril y acarrea microorganismos por acción capilar que contaminan el campo. Un campo húmedo se considera contaminado si la superficie inmediatamente inferior al mismo no es estéril.

d) Mantener los objetos estériles por encima de la cintura. Esto garantizará tener el objeto a la vista y ayudará a prevenir una contaminación accidental.

e) Evítese hablar, toser, estornudar o tratar de alcanzar un campo o un objeto estéril. Esto ayuda a prevenir la contaminación por gotitas de la nariz y la boca o por partículas que caen del brazo del trabajador.

f) Nunca alejarse o dar la espalda a un campo estéril. Esto evita la posible contaminación mientras el campo se encuentra fuera de la vista del trabajador.

g) Todos los elementos que se ponen en contacto con la piel lesionada, que se utilizan para penetrar la piel e inyectar sustancias en el cuerpo, o para entrar en las cavidades corporales normalmente estériles, deben estar esterilizados. Estos objetos incluyen gasas para heridas e incisiones, agujas para inyección y sondas (catéteres) para drenar la orina de la vejiga.

h) Utilizar pinzas esterilizadas y secas cuando sea necesario. Las pinzas empapadas en desinfectante no se consideran estériles.

i) Considerar contaminados los 2,5 cm más exteriores del borde del campo estéril.

j) Considerar que un objeto está contaminado si se tiene alguna duda acerca de su esterilidad.

En resumen, podemos definir un campo estéril como una zona claramente delimitada donde se mantienen unas condiciones de asepsia completa y será una zona libre de microorganismos.

Procedimiento:

1. Lavado antiséptico de manos.

2. Informar al paciente de las dimensiones del campo para que evite movimientos bruscos que contaminen el campo.

3. Asegurarse de que el paquete para preparar el campo estéril está limpio y seco. Revisar también la fecha de expiración para asegurarse de que el producto conserva su validez.

4. Seleccionar un área de trabajo que se encuentre a nivel de la cintura o más arriba.

5. Abrir la cubierta externa del campo quirúrgico y colocar el campo estéril: abrir un paño estéril con la punta de los dedos tocando sólo las esquinas. Mantener el paño alejado del cuerpo y por encima de la cintura y de la superficie de trabajo. 
6. Colocar el paño sobre la superficie de trabajo. Evítese tocar cualquier otra superficie u objeto con el paño. Cualquier porción de paño que cuelgue fuera de la superficie de trabajo se considera contaminado.

7. Colocar los artículos estériles adicionales en el campo según sea necesario.

8. Lavado de manos.

Observaciones:

a) Evitar derramar líquidos sobre el campo porque puede favorecer la penetrabilidad de gérmenes.

b) Todo campo estéril deja de serlo cuando se desatiende.

c) Mantener cerradas las puertas y los movimientos reducidos al mínimo, en las zonas en las que se ejecuten procedimientos estériles.

d) No montar un campo estéril antes de la hora prevista para su uso.
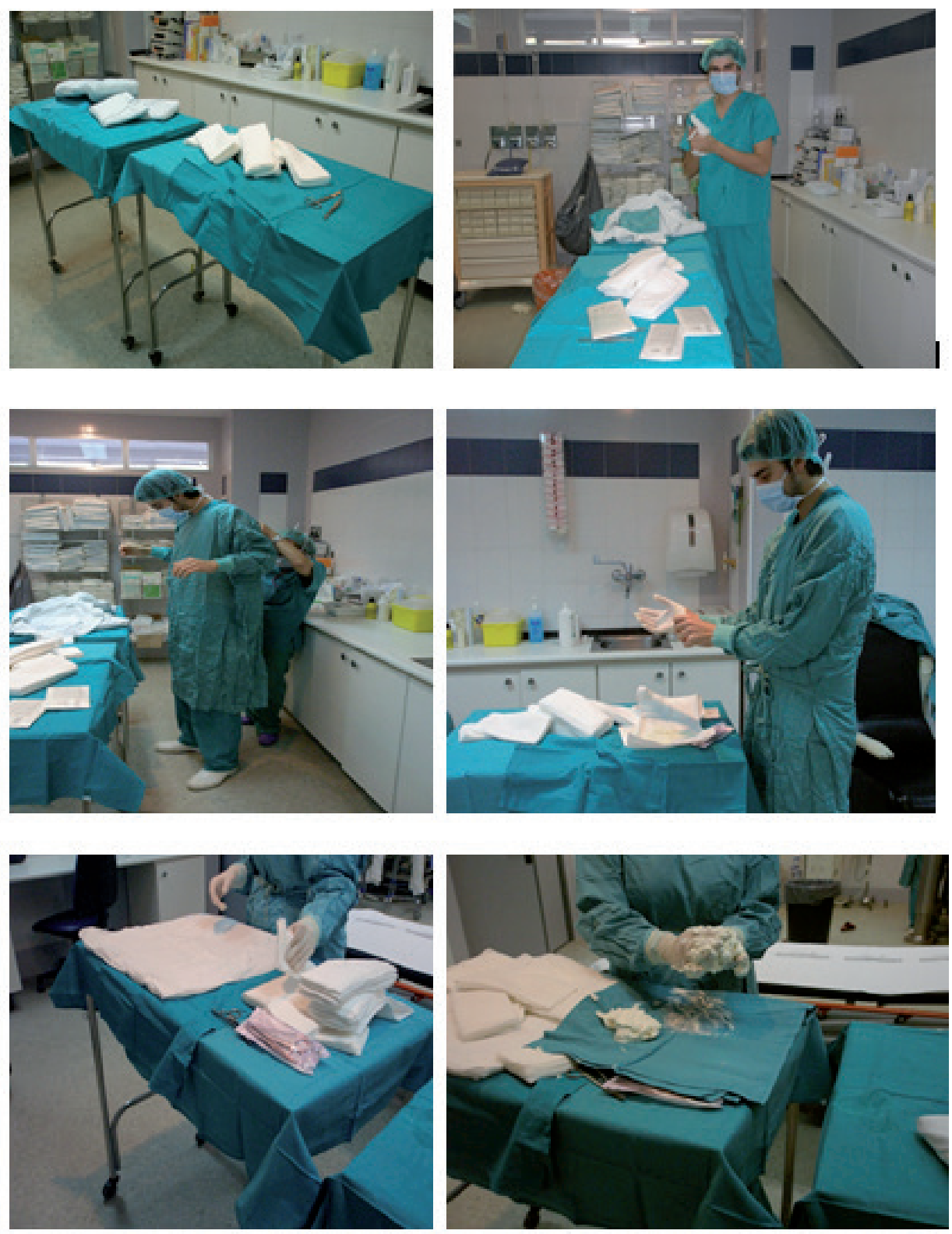

Figura 30. Preparación de un campo estéril. Fuente: Elaboración propia 


\subsection{Aislamiento hospitalario}

Se conoce como aislamiento hospitalario el conjunto de normas que hay que tomar en el hospital para evitar la propagación de las enfermedades infecciosas dentro de las distintas estancias y servicios hospitalarios.

Las áreas hospitalarias en las que el aislamiento debe ser más riguroso son fundamentalmente: quirófanos y áreas quirúrgicas en general, unidades de vigilancia intensiva, unidades de neonatología, unidades de oncología, unidades de infecciosos y unidades de hemodiálisis. Mediante el aislamiento se pretende evitar la propagación de microorganismos entre los pacientes, interrumpiendo la cadena epidemiológica en la vía de transmisión sobre todo.

Cabe señalar que en muchas ocasiones es difícil conseguir el aislamiento completo, pero cuando a la propagación de los gérmenes se le ponen barreras es siempre más difícil que la infección y/o enfermedad infecciosa se extienda.

El ciclo de propagación de los microorganismos viene dado por la cadena epidemiológica en la que consideramos:

a) Agente causal: microorganismo patógeno (bacterias, virus, hongos, parásitos).

b) Reservorio: humano, suelo, fómites o instrumental.

c) Vías de salida: secreciones de nariz y garganta, aire espirado, heces, orina, exudados, vómitos, piel y mucosas, sangre.

d) Vías de transmisión: personas, aire, agua, alimentos, insectos, fómites.

e) Puerta de entrada: boca, nariz, garganta, aparato urinario, heridas en la piel y mucosas.

\subsubsection{Tipos de aislamiento}

a) Aislamiento del paciente.

Este tipo de aislamiento está indicado para proteger al personal del hospital de posibles contagios infecciosos, proteger a los demás pacientes y proteger al paciente de un posible contagio.

Principios generales del aislamiento:

1. Los guantes batas y mascarillas se deberán usar una sola vez y antes de abandonar la habitación del paciente se depositarán en un recipiente al efecto.

2. Las batas, guantes y mascarillas deben estar fuera de la habitación contaminada.

3. Es necesario lavarse las manos antes y después de entrar en contacto con el paciente, aun cuando usemos guantes para ello. 
4. Las mascarillas son ineficaces cuando se humedecen, deben cubrir la nariz y la boca, y no se deben dejar atadas al cuello para luego reutilizarlas.

5. Los materiales contaminados se colocarán en una bolsa limpia e impermeable dentro del área contaminada, y se cerrarán. Luego, una vez fuera del área contaminada se colocarán en una segunda bolsa; esta se cerrará y se rotulará como material contaminado.

b) Aislamiento estricto.

Está indicado para evitar la transmisión de enfermedades muy contagiosas o virulentas capaces de propagarse por vía aérea y por contacto.

Principios generales del aislamiento:

1. Habitaciones separadas (pacientes con la misma infección pueden compartir habitación).

2. Para entrar en la habitación se usarán batas, guantes y mascarilla.

3. Después de estar en contacto con el paciente, o con material posiblemente contaminado, se lavarán las manos.

4. Los artículos contaminados deben ser desechados o enviados a esterilizar, usando la técnica de la doble bolsa.

c) Aislamiento de contacto.

Indicado para evitar la transmisión de infecciones altamente contagiosas o epidemiológicamente significativas que no justifiquen un aislamiento estricto.

Principios generales del aislamiento:

1. Habitaciones separadas (pacientes con el mismo microorganismo pueden compartir habitación).

2. Los que mantengan contacto estrecho con los pacientes usarán mascarilla, batas y guantes (según el tipo de infección).

3. Lavado de manos antes y después de tocar al paciente con material contaminado aunque se usen guantes.

4. Los materiales contaminados deben ser desechados por medio de la técnica de la doble bolsa.

5. Todas las enfermedades de esta categoría se diseminan por contacto estrecho o directo.

6. Algunas de las enfermedades no requieren el uso de las tres barreras:

I) No se suelen requerir ni mascarillas ni guantes para atender a lactantes con virosis respiratorias agudas.

II) No es necesaria la bata para atender a niños con conjuntivitis gonocócica.

III) No se suele usar mascarilla para atender a pacientes infectados con microorganismos multirresistentes, con excepción de los que están afectos de neumonía. 


\section{d) Aislamiento respiratorio.}

Este tipo de aislamiento está indicado para evitar la transmisión de enfermedades infecciosas por vía aérea (transmisión mediante gotitas).

Principios generales del aislamiento:

1. Habitación separada (pacientes con el mismo microorganismo pueden compartir habitación).

2. Uso obligatorio de mascarilla, a ser posible no utilizar mascarillas de papel, ya que su eficacia protectora es muy breve (no es necesario el uso de bata ni de guantes).

3. Lavado de manos antes y después de tocar al paciente o materiales contaminados.

4. Los materiales contaminados se desechan utilizando la técnica de la doble bolsa.

5. El contagio por contacto directo o indirecto sucede en algunas enfermedades de esta categoría, pero es muy poco frecuente, y si sucede, se sumarán las medidas necesarias para evitar la propagación del microorganismo.

e) Aislamiento entérico o digestivo.

Este tipo de aislamiento evita la diseminación a través de materiales fecales y en algunos casos de objetos contaminados por determinados microorganismos.

Principios generales del aislamiento:

1. Se recomiendan habitaciones separadas si la higiene del paciente es deficiente.

2. Se usarán batas si el riesgo de ensuciarse es alto.

3. No es necesario el uso de mascarilla.

4. Se usarán guantes para la manipulación de objetos o sustancias contaminadas.

5. Lavado de manos antes y después de tocar al paciente o sustancias contaminadas.

6. Los materiales contaminados se desechan por el método de la doble bolsa.

f) Asilamiento parenteral.

Este tipo de aislamiento se aplica para prevenir la diseminación de enfermedades transmitidas por la sangre, por líquidos orgánicos u objetos contaminados con los mismos.

Principios generales del aislamiento:

1. La habitación individual se aconseja en caso de que el paciente presente agitación o desorientación importante o su higiene sea deficiente. 
2. No es necesario el uso de mascarilla.

3. Se tomarán precauciones especiales con agujas y objetos punzantes que puedan contaminar al personal. Resulta importante contemplar el uso esporádico de guantes, batas y mascarillas, si se anticipa la posibilidad de exposición a la sangre o líquidos contaminados.

4. Lavado de manos antes y después de entrar en contacto con el paciente.

5. Los materiales contaminados serán eliminados por el método de la doble bolsa.

g) Aislamiento de protección o inverso.

Este tipo de aislamiento se realiza para proteger a pacientes severamente inmunodeprimidos y no infectados.

Principios generales del aislamiento:

1. Habitación individual (flujo de aire laminar).

2. Uso de guantes, mascarilla y bata para todas las personas que entren en la habitación.

3. Mantener la puerta siempre cerrada.

4. Lavado de manos antes y después de atender al paciente.

\section{Normas generales de preparación de medicación}

Este procedimiento va dirigido a preparar, administrar y evaluar la efectividad de los medicamentos prescritos. Estas normas generales son el exponente máximo de la seguridad clínica. La prescripción médica debe estar lo suficientemente clara de manera que no pueda inducir a errores por: mala caligrafía, abreviaturas inapropiadas, decimales omitidos o fuera de su sitio. Ante la más mínima duda, consultar con el facultativo.

El objetivo de este procedimiento va dirigido a preparar y administrar al paciente el tratamiento prescrito por el facultativo en la dosis y el horario indicados, a través de las diferentes vías de administración con una correcta higiene y asepsia.

Procedimiento:

1. No administrar ningún medicamento sin orden médica.

2. Comprobar que la prescripción médica escrita contiene:

a) Nombre del paciente.

b) Fecha de la prescripción de la orden.

c) Nombre y dosis del fármaco a administrar.

d) Vía de administración y frecuencia.

e) Firma del médico que la prescribe. 
3. Transcribir la orden médica a la hoja de tratamiento de enfermería, ajustando la dosis y el horario de la medicación.

4. Comprobar los antecedentes de alergia del paciente y anotarlos (si los hubiera) de forma visible en la hoja de tratamiento de enfermería.

5. Preparar la medicación de cada paciente por separado.

6. Administrar únicamente las medicaciones preparadas personalmente.

7. Desechar la medicación mal identificada, caducada, con cambios en su aspecto, color o esté precipitada.

8. Rechazar la medicación abierta, comprimidos partidos y no devolver al envase la medicación manipulada.

9. Para cargar la medicación y para administrarla usar agujas distintas.

10. Los viales de múltiples usos (ej.: insulinas, heparinas...) serán desinfectados antes de su uso con antiséptico sobre el tapón.

11. Comprobar de nuevo que la medicación preparada es la correcta en dosis, hora y vía de administración.

12. Etiquetar con rotulador el cuerpo de las jeringas, no el forro de la aguja.

13. Comprobar que el paciente que va a recibir el medicamento es el paciente correcto. Preguntarle nombre y apellidos.

En pacientes que no puedan identificarse verbalmente o estén desorientados, verificar el nombre en el brazalete de identificación. En niños, verificar con los padres su identidad.

1. Informar de la medicación administrada siempre que el paciente lo requiera. Evitar dicha información en los casos en que el estado psíquico del paciente no lo permita o en aquellos casos en que exista un acuerdo previo del equipo sanitario.

2. Volver a comprobar la medicación prescrita si el paciente tiene dudas sobre el tratamiento que se le va a aplicar.

3. Permanecer con el paciente mientras toma la medicación.

4. Instruir al paciente y/o familia para la autoadministración si es posible, en dosis y horarios indicados (medicación oral, tópica, rectal, transdérmica o inhaladores).

5. Respetar el derecho del paciente a rechazar medicación, anotarlo en los registros de enfermería y comunicarlo al facultativo.

6. Registrar la administración de un fármaco en la hoja de medicación administrada, indicando:

a) Nombre del fármaco.

b) Dosis.

c) Vía de administración.

d) Hora de administración.

e) Nombre y firma de la enfermera/o que lo administra.

7. Valorar y registrar cualquier efecto secundario que se produzca tras la administración del fármaco y comunicarlo al facultativo.

8. En caso de error u omisión en la administración comunicarlo al facultativo de inmediato, y registrarlo en la hoja de evolución de enfermería y voluntariamente en la hoja de «Errores en la medicación».

9. Registrar cualquier cambio de horario de la medicación prescrita y las causas que lo han producido (ej.: realización de pruebas complementarias). 


\section{Prevención y tratamiento de las úlceras por presión (UPP)}

Las UPP son un problema de salud frecuente en la asistencia sanitaria, con importantes repercusiones físicas y sociales, que pueden influir en la recuperación de los pacientes y complicarse con infecciones, prolongando la estancia y los costes de la asistencia. En España se estima que la prevalencia de uPP a nivel hospitalario es del 8,8 \% (Torra, Rueda, Soldevilla, Martínez y Verdú, 2003). Es por ello que las úlceras por presión se consideran un indicador de calidad de la asistencia sanitaria. En este apartado trataremos la prevención, fisiopatología de las uPP y su tratamiento en sus diferentes estadios y evolución.

\subsection{Fisiopatología de las UPP}

Las UPP también se denominan úlceras por decúbito, escaras o, más coloquialmente, llagas. Una uPP es toda lesión de la piel que se produce en cualquier parte del cuerpo que sufre una presión prolongada sobre un plano duro.

Esta presión no ha de ser necesariamente intensa y es independiente de la posición en la que permanezca el paciente (puede estar sentado, acostado...). La zona de piel afectada por una presión no aliviada puede verse deteriorada, pero también el tejido que se halla bajo ella: grasa, músculo y hueso.

De acuerdo con García-Fernández, Soldevilla Agreda, Verdú y Pancorbo-Hidalgo (2013), las UPP se producen fundamentalmente por la presión directa (el peso del cuerpo aprieta los tejidos entre la cama y el hueso), pero también por la fricción (al subir al paciente hacia la cabecera arrastrándolo) y el deslizamiento (cuando el paciente está sentado y se va resbalando poco a poco). La presión mantenida provoca un bloqueo de riego sanguíneo de la zona afectada, produciéndose la lesión.

Las UPP pueden aparecer en cualquier lugar del cuerpo, dependiendo de la zona de piel que esté sometida a mayor presión y de la postura más frecuente del paciente (figura 31). Las upP suelen aparecer principalmente en aquellas personas que sufren en su piel una presión prolongada y que además pueden tener algunos de estos factores predisponentes:

a) Edad avanzada.

b) Inmovilidad.

c) Incontinencia.

d) Bajo nivel de conciencia.

e) Uso de medicamentos.

f) Alteraciones varias (circulatorias y vasculares, mal estado de la piel, alteraciones respiratorias, endocrinas y/o nutricionales).

g) Afectación mecánica (por férulas, yesos y tracciones). 
h) Factores psicosociales como la depresión, deterioro de la propia imagen, falta de higiene, ausencia de cuidador...

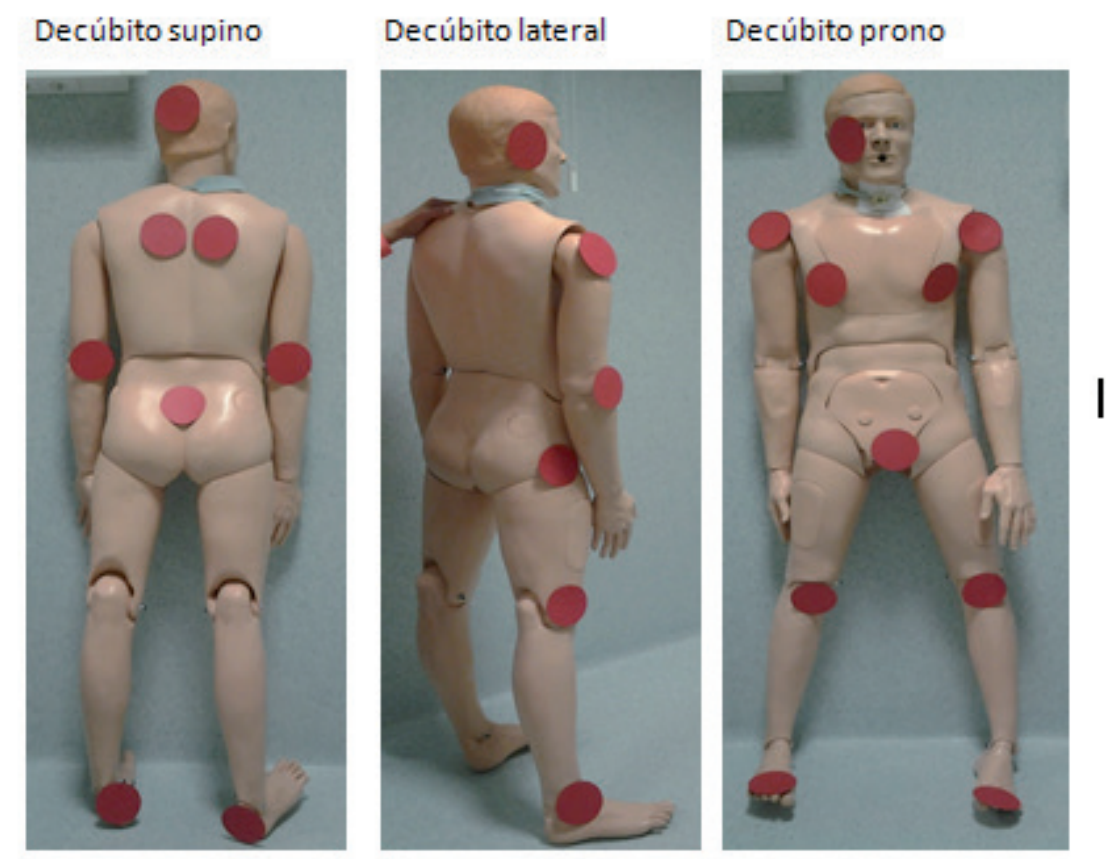

Figura 31. Puntos de presión y riesgo de UPP. Fuente: Elaboración propia

Las UPP se clasifican en cuatro grados, de acuerdo con la profundidad y características que presentan (tabla 12):

1. Grado I: es una úlcera en la que se verá afectada la capa más superficial (epidermis). Se acompaña la lesión de dolor intenso y se caracteriza por una mácula eritematosa, delimitada y de color rojo brillante. Es un eritema reversible en el que, al retirar la presión, la piel recupera su aspecto normal. Es difícil observarlas en personas de piel oscura, encontrando como signos de alarma edemas, induración, calor local y decoloración.

2. Grado II: la lesión afecta a la epidermis y dermis superficial. La úlcera se caracteriza porque la zona eritematosa puede acompañarse de edema, vesícula y ampollas. El enrojecimiento persiste tras desaparecer la presión, no recuperando la piel su aspecto original. Se acompaña de dolor importante en la zona de lesión.

3. Grado III: el daño tisular en esta úlcera abarca incluso el tejido subcutáneo. Se presenta en forma de escara necrótica, gruesa y de color negruzco. Puede no existir dolor al estar afectados tejidos más profundos.

4. Grado Iv: destrucción total del espesor de la piel, extendiéndose la lesión hasta la fascia, el músculo, hueso, etc. Muestran un aspecto de necrosis total, de color negro y pueden complicarse con infecciones graves (osteomielitis, artritis séptica, etc.) que pueden originar sepsis generalizada en el paciente. No existe dolor, pudiendo aparecer incluso insensibilidad de la zona. 


\begin{tabular}{c|lllc}
\hline Grado & \multicolumn{1}{|c}{ Lesión } & \multicolumn{1}{c}{ Color } & Profundidad & Dolor \\
\hline I & $\begin{array}{l}\text { Mácula delimitada } \\
\text { Piel integra }\end{array}$ & Rojo brillante & Epidermis & Sí \\
II & $\begin{array}{l}\text { Eritema y edema } \\
\text { Vesículas o ampollas } \\
\text { Piel agrietada }\end{array}$ & Enrojecimiento & $\begin{array}{l}\text { Dermis } \\
\text { superficial }\end{array}$ & Sí \\
III & Escara necrótica & Negro & $\begin{array}{l}\text { Tejido } \\
\text { subcutáneo }\end{array}$ & No \\
IV & $\begin{array}{l}\text { Escara necrótica } \\
\text { Fístulas }\end{array}$ & Negro con exudado & $\begin{array}{l}\text { Tejido óseo o } \\
\text { muscular }\end{array}$ & Insensibilidad \\
\hline
\end{tabular}

Tabla 12. Características de las upP según grados. Fuente: DAE, 2009

\subsection{Prevención de las UPP}

Hibbs (1987) afirma que el $95 \%$ de las upp son evitables, aunque la literatura relacionada con las mejores medidas de prevención de UPP es contradictoria. De todos modos parece que el uso de estrategias de prevención con intervenciones múltiples son las más adecuadas. Estas estrategias consisten en la detección de personas de riesgo, y la intervención sobre diferentes aspectos que influyen en la aparición de upP como movilidad, nutrición, control de la presión y estado de la piel (Ferrer Solá, Espauella Panicot, Altimires Roset y Ylla-Català Boré, 2013). A continuación se exponen una serie de medidas generales dirigidas a la prevención de UPP y en la tabla 13 se ofrecen unas recomendaciones basadas en los documentos técnicos del GNEAUPP:

1. Evaluación del riesgo de aparición de uPP utilizando una escala validada.

2. Mantener la piel del paciente limpia y seca en todo momento.

3. Realizar la higiene corporal diaria con agua tibia y jabón de $\mathrm{pH}$ neutro, aclarar bien y secar por contacto (sin fricción), secando muy bien los pliegues cutáneos y los espacios interdigitales.

4. Realizar inspección de la piel, al menos una vez al día, teniendo en cuenta especialmente:

a) Prominencias óseas: sacro, talones, caderas, tobillos, codos...

b) Zonas expuestas a humedad.

c) Presencia de sequedad, excoriaciones, eritema, maceración, fragilidad, temperatura, induración.

5. Aplicar los ácidos grasos hiperoxigenados en las zonas de riesgo en sentido circular, evitando los masajes.

6. Si fuera preciso, poner apósitos hidrocelulares en zonas de riesgo.

7. Hidratar el resto de la piel, evitando los masajes.

8. Mantener la ropa de la cama libre de arrugas.

9. Realizar un programa de cambios posturales individualizados. Evitar el arrastre y el contacto directo de las prominencias óseas entre sí. Realizar los cambios posturales cada dos o tres horas en los pacientes encamados, 
siguiendo una rotación programada e individualizada. Si el paciente va a estar en estado sedente, realizar movilizaciones horarias (Cochrane, 2014).

10. Utilizar una superficie especial para el manejo de la presión adecuada, según el riesgo detectado de desarrollar upP y la situación clínica del paciente.

11. Asegurar la nutrición adecuada. Un paciente de alto riesgo de desarrollar una UPP requiere una dieta hiperproteica e hipercalórica.

12. Tratar la incontinencia y eliminar la humedad excesiva.

13. Educar al paciente, familia y cuidadores en la prevención de las UPP.

14. Registrar las medidas adoptadas, así como las no adoptadas.

\begin{tabular}{l|cc}
\multicolumn{1}{c|}{ Medidas } & Riesgo bajo $\quad$ Riesgo moderado & \multicolumn{1}{c}{ Riesgo alto } \\
\hline Evaluación & $\begin{array}{c}\text { Al ingreso y cada 7 días o cambios } \\
\text { clínicos relevantes }\end{array}$ & $\begin{array}{l}\text { Cada 24-48 horas o } \\
\text { cambios relevantes }\end{array}$ \\
\hline $\begin{array}{l}\text { Higiene corporal } \\
\text { Vigilancia zonas de } \\
\text { riesgo }\end{array}$ & Diaria \\
\hline $\begin{array}{l}\text { Ácidos grasos } \\
\text { hiperoxigenados }\end{array}$ & Diaria & Cada 8 horas \\
$\begin{array}{l}\text { Cambios posturales } \\
\text { Cada 2-3 horas y cada 4 por la noche }\end{array}$ & $\begin{array}{l}\text { Colchón dinámico } \\
\text { de celdas grandes o } \\
\text { camas fluidificadas. } \\
\text { Apósitos } \\
\text { hidrocoloides } \\
\text { extrafinos. }\end{array}$ \\
\hline $\begin{array}{l}\text { Superficies especiales } \\
\text { de manejo de presión }\end{array}$ & Colchón estático o de aire alternante \\
\hline
\end{tabular}

Tabla 13. Recomendaciones para la prevención de UPP. Fuente: Conselleria de Sanitat, Generalitat Valenciana, 2007

\subsection{Tratamiento de las UPP}

La primera medida curativa es la prevención. Ante la aparición de una UPP es fundamental extremar las medidas preventivas, además de emplear los tratamientos más adecuados para la curación de la UPP.

Los objetivos generales en el tratamiento de las UPP son promover la cicatrización de la herida y evitar la extensión y demás complicaciones de esta. Para ello se debe:

\section{Limpiar la herida:}

Con ello se pretende eliminar los restos orgánicos e inorgánicos, así como los elementos de desecho presentes en el lecho de la upp que impidan la cicatrización de la herida. 
Se lavará con suero salino por gravedad evitando el uso de antisépticos, que son productos tóxicos que impiden la generación de tejido nuevo. Se evitará en todo momento lesionar los tejidos sanos, por lo que no se frotará la herida y la instilación del suero salino se realizará con poca presión. Entre los efectos adversos que podemos encontrarnos al limpiar una herida están: la hemorragia, la infección y el dolor.

2. Eliminar el tejido necrótico.

La eliminación de tejido muerto o desbridamiento se puede realizar de las siguientes formas:

1. Desbridamiento autolítico. Las propias enzimas y células del sistema inmunológico presentes en el exudado de la herida se encargan de destruir la placa necrótica.

2. Desbridamiento enzimático. Cuando se trata de una herida sin exudado, se aplican productos medicamentosos con esta acción.

3. Desbridamiento quirúrgico. Es el método más rápido pero más agresivo, ya que consiste en eliminar la placa necrótica con instrumental quirúrgico.

El objetivo del desbridamiento es el de acelerar el proceso de cicatrización de la herida. En enfermería, el desbridamiento que vamos a practicar mayormente es el desbridamiento cortante o quirúrgico, en el que retiramos el tejido desvitalizado con ayuda de pinzas y bisturí desde la zona central, más débil, accediendo lo antes posible a uno de los bordes por donde continuar hasta encontrar territorio sano y con ello sangrante. Entre las complicaciones de esta técnica nos podemos encontrar con la hemorragia, la infección y el dolor.

\section{Determinar si la UPP está o no infectada.}

Cuando una herida tiene más de 100.000 microorganismos por gramo de tejido, el proceso de cicatrización se detiene. Por ello, cuando se sospeche que una herida pueda estar infectada, se deberá realizar un cultivo microbiológico de la misma y, en caso afirmativo, utilizar un tratamiento antibiótico local o general.

\section{Mantener el nivel óptimo de humedad.}

La humedad es importante para favorecer la formación de células epiteliales, necesarias para la cicatrización de la herida. Una herida con poco o nulo exudado deberá ser humedecida mediante la utilización de apósitos o hidrogeles fabricados para tal efecto. Por otro lado, el exceso de exudado en una herida puede impedir su cicatrización además de favorecer su extensión, por lo que se utilizarán productos que sean capaces de absorber el exceso de exudado, manteniendo un óptimo grado de humedad que favorezca la formación de células epiteliales.

Para ello, la técnica que se emplea es la de cura en ambiente húmedo. Esta técnica utiliza, para la cicatrización de una lesión, unas condiciones determinadas de hu- 
medad y temperatura establecidas por un material que hace las veces de interfase entre la lesión y el medio ambiente exterior.

Procedimiento:

1. Realizar el lavado de manos.

2. Colocarse los guantes.

3. Colocar al paciente en la posición adecuada según la zona de localización de la lesión.

4. Retirar el apósito. Es aconsejable humedecerlo para facilitar su retirada sin causar traumatismos innecesarios de la herida.

5. Limpieza del lecho de la lesión con suero salino isotónico.

6. Limpiar a chorro por arrastre desde el centro de la herida hacia los extremos y desde la zona más limpia a la menos limpia.

7. Aplicación de producto y apósito de cura húmeda. La elección del apósito debe basarse en el conocimiento de su funcionamiento y prestaciones, así como en las características de cada herida.

8. La frecuencia de cambio de cada apósito vendrá determinada por las características específicas del producto seleccionado.

9. Quitarse los guantes, lavado de manos y registrar el procedimiento.

Las complicaciones más habituales suelen ser el cierre en falso, la infección y la alergia presentada a algún componente de los apósitos o tratamientos tópicos aplicados.

\section{Observaciones:}

1. Existe una amplia gama de apósitos de cura húmeda que permiten cubrir y adaptarse a las diferentes necesidades y requerimientos de cada herida.

2. Un apósito ideal debe ser biocompatible, proteger la herida de agresiones externas físicas, químicas y bacterianas, mantener el lecho de la úlcera continuamente húmedo y la piel circundante seca, eliminar y controlar exudados y tejido necrótico mediante su absorción, dejar la mínima cantidad de residuos en la lesión, ser adaptable a las localizaciones difíciles, respetar la piel perilesional y ser de fácil aplicación y retirada.

3. Es preciso rellenar parcialmente (entre la mitad y tres cuartas partes) las cavidades y tunelaciones con productos basados en el principio de la cura húmeda.

Apósitos basados en la cura húmeda:

Alginatos: En cuanto a su composición son polímeros de cadena larga procedentes de las algas. Entre sus propiedades se encuentran que absorben el exudado, hidratándose, intercambiando iones de calcio por iones de sodio y transformándose en un gel traslúcido. Estos crea un medio húmedo que favorecen la cicatrización, a la vez que pueden retener gérmenes en su estructura. Precisan del exudado para actuar. Tienen propiedades de hemostasia. Se retiran fácilmente de la lesión. Requieren de un apósito secundario de fijación. 
Son muy útiles en UPP de estadio III, IV y úlceras vasculares de exudado moderado o alto, así como en úlceras infectadas, cavitadas y necrosis húmedas. No deben utilizarse en necrosis secas, ni heridas no exudativas.

Hidrogeles: Son compuestos formados por sistemas cristalinos de polisacáridos y polímeros sintéticos, con un contenido de agua del 70 al $90 \%$.

Entre sus propiedades contamos con que favorecen la granulación y el desbridamiento por hidratación, por lo que pueden asociarse con medicamentos hidrosolubles. En utilización conjunta con la colagenasa, potencia la acción de esta última. No son adherentes por lo que presentan una retirada sencilla e indolora, precisando de un dispositivo secundario de sujeción. Se emplean sobretodo en úlceras infectadas, en necrosis secas y en heridas en fase de granulación.

Hidrocoloides: Son compuestos de carboximetilcelulosa sódica (CMC) junto con otros hidrocoloides, sustancias adherentes y en ocasiones compuestos hidroactivos, que le dotan de su potencial de absorción, y una capa de poliuretano que le da la oclusividad o semioclusividad.

Entre sus propiedades contamos que junto con el exudado forman un gel, de color y olor característicos. Tiene capacidad autolítica para la eliminación de la capa necrótica en ambiente húmedo. Además, ejercen una moderada absorción y retención del exudado, controlando la cantidad del mismo entre el apósito y la lesión, creando un gel y un medio ligeramente ácido que le da carácter bacteriostático. Pueden dejar residuos en la lesión y desprender un olor desagradable. Se retirarán cuando el gel sobrepase el perímetro de la lesión para evitar macerar los bordes.

Su uso está indicado en UPP en estadio I, II y III, y protección frente a fricción. Sólo son combinables con alginatos y CMC. No son recomendables en úlceras con exposición a estructuras nobles, ni en úlceras infectadas.

Poliuretanos: Apósitos de película (film) de poliuretano. Existen de varios tipos:

a) Compuestos por una lámina de poliuretano transparente: Las propiedades que posee es que son planos, transparentes, autoadhesivos y elásticos (que favorecen la movilidad y comodidad del paciente). Crean una película protectora que aísla la herida del medio externo, pero no tienen capacidad de absorber el exudado.

Entre sus indicaciones están que son útiles en la prevención, protección ante la fricción, UPP en estadio I y lesiones superficiales. También se pueden usar como apósitos secundarios de fijación. Resultan de fácil aplicación y retirada. No se deben utilizar en heridas infectadas. Los apósitos de espuma (foam) de poliuretano también reciben el nombre de hidrocelulares e hidropoliméricos. 
b) Derivados del poliuretano a los que se les ha asociado una estructura hidrofílica: Entre sus propiedades se encuentran que presentan una alta capacidad de absorción del exudado y no se descomponen en presencia de este, manteniendo la piel perilesional intacta. Tienen capacidad autolítica para la eliminación de la capa necrótica y algunos de ellos pueden manejar la presión, por lo que resultan útiles en la prevención. Pueden combinarse con otros productos. No dejan residuos ya que no forman un gel. La retirada del apósito se lleva a cabo cuando el exudado llegue a un centímetro del borde del apósito.

Está indicado el uso de este tipo de apósitos en todas aquellas lesiones de cualquier etiología, de moderada a altamente exudativas, en todas las fases del proceso de cicatrización. En caso de infección puede utilizarse, recomendándose la supervisión médica.

Apósitos de plata: Son productos bioactivos que contienen plata en diferentes porcentajes. Así, la plata actúa bloqueando el sistema de obtención de energía de las bacterias que se encuentra en la pared celular, sin producir daño alguno a las células humanas. Hay evidencias científicas de que la plata es efectiva frente a un amplio espectro de gérmenes, incluyendo los multirresistentes, no produce efectos secundarios, no interfiere con antibióticos sistémicos y produce escasas resistencias.

Se indica su utilización en la fase de limpieza del proceso de cicatrización para disminuir la carga bacteriana. Muy útiles en heridas infectadas y heridas tórpidas sin signos de infección local.

\section{Aislar la herida.}

Para una correcta cicatrización de la herida, deberá ser aislada mediante la utilización de apósitos que dejen pasar oxígeno al lecho de la herida pero que, a su vez, impidan su contaminación.

\section{Proporcionar cuidados a la piel perilesional.}

Es importante valorar el estado de la piel de alrededor de la herida para evitar su extensión, así como para elegir el tratamiento más adecuado que evite la maceración, descamación, eritema, prurito, dolor, etc., de la piel perilesional. En el tratamiento de las escaras, no se debe olvidar que las úlceras pueden ser dolorosas, por lo que habrá que valorar el uso de analgésicos si fuera preciso. 


\section{Restricciones}

El uso de restricciones tiene unas condiciones muy particulares que se detallarán a lo largo del estudio de esta profesión, en las diferentes asignaturas cursadas, por lo que será abordado de forma muy breve.

Así pues, hay tres tipos de restricciones que se usan en la práctica clínica:

a) Químicas: fármacos sedantes psicotrópicos para tratar o controlar la conducta. El medicamento psicoactivo usado de esta forma constituye un uso inadecuado del medicamento.

b) Físicas: la aplicación directa de fuerza física a un paciente, sin su permiso, para restringir su libertad de movimientos. La fuerza física pueden aplicarla sujetos, dispositivos mecánicos o una combinación de ellos.

c) Aislamiento: confinamiento involuntario de un paciente en una habitación cerrada.

Las restricciones están indicadas sólo si no hay otra opción viable para proteger al paciente; y en ese caso sólo se colocan cuando el paciente es valorado y evaluado por un profesional independiente adecuadamente autorizado.

En la asistencia médica aguda y posquirúrgica, una restricción puede ser necesaria para asegurar que no se va a quitar una vía intravenosa o una sonda de alimentación o que el paciente no salga de la cama tras una intervención quirúrgica. Este tipo de restricción médica puede usarse temporalmente para limitar la movilidad o evitar lesiones al paciente. Los tipos adicionales de actividades que pueden constituir una restricción son:

1. Plegar la sábana del paciente tan tensa que no pueda moverse.

2. Usar la barandilla en la cama para evitar que el paciente salga voluntariamente de la misma.

3. Colocar al paciente en una silla reclinable con una mesa.

4. Colocar al paciente en una silla de ruedas tan cerca de la pared que le impida moverse.

Existe una creciente preocupación con respecto al uso de estos equipos en la administración de cuidados de salud, en lo que se refiere al respeto a los derechos y dignidad de los pacientes y que además requiere ciertas habilidades y destrezas que faciliten su uso. Hay que ser conscientes que las restricciones nunca se usan como un sustituto de la vigilancia.

En la revisión de la literatura sobre el tema, se identifican dos tipos de lesiones relacionadas con las contenciones mecánicas: las causadas por la presión externa del sistema de sujeción, incluyendo laceraciones, hematomas o estrangulamiento, y las indirectas o efectos adversos (mortalidad, úlceras por presión y caídas). 


\section{CAPÍTULO 12}

\section{Cuidados básicos \\ en la hermodinámica}

\section{Introducción}

El Diccionario enciclopédico Taber define la monitorización de los signos vitales como «la recogida y análisis de datos sobre el estado cardiovascular, respiratorio y de temperatura corporal para determinar y prevenir complicaciones». De esta forma, se entiende que los signos vitales a controlar por el personal de enfermería son: la temperatura, el pulso, la respiración y la presión sanguínea de una persona. Actualmente y debido a los avances tecnológicos, se disponen de equipos en los que también se puede controlar la oximetría de pulso junto a las otras constantes vitales, por ello consideraremos esta medición como un signo vital más.

Los signos vitales se valoran y comparan con valores normales aceptados pero no hay que desestimar que existen patrones habituales de cada paciente en una amplia variedad de circunstancias. Por lo tanto, y debido a lo anteriormente expuesto, hay que considerar que el personal de enfermería debe tomar las constantes vitales con tanta frecuencia como la condición del paciente lo requiera.

Es importante conocer que el procedimiento de toma de constantes vitales pertenece a la profesión enfermera, y es responsabilidad de la misma la exactitud en la interpretación de los datos, debido a que estos son de extrema importancia para el control y evolución del paciente. Aunque la medición de un signo vital puede delegarse en otro integrante del personal de cuidados de la salud, constituye una responsabilidad del personal de enfermería:

a) asegurar la exactitud de los datos

b) interpretar los hallazgos del signo vital

c) informar los datos anormales.

\section{Temperatura corporal}

La fiebre se define como la elevación de la temperatura por encima de la variación diaria normal. En general, es un mecanismo que pone en marcha el organismo frente a una posible agresión y en el niño habitualmente se debe a infecciones; no obstante, al tener el mismo mecanismo fisiopatológico para procesos de muy diferentes etiologías, se convierte en un signo totalmente inespecífico. 
La temperatura corporal normal es variable en individuos sanos y sigue un ritmo circadiano que se mantiene con la enfermedad. Es importante definir los términos de febrícula, fiebre e hiperpirexia para posteriormente realizar protocolos de actuación, y poder utilizar los tratamientos farmacológicos y otros en el momento óptimo.

En general, los valores considerados normales en el niño oscilan entre 35,6 y $38,2^{\circ} \mathrm{C}$. La temperatura corporal que excede el percentil $99\left(>37,7^{\circ} \mathrm{C}\right)$ puede ser interpretada como fiebre; sin embargo, no existe una definición aceptada universalmente. A esta importante reflexión llegaron Andreu Guillamon, Balaguer Pallerés, Llagostera Reverter, Sanchis Rico y Stanciuc, en la revisión de la literatura realizada con el fin de conocer si existe consenso en los niveles que determinan la temperatura corporal. Así, la conclusión que finalmente aportaron en su estudio fue que tras la revisión de guías y manuales, y teniendo en cuenta la opinión de los diferentes autores, se considera que la temperatura corporal normal en los seres humanos oscila entre los $36,5-37,5^{\circ} \mathrm{C}$, cifras encontradas en un $40 \%$ de las consultas que se hicieron, la febrícula varía de $37,1-37,9^{\circ} \mathrm{C}$, encontrándose dichos valores en solo dos guías clínicas y la fiebre significa una temperatura igual o superior a $38^{\circ} \mathrm{C}$, habiendo dos guías y tres autores, de un total de diez, que definen la fiebre con esta cifra, representando un $50 \%$ del total. Por otro lado, algunos autores y guías definen la hipotermia como la temperatura corporal inferior a $35^{\circ} \mathrm{C}-36{ }^{\circ} \mathrm{C}$, hallándose estos valores en el $50 \%$ de las búsquedas, ya que no en todos los artículos y guías se definió dicho termino. Por último, unos autores consideran diferencias de $0,5^{\circ} \mathrm{C}$ según el lugar corporal de la toma de la temperatura, siendo este el lugar más frecuente para la toma de la temperatura la axila, pero otros, sin embargo, la consideran mediante la evaluación táctil y rectal. Los padres, sin embargo, estiman la fiebre a una temperatura axilar de $37,7^{\circ} \mathrm{C}$.

\section{Pulso}

El pulso es una sensación palpitante que puede sentirse sobre una arteria periférica como la radial o la carótida, también podemos auscultar el pulso apical sobre la punta del corazón.

Los pulsos periféricos son el resultado de una onda de sangre impulsada dentro de la circulación arterial por la contracción del ventrículo izquierdo. Con leves pausas, el ventrículo izquierdo se contrae de forma incesante para expulsar sangre dentro de una aorta que ya está llena, y las paredes arteriales en el sistema cardiovascular se expanden para compensar el incremento de presión sanguínea. Las características del pulso proporcionan información de la efectividad del corazón como bomba y de lo adecuado del flujo sanguíneo periférico.

La frecuencia del pulso se mide en latidos por minuto. La frecuencia normal del pulso en adolescentes y adultos se halla en un nivel de 60 a 100 latidos por minuto. 
Entre los aspectos que hay que valorar cuando tomamos el pulso periférico están:

a) El ritmo. Se refiere a la regularidad de los latidos del corazón y los intervalos entre los mismos. Si el tiempo que transcurre entre los latidos es el mismo, se denomina pulso regular. Si este tiempo es distinto se denomina arritmia.

b) La frecuencia. Es el número de latidos por minuto. La frecuencia cardíaca varía según la edad, el sexo, la talla, la actividad física y emocional, el calor y la posición del cuerpo. Cuando la frecuencia es superior a las 100 ppm se denomina taquicardia y si es inferior a $50 \mathrm{ppm}$ bradicardia.

c) La tensión o elasticidad. Es el grado de compresión de la pared arterial e indica la presión que tiene la sangre en ese punto. Si el pulso se oblitera con una presión ligera es un pulso suave y si hace falta una presión mayor se denomina pulso duro. En este aspecto influye, entre otros factores, la elasticidad de las arterias.

\section{Respiración}

Bajo condiciones normales, la respiración de los adultos saludables es de 12 a 20 veces por minuto. Debemos saber que los lactantes y niños respiran con más rapidez. La profundidad de las respiraciones varía normalmente de superficial a profunda. El ritmo de la respiración suele ser regular. Un ritmo respiratorio irregular se presenta cuando el ciclo inhalación/exhalación y las pausas intermedias se presentan en intervalos desiguales.

En la respiración hay que valorar la frecuencia, profundidad y ritmo respiratorios por inspección (observando y escuchando) o mediante su audición con el estetoscopio.

Hay que determinar la frecuencia al contar el número de respiraciones por minuto. Es importante conocer que si las respiraciones son muy superficiales y difíciles de detectar, se puede observar la escotadura esternal, donde la respiración es más aparente.

En un lactante o un niño pequeño, se debe valorar la respiración antes de realizar cualquier otro procedimiento sobre él, de manera que el niño no esté llorando, lo cual puede alterar el estado respiratorio.

\section{Oximetría del pulso}

Noguerol Casado y Seco González definen la oximetría de pulso o pulsioximetría como la medición no invasiva del oxígeno transportado por la hemoglobina en el interior de los vasos sanguíneos, realizándose esta medición con un aparato llamado pulsioxímetro o saturómetro. 
La oximetría del pulso es una técnica no invasiva que mide la saturación de oxihemoglobina de la sangre arterial. Un sensor usa un rayo de luz roja e infrarroja que viaja a través de los tejidos y los vasos sanguíneos. Una parte del sensor emite la luz y otra parte la recibe. Luego, el oxímetro calcula la cantidad de luz absorbida por la sangre arterial, la hemoglobina no oxigenada absorbe más luz roja mientras que la oxigenada absorbe más luz infrarroja.

Los transductores que se utilizan están preparados para emplearse sobre un dedo de la mano, un dedo del pie, un lóbulo de la oreja, la frente y el puente de la nariz.

Es importante conocer las limitaciones y las causas de error más comunes a la hora de tomar la oximetría de pulso que, según los nombrados autores son:

a) Anemia severa: la hemoglobina debe ser inferior a $5 \mathrm{mg} / \mathrm{dl}$ para causar lecturas falsas.

b) Interferencias con otros aparatos eléctricos.

c) El movimiento: los movimientos del transductor, que se suele colocar en un dedo de la mano, afectan a la fiabilidad (por ejemplo el temblor o vibración de las ambulancias), se soluciona colocándolo en el lóbulo de la oreja o en el dedo del pie o fijándolo con esparadrapo.

d) Contrastes intravenosos pueden interferir si absorben luz de una longitud de onda similar a la de la hemoglobina.

e) Luz ambiental intensa: xenón, infrarrojos, fluorescentes.

f) Mala perfusión periférica por frío ambiental, disminución de temperatura corporal, hipotensión, vasoconstricción... Es la causa más frecuente de error, ya que es imprescindible para que funcione el aparato que exista flujo pulsátil. Puede ser mejorada con calor, masajes, terapia local vasodilatadora, quitando la ropa ajustada, no colocar el manguito de la tensión en el mismo lado que el transductor.

g) La ictericia no interfiere.

h) El pulso venoso: fallo cardíaco derecho o insuficiencia tricuspídea. El aumento del pulso venoso puede artefactar la lectura, se debe colocar el dispositivo por encima del corazón.

i) Fístula arteriovenosa. No hay diferencia salvo que la fístula produzca isquemia distal.

j) La hemoglobina fetal no interfiere.

k) Obstáculos a la absorción de la luz: laca de uñas (retirar con acetona), pigmentación de la piel (utilizar el 5..$^{\circ}$ dedo o el lóbulo de la oreja).

l) Dishemoglobinemias: la carboxihemoglobina (intoxicación por monóxido de carbono) y la metahemoglobina absorben longitudes de onda similares a la oxihemoglobina. Para estas situaciones son necesarios otros dispositivos como CO-oxímetros.

Esta técnica no sustituye el análisis de gases en sangre arterial, aunque es cierto que la desaturación indica anomalías en el intercambio de gases. De esta manera, presenta ciertas ventajas y desventajas respecto a la gasometría. 
Ventajas respecto a la gasometría:

a) Proporciona una monitorización instantánea, continua y no invasiva.

b) No requiere de un entrenamiento especial. Es fácil de usar.

c) Es fiable en el rango de 80-100\% de saturación, que es el más interesante en la práctica clínica.

d) Además informa sobre la frecuencia cardiaca y puede alertar sobre disminuciones en la perfusión de los tejidos.

e) Es una técnica barata y existen aparatos portátiles muy manejables.

f) La gasometría es una técnica cruenta, que produce dolor y nerviosismo durante la extracción, dando lugar a hiperventilación, lo que puede llevar a sobreestimación de la oxigenación.

g) Asequible en Atención Primaria.

Desventajas respecto a la gasometría:

a) La pulsioximetría no informa sobre el $\mathrm{pH}$ ni la $\mathrm{PaCO}_{2}$.

b) No detecta hiperoxemia.

c) No detecta hipoventilación (importante en pacientes respirando aire con concentración elevada de $\mathrm{O}_{2}$ ).

d) Los enfermos críticos suelen tener mala perfusión periférica.

\section{Tensión arterial}

El Diccionario enciclopédico Taber define la presión arterial como «la tensión ejercida sobre las paredes de las arterias por la fuerza de la contracción del corazón, la resistencia de las arteriolas y los capilares, la elasticidad de los vasos sanguíneos y el volumen y viscosidad de la sangre».

La presión arterial normal se define como un valor de presión arterial sistólica que va de 100 a $120 \mathrm{mmHg}$, y un valor de presión diastólica por debajo de $80 \mathrm{mmHg}$ (en adultos mayores de 18 años). Cuando los valores de presión arterial se encuentran entre 120 y $140 \mathrm{mmHg}$ en la sístole y entre 80 y $90 \mathrm{mmHg}$ en la diástole se diagnostica prehipertensión. El Joint National Committee, en su vII informe, determina las cifras y categorías para establecer la hipertensión y el grado de las mismas. Estas cifras se exponen en la tabla 14.

\begin{tabular}{|lcc|} 
Categoría & PAS $(\mathbf{m m H g})$ & PAD $(\mathbf{m m H g})$ \\
\hline Normal & $<120$ & $<80$ \\
\hline Prehipertensión & $120-139$ & $80-89$ \\
\hline Hipertensión & & \\
\hline \multicolumn{1}{|c}{ Fase 1 } & $140-159$ & $90-99$ \\
\hline \multicolumn{1}{|c|}{ Fase 2 } & $\geq 160$ & $\geq 100$ \\
\hline
\end{tabular}

Tabla 14. Clasificación de la hipertensión según el protocolo de Joint National Committee on the Prevention, Detection, Evaluation and Treatment of High Blood Pressure 
Este mismo organismo ha presentado recientemente (2014) un algoritmo de decisión para ayudar en la toma de decisiones respecto a la presión arterial elevada en adultos (figura 32).

En los protocolos de la Generalitat Valenciana (2007), se define que la valoración de la presión arterial es la medición de la presión arterial, tanto sistólica como diastólica. El objetivo del procedimiento es obtener, con un método no invasivo o indirecto, la medición de la tensión arterial producida por el paso de la sangre a través de una arteria. El equipo que se requerirá para llevar a cabo la técnica es un fonendoscopio y un esfingomanómetro. $\mathrm{Y}$ el procedimiento que se establece es el siguiente:

a) Revisar el perfecto funcionamiento del equipo.

b) Realizar lavado de manos.

c) Preservar la intimidad del paciente.

d) Informar al paciente de la técnica a realizar.

e) Solicitar la colaboración del paciente y familia

f) Colocar al paciente sentado o en decúbito supino.

g) Asegurarse que el paciente está a reposo al menos diez minutos antes de la toma de tensión arterial, con la vejiga urinaria vacía, sin haber fumado o comido recientemente.

h) Proporcionar un entorno tranquilo y confortable.

i) Desvestir la parte superior del brazo del paciente, asegurándose de que no comprima la ropa, apoyado en una superficie lisa y con la fosa antecubital a nivel del corazón.

j) Colocar el manguito del esfingomanómetro dos centímetros por encima de la fosa antecubital y rodear uniformemente el brazo.

k) Palpar la arteria braquial y colocar el fonendoscopio encima $(2 \mathrm{~cm}$ por debajo del manguito). 


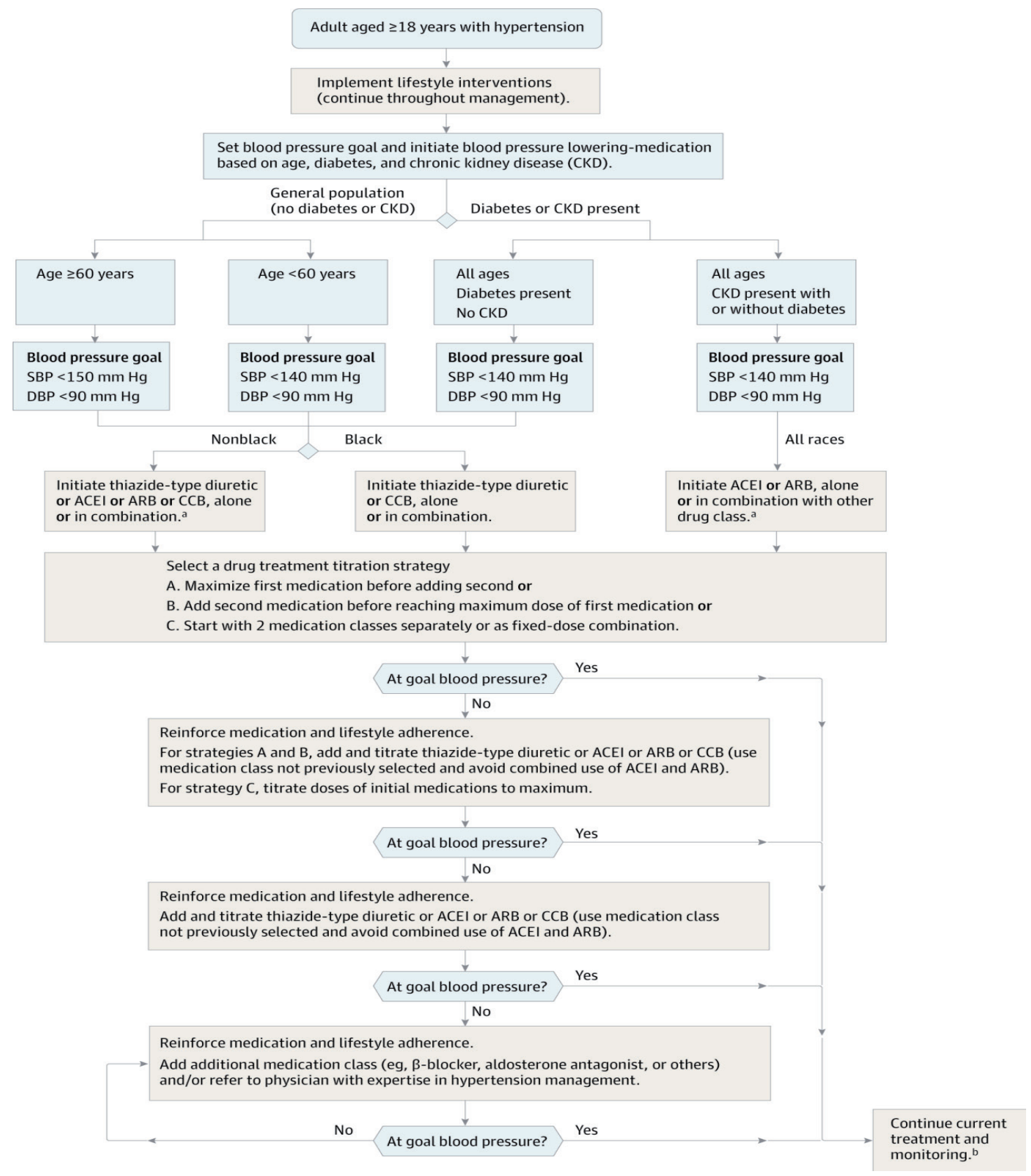

Figura 32. Algoritmo de decisión en HTA de la Joint National Committee, 2014

Leyenda:

SBP indicates systolic blood pressure; DBP, diastolic blood pressure; ACEI, angiotensin-converting enzyme; ARB, angiotensin receptor blocker; and CCB, calcium channel blocker. ACEIS and ARBS should not be used in combination. If blood pressure fails to be maintained at goal, reenter the algorithm where appropriate based on the current individual therapeutic plan.

l) Cerrar con la otra mano la válvula de la perilla.

m) Inflar el manguito hasta que el esfingomanómetro marque $20 \mathrm{mmHg}$ por encima de la tensión arterial habitual del paciente.

n) Abrir la válvula de salida de aire lentamente, hacerlo observando la escala para detectar el lugar en el que se escucha el primer sonido o presión sistólica o máxima, que gradualmente aumenta de tono e intensidad y se modifica progresivamente hasta que desaparece (presión diastólica o mínima). 
o) El siguiente sonido menos intenso es la 2. a cifra o presión diastólica.

p) Continuar disminuyendo la presión del manguito hasta que no se escuchen ruidos, 3. ${ }^{\mathrm{a}}$ cifra o $2 .^{\mathrm{a}}$ presión diastólica.

q) Retirar el manguito y fonendoscopio.

r) Dejar al paciente en posición cómoda.

$s$ ) Realizar lavado de manos.

t) Registrar en la documentación de enfermería las cifras obtenidas, fecha y hora de la toma.

u) Si los valores están fuera de la normalidad, actuar según prescripción médica o avisar al médico.

Observaciones:

a) Revisión del tensiómetro cada seis meses o cuando se precise.

b) Si se duda de alguna cifra obtenida, esperar dos minutos y volver a realizar la medición.

c) El tamaño del esfingomanómetro ha de ser de ancho dos tercios del brazo y de largo el perímetro del brazo más un $20 \%$. Han de ser los apropiados según peso y edad (tabla 15).

d) No tomar la presión arterial en el brazo de una paciente mastectomizada, con fístula arteriovenosa o amputación, tampoco en el brazo que soporta fluidoterapia.

e) Si se realiza la medición MMII colocar el fonendoscopio en el hueco poplíteo.

\begin{tabular}{|c|c|c|}
\hline Tamaño del manguito & $\begin{array}{c}\text { Medidas } \\
\text { del manguito }\end{array}$ & $\begin{array}{c}\text { Circunferencia } \\
\text { del brazo }\end{array}$ \\
\hline Recién nacidos-lactantes prematuros & $4 \times 8 \mathrm{~cm}$ & \\
\hline Lactantes & $6 \times 12 \mathrm{~cm}$ & \\
\hline Niños mayores & $9 \times 18 \mathrm{~cm}$ & 22 a $26 \mathrm{~cm}$ \\
\hline Tamaño para un adulto pequeño & $12 \times 22 \mathrm{~cm}$ & 27 a $34 \mathrm{~cm}$ \\
\hline Tamaño para un adulto & $16 \times 30 \mathrm{~cm}$ & 35 a $44 \mathrm{~cm}$ \\
\hline Tamaño para un adulto grande & $16 \times 36 \mathrm{~cm}$ & $42 \mathrm{a} 52 \mathrm{~cm}$ \\
\hline Tamaño para el muslo de un adulto & $16 \times 42 \mathrm{~cm}$ & \\
\hline
\end{tabular}

Tabla 15. Tamaños recomendados de manguitos para la toma de presión sanguínea.

Fuente: DAE, 2009 


\section{CAPÍTULO 13}

\section{Cuidados básicos del dolor: valoración y tratamiento}

\section{Introducción}

El dolor se considera hoy el quinto signo vital y una de los principales motivos de asistencia. De acuerdo con las normas JCAHO, es esencial valorar y tratar el dolor regularmente para mantener la homeostasis y la calidad de vida del paciente.

La Registered Nurses Association of Ontario (RNAO) (2002) afirma, en su guía de buenas prácticas en enfermería sobre valoración y manejo del dolor, que las enfermeras pueden asumir un papel fundamental en el manejo del dolor, utilizando el conocimiento actual sobre las medidas para mitigarlo y adoptando unas buenas prácticas en la valoración y el manejo del dolor. Las enfermeras tienen la obligación legal y ética de velar para que se utilicen los medios más efectivos dentro del sistema sanitario con el fin de lograr el bienestar y el alivio del dolor de los pacientes.

Los objetivos de este tema son definir el dolor, conocer los diferentes tipos de dolor, cómo realizar su valoración y los distintos tratamientos.

\section{Definición de dolor}

La Asociación Internacional para el Estudio del Dolor (IASP) define el dolor como «aquella experiencia sensorial y emocional desagradable, asociada a una lesión tisular presente o potencial, o descrita en términos de tal daño».

Margo McCaffery, una investigadora en enfermería que ha escrito sobre el cuidado de pacientes con dolor, define el dolor como «todo aquello que el paciente que lo experimenta dice que es un dolor, que existe donde él dice que está» (McCaffery, 1968). El profesional de enfermería depende totalmente del paciente para describir la sensación del dolor, identificar la ubicación e informar sobre la clase de dolor que se está experimentando.

Aunque en nuestra cultura vemos el dolor como algo negativo que queremos evitar, hay que considerar que se trata de un sistema de alerta de nuestro organismo, ya que nos avisa de que algo no funciona bien. Nos ayuda a sobrevivir ya que nos permite detectar situaciones perjudiciales y modificar nuestras conductas. Una 
perspectiva del dolor es que es un mensaje a nuestro yo consciente, para que compruebe las sensaciones dolorosas antes de que empeoren y comprenda cuál es la naturaleza del dolor.

La experiencia de dolor es directa y personal. Es completamente subjetiva. La información más importante en la valoración del dolor es, por tanto, lo que dice el paciente. Aunque el inicio del dolor agudo estimula el sistema nervioso simpático, provocando signos o síntomas (aumento de la frecuencia cardiaca, respiratoria, tensión arterial, etc.), que podrían considerarse objetivos, estos no son una evidencia concluyente para la identificación del dolor, que debe proceder del paciente.

La RNAO (2002) establece los siguientes principios en la valoración y manejo del dolor:

a) Los pacientes tienen derecho a que se alivie su dolor en la mayor medida posible.

b) El dolor agudo que no se ha podido eliminar tiene consecuencias y las enfermeras deben intentar prevenirlo siempre que sea posible.

c) El dolor no aliviado requiere un análisis crítico de los factores e intervenciones relacionados con él.

d) El dolor es una experiencia subjetiva, muy variable y multidimensional, independientemente de la edad o las necesidades específicas de cada persona.

e) Las enfermeras están legal y éticamente obligadas a defender un cambio en el plan de cuidados cuando el manejo del dolor es inadecuado.

f) Para la toma de decisiones relacionadas con el manejo del dolor es necesaria la colaboración de los pacientes y sus familias.

g) La valoración y manejo eficaz del dolor tiene un alcance multidimensional y requiere la intervención interdisciplinar coordinada.

h) La competencia clínica en la valoración y el manejo del dolor exige una formación continuada.

i) El uso efectivo de analgésicos opioides debería facilitar el desarrollo de actividades rutinarias como la deambulación, la actividad física y las actividades de la vida diaria.

j) Las enfermeras están obligadas a participar en la evaluación formal de los procesos y resultados del manejo del dolor a nivel organizativo.

k) Es responsabilidad de la enfermera el negociar con otros profesionales sanitarios los cambios organizativos necesarios para facilitar prácticas.

l) Las enfermeras recomiendan aquellos cambios en la política y la asignación de medios que vayan a respaldar un manejo efectivo del dolor. 


\section{Clasificación del dolor}

El dolor puede clasificarse en función de diferentes criterios. A continuación presentamos algunos de ellos:

1. Según su duración:

a) Agudo: se caracteriza por su comienzo bien definido, la presencia de síntomas y signos físicos objetivos y por acompañarse de hiperactividad del sistema autónomo. Tiene un final predecible y, en general, cumple una función de señal de alarma o de que algo no funciona bien. Aunque ocasionalmente hay factores psicológicos implicados, este dolor no se debe casi nunca a psicopatología o influencias ambientales.

b) Crónico: puede definirse como aquel que persiste después del curso habitual de una enfermedad aguda o después del tiempo razonable para que sane una lesión. Es un dolor que no tiene final predecible. Los factores ambientales y psicopatológicos influyen de forma importante.

2. Según su intensidad: La oms clasifica el dolor según su intensidad, con la finalidad de ir eligiendo el tipo de analgesia que corresponda en: leve, moderado, intenso e incapacitante.

3. Según su mecanismo etiopatológico:

a) Nocioceptivo somático: es un dolor sordo y amortiguado, más localizado sobre fascias, tejido muscular, periostio, articulaciones, ligamentos y tendones.

b) Nocioceptivo visceral: aparece a consecuencia de la estimulación visceral. Es un dolor sordo, difuso y difícil de localizar.

c) Neuropático: aparece cuando hay lesión del nervio y es un dolor quemante o urente, de tipo eléctrico como una descarga.

d) Psicógeno: Interviene el ambiente psicosocial que rodea al individuo.

e) Mixto: posee características nocioceptivas y neuropáticas de forma simultánea.

4. Según sus características:

a) Indicental o eruptivo: dolor que aparece de forma brusca ante la movilización. Es de difícil control.

b) Localizado: se produce en su lugar de origen y no irradia hacia otras zonas.

c) Referido: parte de las estructuras profundas y se irradia a otras partes del cuerpo.

d) Superficial: emerge del tejido donde abundan los nocioceptores, como la piel, los dientes y las mucosas y es fácilmente localizable. Se halla limitado a la parte del cuerpo inervado por el nervio afectado. Este es un concepto contrapuesto al de dolor visceral.

e) Dolor cólico: dolor de características agudas que puede estar desencadenado por numerosas enfermedades. 


\section{Valoración del dolor}

El dolor es todo aquello que el paciente dice que lo es, y existe siempre que el paciente dice que lo está sufriendo. La valoración del dolor es siempre subjetiva. En los pacientes que pueden comunicarse verbalmente, informar por si mismos de la presencia de dolor es el criterio de referencia para valorar su grado y su tipo. El profesional también valora otras conductas relacionadas con el dolor, como hacer muecas, balancearse o ponerse a la defensiva. El aumento de la frecuencia cardíaca y de la presión arterial son indicadores de la respuesta fisiológica al dolor, pero no tienen por qué demostrar una relación proporcional a la magnitud del dolor experimentado por el paciente.

Así, debemos tener en cuenta que la valoración de la experiencia dolorosa puede realizarse por dos procedimientos complementarios y, por tanto, no mutuamente excluyentes: valoración subjetiva y la valoración objetiva.

En la valoración del dolor deben considerarse los siguientes parámetros:

a) Localización del dolor

b) Efectos del dolor en las funciones y actividades de la vida diaria

c) Nivel de dolor en estado de reposo o de actividad

d) Manejo de la medicación

e) Factores desencadenantes o precipitantes

f) Calidad del dolor (¿Qué palabras utiliza la persona para describir el dolor? Dolor sordo, punzante, etc.?)

g) Irradiación del dolor (¿El dolor va más allá del foco inicial?)

h) Severidad del dolor (escala de intensidad de 0 a 10)

i) Frecuencia temporal (ocasional, intermitente, continua)

\subsection{Obtención de datos subjetivos}

Para la obtención de datos subjetivos respecto al dolor, existen múltiples escalas que podemos utilizar en la actualidad. Podemos realizar una clasificación de las escalas más utilizadas y más conocidas en nuestro ámbito (Montero Ibáñez y Manzanares Briega, 2005):

1. Escalas unidimensionales:

a) Escala verbal simple: En esta escala se utiliza las palabras como «leve», «moderado» o «intenso» para determinar la intensidad del dolor. Así, se pide al paciente que seleccione la palabra que describa mejor el dolor que sufre. Las limitaciones de esta escala son que el paciente tiene que ser capaz de comprender el significado de esas palabras.

b) Escala numérica de intensidad de dolor: En esta escala de tipo Likert de 11 puntos, el 0 significa «ausencia de dolor» y el 10 significa «el peor dolor posible». La escala numérica de intensidad del dolor requiere que 
los pacientes seleccionen el número que mejor se ajusta a la intensidad de dolor que sufren; cuanto mayor es el valor que señalen más intenso es el dolor. Por lo general, un dolor leve se considera en el intervalo entre 1 y 3 ; el dolor moderado se considera en el intervalo entre 4 y 6 ; y el dolor intenso se considera en el intervalo entre 7 y 10 (figura 33).



Figura 33. Escala numérica de intensidad de dolor. Fuente: Elaboración propia

c) Escala de la expresión facial (Faces Pain Scales [FPS]): Esta escala se utiliza en niños de dos meses a siete años. En los niños de siete a diez años, pueden utilizarse las mismas escalas de valoración numérica que en los adultos. Esta escala utiliza seis caras que van desde la felicidad, con amplia sonrisa, a la tristeza, con lágrimas en el rostro. Cada rostro tiene una puntuación asignada y se le pide al paciente que seleccione el rostro que mejor describe cómo se siente. Esta escala puede utilizarse en pacientes con incapacidad para describir el dolor, dificultad para entender los métodos de valoración, deterioro cognitivo o analfabetos (figura 34).

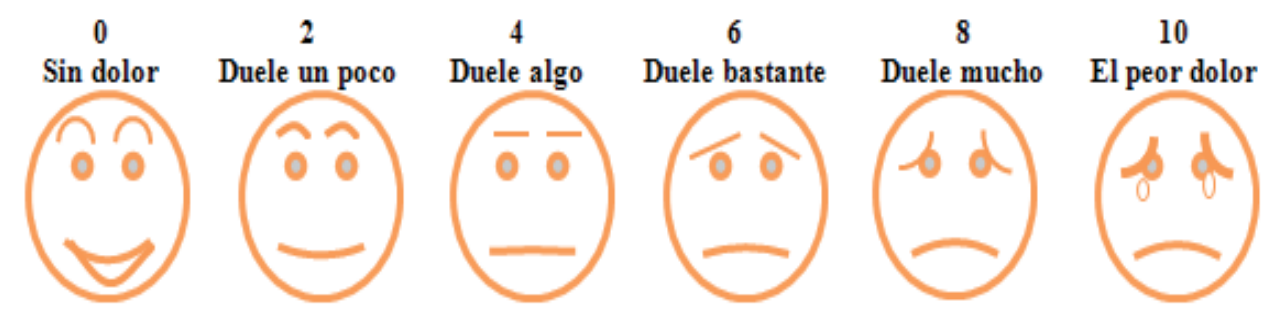

Figura 34. Escala de dolor de la expresión facial. Fuente: Google imágenes. Imagen libre

d) Escala visual analógica: La EVA es una línea de $10 \mathrm{~cm}$, con ausencia de dolor en un extremo y el peor dolor posible en el otro. Cuando se utiliza esta escala, el profesional pide al paciente que marque sobre la línea la intensidad del dolor que sufre. Si el paciente marca la línea a $7 \mathrm{~cm}$, el profesional anotaría un nivel de dolor de 7/10. Esta herramienta es una de las escalas unidimensionales del dolor más sencillas y básicas, y una de sus limitaciones es que algunos ancianos tienen dificultades a la hora de marcar en la línea y colocar la marca por encima o por debajo de $10 \mathrm{~cm}$ (figura 35).

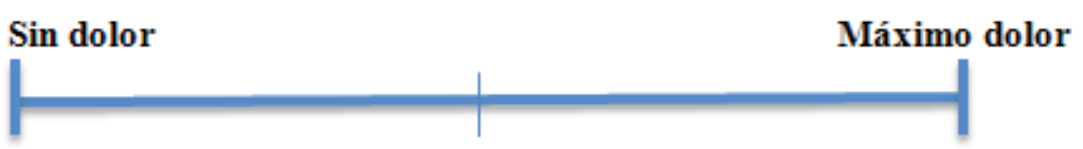

Figura 35. Escala visual analógica. Fuente: Elaboración propia 
2. Escalas multidimensionales:

Las escalas multidimensionales también sirven para valorar el dolor crónico, el dolor neoplásico o el de afecciones medicoquirúrgicas complejas. La que vamos a tratar en esta sección es el cuestionario de McGill, ya que es el más extendido. Este cuestionario cuenta con una combinación de índices que mide la intensidad del dolor, el estado de ánimo, la localización del dolor (a través de un esquema corporal), descriptores verbales y preguntas sobre la eficacia de los medicamentos.

Se utiliza con mayor frecuencia en investigación o con pacientes que reciben un tratamiento activo para el dolor durante un período prolongado. Se considera que la herramienta es válida y fiable y se ha traducido a diversos idiomas. Entre sus limitaciones se encuentran el hecho de puntuar y sopesar el apartado de descriptores verbales, y la dificultad para traducir este apartado en palabras que indican síndromes.

El cuestionario puede consultarse en el trabajo de Serrano-Atero et al. (2002) sobre la valoración del dolor disponible en http://revista.sedolor.es/ pdf/2002_02_06.pdf.

\subsection{Obtención de datos objetivos}

Además de la experiencia subjetiva de dolor, este tiene efectos objetivos en otros sistemas corporales. El dolor agudo puede activar en los pacientes una respuesta de lucha frente al estrés o de huida del mismo. En un episodio de este tipo, la presión arterial, el pulso y la respiración pueden aumentar, y el paciente sentirá el deseo imperioso de alejarse del estímulo doloroso. No obstante, es posible que estas respuestas observadas habitualmente no se produzcan en el caso del dolor crónico, porque los pacientes se han adaptado al estrés continuado y constante. Por lo tanto, el personal de enfermería no puede considerar un aumento de las constantes vitales como una indicación del nivel de dolor en pacientes con dolor crónico. Tienen que considerar los datos de las constantes vitales junto con otros indicadores, porque no hay modo de aislar los cambios con otras causas. Es posible también que aumente la tensión muscular, y el paciente puede responder defendiendo o protegiendo la zona afectada.

Tratar de forma insuficiente el dolor puede contribuir a que aparezcan náuseas, diaforesis y vómitos. Proporcionar analgésicos ayudará a aliviar estos efectos no deseados.

Además de las respuestas fisiológicas, el dolor se manifiesta con respuestas conductuales observables. La RNAO (2002) recomienda, en su guía sobre valoración y tratamiento del dolor, observar las siguientes conductas en personas con incapacidad cognitiva y verbal: 
a) Apatía

b) Disminución de la interacción

c) Reducción de ingesta y alteración del patrón de sueño

d) Balanceo

e) Verbalización negativa

f) Fruncir el ceño o muecas

g) Respiración ruidosa

h) Irritabilidad y agitación

Por último, como procedimiento específico para valorar el dolor, estableceremos:

a) Realizar una valoración exhaustiva del dolor que incluya la localización, características, aparición/duración, frecuencia, calidad, intensidad o severidad del dolor y factores desencadenantes.

b) Observar las claves no verbales de molestias, especialmente en aquellos pacientes que no pueden comunicarse eficazmente.

c) Asegurarse de que el paciente reciba los cuidados analgésicos correspondientes.

d) Utilizar estrategias de comunicación terapéuticas para reconocer la experiencia del dolor y mostrar aceptación de la respuesta del paciente al dolor.

e) Considerar las influencias culturales sobre la respuesta al dolor.

f) Determinar el impacto de la experiencia del dolor sobre la calidad de vida (sueño, apetito, actividad, función cognoscitiva, humor, relaciones, trabajo y responsabilidad de roles).

g) Evaluar las experiencias pasadas con el dolor que incluya la historia individual y familiar de dolores crónicos o que conlleven incapacidad, si es el caso.

h) Utilizar un método de valoración adecuado que permita el seguimiento de los cambios en el dolor y que ayude a identificar los factores desencadenantes reales y potenciales.

i) Determinar la frecuencia necesaria para la realización de una valoración de la comodidad del paciente y poner en práctica un plan de seguimiento.

j) Controlar los factores ambientales que puedan influir en la respuesta del paciente a las molestias (temperatura de la habitación, iluminación y ruidos).

k) Disminuir o eliminar los factores que precipiten o aumenten la experiencia del dolor (miedo, fatiga, monotonía y falta de conocimientos).

$l$ ) Enseñar el uso de técnicas no farmacológicas.

$m$ ) Proporcionar a la persona un alivio del dolor óptimo mediante analgésicos prescritos.

n) Utilizar medidas de control del dolor antes de que sea severo. 


\subsection{Consideraciones asociadas a las etapas del ciclo vital}

\subsubsection{Recién nacidos, lactancia e infancia}

El dolor no identificado y tratado de forma insuficiente es habitual en los recién nacidos, lactantes y niños, a pesar de la abundancia de herramientas para valorar el dolor. Los recién nacidos y los lactantes preverbales corren el riesgo de ser tratados insuficientemente, a causa de la falsa creencia de que no sufren dolor. Además, se les somete a muchas intervenciones dolorosas como la prueba del talón, venopunciones, vacunas, inyecciones de vitamina $\mathrm{K}$ o circuncisión. Son muchos los profesionales sanitarios que temen los efectos adversos asociados a la administración de analgésicos.

Gran parte de las investigaciones sobre la fisiología del dolor se han realizado en recién nacidos. El número de receptores del dolor en los bebés es parecido al de los adultos. Las conexiones existen entre los sistemas nerviosos periférico y central a partir de las 30 semanas de gestación. Los recién nacidos prematuros tienen una mayor sensibilidad al dolor, en comparación con los demás niños, algo que se cree que se debe a que el número de neurotransmisores inhibidores es insuficiente hasta el nacimiento a término. Comparados con los niños de mayor edad, los recién nacidos muestran más respuestas hormonales, metabólicas y cardiovasculares ante el dolor, y pueden necesitar dosis más elevadas de analgésico para controlarlo bien. Tratar el dolor de forma inadecuada puede causar un retraso en la curación y tener consecuencias en el comportamiento como problemas de aprendizaje, trastornos psiquiátricos y problemas de desarrollo neurológico.

\subsubsection{Personas mayores}

El dolor predomina en los adultos de edad avanzada, y un $80 \%$ de todos los pacientes que se encuentran en centros de asistencia prolongada, y entre un $25 \%$ y un $50 \%$ de los ancianos que viven en casa, refieren dolor crónico diario. El dolor no es una consecuencia normal del envejecimiento.

La enfermedad crónica puede influir en la valoración precisa del dolor, como sucede en la artrosis, la enfermedad vascular periférica o el cáncer. Los pacientes sometidos a intervenciones quirúrgicas o diagnósticas pueden sufrir dolor agudo. Es posible que no sean capaces de diferenciar si el dolor ha sido inducido quirúrgicamente o si es un dolor crónico procedente de anteriores afecciones dolorosas.

Se sabe poco acerca del efecto que tiene el envejecimiento en la percepción del dolor. No hay pruebas que indiquen que la sensación de dolor sea menor en los ancianos, una percepción errónea frecuente. La transmisión a lo largo de las fibras nerviosas que canalizan el dolor puede alterarse con la edad, pero no está claro cómo afecta este cambio a la experiencia del dolor. Los estudios sobre sensibilidad y tolerancia al dolor han indicado que probablemente los cambios en la percepción de este no son clínicamente significativos. 
Algunas cuestiones relacionadas con los profesionales sanitarios también pueden influir en el tratamiento del dolor en las poblaciones de mayor edad. Puesto que es probable que los ancianos presenten más efectos secundarios por la analgesia, sobretodo en el caso de opiáceos, puede que los profesionales sanitarios traten de un modo insuficiente el dolor en estos pacientes.

El profesional de enfermería valora si el paciente de edad avanzada tiene alguna alteración auditiva. Si es así, se sitúa delante del paciente, habla despacio, con un tono de voz normal, reduce el ruido ajeno y proporciona instrucciones por escrito. Puesto que es posible que los adultos mayores procesen la información más lentamente que los pacientes más jóvenes, el personal de enfermería también les deja tiempo suficiente para responder.

La alteración cognitiva, la demencia y la confusión son más frecuentes en los ancianos. Valorar con precisión el dolor es más complicado cuando los pacientes sufren estas afecciones. Sin embargo, no hay pruebas de que los pacientes con una alteración cognitiva experimenten menos dolor. El personal de enfermería no debe considerar que la información relativa al dolor procedente de estos pacientes sea menos válida que la de otros enfermos. Los profesionales sanitarios pueden observar las conductas relacionadas con el dolor (p.e. inquietud, ponerse a la defensiva, pasear con nerviosismo) que muestran los pacientes para valorar este síntoma, pero estas observaciones no son específicas del dolor y pueden responder a otras situaciones.

\subsection{Consideraciones culturales y ambientales}

Estudios en EE. UU. han demostrado que es más probable que los profesionales sanitarios puntúen más bajo el dolor en los pacientes de grupos raciales o étnicos minoritarios que en los pacientes caucásicos. También se observan diferencias en cuanto a las expectativas de recibir un tratamiento apropiado para el dolor. Los afroamericanos, los hispanos y otros pacientes pertenecientes a minorías raciales o étnicas reciben menos analgésicos, en comparación con la población caucásica, en diversas situaciones, como en el dolor oncológico, el dolor postoperatorio inmediato, el dolor torácico, el dolor agudo que aparece en urgencias y la lumbalgia crónica. Esta diferencia puede deberse a factores relacionados con el paciente, como diferencias nociceptivas, procesos de comunicación o comportamientos relativos al dolor. En estudios sobre dolor inducido experimentalmente, no existen pruebas directas que relacionen los factores biopsicosociales con las diferencias étnicas en cuanto a la existencia del dolor. Sin embargo, puede haber diferencias relacionadas con la raza en cuanto a la buena disposición para comunicar el dolor, con el fin de evitar ser estereotipado.

Existen diferencias sexuales relacionadas con el dolor. Enfermedades como la fibromialgia, el síndrome de colon irritable, las migrañas y el dolor articular temporomandibular predominan más en las mujeres que en los hombres. Todos los pacientes muestran una mayor respuesta fisiológica al dolor, incluido el aumento de 
la frecuencia cardíaca y de la presión arterial. A pesar de la considerable atención dedicada a factores biológicos (como las influencias hormonales y genéticas), los factores psicológicos y sociales también podrían explicar las diferencias sexuales a la hora de comunicar el dolor. Se desconoce si existen diferencias específicas de uno u otro sexo que sean fundamentales en los mecanismos básicos del dolor. Es necesario alcanzar una mayor comprensión de las cuestiones fisiológicas, sociales y psicológicas que influyen en el mismo.

El profesional debe valorar factores socioculturales como la pertenencia a una etnia, la aculturación y el sexo, que influyen en la conducta y expresión relacionadas con el dolor. También debe identificar variables sociales y contextuales que pueden ser causa de disparidad relativa al dolor entre las minorías raciales y étnicas.

\section{Tratamiento del dolor}

En lo que respecta al tratamiento del dolor, debemos ser conscientes de la multidimensionalidad del mismo, por ello debemos conocer que el tratamiento también puede ser abarcado desde varios aspectos:

\subsection{Tratamiento no farmacológico del dolor}

En cuanto a las técnicas que pueden ayudar a la reducción del dolor de forma no farmacológica, ya hemos tratado alguna en el apartado de comodidad. Así, debemos conocer que también podemos realizar el alivio del dolor a través del tacto (masaje) o usar técnicas de relajación para aliviarlo.

El control ambiental de los elementos que envuelven al paciente también es un factor no farmacológico para conseguir la reducción e incluso la paliación del dolor. De esta manera reducir la luz de la habitación, controlar que la temperatura sea muy agradable para el paciente, el olor, e incluso el tacto con el que el paciente siente las sábanas, toallas etc. puede colaborar a la reducción del mismo.

\subsection{Tratamiento farmacológico del dolor}

Aunque desde enfermería no vamos a prescribir los fármacos a administrar, sí debemos conocer que hay componentes y herramientas desarrolladas para el control del dolor, así como también debemos conocer la escalera analgésica para el tratamiento del dolor propuesta por la oms (figura 36), ya que, como sanitarios, debemos conocer hasta donde podemos llegar con la terapia farmacológica. A continuación se expone dicha escalera. 


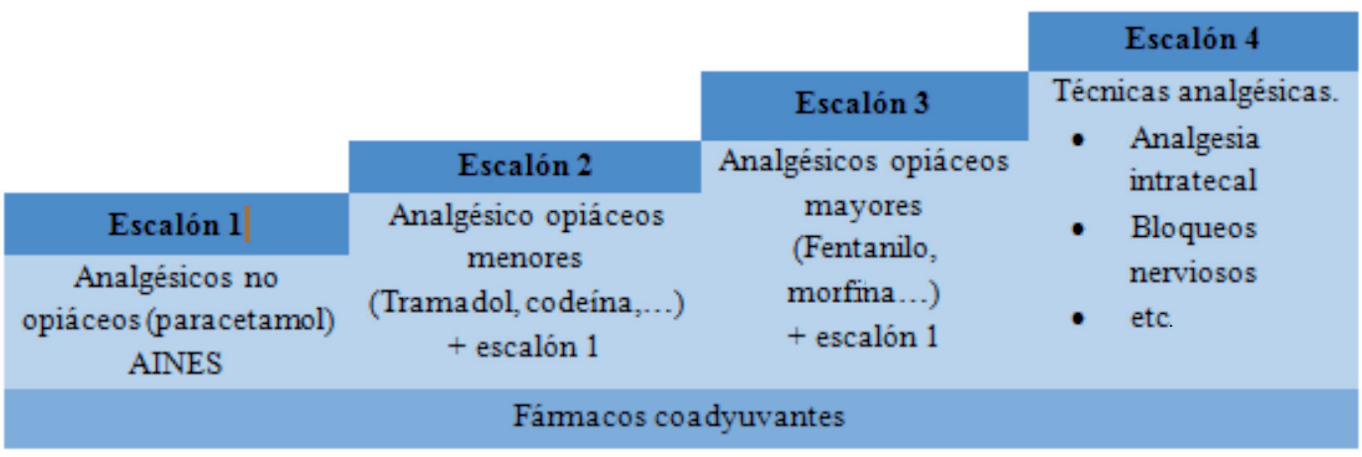

Figura 36. Escalera analgésica de la oms. Fuente: Elaboración propia

\subsection{Educación de paciente y prevención de efectos adversos relacionados con el dolor}

El dolor no es una buena experiencia, y puede afectar tanto desde el punto de vista físico como emocional. Para el personal de enfermería que atiende a pacientes que sufren dolor, el tratamiento apropiado es un factor crucial. El dolor agudo que no recibe un tratamiento adecuado puede alterar la función respiratoria, disminuir la respuesta inmunitaria y prolongar la estancia en el hospital. En los pacientes con dolor crónico, el tratamiento apropiado del dolor disminuye el estrés y aumenta la capacidad funcional del paciente.

Si el dolor agudo no se trata o se hace de forma insuficiente, los pacientes tienen riesgo de sufrir síndromes de dolor neuropático más difíciles de tratar, como el síndrome del dolor regional complejo. La presencia continua de estímulo doloroso en los nervios periféricos causa plasticidad neuronal y transfiere el estímulo doloroso al sistema central. Estos síndromes son muy difíciles de tratar.

Los pacientes que se han sometido a una intervención quirúrgica o que han sufrido una lesión por aplastamiento tienen un mayor riesgo de sufrir síndrome del dolor regional complejo. El profesional debe saber que, cuando un paciente con una lesión de este tipo sigue refiriéndose a un nivel elevado de dolor y empieza a experimentar la consiguiente pérdida funcional, sensibilidad térmica, inflamación u otras alteraciones cutáneas, es posible que sufra un síndrome del dolor regional complejo. También deben estar alerta ante los términos que suelen utilizar los pacientes para informar de un dolor neuropático, como quemazón, hormigueo doloroso, sensación de alfileres y agujas (sensación parestésica) y entumecimiento doloroso.

El hecho de enseñar a los pacientes las ventajas de controlar el dolor puede ayudar a corregir la percepción errónea que algunos enfermos tienen sobre tolerar el dolor estoicamente, en lugar de tomar medicación para aliviarlo. El dolor tiene muchas consecuencias negativas, y es importante ayudar a los pacientes a comprender que 
informar del dolor y tratarlo es una forma de mantener un nivel elevado de salud y de evitar algunos síndromes de dolor crónico. Si el paciente sigue rechazando los analgésicos, el personal de enfermería ha de considerar la posibilidad de hacerse las siguientes preguntas:

a) ¿Tiene el paciente prejuicios negativos con respecto a la toma de analgésicos?

b) ¿Puede permitirse el paciente los medicamentos prescritos?

c) ¿Existen efectos secundarios como estreñimiento, náuseas o sensación de mareo que sean la causa del rechazo del paciente a tomar los analgésicos?

En algunos casos, puede administrarse a los pacientes antieméticos o laxantes, o ajustar la dosis para facilitarles la tolerancia a los analgésicos. Si un paciente sigue rechazando la toma de analgésicos, es muy importante comprender cuál es la causa principal de este rechazo para poder administrar el tratamiento apropiado. 


\section{CAPÍTULO 14}

\section{Cuidados básicos \\ de los catéteres intravenosos}

\section{Introducción}

En este apartado trataremos de forma muy básica y sólo como a modo de recordatorio la inserción del catéter venoso periférico. Además, para ampliar conocimientos y dado que se espera una nueva etapa de aprendizaje en un ambiente todavía no explorado, trataremos el uso de los dispositivos intravasculares más utilizados que son los catéteres intravenosos periféricos, su inserción y mantenimiento.

\section{Técnica de inserción de catéteres periféricos}

Según la Guía de Actuación de Enfermería. Manual de procedimientos generales de la Generalitat Valenciana (2007), la inserción de catéteres intravenosos periféricos se refiere a la introducción de un catéter periférico para un acceso vascular, que se realiza con el fin de mantener un acceso venoso con fines terapéuticos, diagnósticos y, también, en caso de emergencia. El procedimiento a llevar a cabo es el siguiente:

a) Realizar el lavado de manos

b) Preparar el material necesario (a modo de recordatorio)

c) Preservar la intimidad del paciente

d) Informar al paciente del procedimiento a realizar

e) Solicitar su colaboración

f) Colocar al paciente en una posición cómoda según la zona de punción

g) Seleccionar la vena más adecuada según el estado del paciente, características de la solución a infundir, calibre del catéter. Hay que asegurarse de que el punto elegido no va a dificultar las actividades de la vida diaria del paciente y elegir venas que se palpen con facilidad, blandas, llenas y no obstruidas, si es posible

h) Proceder a la desinfección alcohólica de las manos

i) Colocar el compresor $10-15 \mathrm{~cm}$ por encima de la zona de punción. El torniquete debe estar lo bastante apretado como para detener la circulación venosa, pero no la arterial

j) Utilizar los dedos índice y medio de la mano no dominante para palpar la vena 
k) Desinfectar la zona desde el centro hacia fuera y dejar secar

l) Colocarse los guantes

$m$ ) Retirar la funda del catéter y cogerlo con la mano dominante

n) Fijar la piel con la mano no dominante para evitar que la vena se desplace

o) Insertar el catéter

p) Seguir introduciendo el catéter hasta que se observe la sangre refluir. Cuando refluya la sangre avanzar un poco el catéter e ir introduciendo la cánula a la vez que se retira la guía o aguja. No debe notarse resistencia

q) Retirar el compresor

r) Comprobar la permeabilidad del catéter introduciendo SSF, unos 2-3 cc observando que no haya obstrucción o extravasación del líquido introducido

s) Conectar el equipo de infusión o el obturador. En los equipos de bioseguridad el obturador asegura la permeabilidad del catéter

t) Colocar una gasa estéril debajo de la conexión catéter-equipo y obturador para evitar lesiones en la piel

u) Fijar el catéter mediante apósito estéril

v) Fijar el equipo de infusión a la piel para evitar tracciones

$w)$ Desechar el material punzante en el contenedor destinado para ello

$x$ ) Recoger el material

y) Dejar al paciente en una posición cómoda

z) Retirarse los guantes

aa) Realizar el lavado de manos

$b b)$ Registrar en la documentación de enfermería: el procedimiento, motivo, fecha y hora, calibre del catéter, número de intentos de venopunción, incidencias y respuesta del paciente

Observaciones:

a) Las venas utilizadas generalmente para el tratamiento intravenoso son la basílica, cefálica y las interóseas

b) Evitar las venas de las zonas de flexión. No utilizar venas con flebitis, infiltrados, esclerosadas, duras, las venas del miembro donde se le ha realizado un mastectomía o tiene una fístula arteriovenosa, las venas de miembros inferiores o la extremidad afectada por un accidente cerebrovascular

c) En los niños las venas de elección son las de los pies y cuero cabelludo

d) Si el enfermo tiene gran cantidad de pelo, no rasurar, cortar el vello con unas tijeras

e) En cada intento de inserción utilizar un nuevo catéter

En el siguiente enlace se puede observar la técnica de inserción de un catéter venoso periférico: https://www.youtube.com/watch?v=GAqkuioKeIM. 


\section{Cuidados de los catéteres periféricos}

El cuidado de los catéteres venosos periféricos es de suma importancia. Así, se definen estos cuidados como el conjunto de actividades realizadas por la enfermera al paciente portador de catéter periférico, con el objetivo de mantener el catéter permeable y prevenir infecciones.

Actualmente existen estudios vigentes para comprobar, determinar y verificar cuales de estos cuidados son más adecuados, pero, hasta la publicación de dichos estudios, los cuidados más relevantes y que han demostrado cierta eficacia en la práctica clínica se reflejan en la tabla 16 (Estrategia de mejora de la calidad de los cuidados. Protocolos de Cuidados de Enfermería Basados en la Evidencia, Gobierno de Aragón, 2009).

\section{Actividad}

\section{Niveles \\ de evidencia}

\section{Excepciones}

\section{Higiene de las manos}

Realizar una correcta higiene de las manos, bien lavándolas con un jabón antiséptico, o utilizando soluciones hidroalcohólicas. Garantizar la higiene de manos antes y después de palpar las zonas de inserción de los catéteres, así como antes y después de insertar, reemplazar, acceder, reparar o colocar un apósito a un catéter intravascular. La palpación del sitio de inserción no puede hacerse después de la aplicación de antiséptico, a no ser que se mantenga la técnica aséptica.

El uso de guantes no excluye el lavado de manos.

Categoría IA

\section{Información al paciente}

Informar al paciente sobre el procedimiento a realizar y los motivos de la inserción.

Animar a los pacientes a comunicar al personal sanitario cualquier cambio que noten en la zona de inserción de su catéter o cualquier molestia.

\section{Selección del punto de inserción del catéter periférico}

En adultos, para la inserción de un catéter periférico usar una zona en una extremidad superior, en lugar de una extremidad inferior. Cambiar cualquier catéter colocado en una extremidad inferior por otro en la extremidad superior lo antes posible.

En caso de intervención quirúrgica o pruebas diagnósticas, seguir protocolo específico.

En pacientes afectos de hemiplejías, portadores de fístulas arteriovenosas o mastectomizadas, no utilizar la extremidad afectada.

Los catéteres venosos periféricos se insertarán preferiblemente desde la zona distal a la proximal.

Cuando no hay otras indicaciones (cirugía, intervenciones previas), se canalizará la extremidad superior no dominante, teniendo en cuenta las preferencias del paciente.

Categoría IA

Grado C

Categoría II
Categoría IA En los pacientes pediátricos, se pueden usar con preferencia mano, dorso del pie, o Grado C cuero cabelludo como zonas de inserción.

Grado C Categoría II
Grado C 


\section{Actividad}

\section{Selección del dispositivo intravascular periférico}

Elegir el catéter, técnica de inserción y la zona con el menor riesgo de complicaciones (infecciosas y no infecciosas), dependiendo de la duración previsible y del tipo de terapia intravenosa.

Seleccionar el tipo de catéter en función del objetivo buscado y de la experiencia de los profesionales que habitualmente manejan estos catéteres.
Niveles
de evidencia

Excepciones

Utilizar el catéter de menor calibre necesario.

Categoría IA

Categoría IB

\section{Preparación de la zona de inserción}

Si la zona de inserción presenta gran cantidad de vello, este se recortará con tijeras o maquinilla eléctrica. Debe evitarse hacer cortes o erosionar la piel, porque aumenta el riesgo de infección.

\section{Uso de antisépticos}

Aplicar sobre la piel limpia un antiséptico adecuado, antes de insertar el catéter y al cambiar el apósito. Aunque sea preferible una preparación de clorhexidina al $2 \%$, se puede utilizar tintura de yodo, un yodóforo (ej. povidona yodada) o alcohol al $70 \%$.

Dejar que el antiséptico permanezca en la zona de inserción y que se seque al aire antes de la inserción del catéter. En el caso de la povidona yodada, dejarla en la piel durante al menos dos minutos, o más si todavía no está seca.

No palpar el punto de inserción después de que la piel se haya desinfectado con antiséptico.

\section{Técnica aséptica durante la inserción y cuidado del catéter}

Mantener técnica aséptica para la inserción y el cuidado de catéteres intravasculares.

La utilización de guantes limpios en lugar de estériles para la colocación de catéteres intravasculares periféricos es aceptable, siempre y cuando no se toque la zona de inserción tras la aplicación de los antisépticos cutáneos.

\section{Elección del apósito y fijación del catéter}

Utilizar un apósito estéril de gasa o un apósito estéril transparente semipermeable, para cubrir la zona de inserción del catéter.

Si el paciente presenta exceso de sudoración, o si la zona de inserción presenta sangrado o exudación, es preferible usar un apósito de gasa, en vez de uno transparente semipermeable.

No se recomienda el uso de corbata para la fijación de los dispositivos intravasculares periféricos. De ser necesario, la fijación debe realizarse lo más distal posible del punto de inserción, sin romper la asepsia, utilizando para ello tiras adhesivas estériles, y sin tapar el punto de inserción.
Categoría IA En niños menores de 2 meses no hay evidencia sobre el uso de clorhexidina. Asunto sin resolver

Categoría IB

Categoría IA

Categoría IA

Categoría IA

Categoría IA

Categoría II

Grado C 
Niveles

de evidencia

\section{Mantenimiento del catéter}

Observar la zona de inserción del catéter diariamente, mediante palpación sobre el apósito con el fin de averiguar la sensibilidad, o mediante inspección si se utiliza un apósito transparente.

Cambiar el catéter periférico venoso si el paciente presenta signos de flebitis (por ejemplo: calor, hipersensibilidad, eritema, y cordón venoso palpable), infección o mal funcionamiento del catéter.

Sustituir el apósito de la zona de inserción del catéter si está húmedo, aflojado o visiblemente sucio.

En adultos, cambiar los catéteres venosos periféricos al menos cada 72-96 horas para prevenir la aparición de flebitis. Cuando las zonas de acceso venoso son limitadas, y no hay evidencia de flebitis o infección, los catéteres venosos periféricos pueden permanecer en la misma zona durante períodos más largos, aunque el paciente y la zona de inserción tendrán que ser estrechamente vigilados.

Cuando no se puede asegurar que se aplicó una técnica aséptica (caso de urgencia) proceder a cambiar el catéter lo antes posible y siempre dentro de las primeras 48 horas.

$\begin{array}{ll}\text { Categoría II } & \begin{array}{l}\text { En pacientes } \\ \text { pediátricos dejar } \\ \text { los catéteres } \\ \text { venosos periféricos } \\ \text { hasta que la terapia }\end{array} \\ \text { intravenosa haya } \\ \text { Categoría IB } \\ \text { finalizado, a no ser } \\ \text { que se produzcan } \\ \text { complicaciones } \\ \text { (flebitis o } \\ \text { extravasación). } \\ \text { Categoría IB }\end{array}$

Categoría IB

Categoría II
A menos que se sospeche o se haya diagnosticado una infección relacionada con el catéter, no cambiar los sistemas de infusión, incluidos todos los elementos colaterales y dispositivos adicionales antes de que hayan transcurrido 72 horas.

Para el cambio del sistema utilizado para la infusión intermitente, no existe recomendación.

Cuando el sistema de infusión se haya utilizado para administrar sangre, productos sanguíneos o emulsiones lipídicas se cambiará en el plazo de 24 horas desde el inicio de la infusión.

Cambiar el sistema de infusión utilizado para administrar infusiones de Propofol cada seis o doce horas, dependiendo de su uso, según las recomendaciones del fabricante.

Tapar todas las llaves de cierre cuando no se estén usando.

Mantener los equipos de terapia en forma de circuito cerrado.
Categoría IA

(Asunto sin resolver)

Categoría IB

Categoría IA

Categoría IB

Grado C

\section{Precauciones}

En caso de obstrucción del catéter, no lavarlo nunca con jeringa y suero fisiológico, ya que el trombo formado se desprenderá al torrente sanguíneo. Se procederá a su retirada.

Grado C 


\section{Retirada del catéter}

Retirar lo antes posible cualquier catéter intravascular que ya no sea indispensable.

Categoría IA

Para retirar el catéter presionar el punto de inserción con una gasa Grado C impregnada con un antiséptico, a la vez que se retira.

\section{Registro}

Anotar:

a) El tipo de catéter periférico y el calibre del mismo.

b) La fecha y lugar de inserción.

c) La fecha de los cambios del sistema, del apósito y de la vía.

d) Incidencias relacionadas con el mantenimiento del catéter.

e) Nombre de la enfermera.

\section{Niveles de evidencia referidos:}

Grados de recomendación (los siguientes grados de recomendación derivan de los niveles de efectividad establecidos por el Instituto Joanna Briggs (Rev. 2008).

GRADO A: Efectividad demostrada para su aplicación.

GRADO B: Grado de efectividad establecido que indica considerar la aplicación de sus resultados.

GRADO C: Efectividad no demostrada.

Categorización elaborada por los Centers For Disease Control and Prevention (CDC) y el Healthcare Infection Control Practices Advisory Committee (HICPAC)

CATEGORÍA IA: Fuertemente recomendada para su implantación, y fuertemente sustentada por estudios experimentales, clínicos o epidemiológicos bien diseñados.

CATEGORÍA IB: Fuertemente recomendada para su implantación, y sustentada por algunos estudios experimentales, clínicos o epidemiológicos, y por un sólido razonamiento teórico.

CATEGORÍA IC: Requerida por las reglamentaciones, normas o estándares estatales o federales de EE. UU. CATEGORÍA II: Aconsejada para su implantación y sustentada por estudios sugestivos clínicos o epidemiológicos o por un razonamiento teórico.

ASUNTO SIN RESOLVER: Se trata de un tema sobre el que no existe suficiente evidencia o no hay consenso en cuanto a su eficacia.

Tabla 16. Cuidados de catéteres vasculares periféricos. Fuente: Departamento de Salud y Consumo. Gobierno de Aragón 


\section{CAPÍTULO 15}

\section{Cuidados básicos perioperatorios}

\section{Introducción}

La cirugía se conoce desde la antigüedad. Se han descubierto tratados egipcios y mesopotámicos donde ya se describen técnicas de suturar heridas y realizar amputaciones o extracciones dentales. Sin embargo, los avances más importantes en cirugía surgen en el siglo XIX con el descubrimiento de la anestesia, la antisepsia y la hemostasia.

\section{El proceso quirúrgico}

Hacia el año 1800, la cirugía se limitaba a lo esencial para salvar vidas, como la extracción de balas de músculos, amputación de miembros, extracciones dentales, incisión de abscesos y reparación de fracturas óseas. Casi el $80 \%$ de las heridas eran sépticas. Hoy en día, la cirugía ha avanzado en el uso de técnicas y el control de infecciones.

En el denominado proceso quirúrgico se dan un conjunto de características que son comunes a todos los enfermos que, por una u otra razón, deben someterse a una intervención quirúrgica. Este es el motivo por el que se habla específicamente de unos cuidados de enfermería perioperatorios, que son aplicados por los profesionales de enfermería quirúrgica. Habitualmente se divide el proceso quirúrgico en tres apartados que, aun desarrollándose sin solución de continuidad, pueden diferenciarse claramente: preoperatorio, intraoperatorio y postoperatorio (figura 37 ).

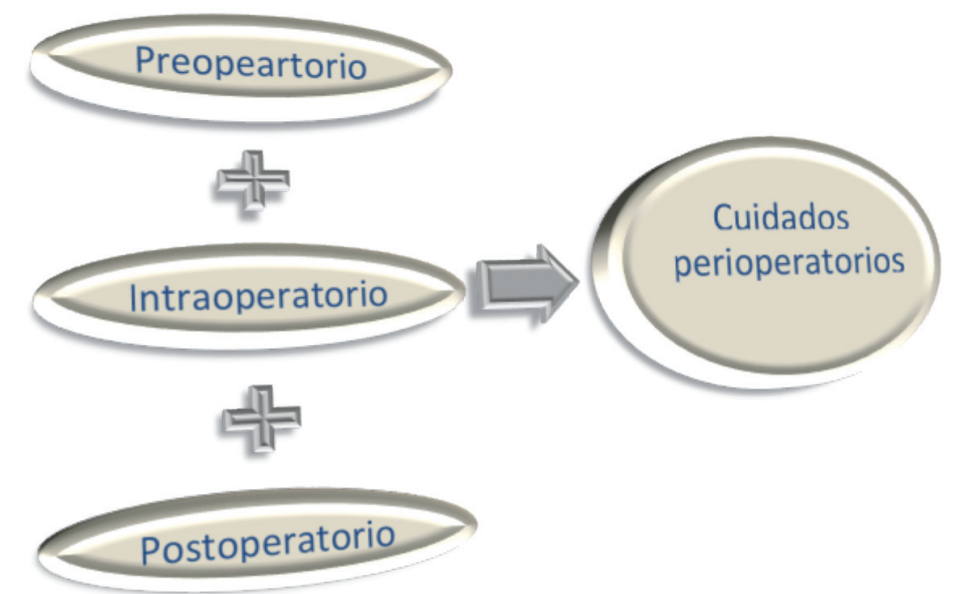

Figura 37. Cuidados perioperatorios. Fuente: Elaboración propia 
Desde esta perspectiva definimos a los cuidados perioperatorios como los cuidados que necesita un paciente ante un acto quirúrgico. Sin olvidar que se trata de un cuidado continuo y sin interrupción durante todo el proceso, distinguimos los cuidados en el preoperatorio, que es la preparación del paciente antes de entrar a quirófano; cuidados intraoperatorios son aquellos que se le realizan al paciente mientras se lleva a cabo la cirugía; y cuidados postoperatorios que son los realizados inmediatamente después de la operación en la sala de reanimación.

Actualmente, podemos distinguir diversos tipos de cirugía. Así, la cirugía se puede clasificar según su duración en:

a) Cirugía ambulatoria: Es una cirugía sencilla que no requiere cuidados postoperatorios expertos.

b) Cirugía en el mismo día: El ingreso se realiza el mismo día. Requiere cuidados postoperatorios expertos, con valoración de enfermería.

c) Ingreso hospitalario precoz: El ingreso se realiza días antes de la cirugía. Necesita cuidados y tratamientos especiales antes de la intervención.

Según el propósito, la cirugía puede clasificarse en:

a) Diagnóstica: Su objetivo es poder diagnosticar una enfermedad, por ejemplo biopsia y laparotomía.

b) Curativa: Se pretende extirpar o reparar la parte dañada de un órgano (por ejemplo, apendicitis).

c) Paliativa: Es el procedimiento quirúrgico para evitar incapacidades, aliviar el dolor y/o prolongar la vida (por ejemplo, colostomía).

d) Restaurativa: Su propósito es la reconstrucción de una articulación (por ejemplo, prótesis de cadera), la unión de los bordes de una herida quirúrgica, la corrección de deformidades, etc.

e) Estética: Para mejorar el aspecto del paciente (por ejemplo, rinoplastia).

\section{Cuidados básicos preoperatorios}

La fase preoperatoria abarca el periodo de tiempo que va desde el momento en que el paciente acepta someterse al tratamiento quirúrgico que se le ha prescrito, hasta su traslado al quirófano donde será intervenido.

La mayor parte de la responsabilidad de esta etapa corre a cargo de la enfermera de hospitalización, que será la que esté en contacto con el paciente en los días previos a su intervención. En ocasiones se habla de un preoperatorio inmediato, que en su etapa más tardía se desarrollaría dentro del quirófano, en los momentos previos a la anestesia del paciente, y que correría a cargo de las enfermeras del bloque quirúrgico.

Es un periodo que puede durar desde horas (en el caso de las intervenciones de emergencia) hasta varios meses. Pero, independientemente de su duración, la actuación de enfermería va dirigida a asegurar las mejores condiciones físicas y psi- 
cológicas del paciente. Para esto será imprescindible una minuciosa valoración y la elaboración de un plan de cuidados individualizado, que garantice que el sujeto se encuentra en condiciones físicas y psicológicas óptimas, para poder abordar el acto quirúrgico y el periodo postoperatorio con los menores riesgos y complicaciones posibles.

\subsection{Recepción del paciente}

La persona que ingresa en un hospital para una intervención quirúrgica experimenta una serie de sensaciones negativas que pueden afectar su estabilidad emocional. Estas sensaciones vienen precedidas de unos cambios que sufre la persona en el momento de tener que ser ingresado en un centro hospitalario:

a) El paciente, durante un periodo de tiempo indeterminado, cambia su lugar de residencia habitual por el hospital, separándose de su ambiente familiar.

b) El paciente experimenta una gran ansiedad debido a su nueva situación (intervención, riesgos, etc.).

c) En el seno familiar pueden surgir conflictos debido a la situación de hospitalización. El paciente siente cómo depende de otras personas, además, pierde su intimidad al llegar al hospital.

En definitiva, en la vida del paciente se producen grandes cambios que van a repercutir en el individuo, generándole una gran ansiedad e incertidumbre.

En esta fase preoperatoria, se le realizará al paciente una valoración exhaustiva de enfermería, junto a una exploración física que comprenderá el estado neurológico, cardiovascular, respiratorio, digestivo, genitourinario, piel y anexos, estado sensorial y músculo-esquelético. Además se realiza una valoración de los factores de riesgo determinados por: la edad, el estado nutricional, la existencia de alteraciones respiratorias, enfermedad cardiovascular, insuficiencia renal, diabetes mellitus, uso de medicamentos, tabaquismo, alcohol y otras drogas.

Por último, el paciente se someterá a una batería de pruebas diagnósticas que, normalmente son:

a) Radiografía anteroposterior de tórax.

b) Electrocardiograma.

c) Análisis de sangre: hemograma, pruebas de coagulación y bioquímica.

Con lo que respecta al procedimiento a realizar de forma preoperatoria con el paciente por parte de la enfermera de hospitalización, presentamos el siguiente procedimiento tipo, que podrá variar en función de la organización de diferentes unidades de hospitalización:

a) Informar al paciente y familia sobre los cuidados de enfermería preoperatorios y normas de higiene a realizar (entregar hoja informativa). 
b) Resolver las dudas que se planteen, disminuyendo en la medida de lo posible la ansiedad del paciente y familiares. Nunca dar información sobre el diagnóstico y el pronóstico.

c) Informar al paciente y familia sobre el día de la intervención, dónde deben esperar y dónde les informará el cirujano (sala de espera de Reanimación).

d) Revisar la historia clínica del paciente.

e) Comprobar que las uñas estén limpias, cortas y sin esmalte.

f) Efectuar ducha con lavado de cabeza incluido, bajo supervisión de enfermería, para asegurar la limpieza adecuada y correcta. Si hay contraindicaciones para la ducha, se lavará al paciente en cama.

g) Cena ligera.

h) Ayunas desde las 00:00 horas.

El mismo día de la intervención quirúrgica tendríamos en cuenta lo siguiente:

1. Higiene corporal:

a) Ducha: Se recomienda ducha o baño con jabón de todo el cuerpo, incluida la cabeza, como mínimo la noche antes de la intervención (Noorani, 2010), para disminuir la flora bacteriana de la piel del paciente.

b) Uñas recortadas y sin esmalte.

c) En pacientes urgentes, lavar con agua y jabón y antiséptico la zona operatoria.

d) Higiene bucal con antiséptico tipo hexetidina.

2. Eliminación del vello: No hay diferencias en la infección del campo quirúrgico entre pacientes a los que se ha rasurado el vello y a los que no. En caso necesario, el rasurado se realizará lo más cerca posible de la intervención y se utilizará preferiblemente maquinilla eléctrica o crema depilatoria (Tanner, 2006).

3. Aplicación de povidona yodada al $10 \%$ con movimientos circulares de dentro a fuera.

4. Vestir al paciente con ropa quirúrgica (bata quirúrgica, gorro y calzas).

5. Retirar prótesis dental, joyas, gafas y lentes de contacto si tuviera, en presencia de familiares, a ser posible, entregándoles a estos los objetos.

6. Administrar la medicación indicada en el tratamiento médico.

7. Control de constantes vitales.

8. Cumplimentar la hoja de preparación quirúrgica.

9. Comprobar que la historia clínica del paciente está completa.

\section{Cuidados básicos intraoperatorios}

El periodo intraoperatorio se inicia con la llegada del paciente al quirófano y finaliza cuando, aún bajo los efectos de la anestesia, ingresa a la denominada sala de despertar.

Durante este periodo de tiempo, las enfermeras responsables del paciente son las del bloque quirúrgico, que cuidarán de él durante la intervención quirúrgica y hasta su traslado a la sala de despertar. 
En algunos manuales se incluyen la estancia en la sala de despertar dentro de la fase intraoperatoria, argumentando que orgánicamente este servicio pertenece a los responsables del bloque quirúrgico. En nuestra opinión es más correcto incluirlo en el denominado postoperatorio inmediato, dado que el personal de enfermería es otro y además tiene funciones bien diferenciadas en uno y otro lugar. En realidad es una cuestión organizativa sin demasiada importancia, pero lo que sí es de suma trascendencia es que la conexión entre los profesionales en el momento del traspaso del paciente se realice de una forma adecuada, que permita la continuidad de los cuidados de enfermería durante todo el proceso.

La fase intraoperatoria se desarrolla en el denominado bloque quirúrgico, que es un servicio del hospital con características estructurales y de funcionamiento especial y que veréis más adelante.

\section{Cuidados básicos postoperatorios}

El postoperatorio comienza cuando acaba la intervención quirúrgica y el paciente ingresa en la Unidad de Vigilancia Posquirúrgica. Algunos pacientes que reciben un anestésico local, o que son sometidos a intervenciones que no requieren anestesia general, pueden pasar desde el quirófano a su habitación o ser dados de alta. La duración del postoperatorio depende del tiempo necesario para la recuperación del estrés y de la alteración causada por la cirugía y la anestesia, pudiendo ser de sólo pocas horas o abarcar varios meses.

El postoperatorio puede dividirse en dos fases:

a) La primera es el postoperatorio inmediato, que abarca el periodo que va desde el final de la intervención quirúrgica hasta la desaparición de los efectos de la anestesia. Durante esta primera fase del postoperatorio, que suele durar sólo unas horas, el enfermo se encuentra en la unidad de vigilancia postquirúrgica.

b) La segunda fase es el postoperatorio tardío o periodo de resolución y curación, que puede llegar a ser incluso de meses en caso de intervenciones mayores.

En el postoperatorio inmediato, los cuidados de enfermería irán dirigidos a valorar y vigilar:

a) Vía aérea y respiración, por si se produjese una alteración del intercambio gaseoso.

b) Circulación, cabe la posibilidad de producirse hipotensión o arritmias cardíacas.

c) Metabolismo, vigilando la integridad y turgencia de la piel, temperatura, tipo y cantidad de líquidos intravenosos administrados y diuresis.

d) Mantenimiento de la seguridad y bienestar dirigido a prevenir lesiones y promocionar el bienestar físico y psicológico. 


\section{Referencias bibliográficas}

Aguilera, L.; DíAz, S. y SÁnchez, G. (2012): Trastornos del sueño en el paciente adulto hospitalizado. Rev Hosp Univ Chile. 21:13-20. Disponible en URL: http://www.captura.uchile.cl/handle/2250/17090.

Albella Vallverdú, F.; Barragán Gonzalo, M. C.; Cherrail Marquinez, I. y Comas Serrano, M. (2013): Evaluación de la calidad del sueño en los pacientes ingresados en nefrología. XXXVI Congreso Nacional sEDEN. Disponible en URL: http://www.revistaseden.org/files/3408_Articulo\%205.pdf.

Alfaro-LeFevre, R. (1996): Instructor's manual for critical thinking in nursing: A practical approach. Filadelfia, EE. UU.: WB Saunders.

- (2003): Aplicación del proceso enfermero. Fomentar el cuidado en colaboración. 5. Edición, Barcelona: Elsevier, Doyma.

Baccaro, F.; SÁnchez, A. (2009): Determinación de la desnutrición hospitalaria: comparación entre la valoración global subjetiva y el índice de masa corporal. Rev Gastroenterol Mex. 74,2. Disponible en URL: http://scielo.isciii.es/scielo. php?pid=S0212-16112008000800022\&script $=$ sci_arttext.

Bello, N. (2010): Fundamentos de enfermería. Parte II. Ecimed. La Habana. Disponible en URL: http://gsdl.bvs.sld.cu/cgi-bin/library? $=\mathrm{d}-00000-00---o f f-$ 0enfermeria--00-0----0-10-0---0---0direct-10---4-------0-11--11-11-50---20-help-$-00-0-1-00-0-0-11-1-00-00 \& \mathrm{a}=\mathrm{d} \& \mathrm{c}=$ enfermeria $\& \mathrm{cl}=\mathrm{CL} 2.16 \& \mathrm{~d}=\mathrm{HASH} 954 \mathrm{~d} 11$ 332e1d43c566fc91.6.

Benavent Garcés, M. A.; Ferrer Ferrandis, E. y Francisco del Rey, C. (2009): Fundamentos de enfermería. 2. edición. Difusión y Avances de Enfermería (DAE), España: DAE.

BulecheK, G. M., Butcher, H. K. y Dochterman, J. M. (2008): Nursing interventions classification (NIC). 5. Edición, San Luis, EE. UU.: Mosby.

Consellería de Bienestar Social (2004): Protocolo de valoración nutricional. Servicios de Farmacia Sociosanitarios. Generalitat Valenciana.

Craven, R. y Himle, C. (1996): Fundamentals of nursing: human health and functioning. 2. ${ }^{a}$ Edición, Filadelfia, EE. UU.: Lippincott-Raven.

Crisp, J.; TAYlor, C. (2009): Potter and Perry's Fundamentals of Nursing, 3. ${ }^{\mathrm{a}} \mathrm{ed}$. Chatswood, nsw, Australia: Mosby Elsevier.

Cochrane (2014): Cambios de posición para la prevención de úlceras de decúbito en adultos (Revision Cochrane traducida). Cochrane Database of Systematic Reviews. Issue 4. Art. No.: CD009958. Dor: 10.1002/14651858.

Felanfe (2008). Evaluación del estado nutricional en paciente hospitalizado. 2009. Federación Latinoamericana de Terapia Nutricional, Nutrición Clínica y Metabolismo. Disponible en URL: http://www.aanep.com/docs/consenso_ evaluacion_nutricional_FELANPE_2008.pdf.

Ferrer Solá, M.; Espauella Panicot, J.; Altimires Roset, J. y Ylla-Català Boré, E. (2013): Prevención de las úlceras de talón en un hospital de media estancia. Estudio comparativo de vendaje clásico almohadillado respecto a las taloneras hidrocelulares de poliuretano. Revista Española de Geriatría y Gerontología. 48(1): 3-8.

Francis, R. (2013): Report of the Midstaffordshire NHS Foundation Turst Public Inquiry. Reino Unido. Disponible en URL: http://www.midstaffspublicinquiry. com/report. 
García-Fernández, F. P.; Soldevilla Agreda, J. J.; Verdú, J. y Pancorbo-HidalGO, P. L. (2014): A New Theoretical Model for the Development of Pressure Ulcers and Other Dependence-Related Lesions. Journal of Nursing Scholarship; 46; $1: 28-38$.

Garling, P. (2008): Final report of the Special Commission of Inquiry Acute Care Services in NSW Public Hospitals. Special Commission of Inquiry: Acute Care Services in New South Wales Public Hospitals. Sydney, Australia.

Gobierno de Aragón. Departamento de Salud y Consumo (2009): Estrategia de mejora de la calidad de los cuidados: Protocolos de Cuidados de Enfermería Basados en la Evidencia. Zaragoza. Instituto Aragonés de Ciencias de la Salud.

Henderson, V.; Nite, G. (1978): Principles and Practice of Nursing, 6th ed. New York: Macmillian.

HibBs, P. (1987): Pressure area care for the City \& Hackney Health Authority. London: St. Bartholomews Hospital.

Institute of Medicine (2010): The Future of Nursing: Leading Change, Advancing Health. EE. UU.

IYeR, P. W., TAPTich, B. J. y Bernocchi-Losey, D. (1997): Procesos y diagnósticos en enfermería. 3. ${ }^{\mathrm{a}}$ Edición, México: McGraw-Hill Interamericana.

Joint National Committee (2014): Evidence-Based Guideline for the Management of High Blood Pressure in Adults: Report From the Panel Members Appointed to the Eighth Joint National Committee (JNC 8) JAMA; 311(5): 507-520. DOI:10.1001/jama.2013.284427.

KerLINGER, F. N. (1975): Investigación del comportamiento: técnicas y metodología. México: Nueva Editorial Interamericana.

Kitson, A.; Athlin, A. M. y Conroy, T. (2014): Anything but Basic: Nursing's Challenge in Meeting Patients' Fundamental Care Needs. Journal of Nursing Scholarship. 46(5): 331-9.

Kitson, A.; Conroy, T.; Wengstrom, Y.; Profetto-McGrath, Y. y Robertson-Malt S., Defining (2010): Fundamentals of care. International Journal of Nursing Practice. 16: 423-434.

Kohm, L.; Corrigan, J. M. y Donaldson, M. C. (1999): To Err is Human: Building a Safer Health System. Institue of Medicine. EE. UU.

Kozier, B.; Erb, G. y Olivieri, R. (1993): Eliminación fecal, Eliminación urinaria. En: Kozier, B.; Erb, G.; Olivieri, R.: Enfermería Fundamental. Conceptos, procesos y práctica, 4. ${ }^{\mathrm{a}}$ ed. Madrid: Mc Graw-Hill-Interamericana, pp. 1245-1333.

LANGER, G. y ASTRID, F. (2014): Nutritional interventions for preventing and treating presure ulcers. Cochrane Database Syst Rev. Jun, 12; 6: CD003216.

Leandro Merhi, V. A.; Marques de Oliveira, M. R.; Caran, A. L.; Menuzzo Graupner Tristao, T.; Miante Ambo, R.; Tanner, M. A.; Marton Vergna, C. (2007): Tiempo de hospitalización y estado nutricional en pacientes hospitalizados. Nutr Hosp.; 22(5): 590-5. Diposnible en URL: http://scielo.isciii.es/pdf/ $\mathrm{nh} / \mathrm{v} 22 \mathrm{n} 5 /$ original10.pdf.

Léger, D.; Morin, C. M.; Uchiyama, M.; Hakimi, Z.; Cure, S. y Walsh, J. K. (2012): Chronic insomnia, quality-of-life, and utility scores: Comparison with good sleepers in a cross-sectional international survey. Sleep Med.;13: 43-51.

LynN, P. (2012): Enfermería clínica de Taylor. Cuidados básicos del paciente. I y II. 3. ${ }^{a}$ edición. Barcelona: Lippincott Williams \& Wilkins. 
Martín Peña, G.; Gómez Candela, C.; De Cos Blanco, A. I. y Cabré Gelada, E. (2005): Nutrition assessment in hospitalized patients in Spain. Med Clin..22; 125(14): 534-542.

MCCAFFery, M. (1968): Nursing practice theories related tocognition, bodily pain, and man-environment interactions. Los Angeles: UCLA Students Store.

Medina Cordero, A.; Feria Lorenzo, D. J. y Oscoz Muñoa, G. (2009): Los conocimientos sobre el sueño y los cuidados enfermeros para un buen descanso. Enfermería Golbal. 8(3). Disponible en URL: http://revistas.um.es/eglobal/ article/view/75151.

Ministerio de SAnidad y Consumo (2006): Estudio Nacional sobre los efectos adversos ligados a la hospitalización. ENEAS 2005. España. Disponible en URL: http://www.errorenmedicina.anm.edu.ar/pdf/recursos/documentos/43_estudio_ENEAS.pdf.

Montero IbáÑEz, R.; Manzanares Briega, A. (2005): Escalas de valoración del dolor. Jano 68 (1553): 41-44. Disponible en URL: http://www.jano.es/ficheros/ sumarios/1/68/1553/41/1v68n1553a13072240pdf001.pdf.

MuÑoz, Y. M. (2009): Determinación de riesgo de desnutrición en pacientes hospitalizados. I: Enfoque teórico. Invenio; 12(22): 121-143. Disponible en URL: http://www.redalyc.org/articulo.oa?id=87713361007.

National Institute for Health and Clinical Excellence - Clinical Guidelines. (2006): Nutrition support in adults: oral nutrition support, enteral tube feeding and parenteral nutrition. United Kingdom. Disponible en URL: http://www. nice.org.uk/guidance/cg032.

Nenclares Portocarrero, A.; Jiménez Genchi, A. (2008): Estudio de validación de la traducción al español de la escala Atenas de Insomnio. Salud mental; 28 (5): 34-9. Disponible en URL: http://www.redalyc.org/articulo.oa?id=58252805.

Nightingale, F. (1860/1980): Notes on Nursing. What it is and What it is Not. Edinburgh: Churchill Livingstone.

Noorani, A.; Rabey, N.; Walsh, S. R. y Davies, R. J. (2010): Systematic review and meta-analysis of preoperative antisepsis with chlorhexidine versus povidone-iodine in clean-contaminated surgery. Br J Surg. 7(11): 1614-1620.

Pasic, Z.; Smajlovic, D.; Dostovic, Z.; Kojic, B. y Selmanovic, S. (2011): Incidence and types of sleep disorders in patients with stroke. Med Arh; 65: 225-7.

Phaneuf, M. (1999): La Planificación de los cuidados enfermeros. Madrid: McGraw-Hill Interamericana.

Potter, P. y Perry, A. (1996): Eliminación intestinal, Eliminación urinaria. En: Potter, P., Perry, A.: Fundamentos de Enfermería. 3. ${ }^{a}$ ed. Madrid: Mosby/Doyma, pp. 1409-1508.

Registered Nurses Association of Ontario (2002): Valoración y manejo del dolor. Toronto, Canada: Registered Nurses Association of Ontario. Disponible en URL: http://www.evidenciaencuidados.es/es/attachments/article/46/ GuiaRNAOManejoDolor.pdf.

Roper, N.; Logan, W. W. y Tierney, A. J. (1983): Using A Model for Nursing, 6th ed. Edinburgh: Churchill Livingstone.

Sackett, D. L.; Rosenberg, W. M.; Gray, J. A; Haynes, R. B. y Richardson, W. S. (1996): Evidence based medicine: what it is and what it isn't. BMJ. 13, 312(7023): 71-72. 
San Miguel Samano, M. T. y SÁnchez Méndez, J. L. (2011): Interacciones alimento/medicamento. Inf Ter Sist Nac Salud; 35: 3-12. Disponible en URL: http:// www.msssi.gob.es/biblioPublic/publicaciones/recursos_propios/infMedic/ docs/vol35_1_Interacciones.pdf

Serrano-Atero, V. M.; Caballero, J.; Cañas, A.; García Saura, P. L.; SerranoÁlvarez, C. y Prieto, J. (2002): Valoración del dolor (II). Rev Soc Esp Dolor:;9:109-21. Disponible en URL: http://revista.sedolor.es/pdf/2002_02_06.pdf

Sociedad Española de Medicina Oral del Sueño. Funciones del Sueño. Disponible en URL: http://www.semods.es/funciones sueno.html.

Stone, K. L.; Ensrud, K. E. y Ancoli-Israel, S. (2008): Sleep, insomnia and fallsin elderly patients. Sleep Med. 9;1: 18-22.

Talens Belén, F. y Casabona Martínez, I. (2013): Implementación de las técnicas en los cuidados de Enfermería: Un reto para la práctica clínica. Index de Enfermería; 22(1-2). Disponible en URL: http://scielo.isciii.es/scielo.php?pid=S1132$12962013000100002 \&$ script $=$ sci_arttext.

TAnner, J.; Woodings, D. y Moncaster, K. (2008): Eliminación preoperatoria de vello para reducir la infección del área quirúrgica (Revisión Cochrane traducida). En: La Biblioteca Cochrane Plus, 4. Oxford: Update Software Ltd. Disponible en URL: http://www.bibliotecacochrane.com/BCPGetDocument. asp?SessionID $=\% 206246998 \&$ DocumentID $=$ CD004122.

Torra, J. E.; Rueda, J.; Soldevilla, J. J.; Martínez, F. y Verdú, J. (2003): Primer estudio nacional de prevalencia de úlceras por presión en España. Gerokomos.;14: 37-47.

Venlateshiah, S. B. y Collop, N. A. (2012): Sleep and sleep disorders in the hospital. Chest.141: 1337-1345.

Vico-Romero, J.; Cabré-Roure, M.; Monteis-Cahis, R.; Palomera-Faneges, E. y Serra-Prat, M. (2014): Prevalencia de trastornos del sueño y factores asociados en pacientes hospitalizados. Enfermería Clínica. 24(5): 276-282.

Young, J. S.; Bourgeois, J. A.; Hilty, D. M. y Hardin, K. A: (2008): Sleep in hospitalized patients, 1: Factors affecting sleep. J Hosp Med; 15: 473- 482. 


\section{Índice de tablas}

Tabla 1. Cuidados básicos reflejados por diferentes autoras.

Adaptado de Kitson et al., 2010.

Tabla 2. Factores que pueden afectar el estado nutricional.

Tabla 3. Observaciones clínicas para la valoración nutricional

Tabla 4. Valores del IMC. Fuente. Adaptado de FelanPE. 2009

Tabla 5. Datos bioquímicos con implicaciones nutricionales.

Fuente. MedlinePlus

Tabla 6. Encuesta «Determine your nutritional Health».

Fuente ELANPE, 2009.

Tabla 7. Interacciones fármacos-alimentos.

Tabla 8. Horas de sueño según edad.

Tabla 9. Factores que afectan al sueño según los profesionales de enfermería. Fuente. Medina Cordero, 2009

Tabla 10. Fármacos que pueden alterar el ciclo del sueño. Fuente: Lynn, 2012

Tabla 11. Aplicaciones de antisépticos químicos.

Fuente. Elaboración propia.

Tabla 12. Características de las UPP según grados.

Fuente. DAE, 2009.

Tabla 13. Recomendaciones para la prevención de UPP.

Tabla 14. Clasificación de la hipertensión según el protocolo de Joint National Committee on the Prevention, Detection, Evaluation and Treatment of High Blood Pressure

Tabla 15. Tamaños recomendados de manguitos para la toma de presión sanguínea. Fuente. DAE, 2009.

Tabla 16. Cuidados de catéteres vasculares periféricos.

Fuente. Departamento de Salud y Consumo. Gobierno de Aragón. 


\section{Índice de figuras}

Figura 1. El proceso de cuidar. Benavent, 2009

Figura 2. Columna vertebral. Fuente: Google Imágenes. Imagen libre

Figura 3. Vértebra. Fuente: Google imágenes. Imagen libre.

Figura 4. Disco intervertebral. Fuente: Google imágenes. Imagen libre.....

Figura 5. La postura. Fuente. Google imágenes. Imagen libre

Figura 6. Decúbito supino o dorsal. Fuente: Elaboración propia.

Figura 7. Decúbito lateral. Fuente: Elaboración propia.

Figura 8. Decúbito prono. Fuente: Elaboración propia

Figura 9. Posiciones semi-Fowler, Fowler y Fowler alta.

Fuente: Elaboración propia.

Figura 10. Posición Trendelenburg. Fuente: Elaboración propia.

Figura 11. Posición anti-Trendelenburg. Fuente: Elaboración propia.

Figura 12. Posición de Roser o Proetz. Fuente: Elaboración propia.

Figura 13. Posición de punción lumbar. Fuente: Elaboración propia.

Figura 14. Paciente al borde de la cama. Fuente: Elaboración propia

Figura 15. Etapas del sueño. Fuente. Elaboración propia.

Figura 16. Botella. Fuente: Elaboración propia.

Figura 17. Orinal tipo cuña. Fuente: Elaboración propia.

Figura 18. Valores del pH. Fuente. Google imágenes. Imagen libre.

Figura 19. Pliegue en mitra. Fuente: Elaboración propia.

Figura 20. Unidad de paciente. Fuente: Elaboración propia.

Figura 21. Modelo de habitación individual. Fuente: Elaboración propia. .

Figura 22. Dirección del masaje. Fuente: Elaboración propia.

Figura 23. Métodos de antisepsia. Fuente: Elaboración propia.

Figura 24. Paquete de esterilización. Fuente: Elaboración propia.

Figura 25. Modelo de servicio de esterilización.

Fuente. Elaboración propia.

Figura 26. Medidas generales para la prevención de infecciones

de la Generalitat Valenciana. Fuente. Conselleria de Sanitat,

Generalitat Valenciana, 2007.

Figura 27. Momentos para la higiene de manos según la oMs.

Fuente. OMS.

Figura 28. Cartel de lavado de manos de la oms

Figura 29. Cartel sobre el uso de solución alcohólica de la oms.

Fuente. OMS.

Figura 30. Preparación de un campo estéril. Fuente. Elaboración propia...

Figura 31. Puntos de presión y riesgo de UPP.

Fuente. Elaboración propia.

Figura 32. Algoritmo de decisión en HTA de la Joint

National Committee. 2014.

Figura 33. Escala numérica de intensidad de dolor.

Fuente. Elaboración propia.

Figura 34. Escala de dolor de la expresión facial.

Fuente: Google imágenes. Imagen libre. 
Figura 35. Escala visual analógica. Fuente: Elaboración propia.

Figura 36. Escalera analgésica de la oms. Fuente: Elaboración propia......... Figura 37. Cuidados perioperatorios. Fuente: Elaboración propia. 